$\longrightarrow$

global omnium

Indicadores de

Desempeño para

Servicios de

Saneamiento
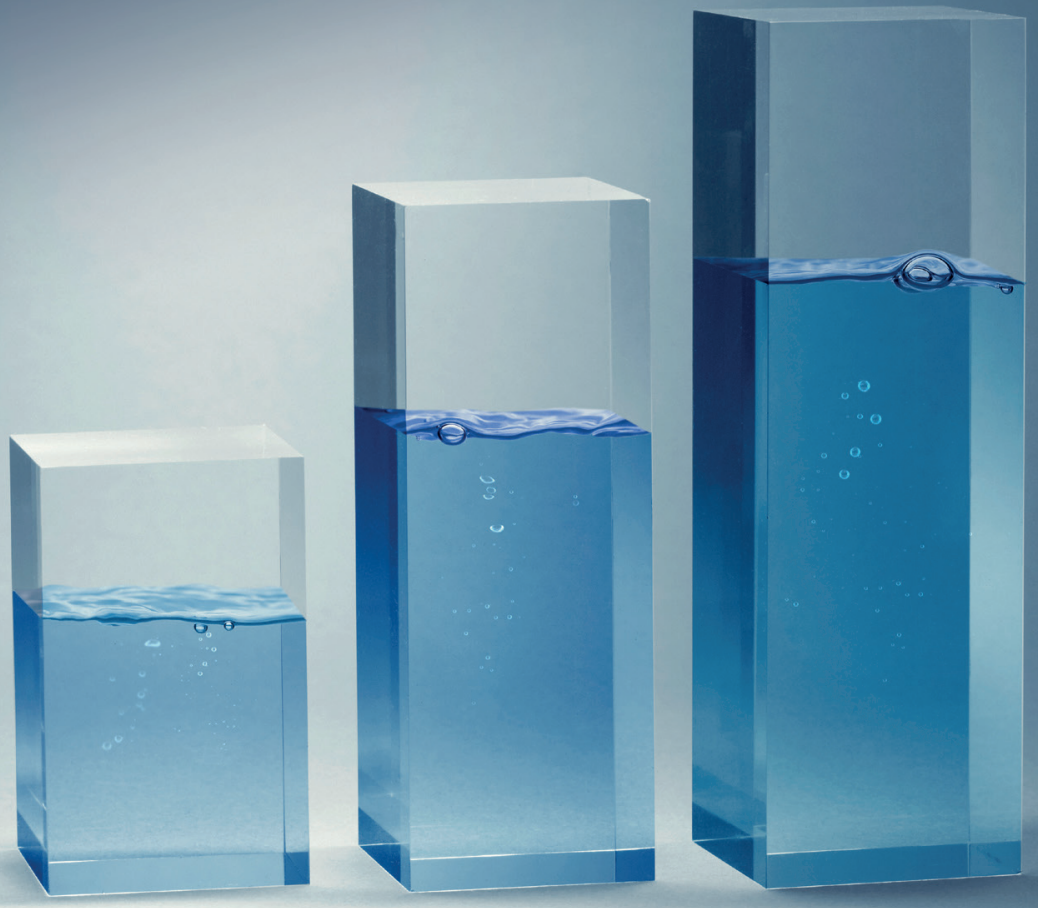

Grupo Especialista en Benchmarking y Evaluación del Desempeño de la IWA 


\section{INDICADORES DE DESEMPEÑO PARA SERVICIOS DE SANEAMIENTO}





\section{INDICADORES DE DESEMPEÑO PARA SERVICIOS DE SANEAMIENTO}

Rafaela Matos, Adriana Cardoso, Richard Ashley, Patrícia Duarte, Alejo Molinari, Andreas Schulz 
Título original Performance Indicators for W astewater Services

(C) 2003, IWA Publishing

(C) 2020, de la edición traducida: Editorial Universitat Politècnica de València www.lalibreria.upv.es

Ref.:6671_01_01_01

Traducción: Elvira Estruch Juan

Maquetación: Elvira Estruch Juan

ISBN: 978-84-9048-846-1 (versión impresa)

ISBN: 978-84-9048-985-7 (versión electrónica)

Depósito legal: V-2619-2020

DOI: https://doi.org/10.4995/ITA.2020.6671

La Editorial UPV autoriza la reproducción, traducción y difusión parcial de la presente publicación con fines científicos, educativos y de investigación que no sean comerciales ni de lucro, siempre que se identifique y se reconozca debidamente a la Editorial UPV, la publicación y los autores. La autorización para reproducir, difundir o traducir el presente estudio, o compilar o crear obras derivadas del mismo en cualquier forma, con fines comerciales/lucrativos o sin ánimo de lucro, deberá solicitarse por escrito al correo edicion@editorial.upv.es. 


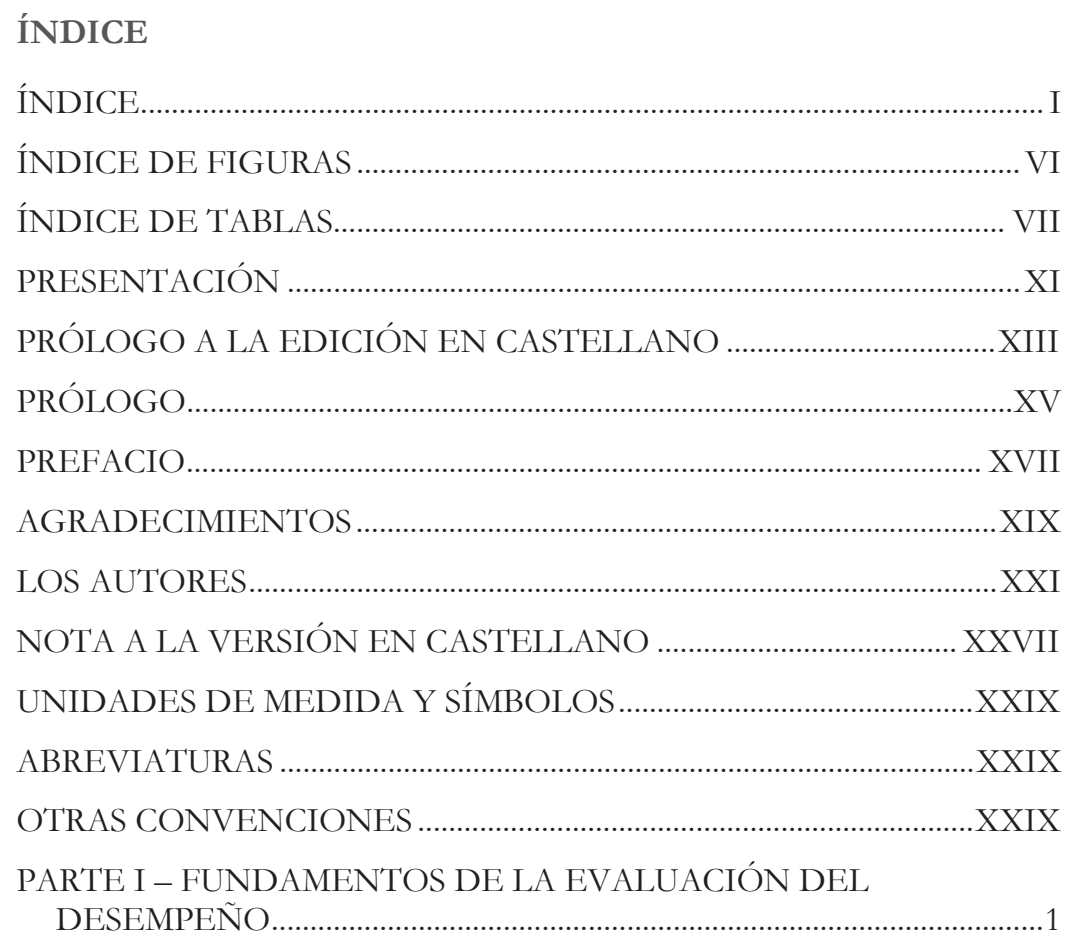

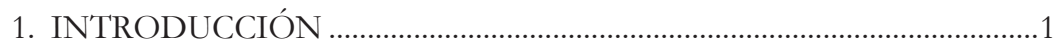

1.1 Balance tras 20 años de la publicación de los sistemas de indicadores de desempeño de la IWA............................................................................

1.2 La industria del agua, contexto, motivaciones y desafíos .........................2

1.3 El enfoque de la IWA en la gestión de servicios de agua ......................... 4

1.4 La creciente importancia de los sistemas de evaluación del

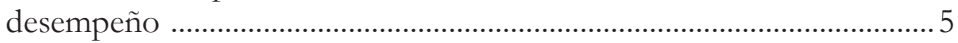

1.5 Usuarios de los sistemas de evaluación del desempeño en servicios

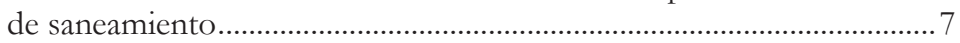

1.6 Objetivos de la serie de manuales de la IWA sobre buenas prácticas 10

1.7 Acerca de este manual..................................................................................11

2. SISTEMAS DE INDICADORES DE DESEMPEÑO..............................13

2.1 Sistema de indicadores de desempeño.......................................................13

2.2 Requisitos para la definición de un sistema de indicadores de

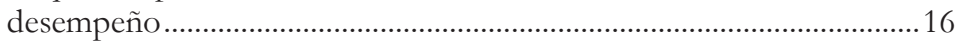

3. DE LA EVALUACIÓN DEL DESEMPEÑO A LA MEJORA ..............19

3.1 Indicadores de desempeño como base del benchmarking.....................19

3.2 ¿Qué es el benchmarking? ........................................................................21

3.3 ¿Por qué hacer benchmarking? .............................................................23 
Gobiernos / reguladores .................................................................... 24

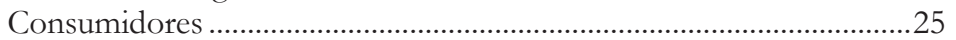

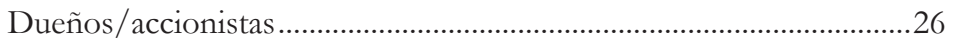

3.4 El Marco de Benchmarking de la IWA..................................................26

4. EL SISTEMA IWA DE INDICADORES DE DESEMPEÑO............... 29

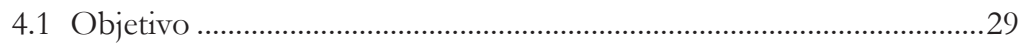

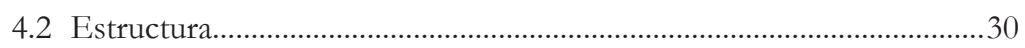

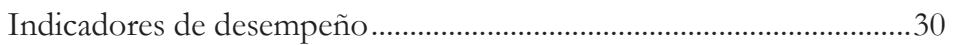

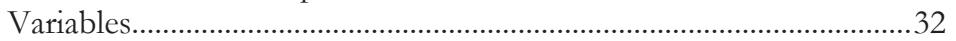

Información de contexto y otros datos del Sistema...............................33

4.3 Utilización del sistema de indicadores de desempeño de la IWA ........34

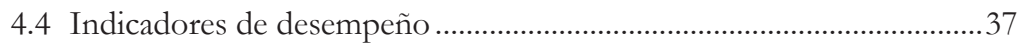

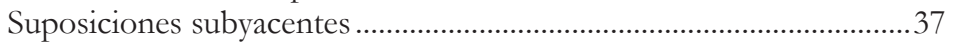

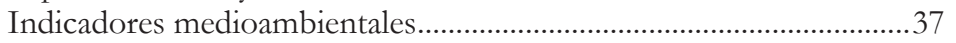

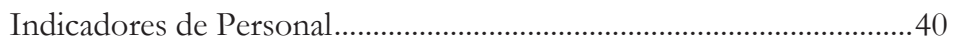

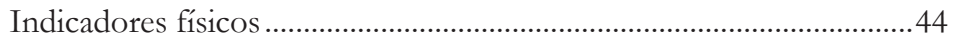

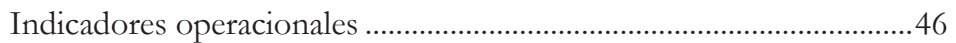

Indicadores de calidad del servicio ..........................................................53

Indicadores económicos y financieros....................................................58

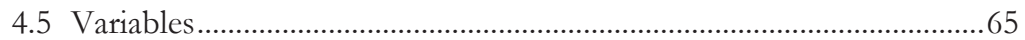

4.6 Factores explicativos .........................................................................67

Tipos de factores explicativos ...............................................................67

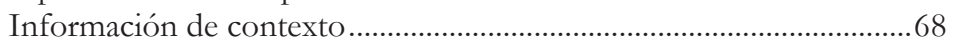

Indicadores de desempeño y variables como factores explicativos ...71

Otros factores explicativos.........................................................................

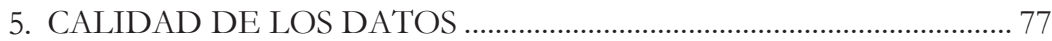

5.1 Introducción .............................................................................................

5.2 Gestión completa de la calidad de los datos: exactitud y fiabilidad ....79

5.3 Un nuevo enfoque en la calidad de los datos........................................... 81

6. IMPLEMENTACIÓN DE UN SISTEMA DE ID ……………………....... 83

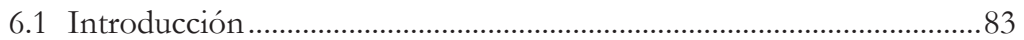

6.2 Uso de los indicadores de la IWA en un sistema de evaluación del desempeño.

6.3 Definición de los objetivos...................................................................... 85

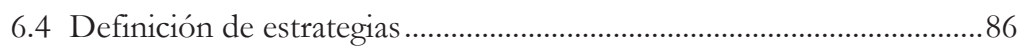

6.5 Establecimiento de factores críticos de éxito ........................................... 87

6.6 Establecimiento de un sistema de indicadores del desempeño ............87

Definición de los principios estratégicos de la evaluación del

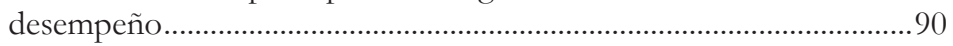

Selección de los ID a evaluar ....................................................................93

6.7 Evaluación de los indicadores de desempeño........................................100

6.8 Mejora continua …………………………………………….....................101 
PARTE II - ESPECIFICACIONES DEL SISTEMA DE ID DE LA IWA.

1. DEFINICIONES

1.1 Definiciones del balance de aguas residuales

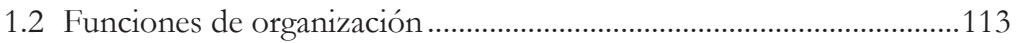

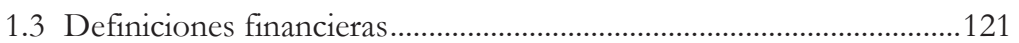

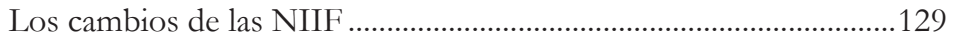

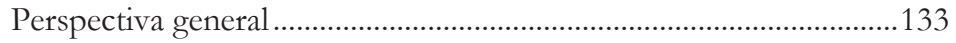

Impacto en los Ratios Financieros ....................................................... 141

1.4 Definiciones complementarias............................................................... 148

Definiciones relacionadas con el servicio de saneamiento.................148

Definiciones relacionadas con la población.........................................159

2. INDICADORES DE DESEMPEÑO ........................................................ 163

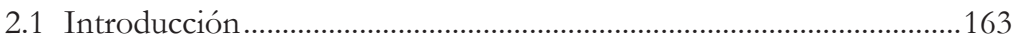

2.2 Listado de referencia rápida de los ID de la IWA .................................164

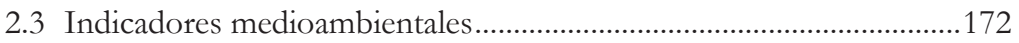

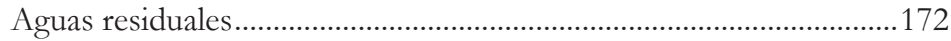

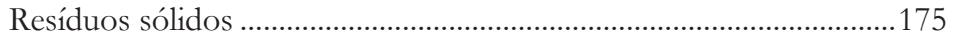

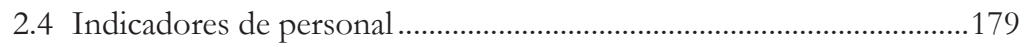

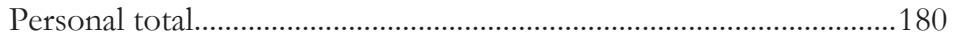

Personal por función principal .............................................................181

Personal de servicios técnicos por actividad........................................183

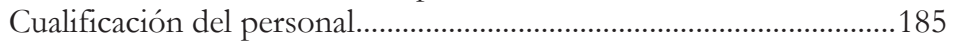

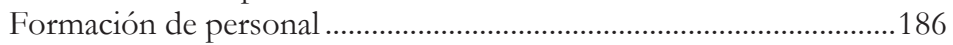

Seguridad y salud del personal .............................................................187

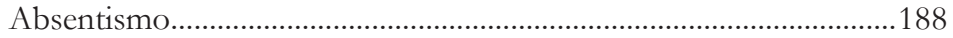

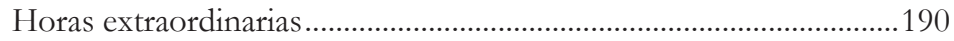

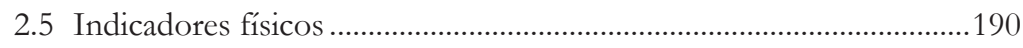

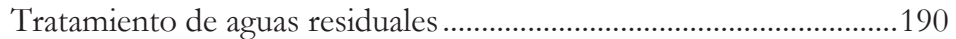

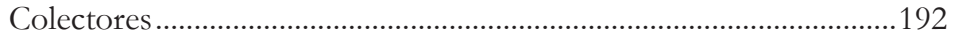

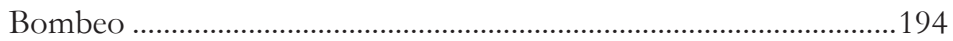

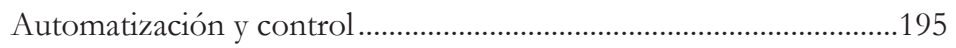

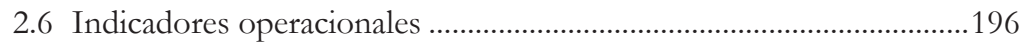

Inspección y mantenimiento de colectores ............................................196

Inspección y mantenimiento de depósitos de retención y DSUs ....200

Inspección de bombas y estaciones de bombeo .................................203

Calibración de equipos..............................................................................204

Inspección de equipos eléctricos y de transmisión de señales...........205

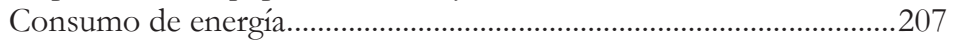

Rehabilitación de colectores..................................................................208

Rehabilitación de bombas ......................................................................212

Entrada / Infiltración / Exfiltración (E/I/E) .....................................213

Averías ............................................................................................ 215 
Control de tanques de tormenta .......................................................219

Monitorización de la calidad de aguas residuales y lodos..................220

Disponibilidad de vehículos ................................................................229

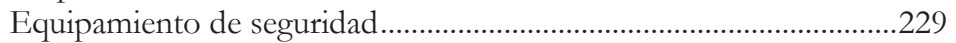

2.7 Indicadores de calidad del servicio .......................................................230

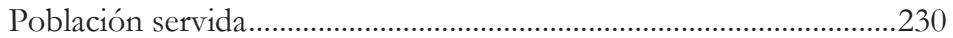

Tratamiento de aguas residuales .........................................................231

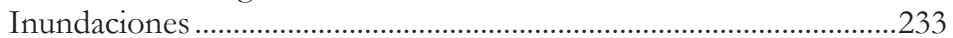

Interrupciones ....................................................................................23

Instalación y reparación de acometidas ……….................................238

Quejas de los usuarios......................................................................239

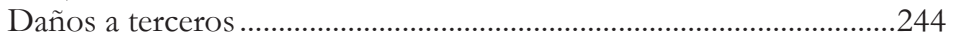

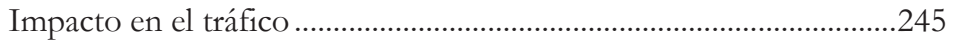

2.8 Indicadores económicos y financieros ..................................................245

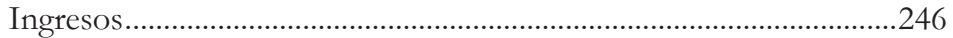

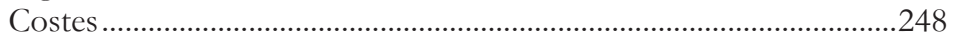

Componentes de los costes de explotación por tipo de coste...........251

Componentes de los costes de explotación por función principal

(internos y externalizados) .....................................................................253

Componentes de los costes de explotación por función técnica .....255

Componentes de los costes de capital ................................................256

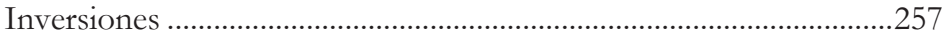

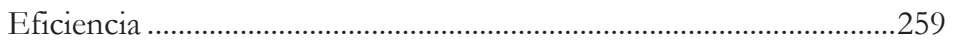

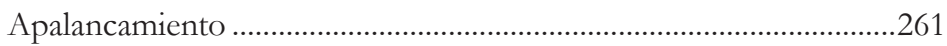

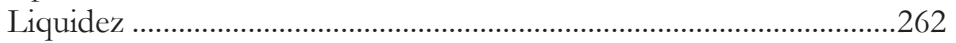

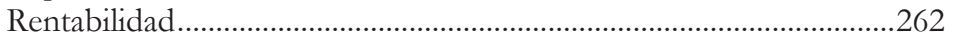

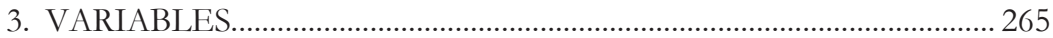

3.1 Sección A - Datos medioambientales...................................................266

3.2 Sección B - Datos de personal .............................................................22

3.3 Sección C - Datos de activos físicos .......................................................2.28

3.4 Sección D - Datos operacionales ...........................................................28

3.5 Sección E - Datos sobre demografía y clientes ......................................309

3.6 Sección F - Datos de calidad del servicio ..............................................311

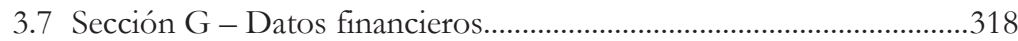

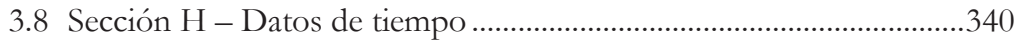

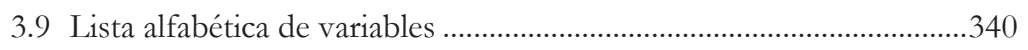

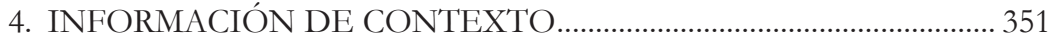

4.1 Lista de referencia rápida de IC ...............................................................351

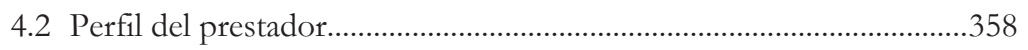

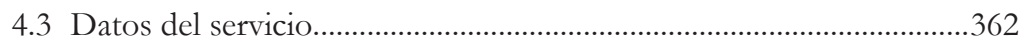

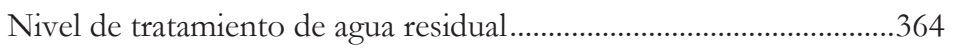

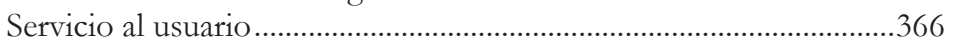

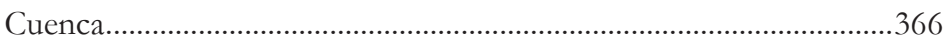




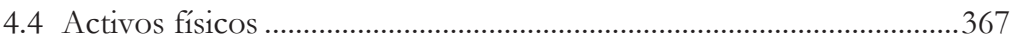

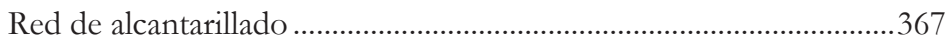

Pozos de registro e imbornales ..............................................................372

Aliviaderos y tanques de tormenta ........................................................373

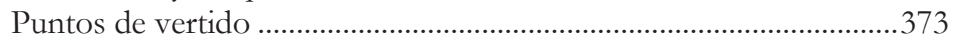

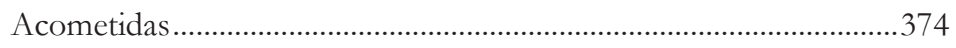

Almacenamiento de aguas residuales ...................................................375

Almacenamiento de aguas pluviales.......................................................375

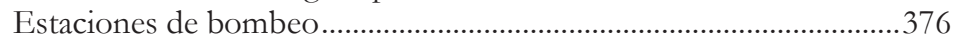

Estaciones Depuradoras de Aguas Residuales (EDAR) ....................376

Recursos tecnológicos.........................................................................379

4.5 Demografía y economía.....................................................................382

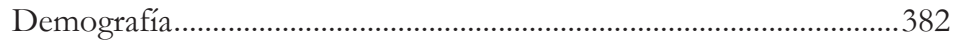

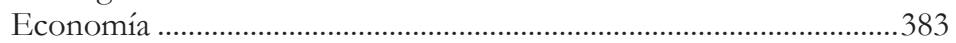

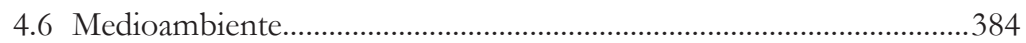

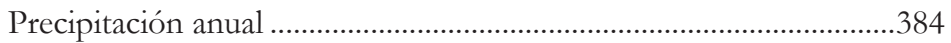

Precipitaciones de corta duración............................................................384

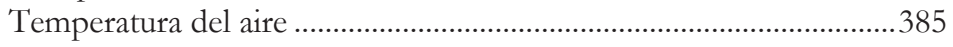

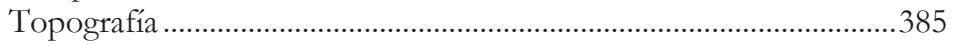

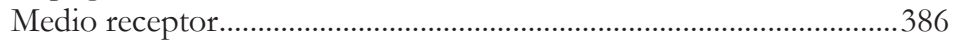

5. INCERTIDUMBRE Y PROPAGACIÓN DE LA

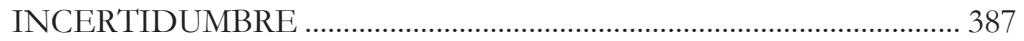




\section{ÍNDICE DE FIGURAS}

Figura 1. Contexto de los prestadores de agua ....................................................

Figura 2. Componentes de un sistema de indicadores de desempeño ............ 15

Figura 3. El modelo de evaluación y mejora del desempeño............................... 21

Figura 4. Gobiernos y reguladores: ¿Por qué evaluar el despemeño?.............. 25

Figura 5. Consumidores: ¿Por qué hacer benchmarking? ................................. 25

Figura 6. Dueños/accionistas: ¿Por qué hacer benchmarking? ......................... 26

Figura 7. Marco de benchmarking de la IWA (Cabrera Jr. et al., 2011).......... 27

Figura 8. ID como parte de un sistema de evaluación del desempeño. .......... 88

Figura 9. Fases del proceso de implementación de un Sistema de ID. .......... 92

Figura 10. Proceso de selección de ID e IC........................................................... 95

Figura 11. Ejemplo del flujo de datos sobre ID e IC y responsabilidades

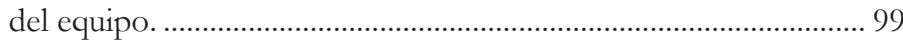

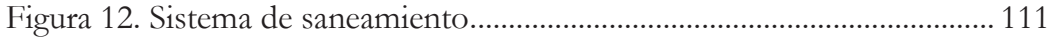

Figura 13. Balance de aguas residuales.............................................................. 112

Figura 14. Prestación del servicio en términos de clientes y principales

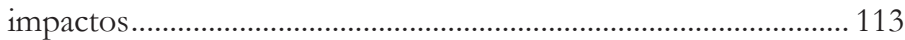

Figura 15. Funciones de los prestadores de agua................................................. 114 


\section{ÍNDICE DE TABLAS}

Tabla 1. Grado de correlación entre las etapas del marco de benchmarking de la IWA y proyectos típicos de indicadores de desempeño

Tabla 2. ID Medioambientales de aguas residuales (II \#190) ................................ 38

Tabla 3. ID Medioambientales de aguas residuales (II \#195) ................................39

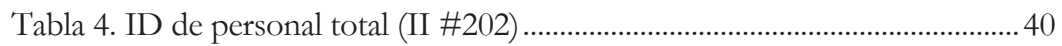

Tabla 5. ID de personal por función principal (II \#201)......................................... 41

Tabla 6. ID Personal de servicios técnicos por actividad (II \#201) ...................... 42

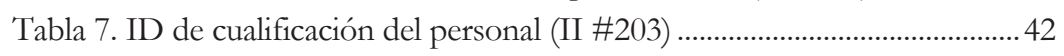

Tabla 8. ID de formación de personal (II \#204) ......................................................... 43

Tabla 9. ID de seguridad y salud del personal (II \#205) .......................................... 43

Tabla 10. ID de horas extraordinarias (II \#206)........................................................ 44

Tabla 11. ID de horas extraordinarias (II \#208)...................................................... 44

Tabla 12. ID de capacidad de tratamiento de aguas residuales (II \#208) ........... 45

Tabla 13. ID de capacidad de los colectores (II \#210)............................................ 45

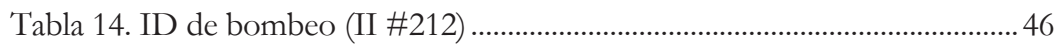

Tabla 15. ID de automatización y control remoto (II \# 213) ...................................46

Tabla 16. ID de inspección y mantenimiento de activos físicos (II \#212) ......... 47

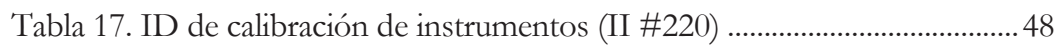

Tabla 18. ID de inspección de equipos eléctricos y transmisión de señales

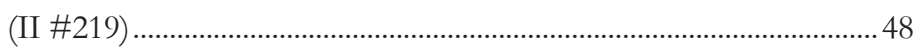

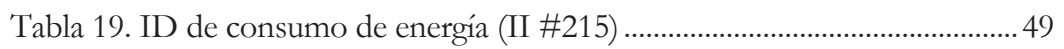

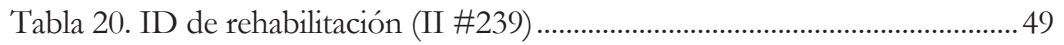

Tabla 21. ID de entrada, infliltración y exfiltración de agua (II 221) .....................50

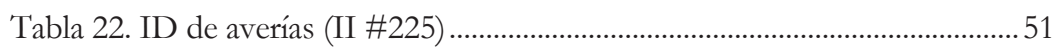

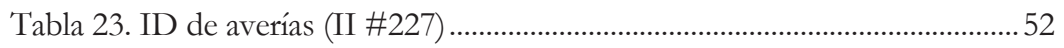

Tabla 24. ID de supervisión de calidad del agua residual y lodos (II \#228)...... 52

Tabla 25. ID de disponibilidad de vehículos (II \#237) .......................................53

Tabla 26. ID de equipamiento de seguridad (II \#237) ........................................53

Tabla 27. ID de cobertura del servicio (II \#232) ..................................................54

Tabla 28. ID de tratamiento de aguas residuales (II \#233) ................................54

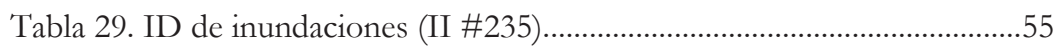

Tabla 30. ID de instalación y reparación de acometidas y contadores

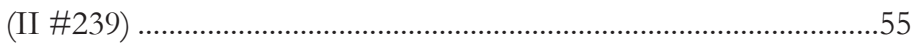

Tabla 31. ID de instalación y reparación de acometidas (II \#240)....................56

Tabla 32. ID de quejas de los usuarios (II \#266) ................................................56 
Tabla 33. ID de responsabilidad por daños a terceros y perturbaciones en el tráfico (II \#246)

Tabla 34. ID de ingresos (II \#248) ......................................................................... 59

Tabla 35. ID de Costes (II \#250) .......................................................................... 59

Tabla 36. ID de composición de costes de explotación por tipo de coste (II \#253)

Tabla 37. ID sobre la composición de costes de explotación por función principal del prestador (II \#255)

Tabla 38. ID de composición de costes de explotación por la función técnica (II \#255)

Tabla 39. ID de la composición de los costes de capital (II \#246) ................. 62

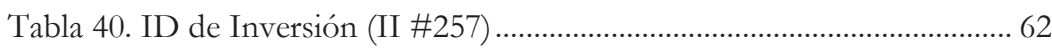

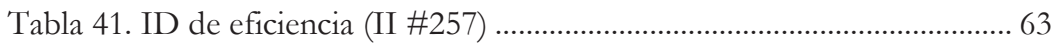

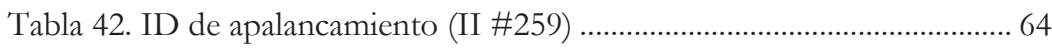

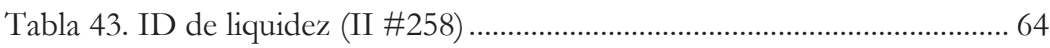

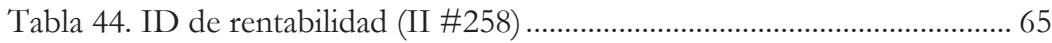

Tabla 45. Ejemplo de tabla de datos de entrada para variables ........................ 66

Tabla 46. Tipos de información de contexto del sistema de ID IWA ........... 69

Tabla 47. Ejemplos de variables que pueden ser relevantes como factores explicativos .......................................................................... 72

Tabla 48. Otros factores explicativos: nivel de externalización....................... 73

Tabla 49. Otros factores explicativos: servicio al cliente.................................. 74

Tabla 50. Otros factores explicativos: recursos tecnológicos ........................... 75

Tabla 51. Ejemplo de diferencias en la calidad de los datos en dos

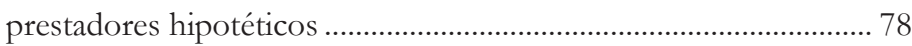

Tabla 52. Bandas de exactitud recomendadas...................................................... 80

Tabla 53. Bandas de confianza recomendadas para la fiabilidad de los datos

Tabla 54. Ilustración de los tipos de participantes e implicaciones de los datos para la asignación de niveles de importancia relativos al conjunto de ID que se dan en este manual ...................................... 97

Tabla 55. Funciones de organización - Administración general.................... 115

Tabla 56. Funciones de organización - Gestión de recursos humanos ........ 116

Tabla 57. Funciones de organización - Financiera y comercial ...................... 118

Tabla 58. Funciones de organización - Servicio de atención al usuario ....... 118

Tabla 59. Funciones de organización - Planificación y construcción .......... 119

Tabla 60. Funciones de organización - Operaciones y mantenimiento........ 120

Tabla 61. Estructura de ganancias y pérdidas anuales .................................... 123

Tabla 62. Definiciones detalladas relacionadas con la Tabla 61 .................... 124 
Tabla 63. Definiciones de inversiones ............................................................ 127

Tabla 64. Cargos anuales en la situación financiera ......................................... 127

Tabla 65. Estructura del Balance General al final del año ............................. 128

Tabla 66. Comparación de las Ganancias y Pérdidas...................................... 130

Tabla 67. Balance General comparativo al final del año ................................ 132

Tabla 68. Cuestiones clave de las NIC/NIIF ................................................... 134

Tabla 69. Impacto en los Indicadores Financieros (Ganancias y pérdidas)......................................................................................... 144

Tabla 70. Impacto en los Indicadores financieros (Balance General) .......... 145

Tabla 71. De NIIC a GAAP: Ajustes …………………………………........... 146 



\section{PRESENTACIÓN}

Desde Global Omnium nos complace colaborar con la Universidad Politécnica en la edición del libro "Indicadores de desempeño para servicios de saneamiento. Manual de buenas prácticas"

Este manual de buenas prácticas elaborado por la International Water Asociation, proporciona los fundamentos sobre Indicadores de desempeño para servicios de saneamiento, y detalla una lista completa de dichos indicadores.

Los contenidos del manual servirán a los operadores de servicios de saneamiento a evaluar mejor el desempeño de dichos servicios, mejorar los procesos de toma de decisiones, y contribuir al debate de una posible regulación de los servicios a través de herramientas que cuentan con un consenso internacional en el mundo del agua.

Desde Global Omnium nos satisface contribuir en este libro sobre el saneamiento urbano para el futuro de nuestras ciudades y el hecho de que se traduzca al castellano difundirá la temática en todo el mundo de habla hispana, donde nuestro grupo Global Omnium está trabajando.

Dionisio García Comín

Consejero Delegado

Global Omnium 



\section{PRÓLOGO A LA EDICIÓN EN CASTELLANO}

Con la publicación de este manual se culmina el proyecto de traducir al español los tres manuales de buenas prácticas que la International Water Association tiene publicados sobre evaluación del desempeño y benchmarking en servicios de agua potable y saneamiento.

En el caso de este manual de indicadores de desempeño para servicios de saneamiento, la publicación que tienen entre sus manos no es una traducción exacta de la original en inglés publicada en el año 2003. Del texto original se mantiene el sistema de indicadores al completo, es decir los indicadores, variables, estructura y definiciones, y por tanto la propuesta de indicadores que en su día formuló el correspondiente grupo de trabajo de la IWA.

Sin embargo, por coherencia con el resto de la serie de manuales, se han actualizado los capítulos de fundamentos de la evaluación del desempeño. Dichos capítulos, que conforman la primera parte del manual, constituyen el nexo entre los tres manuales de la serie y ayudan a comprender el papel que juega cada uno de los manuales en la serie.

Quiero agradecer a Global Omnium, como ya hice con los dos anteriores manuales, su apoyo para publicar estos tres volúmenes traducidos al español con la calidad y detalle que merecían. Con la publicación de este tercer manual, los profesionales del agua de habla hispana cuentan, por fin, con las principales referencias sobre la materia disponibles en su lengua, lo que sin duda contribuirá a una mejor gestión y gobernanza de los servicios de abastecimiento y saneamiento de agua en todos los países de lengua española.

De hecho, desearía que esta gran iniciativa no terminara aquí, y que tan solo fuera el primer paso en un esfuerzo por traducir al español otras obras de referencia que IWA Publishing ha publicado en los últimos tiempos. La IWA es la asociación del mundo del agua con una mayor presencia internacional, si bien dicha presencia es inferior en América Latina que en el resto de regiones del mundo. El idioma ha supuesto una barrera fundamental que ha impedido una mayor implantación de IWA, y por ello gran parte de la información técnica que se genera en el seno de la Asociación ha tenido mayores dificultades para llegar a la región. 
Estoy convencido que los esfuerzos que IWA está realizando por hablar cada vez más español redundarán en la participación de un mayor número de profesionales del agua de América Latina en nuestra Asociación, enriqueciendo los intercambios técnicos y de experiencias que la han caracterizado desde siempre.

Enrique Cabrera Rochera Vicepresidente de la International Water Association Presidente del Grupo Especialista IWA de Benchmarking y Evaluación del Desempeño 


\section{PRÓLOGO}

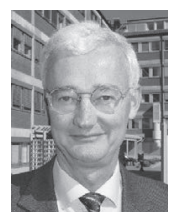

\section{Peter Stahre}

Vice Director de Malmo Water and Wastewater Works, Suecia

Presidente del grupo de ID de las 6 ciudades escandinavas

Durante la última década ha habido una demanda creciente para que los servicios de abastecimiento de agua y saneamiento se gestiones de una forma más eficiente y eficaz. Actualmente, no existe ningún sistema de evaluación del desempeño generalmente aceptado para hacer comparaciones consistentes del desempeño de los servicios de agua y saneamiento. Es por ello que la IWA ha asumido el rol principal en la elaboración de un lenguaje de referencia para tales comparaciones. Las definiciones de los indicadores de desempeño que se presentan en este manual pueden ser tomadas como un diccionario de este lenguaje de referencia, junto con las del Manual de Indicadores de Desempeño para Servicios de Abastecimiento de Agua. Los indicadores describen las características y el desempeño de las características individuales de los prestadores de servicios. Para cumplir con su propósito, cada indicador no sólo debe ser definido con mucha precisión, sino también comprendido y generalmente aceptado a nivel internacional.

El valor numérico de un indicador de desempeño individual tiene muy poco valor hasta si no se analiza en su contexto. Esto se puede hacer, por ejemplo, observando la evolución del indicador a lo largo del tiempo, o comparando su valor con el de otros prestadores. Este tipo de comparaciones se denominan benchmarking métrico ${ }^{1}$. Se debe matizar que las iniciativas de benchmarking métrico no incluyen todos los indicadores presentados en el manual, sino que para cada aplicación específica se debe seleccionar un sub grupo apropiado de éstos. Es fácil caer en la trampa de incluir demasiados indicadores. Tal y como se indica en el manual, un sistema de indicadores del desempeño debería ser implementado preferentemente como un procedimiento "paso a paso". Para ello, un buen consejo es empezar con un sistema pequeño.

El benchmarking métrico es un análisis comparativo de naturaleza cuantitativa que permite monitorizar el desempeño a largo plazo de un prestador de servicios.

1 NdelT. Actualmente la IWA recomienda utilizar el término "Evaluación comparativa del desempeño" en lugar de "benchmarking métrico". Véase el apartado I-3. 
El benchmarking ha demostrado ser una poderosa herramienta de gestión en la planificación estratégica de un prestador, que se utiliza, entre otros propósitos, para controlar el cumplimiento de los objetivos preestablecidos. También se utiliza para comparar el desempeño entre prestadores de servicios. Un resultado importante del benchmarking métrico es la identificación de las áreas con un buen desempeño, así como de aquellas que tienen necesidad de mejoras. Sin embargo, el benchmarking métrico no da ninguna explicación de por qué hay diferencias en el desempeño del sistema.

Para explorar las diferencias que se hayan identificado a través de un sistema de indicadores entre distintos servicios, es necesario llevar a cabo un análisis más detallado. Por razones prácticas, dicho análisis está restringido a incluir sólo los peores y mejores resultados, en la comparación del benchmarking métrico. Si se desea llevar a cabo un análisis más en profundidad, serán necesarios indicadores de desempeño más detallados, así como otra información relevante. Este proceso se conoce como benchmarking de procesos ${ }^{2}$. Un rasgo característico de éste es que se centra en procesos seleccionados y no en el negocio en su conjunto. Su objetivo es mejorar el desempeño "aprendiendo de los demás".

La aplicación más avanzada de los indicadores de desempeño es cuantificar la eficiencia y eficacia de un prestador de servicios, lo que se denomina evaluación del desempeño. En la evaluación del desempeño, los indicadores se utilizan conjuntamente con otros tipos de información (características del sistema, factores ambientales, etc.). La relación entre los diferentes componentes a menudo forma un rompecabezas muy complejo.

Para una implementación exitosa del benchmarking en una organización, tal y como se enfatiza en el manual, es crucial la participación activa de los altos directivos y un compromiso de los representantes de los departamentos o secciones involucrados en la recolección de datos. Es importante que la utilización de los indicadores impregne los diferentes niveles de la organización, especialmente en los indicadores económicos. Con una combinación de un enfoque de arriba hacia abajo y de abajo hacia arriba, los indicadores se convierten en una herramienta muy poderosa para mejorar los servicios de agua y aguas residuales.

2 NdelT: actualmente la IWA recomienda que al tradicionalmente llamado "benchmarking de procesos" se le denomine "mejora del desempeño". Véase el apartado I-3. 


\section{PREFACIO}

Al inicio del proyecto de desarrollo de este manual, entendimos que no sería una tarea fácil, a pesar de los precedentes y la información útil ya disponible del manual de abastecimiento de agua. Igual que con la mayor parte de nuestro trabajo, también esperábamos que requiriera mucha dedicación y uso de tiempo personal. En ambas percepciones se demostró que estábamos en lo cierto.

En los últimos dos años hemos pasado mucho tiempo volando hacia el aeropuerto de Lisboa, que es donde se encuentra la oficina del LNEC, y conciliando nuestras diversas perspectivas en una forma que creemos que ahora tiene cierta validez internacional. Los miembros más jóvenes del grupo fueron los que más horas trabajaron, y olvidaron el significado de los fines de semana, incluso cuando al final se les llevó a trabajar en el manual en el hermoso Algarve.

La variedad de nuestros antecedentes personales y culturales nos permitió compartir una visión diversa de los servicios de saneamiento que se pueden encontrar a lo largo del mundo, junto con puntos de vista muy diferentes. Cada uno de nosotros tuvimos que desafiar los paradigmas o cajas en los que pensamos, y esperamos que emerja lo que esperamos sea un producto verdaderamente aplicable.

Sin embargo, todavía no estamos completamente satisfechos con el resultado. Quizás si hubiera un sistema de indicadores para evaluar la efectividad de los manuales, podríamos tener algunos medios para evaluar la calidad de nuestro producto. Sin embargo, estamos seguros de que este manual es solo el comienzo del proceso de desarrollo de un proceso mundial para evaluar el desempeño de los servicios de saneamiento.

Todos deseamos continuar involucrados en las aplicaciones del manual y ayudarlo a evolucionar a lo largo de este camino. Si el manual le ha inspirado a usarlo, estaremos encantados de haber logrado nuestro objetivo y nos complacerá trabajar con usted en sus empeño.

Y finalmente, el viaje es siempre más importante que el resultado final y en nuestro viaje ganamos en entusiasmo, respeto y amistad. 
Esperemos que haga este viaje y al hacerlo enriquezca su experiencia, desafíe y amplíe su pensamiento y siga avanzando en el camino hacia un servicio de saneamiento verdaderamente sostenible.

Los autores 


\section{AGRADECIMIENTOS}

Como líder del Grupo de Trabajo de la IWA sobre " Indicadores de desempeño para servicios de saneamiento" deseo expresar mi agradecimiento a todos aquellos que hicieron posible este trabajo.

En primer lugar, me gustaría agradecer el trabajo realizado a mis coautores, Richard Ashley, Alejo Molinari, Andreas Schulz, Adriana Cardoso y Patrícia Duarte. Ha sido un privilegio trabajar con un equipo tan excelente y dedicado. Su apoyo, estímulo y trabajo fueron un incentivo constante para continuar con nuestro compromiso. Se merece una mención especial Richard Ashley quien adicionalmente tuvo el delicado trabajo de revisión editorial. Una palabra de aprecio también se debe a Renato Parena, Presidente del "Grupo Especialista de Estadística y Economía" de la IWA, por su amable y generosa ayuda en relación con los indicadores financieros y asuntos relacionados. Finalmente, Enrique Cabrera y su equipo, del ITA de Valencia, merecen también nuestra gratitud por proporcionar el software SIGMA Lite WW.

También me gustaría agradecer especialmente la confianza y continuo apoyo de Francisco Cubillo, Presidente del Grupo Especialista en Operaciones y Mantenimiento de la IWA.

El núcleo del equipo tuvo numerosas reuniones a lo largo del desarrollo del proyecto. Fue claramente una experiencia de aprendizaje interesante e interactiva. Hay tantas personas que han añadido un enorme valor al trabajo que no es posible nombrarlas a todas.

Hemos recibido consejos, comentarios y sugerencias en debates con la industria, talleres y discusiones generalizadas en la web. Las personas involucradas representan una amplia gama de universidades, instituciones de investigación, agencias gubernamentales, empresas y profesiones relacionadas con las aguas residuales. A todos ellos los autores les expresan su gratitud.

El estímulo, la ayuda y la asistencia continua del equipo de indicadores de desempeño servicios de abastecimiento de agua representó una contribución importante. Un agradecimiento especial a Helena Alegre por su permanente disponibilidad y amistad. 
Por último, deseo reconocer especialmente a mi Institución, el Laboratorio Nacional de Ingeniería Civil (LNEC), en Lisboa (Portugal), por haber impulsado este proyecto y por el apoyo financiero necesario durante los dos años de duración del proyecto.

Rafaela Matos

Líder del Grupo de Trabajo de la IWA sobre "Indicadores de Desempeño para Servicios de Saneamiento" 


\section{LOS AUTORES}

\section{Rafaela Matos}

Laboratório Nacional de Engenharia Civil (LNEC) - DHA - NES

Av. do Brasil, 101

PT-1700-066 Lisboa, Portugal

Teléfono (directo): + 3512184436 26; Fax: + 351218443032

E-mail: rmatos@lnec.pt

Nacida en Lourenço Marques, Mozambique, en 1954, se graduó en ingeniería civil en la Universidad Técnica de Lisboa, Portugal, en 1977. Rafaela se convirtió en investigadora del Laboratorio Nacional de Ingeniería Civil (LNEC) en 1987 con la tesis "Metodologías de evaluación y análisis de aguas pluviales urbanas - estudio basado en datos experimentales en Portugal". Por su trabajo de investigación fue galardonada con el Premio Nacional de Medio Ambiente (1988), el Premio de Hidráulica y Recursos Hídricos (1988-1989), y el premio institucional del LNEC, el premio Manuel Rocha (1992). En el año 2000 fue nombrada con el cargo de Investigadora Principal. Ha estado profundamente involucrada en Regulación y Normas, desde 1985, siendo corresponsable de los proyectos de Regulación del Abastecimiento de Agua y Saneamiento para Portugal (Europa), para Macao (Sur de China), para S. Tomé y Príncipe (África), y para Mozambique (África). Es la delegada portuguesa en las actividades del CEN/TC 165 - Ingeniería de Aguas Residuales, desde 1991, y presidió el Comité Técnico Nacional de Normalización CT90 sobre abastecimiento de agua y aguas residuales, entre 1994 y 1999. Es delegada portuguesa y enlace oficial del CEN/TC 165 en el ISO/TC224 - Indicadores de desempeño de los servicios de abastecimiento de agua saneamiento, desde 2002.

Es autora o coautora de más de 200 publicaciones científicas y técnicas. Ha organizado veinte eventos técnicos y científicos nacionales y quince internacionales. Su campo de especialización es la modelización del drenaje urbano y el control de las inundaciones, el diagnóstico y rehabilitación de los sistemas de alcantarillado, la gestión de las aguas urbanas y la evaluación del desempeño de los sistemas de alcantarillado. Ha sido Jefa de la División de Suministro de Agua y Saneamiento del LNEC entre 1990 y 2002, coordinando un equipo de 20 personas que se ocupan de la investigación aplicada sobre el ciclo urbano del agua. Presidió la Asociación Portuguesa de Abastecimiento de Agua, Saneamiento y Residuos Sólidos (APESB), entre 
1993 y 1999. Dentro de la Asociación Internacional del Agua (IWA International Water Association), es miembro del Comité Conjunto de Drenaje Urbano (JCUD) desde el año 2000. Es la líder del Grupo de Trabajo de la IWA sobre "Indicadores de desempeño para servicios de saneamiento".

\section{Adriana Cardoso}

Laboratório Nacional de Engenharia Civil (LNEC) - DHA - NES

Av. do Brasil, 101

PT-1700-066 Lisboa, Portugal

Teléfono (directo): + 35121844 3618; Fax: + 351218443032

E-mail: macardoso@lnec.pt

Nacida en Lisboa, Portugal, en 1964. Se graduó en ingeniería civil en la Universidad Técnica de Lisboa, Portugal, en 1987. Obtuvo un máster en Hidráulica y Recursos Hídricos en la Universidad Técnica de Lisboa en 1992. Es estudiante de doctorado en la Universidad Técnica de Lisboa y asistente de investigación en la División de Aguas Urbanas del Laboratorio Nacional de Ingeniería Civil (LNEC).

Su actividad en el campo del agua urbana se ha centrado principalmente en la modelización del drenaje urbano, la evaluación del desempeño de los sistemas de alcantarillado y su rehabilitación. Es autora y coautora de más de 50 artículos, informes y tesis. Es miembro del Grupo Especialista en Abastecimiento de Agua y Saneamiento de la Asociación Portuguesa de Recursos Hídricos (APRH) desde 1993 y fue Secretaria General de la Asociación Portuguesa de Abastecimiento de Agua, Saneamiento y Residuos Sólidos (APESB), entre 1996 y 1999. Es miembro del Grupo de Trabajo de la IWA sobre "Indicadores de desempeño para servicios de saneamiento". 


\section{Richard Ashley}

Pennine Water Group

School of Engineering, Design \& Technology

Universidad de Bradford

BD7 1DP West Yorkshire, UK

Teléfono (directo): +44 1274 233865; Fax: +44 1274233888

email r.ashley@,bradford.ac.uk

Nacido en Londres en 1948, se graduó en ingeniería civil en 1972, mientras trabajaba para el Greater London Council rehabilitando el sistema de alcantarillado principal de la capital. Después de un breve periodo como ingeniero de estructuras, se incorporó al Thames Polytechnic como profesor de ingeniería hidráulica y de salud pública. Realizó investigaciones sobre la carga de olas en estructuras a cierta distancia de la costa con el Instituto Marítimo Nacional y recibió un título de MPhil en 1981. Se trasladó al Instituto Tecnológico de Dundee en 1982, convirtiéndose en ingeniero civil colegiado (MICE) en 1988, después de haber obtenido anteriormente el título de miembro de la Institución de Gestión del Agua y del Medio Ambiente. Catedrático de Ingeniería Hídrica y Ambiental de la Universidad de Abertay Dundee y cofundador y director del Centro de Tecnología de Aguas Urbanas.

Se trasladó a la Universidad de Bradford en 2000, como profesor de hidráulica urbanas, donde estableció conjuntamente el Pennine Water Group (con la Universidad de Sheffield), un centro de becas de excelencia para plataformas financiado por el EPSRC del Reino Unido. Es profesor visitante en la Universidad Técnica de Delft, miembro del comité conjunto IWA/IAHR sobre drenaje urbano y fundador y antiguo presidente del grupo de trabajo de sistemas y procesos de alcantarillado. Ha publicado/presentado unos 200 artículos en el campo del drenaje urbano y es editor jefe y autor del próximo informe científico y técnico de IWA sobre Sólidos en el sistema de alcantarillado (estado del arte). Es colaborador del próximo Glosario de Drenaje Urbano de la IWA y colaborador de varios capítulos de libros. Es el Presidente de la Región de Yorkshire y Humberside de la Institución de Ingenieros Civiles y trabaja en dos importantes proyectos del Reino Unido que tratan sobre el control de las inundaciones debidas al drenaje en respuesta al cambio climático y el desarrollo de sistemas de gestión del ciclo de agua más sostenibles para nuevos desarrollos. 


\section{Patrícia Duarte}

Laboratório Nacional de Engenharia Civil (LNEC) - DHA - NES

Av. do Brasil, 101

PT-1700-066 Lisboa, Portugal

Teléfono (directo): + 35121844 3842; Fax: + 3512184430 32;

E-mail: pduarte@lnec.pt

Nacida en Lisboa en 1973, se graduó en ingeniería ambiental en 1996, en la Universidade Nova de Lisboa. Desde el comienzo de 2003 es estudiante de doctorado en Ingeniería Civil Hidráulica con un trabajo de tesis sobre la concepción de redes de distribución de agua basada en la optimización de su eficiencia técnica. Trabajó en el LNEC en los tres años anteriores como becaria de investigación en un proyecto de rehabilitación de sistemas de abastecimiento de agua y saneamiento.

Es miembro del grupo de trabajo de la IWA sobre "Indicadores de desempeño para servicios de saneamiento". También ha sido miembro del equipo coordinador de las pruebas de campo de los indicadores de desempeño de los servicios de abastecimiento de agua de la IWA y ha traducido al portugués el Manual de Buenas Prácticas de Servicios de Abastecimiento de Agua de la IWA (Alegre et al., 2000). También ha colaborado en la segunda edición de dicho Manual. Antes de su actividad en el LNEC, trabajó durante dos años en una empresa privada de gestión de servicios de abastecimiento de agua y saneamiento.

\section{Alejo Molinari}

Ente Tripartito de Obras y Servicios Sanitarios (ETOSS)

Av. Callao 982

(C1023 AAP) Buenos Aires, Argentina

Teléfono/ Fax:: +54114816 5068;

E-mail: amolinari@etoss.org.ar

Nacido en Santa Rosa (L.P.), Argentina, en 1955, se graduó en Ingeniería Civil en la Universidad Nacional del Sur (Argentina), en 1979, y en la Universidad de Padua, Italia, en 1980. También tiene un MBA de la Universidad Austral (Argentina) en 1991 y otros títulos en Regulación y Estrategia de Servicios Públicos, del PURC de la Universidad de Florida 
(EE.UU.) y en Regulación Económica de Servicios Públicos del CEER de la Universidad UADE (Argentina). Es doctor en Ingeniería Civil.

Ha desarrollado la primera parte de su carrera en la gestión de grandes proyectos de infraestructura en Europa y Oriente Medio. En 1994 fue nombrado Gerente de Administración de Activos del Ente Regulador de los Servicios de Agua y Saneamiento de la Región de Buenos Aires (ETOSS). Sus funciones incluían los estudios requeridos para futuras inversiones, así como en el programa de mantenimiento predictivo de activos. En el año 2000 se convirtió en Gerente de la Calidad del Servicio de la misma entidad, siendo responsable de la calidad de los servicios de agua, alcantarillado y tratamiento de aguas residuales, coordinando un grupo de 11 especialistas.

Está a cargo del Centro de Intercambio de Información sobre Regulación de la Asociación Federal de Entes Reguladores de Agua y Saneamiento (AFERAS) argentina; y ha sido designado como líder del proyecto de benchmarking para la Asociación de Reguladores de Agua y Saneamiento de las Américas (ADERASA). Como consultor, ha desarrollado recientemente el benchmarking regulatorio para el Organismo Regulador de Agua y Saneamiento de Bolivia (SISAB - Sistema de información medioambiental de Bolivia); y asistió a la Universidad ULBRA en Porto Alegre (Brasil) en la creación de un Máster en Estrategia y Regulación de Servicios Públicos.

Ha organizado varios eventos nacionales e internacionales y ha sido ponente en numerosos seminarios y eventos internacionales sobre estrategia, regulación y benchmarking de servicios públicos.

\section{Andreas Schulz}

Emschergenossenschaft/Lippeverband

Kronprinzenstraße 25, 45128 Essen, Alemania

Teléfono: +49 (0) 201/104-2723; Fax: +49 (0) 201/104-2786

E-mail: aschulz@eglv.de

Nacido en 1956 en Wattenscheid, desde entonces incorporado a la ciudad de Bochum. Estudió Ingeniería Civil en la Universidad Técnica de Berlín, especializándose en el diseño de ingeniería hidráulica en el campo de "Diseño e ingeniería hidráulica agrícola", graduándose en 1981. Obtuvo su doctorado en 1986 con una tesis sobre la hidráulica de los cuerpos de agua naturales y 
artificiales y de las vías fluviales. Desde 1987 trabaja en Emschergenossenschaft/Lippeverband. Primero en el campo de la planificación y construcción de plantas de tratamiento de aguas residuales y pluviales, luego, en canales y vías fluviales, y más recientemente como jefe del departamento de Tecnología de la Construcción. En 1997 se le confió la creación de un equipo de supervisión técnica en la División Técnica a nivel de Junta Directiva. Desde mediados de 2001 está a cargo del departamento de Mercado y Cliente. Es el responsable de la coordinación del desarrollo de los sistemas de benchmarking dentro de las asociaciones. Ha sido y sigue siendo miembro activo de varios grupos de trabajo de la DVWK y la ATV, y es también el portavoz del equipo ad hoc de "Benchmarking". 


\section{NOTA A LA VERSIÓN EN CASTELLANO}

El presente documento no se trata simplemente de una traducción del Manual de Indicadores de Desempeño para Servicios de Saneamiento, sino que además es una adaptación de éste. Para ello, el documento se ha reestructurado en dos partes.

El mayor cambio se encuentra en la primera parte de este manual, que se ha actualizado para armonizarlo con la metodología que se presenta en el manual gemelo de servicios de abastecimiento de agua, actualizado en 2014. De este modo, en la primera parte del manual el lector encontrará información detallada de cómo implementar un sistema de indicadores.

Con respecto a la segunda parte del manual, ésta contiene el sistema de indicadores de la IWA para servicios de saneamiento: indicadores, variables e información de contexto. El mayor cambio es visual ya que se ha actualizado la forma de presentar elementos. El sistema de indicadores del desempeño es el original, con alguna pequeña adaptación en la fórmula de algunos indicadores financieros. De este modo, se han equiparado a los actualizados en la segunda y tercera edición del manual de servicios de agua. Los cambios se detallan a continuación en la siguiente tabla.

\begin{tabular}{|l|l|}
\hline Indicadores financieros adaptados \\
\hline wFi1 - & Ingresos unitarios (EUR/p.e./año) \\
\hline wFi5 - & $\begin{array}{l}\text { Costes totales unitarios por población equivalente } \\
\text { (EUR/p.e./año) }\end{array}$ \\
\hline $\begin{array}{l}\text { Costes totales unitarios por longitud de colector (EUR/km } \\
\text { red/año) }\end{array}$ \\
$\begin{array}{l}\text { wFi7 -Costes de explotación unitarios por población equivalente } \\
(\text { EUR/p.e./año) }\end{array}$ \\
\hline $\begin{array}{l}\text { wFi8 -Costes de explotación unitarios por longitud de colector } \\
(\text { EUR/km red/año) }\end{array}$ \\
$\begin{array}{l}\text { wFi9 -Costes de capital unitarios por población equivalente } \\
(\text { EUR/p.e./año) }\end{array}$ \\
$\begin{array}{l}\text { wFi10 -Costes de capital unitarios por longitud de colector } \\
(\text { EUR/km red/año) }\end{array}$ \\
\hline
\end{tabular}

Sobre la información de contexto, se han mantenido los mismos elementos. Sin embargo, debido a que en la edición original del 2003 no tenían ningún código que permitiese hacer referencia rápida a éstos, en esta traducción se 
les ha asignado códigos de forma que se numeran como wCI, de forma análoga al manual de servicios de abastecimiento de agua.

El orden de algunos elementos del manual, como los autores, se ha alterado para estandarizar el manual su análogo. El contenido del "Anexo I Glosario" se encuentra en el apartado II. 1.4-Definiciones complementarias. El "Anexo 2 - Definiciones de las variables" es actualmente el apartado II.3-Variables. El "Anexo 3 - Ejemplo de la asignación de los niveles significancia" se ha eliminado, ya que dicho sistema ya no se utiliza. Finalmente, el manual de Sigma Lite del Anexo 4 se ha suprimido debido a que en el programa SIGMA se encuentra un manual actualizado del software. Dicho software ya no se proporciona en forma de CD, sino que se puede descargar de forma gratuita en www.sigmalite.com/sigma-es.php. 


\section{UNIDADES DE MEDIDA Y SÍMBOLOS}

EUR Euro

$\% \quad$ porcentaje

$\mathrm{km} \quad$ kilometro

$\mathrm{km}^{2} \quad$ kilómetro cuadrado

$\mathrm{kPa}$ kilopascal

$\mathrm{kW} \quad$ kilovatio

$\mathrm{kWh}$ kilovatio $\mathrm{x}$ hora

1 litro

m metro

$\mathrm{m}^{2} \quad$ metro cuadrado

$\mathrm{m}^{3} \quad$ metro cúbico

${ }^{\circ} \mathrm{C}$ grados Celsius

\section{ABREVIATURAS}

BAI Beneficio antes de impuestos

BAII Beneficio antes de intereses e impuestos

B.O. Beneficio operativo

BE Beneficios de explotación

CI Contribución a la inversión

DBO5 Demanda biológica de oxígeno

DQO Demanda química de oxígeno

DSU Desbordamientos del sistema unitario

EDAR Estación depuradora de aguas residuales

IC Información de contexto

ID Indicador de desempeño

Hab. Habitantes

No. Número

ONG Organización no gubernamental

p.e. población equivalente

SUDS Sistema urbano de drenaje sostenible

\section{OTRAS CONVENCIONES}

Los términos escritos en el formato texto están definidos en el apartado II-1.4. 



\section{PARTE I}

\section{FUNDAMENTOS DE LA EVALUACIÓN DEL DESEMPEÑO}





\section{INTRODUCCIÓN}

\subsection{Balance tras 20 años de la publicación de los sistemas de indicadores de desempeño de la IWA}

El primer manual de buenas prácticas sobre indicadores de desempeño para servicios de abastecimientos de agua nació en 2000. Desde entonces, la industria del agua y las diferentes partes interesadas han mostrado una aceptación general de la necesidad de evaluar el desempeño de los servicios de agua y el uso de indicadores de desempeño. Como consecuencia, la metodología de la IWA ha sido un referente en muchas regiones, y sus indicadores se han aplicado a muchos contextos diferentes.

Durante este tiempo los sistemas de Indicadores de desempeño de la IWA (IWA ID) se han convertido en el estándar de la industria para la evaluación del desempeño. La inclusión de sus conceptos en las normas nacionales e internacionales, su uso por los reguladores de los servicios de agua en todo el mundo y la inspiración o incluso mayor presencia en la mayoría de los proyectos activos de evaluación del desempeño internacional y benchmarking son una prueba de ello. Los sistemas IWA ID son a menudo citados como un logro clave de la IWA, un proyecto exitoso si el éxito se mide por el número de iniciativas en las que el manual de ID de la IWA está presente de alguna manera (ya sea como referencia, fuente de inspiración o incluso en la Fundación del proyecto).

Sin embargo, aún queda mucho por hacer y todavía quedan retos por delante. Aunque muchos proyectos incluyen los indicadores de desempeño de la IWA de una u otra forma, no es así con el marco y la metodología de este sistema que, salvo algunas excepciones, no se implementan completamente. Esto es especialmente cierto en torno a cuestiones relacionadas con la evaluación de la calidad de los datos y su confianza, así como en la coherencia entre los sistemas de gestión y los indicadores definidos (a menudo no basados en objetivos claros y estratégicos). Además, los indicadores de desempeño de la IWA no satisfacen plenamente las necesidades de las regiones en desarrollo.

Por último, la evaluación del desempeño también fue una parte clave de los Objetivos de Desarrollo del Milenio en lo referente al agua y lo será de igual modo o más en los Objetivos de Desarrollo Sostenible. Aunque los indicadores de desempeño de la IWA no se centran en el mismo nivel 
macroeconómico, todavía hay margen para mejorar las métricas utilizadas en estas iniciativas, especialmente dada la gran importancia que tienen los indicadores en el resultado real.

\subsection{La industria del agua, contexto, motivaciones y desafíos}

Desde la publicación de la primera edición de este manual, ha habido una evolución significativa en la industria del agua en relación con la evaluación del desempeño. La industria ha sido testigo de una creciente madurez en la gestión de los servicios de agua en diversas partes del mundo. Esto ha dado lugar a reformas institucionales encaminadas a crear una escala adecuada para los servicios de agua y saneamiento, aumentando su eficiencia, transparencia y rendición de cuentas mediante entidades reguladoras. Estas reformas todavía están en curso en algunos países y otras seguramente seguirán en un futuro próximo.

Los principios de recuperación de los costes totales se han convertido en un ingrediente más común en la gobernanza de los servicios de agua, como consecuencia de una perspectiva modificada en términos de fijación de precios y evaluación de la eficiencia. Las cuestiones ambientales, con un mayor enfoque en la energía, también se perciben ahora con mayor importancia. Sin embargo, la sostenibilidad del servicio como concepto aún no está tan presente como debería, y las perspectivas a largo plazo para la sostenibilidad de la infraestructura siguen siendo una de las cuestiones clave que rara vez se abordan adecuadamente.

El suministro público de agua y el servicio de saneamiento son servicios esenciales para las comunidades, formando parte de los llamados "servicios de interés general", vitales para el bienestar general, la salud pública y la seguridad colectiva de las poblaciones, así como para las actividades económicas y la preservación del medio ambiente. De hecho, las Naciones Unidas han reconocido el Derecho Humano al Agua y al Saneamiento, reforzando la idea de que todas las personas tienen derecho a agua suficiente, segura, aceptable, accesible y asequible para usos personales y domésticos.

Dichos servicios permiten grandes economías de escala y los costes unitarios de instalación y producción disminuyen a medida que aumenta la demanda, 
hasta cierto punto. Por otra parte, también hay un margen significativo de economía, donde los costes de la unidad de producción tienden a disminuir a medida que se integran actividades similares (por ejemplo, donde el suministro de agua y el saneamiento y disposición de aguas residuales se gestionan conjuntamente) debido a las sinergias en la Gestión de recursos humanos, equipos e instalaciones.

El alto valor de los activos, derivados de un sector con un valor patrimonial elevado, también caracterizan dichas actividades. Además, se trata de infraestructuras diseñadas a largo plazo, construidas a lo largo de muchas décadas, diseñadas para situaciones punta y que resultan en bienes inactivos que no se utilizan durante períodos prolongados. Las infraestructuras muestran un alto grado de inmovilización, ya que están destinadas a un propósito específico y por esta razón su transacción es difícil. Este mercado muestra una alta relación entre los valores de los activos y los ingresos generados y la baja elasticidad precio-demanda, ya que se trata de servicios estructurales esenciales.

Se pueden identificar diferentes mercados relevantes en el sector del agua. El más importante es el mercado de transacciones entre prestadores de agua y saneamiento y usuarios finales, que es un monopolio natural. Otros mercados son el mercado de transacciones entre las empresas de servicios a en alta y en baja, que en general son un monopolio legal; el mercado de transacciones entre los prestadores y los proveedores de bienes y servicios, que es un mercado competitivo; y el mercado de transacciones con los propietarios de los recursos hídricos, un cuasi-monopolio.

Estas características contribuyen a limitar la competencia dentro del sector en lo que se refiere al servicio al consumidor. En términos prácticos, sólo es factible la existencia de un operador por cada área geográfica servida, lo que origina un monopolio, ya sea a nivel local o regional. El usuario en tal contexto no puede elegir ni el operador ni el precio-calidad más conveniente. Los monopolios naturales ocurren cuando la estructura de costes se caracteriza por la caída de los costes marginales de producción promedio a medida que el sistema productivo se desarrolla, debido a la existencia de economías de escala. En tales casos, el coste total de producción para una demanda determinada es inferior cuando el proveedor de servicios solo uno. 
Por supuesto, este hecho no incentiva a los prestadores de agua y saneamiento a incrementar su eficiencia y eficacia. Es por ello que esta debilidad importante del sector debe minimizarse en la medida de lo posible.

El sector del agua se enfrenta a futuros grandes desafíos, y éstos están en constante evolución. Las presiones actuales sobre el sector incluyen:

- la adaptación al cambio climático, teniendo en cuenta las situaciones potenciales de estrés hídrico y de fenómenos extremos,

- la reducción del consumo de energía en una actividad con un consumo energético considerable, como la recogida y tratamiento de aguas residuales; - mantener el ritmo de crecimiento de la población, especialmente en las zonas urbanas de rápido crecimiento, pero también con los cambios sociales (migraciones, envejecimiento, etc.);

- las presiones financieras inducidas por la economía mundial;

- la evolución de las expectativas de los usuarios y las presiones políticas para reducir el precio de las tarifas;

- el aumento de la edad de las infraestructuras y la sostenibilidad global del servicio.

Mantener de forma sostenible un sistema de abastecimiento de agua y saneamiento es tan difícil e importante como realizar la inversión capital inicial. La provisión de agua potable segura y saneamiento es un servicio y requiere una actitud orientada al servicio por parte de los prestadores involucrados. Normalmente, estos servicios pueden establecerse de un modo asequible para los consumidores y ser administrados y operados de acuerdo con los principios de buenas prácticas comerciales y normativas, que tienen por objeto proteger a los consumidores y al medio ambiente.

La forma en la que se lleva a cabo la gestión variará de acuerdo con la situación local, y puede ser pública, privada o mixta. En cualquier caso, el objetivo esencial a alcanzar es la mejora continua de la calidad del servicio.

\subsection{El enfoque de la IWA en la gestión de servicios de agua}

La gestión de los servicios de agua debe seguir un enfoque integrado. Históricamente, la gestión técnica de los servicios se ha centrado en el lado 
de la ingeniería del negocio, considerando las decisiones de la alta dirección y las decisiones financieras como insumos o restricciones. Sin embargo, los servicios de agua en mayor medida que en otros sectores, dependen en gran medida de criterios técnicos para enfrentar decisiones estratégicas. Una porción importante de todas las inversiones en servicios de agua está destinada a expandir, mantener y renovar infraestructuras (las redes de abastecimiento de agua y saneamiento); al mismo tiempo, la capacidad para hacer frente a nuevas limitaciones (medioambientales, sociales, calidad del servicio, etc.) depende en gran medida de las características de la red. Por ejemplo, las posibles decisiones estratégicas de expandir la red, aumentar la resiliencia a la escasez de agua, mejorar la calidad del agua o reducir el uso de energía no pueden ser tomadas de manera eficiente sin considerar las decisiones técnicas. Un sistema de evaluación del desempeño debe entonces basarse en descubrir los aspectos críticos que impulsan el éxito de tales iniciativas.

Por esta razón, el marco de ID de la IWA aboga por una selección de indicadores que se basa directamente en los objetivos estratégicos del servicio. Una integración que debe estar claramente establecida para la gestión estratégica de las infraestructuras.

La gestión de las infraestructuras siempre debe tener como objetivo general la sostenibilidad del servicio con el tiempo. Esto implica entender la evolución de los infraestructuras, así como la de la demanda y las restricciones del servicio (por ejemplo, la necesidad de mejorar la calidad del servicio, los estándares ambientales más exigentes o los nuevos desafíos como el cambio climático). Una vez que se hayan fijado los objetivos estratégicos a largo plazo, se debe continuar con los objetivos a medio y corto plazo, para así determinar las medidas adecuadas de evaluación del desempeño que controlen y ayuden a alcanzar tales objetivos.

\subsection{La creciente importancia de los sistemas de evaluación del desempeño}

En los últimos 20 años los sistemas de evaluación del desempeño en el sector del agua se han convertido en una práctica común en todo el mundo, aumentando también de forma importante la necesidad de su uso. Los servicios de agua siempre han estado enmarcados en una realidad compleja, 
en la que los factores macroeconómicos, sociales y ambientales eran relevantes para las funciones básicas del prestador. La cantidad de factores entrelazados sigue creciendo $y$, por tanto, también la complejidad de los servicios (por ejemplo, el nexo agua-energía se ha vuelto mucho más relevante en el pasado reciente y las emisiones directas e indirectas de gases de efecto invernadero se deben de tener en cuenta al gestionar los servicios de abastecimiento de agua y saneamiento).

Esta creciente complejidad requiere el uso de herramientas sistemáticas que proporcionen una visión global y apoyen la toma de decisiones. Herramientas que, al igual que los sistemas de evaluación de desempeño, pueden ser configuradas para considerar simultáneamente las diferentes restricciones y factores clave de una manera simplificada.

Los sistemas de evaluación del desempeño también pueden utilizarse para facilitar la comunicación entre los diferentes actores involucrados en los servicios de abastecimiento de agua y saneamiento. Al proporcionar información simple, agregada y confiable, los indicadores de desempeño representan una buena herramienta de comunicación entre los diferentes niveles de gestión, entre los gestores de los servicios y los políticos y reguladores e incluso con la sociedad en general.

Otros ejemplos sobre por qué los sistemas de evaluación del desempeño representan una herramienta cada vez más importante son:

- La presión de la sociedad para aumentar la transparencia y la rendición de cuentas, como se describe en la Carta de Lisboa.

- El aumento de la cantidad datos disponibles de para los gestores de los servicios recogidos por los nuevos sistemas de información, sensores de adquisición de datos en tiempo real, herramientas y software (exceso de datos).

- Incremento del estrés financiero con poco a nada de espacio para malas inversiones e ineficiencias en el uso del capital.

- Requisitos adicionales para la recuperación de costes y la necesidad de mejorar los procesos internos para incrementar la eficiencia del proceso. 


\subsection{Usuarios de los sistemas de evaluación del desempeño en servicios de saneamiento}

Las entidades o partes interesadas más importantes en el servicio de saneamiento:

- los prestadores del servicio de saneamiento, que son las organizaciones públicas, privadas o mixtas que gestionan los sistemas de alcantarillado y/o tratamiento de aguas residuales;

- los consumidores o usuarios directos, con quien el prestadores del servicio de saneamiento tiene una relación entre proveedor y cliente;

- las partes interesadas indirectamente, que no tienen una conexión directa con el sistema, pero pueden verse afectadas por él o por su impacto en el medio ambiente circundante (por ejemplo, las consecuencias de las roturas de colectores, el impacto cuantitativo o cualitativo de las inundaciones por aguas residuales, etc.);

- las partes interesadas proactivas, como las organizaciones medioambientales, las agencias de protección al consumidor y otros grupos de presión;

- los órganos de gestión de políticas, a nivel local, regional y nacional;

- las agencias reguladoras, responsables de la regulación económica y de la calidad del servicio, así como de la creación y verificación del cumplimiento de las obligaciones legales y de otra índole;

- las agencias financieras, de especial importancia en un sector tan intensivo en capital como la industria del agua.

Otras partes interesadas pueden incluir organismos internacionales, desde asociaciones humanitarias hasta organizaciones políticas y multinacionales.

Independientemente de su naturaleza (privada, pública o mixta) o situación geográfica, se puede asumir que todos los prestadores del servicio de saneamiento, comparten un propósito común y objetivos de gestión, que se puede expresar como: "Lograr la mayor satisfacción del consumidor y calidad del servicio en consonancia con el marco regulatorio vigente, al tiempo que se hace el mejor uso de los recursos disponibles". (Faria \& Alegre, 1996). 


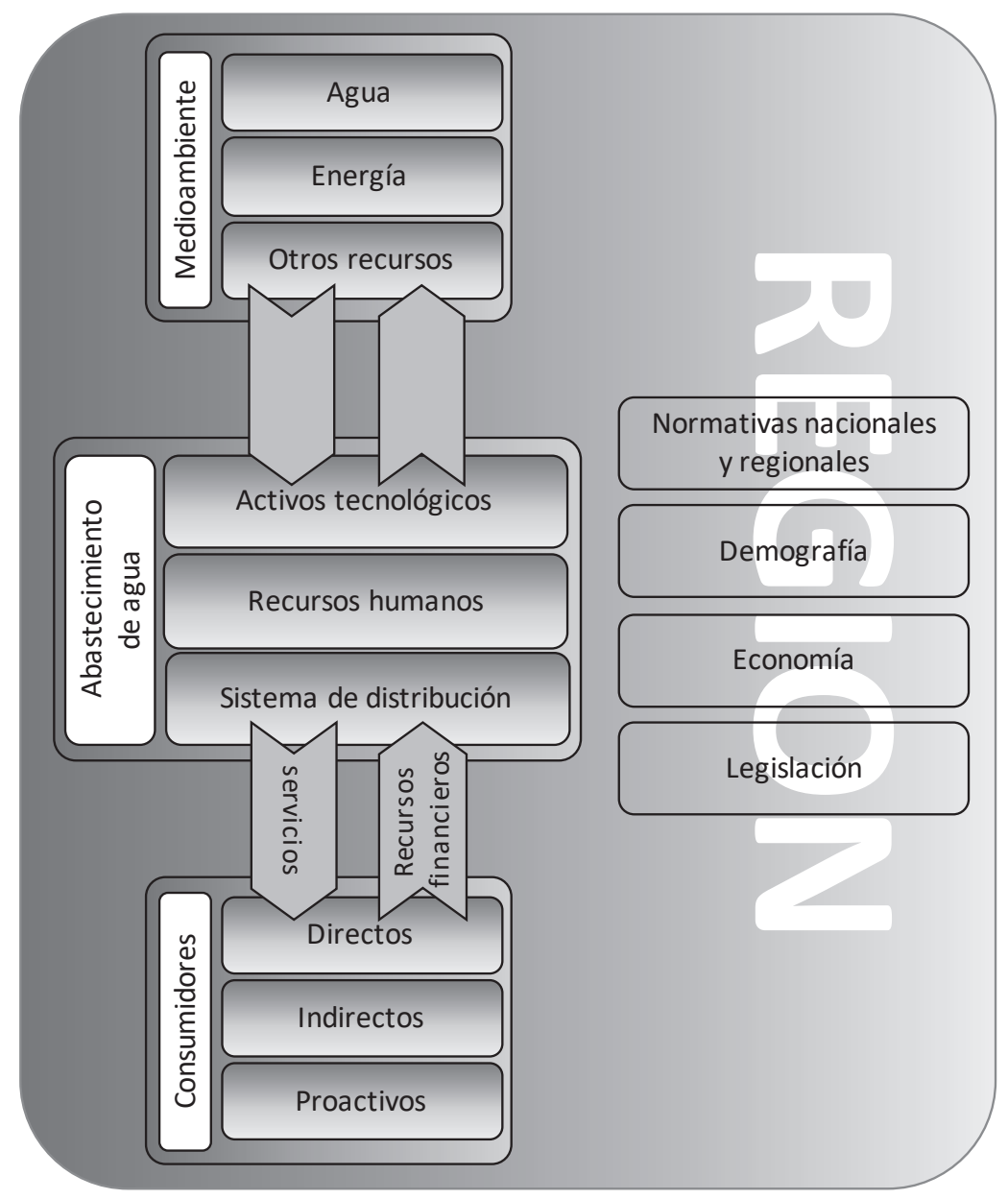

Figura 1. Contexto de los prestadores de servicios de saneamiento

$\mathrm{Al}$ considerar las relaciones entre las partes interesadas, los recursos y los valores (ver Figura 1), es posible identificar cinco tipos de objetivos de gestión:

- proporcionar un nivel de servicio adecuado a los consumidores, cumpliendo con las normativas nacionales y regionales, así como las obligaciones legales y otros compromisos;

- obtener la mayor productividad posible de los recursos humanos y ofrecer las mejores oportunidades de empleo y carrera según las capacidades y aptitudes de los individuos;

- proteger y asegurar un uso sostenible del agua y otros recursos naturales; 
- alcanzar el uso más eficiente de los recursos financieros;

- planificar, construir, mantener y operar las infraestructuras del prestadores de la manera más eficiente y efectiva posible.

Los indicadores de desempeño pueden ser útiles para todas las entidades mencionadas, con los siguientes beneficios y usos potenciales:

Para prestadores del servicio de saneamiento:

- posibilitan alcanzar una mejor calidad del servicio, así como una respuesta oportuna de los gerentes;

- permiten un seguimiento más fácil de los efectos de las decisiones de gestión, particularmente en lo que se refiere a calidad, servicio al cliente, sostenibilidad y eficiencia económica;

- proporcionan información clave para realizar un enfoque proactivo de la gestión, con menos dependencia de las averías que se puedan ocasionar en el sistema (enfoque reactivo);

- destacan las fortalezas y debilidades de los departamentos, identificando la necesidad de medidas correctivas para mejorar la productividad, procedimientos y rutinas;

- asisten en la implementación de un programa de gestión total de calidad, como una forma de promover la calidad y eficiencia en toda la organización;

- facilitan la implementación de procedimientos de benchmarking, tanto internamente, para comparar el desempeño en diferentes ubicaciones o sistemas, y externamente, para comparar con otros prestadores similares, promoviendo así mejoras en el desempeño;

- proporciona una base técnica sólida para auditar funcionamiento del servicio y predecir el efecto de las recomendaciones que resultan de la auditoría.

Para los órganos de gestión de políticas tanto a nivel nacional como regional:

- proporcionan una base común para comparar el desempeño de los prestadores de agua y saneamiento, identificando posibles medidas correctoras;

- apoyan la formulación de políticas para el sector del agua, dentro de la gestión integrada de los recursos hídricos, incluyendo la asignación de recursos, las inversiones y el desarrollo de nuevas herramientas reguladoras. 
Para las agencias reguladoras:

- proporcionan una herramienta de monitorización clave para proteger los intereses de los consumidores de un servicio monopolístico, evaluando el desempeño, comparando los distintos prestadores y supervisando que se cumplan las metas establecidas.

Para los organismos financieros:

- proporcionan asistencia para evaluar las prioridades de inversión, la selección de proyectos y su seguimiento.

Para los consumidores y partes interesadas proactivas:

- suponen un medio para traducir procesos complejos en información fácil de entender, reflejando la calidad del servicio prestado.

Para organismos supranacionales:

- proporcionan un leguaje muy apropiado para identificar las principales asimetrías junto con sus causas y evolución del sector del agua alrededor del mundo, ayudando así a la definición de estrategias.

\subsection{Objetivos de la serie de manuales de la IWA sobre buenas prácticas}

El objetivo principal de este manual es proporcionar directrices para el establecimiento de una herramienta de gestión para los prestadores de agua y saneamiento basada en el uso de indicadores de desempeño.

Otros objetivos complementarios son proporcionar un marco coherente de indicadores que:

- permitan futuras comparaciones entre los prestadores en el ámbito de las iniciativas de evaluación comparativa del desempeño,

- puedan ser adoptados por los organismos reguladores,

- permitan ampliar y consolidar progresivamente las estadísticas internacionales recogidas por la IWA

El Sistema de ID de la IWA incluye indicadores de desempeño potencialmente relevantes en los altos niveles de la gestión estratégica de los prestadores de agua y saneamiento. Su objetivo es incorporar todos los aspectos 
relevantes necesarios para expresar los objetivos y resultados de la gestión en términos de rendimiento de un prestadores de servicios agua y saneamiento. Pueden ser necesarios indicadores complementarios dependiendo del contexto y las circunstancias locales, y serán necesarios para evaluar al nivel de funciones, procesos y tareas. Sin embargo, éstos tienden a ser mucho más dependientes de la organización. Por lo tanto, no están incluidos en el sistema, pero pueden acomodarse fácilmente dentro de la misma estructura y principios.

\subsection{Acerca de este manual}

Se invita al lector a leer secuencialmente la primera parte (Parte I) del manual. A partir de los conceptos básicos utilizados, se explica cuáles son los componentes clave del sistema de ID de la IWA, así como su fundamento y recomienda una metodología de implementación general.

La parte II, las "páginas amarillas", contiene el propio sistema de ID de saneamiento de la IWA, con la definición de todos los elementos del sistema y sus relaciones. Si bien la primera parte pretende ser un manual adecuado sobre cómo implementar y utilizar indicadores de desempeño, la segunda parte es la herramienta de referencia necesaria para aplicarlos. 



\section{SISTEMAS DE INDICADORES DE DESEMPEÑO}

\subsection{Sistema de indicadores de desempeño}

El objetivo final de cualquier sistema de indicadores de desempeño es proporcionar información. Es importante resaltar la diferencia entre información y datos. Una definición correcta de la información sería "datos que se pueden utilizar con el fin de tomar decisiones". Por consiguiente, un sistema de indicadores de desempeño no sólo tiene por objeto proporcionar el valor de unos cuantos ratios, sino también de todos los elementos complementarios (calidad de los datos, factores explicativos, contexto) necesarios para tomar las decisiones adecuadas.

Un sistema de indicadores de desempeño es el resultado de considerar todas las áreas de interés, partes interesadas y factores que influyen en un determinado entorno. En el caso de los prestadores servicios de saneamiento, un sistema completo incluiría toda la empresa, las partes interesadas, los usuarios, el medio ambiente, y todas las áreas relacionadas que merecen ser monitoreadas con fines de gestión.

Como consecuencia, un sistema de indicadores de desempeño comprende un conjunto de indicadores de desempeño y datos relacionados que representan la realidad del contexto de los prestadores (Figura 2). La clasificación de estos datos depende del papel activo que desempeñan.

Datos: Un dato básico del sistema es aquel valor que puede medirse en campo o se puede obtener fácilmente. En función de su naturaleza y de su papel dentro del sistema, pueden considerarse variables, información de contexto o factores explicativos

Variables: Una variable es un dato del sistema que se puede combinar mediante una fórmula para definir indicadores de desempeño. Una variable completa consiste en un valor (resultado de una medición o un registro) expresado en unas unidades específicas y un grado de confianza que indica la calidad del dato representado por la variable

Indicadores de desempeño: Son medidas de la eficiencia y efectividad de la prestación de servicios y son el resultado de combinar varias variables. La información proporcionada por un indicador de desempeño es el resultado 
de una comparación (con una meta, valores previos del mismo indicador o valores del mismo indicador en otros prestadores).

Los indicadores individuales deben ser únicos y apropiados para representar todos los aspectos relevantes del desempeño de un prestadores de una forma adecuada e imparcial. Cada indicador de desempeño debe contribuir a expresar el nivel actual de desempeño en una cierta área para un periodo de tiempo, permitiendo una clara comparación con los objetivos marcados y simplificando lo que, de otra forma, supondría un complejo análisis.

Un indicador de desempeño consiste en un valor (resultado de evaluar la fórmula) expresado en unas unidades específicas y un grado de confianza que indique la calidad de la información representada por el indicador.

Típicamente, los indicadores de desempeño expresan ratios entre variables; estas pueden ser afines (p.ej. \%) o no afines (p.ej. $€ / \mathrm{m}^{3}$ ). En el último caso, el denominador deberá representar una dimensión del sistema (p.ej. número de acometidas, longitud total de tuberías, costes anuales, etc.) para permitir comparaciones. El uso de variables como denominadores que puedan variar mucho de un año a otro, particularmente si no está controlado por el prestador, debe evitarse (p.ej. el consumo anual, que puede verse afectado por las condiciones metrológicas u otros factores externos), a menos que el numerador varíe en la misma proporción.

Debe definirse una formula clara de procesamiento para cada indicador, especificando todas las variables requeridas y su combinación algebraica.

Información de contexto: la información de contexto está formada por datos que proporcionan información sobre las características inherentes prestadory que explican las diferencias con otros sistemas. Hay dos tipos posibles de información de contexto:

- Información que describe contexto puro y factores externos a la gestión del sistema. Estos elementos permanecen relativamente constantes en el tiempo (demografía, geografía, etc.) y en todo caso no están afectados por decisiones de gestión. En algunos países (p.ej. Alemania) esta información se conoce como "información estructural". 


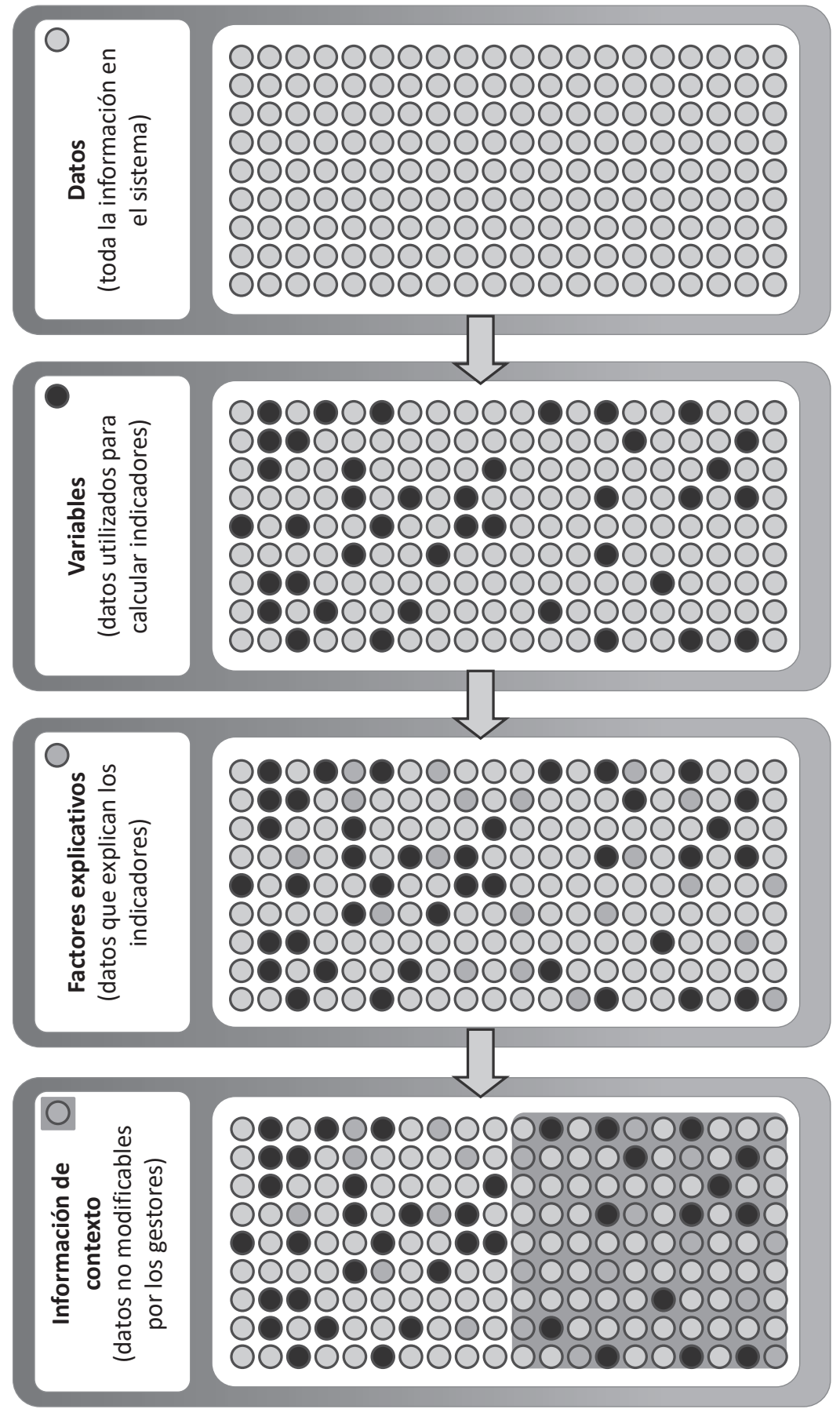

Figura 2. Componentes de un sistema de indicadores de desempeño 
- Algunos datos, por otro lado, no son modificables por las decisiones de gestión a corto y medio plazo, pero las políticas de gestión pueden influir en ellas a largo plazo (p.ej. el estado de las infraestructuras del prestador.

La información de contexto es especialmente útil cuando se comparan indicadores de prestadores diferentes.

Factores explicativos: Un factor explicativo es cualquier elemento del sistema de indicadores del desempeño que pueda ser utilizado para explicar el valor de los indicadores, por ejemplo, el desempeño obtenido en la fase de análisis. Esto incluye indicadores, variables, información de contexto y otros datos que no juegan un papel activo antes de la fase de análisis.

El uso de indicadores de desempeño debería ir siempre unido al establecimiento de un sistema de evaluación del desempeño apropiado, en el que todos los elementos mencionados estén presentes y definidos, y estén dirigidos a cumplir un claro objetivo o a obtener información de asuntos o temas específicos. La propuesta de este manual representa en sí misma un sistema completo de indicadores de desempeño que pueden ser utilizados "tal cual", completados con elementos adicionales o simplificados mediante una selección de una parte de sus elementos para satisfacer necesidades particulares.

\subsection{Requisitos para la definición de un sistema de indicadores de desempeño}

Una cantidad considerable de los problemas que se originan en el uso de indicadores de desempeño puede resolverse en la etapa de definición del sistema de ID. Establecer los objetivos y las limitaciones del sistema es útil para elegir y definir los indicadores. Aunque la definición y selección de indicadores de desempeño se tratan en el capítulo de implementación, hay algunos principios que se deben tener en cuenta en la etapa de definición.

\section{Indicadores de desempeño}

Individualmente, un indicador de desempeño debe de cumplir con los siguientes requisitos: 
- estar claramente definido y tener un significado conciso;

- ser razonablemente alcanzable (cualidad que depende principalmente de las variables relacionadas);

- ser auditable;

- ser tan universal como sea posible y proporcionar una medida independiente de las condiciones particulares del prestador,

- ser simple y fácil de entender;

- ser cuantificable de forma que proporcione una medida objetiva del desempeño del servicio, evitando cualquier evaluación personal o subjetiva; e

- incluir información sobre la calidad de los datos de las variables.

Colectivamente, los ID deben cumplir con los siguientes requisitos:

- cada ID debe proporcionar información diferente a la de los otros indicadores del sistema;

- las definiciones de cada ID deben ser unívocas (este requisito se hace extensivo a sus variables)

- sólo deben establecerse los ID que se consideren esenciales para la evaluación eficaz del desempeño.

Los ID deben estar orientados a objetivos y cumplir con los principios y normas aceptados comúnmente, como la ISO 24510:2007, 24511:2007, y 24512:2007 así como las NIC/NIIF (Normas Internacionales de Contabilidad /Normas Internacionales de Información Financiera promulgadas por la Junta de Normas Internacionales de Contabilidad - IASB por sus siglas en inglés) (ver II-1.3). En los servicios regulados económicamente, las cuentas regulatorias deben ser tenidas en cuenta.

\section{Variables}

Cada variable debe cumplir con los siguientes requisitos:

- su definición debe ser unívoca;

- se debe ajustar a la definición del ID para el que se utiliza;

- ser razonablemente alcanzable;

- referirse a la misma zona geográfica y el mismo periodo de tiempo o fecha de referencia que el ID para el que se utiliza; 
- ser tan fiable y precisa como requieran las decisiones que se tomarán a partir de ella;

- incluir información sobre la calidad de los datos.

Algunas de las variables en los sistemas de ID a menudo se obtienen a partir de datos externos. Es por ello que su disponibilidad, exactitud, fechas de referencia y zona geográfica correspondiente están por lo general fuera del control del prestador. En este caso, las variables también deben cumplir con los siguientes requisitos:

- ser recogidas, siempre que sea posible, de encuestas oficiales;

- ser fundamentales para la evaluación o interpretación de los ID; y

- colectivamente, ser tan pocas como sea posible

\section{Información de contexto y otros datos}

La información de contexto y el resto de datos del sistema (factores explicativos) deben seguir los mismos principios que las variables y los ID. Sin embargo, no se considera que el grado de detalle y de fiabilidad deban ser tan altos como los requeridos para los ID y variables. Así, los requisitos que deben cumplir son:

- Su definición debe ser unívoca

- Ser razonablemente alcanzable

- Si provienen de fuentes externas, ser recogidas, si es posible, de encuestas oficiales

- Ser fundamentales para la evaluación o interpretación de los ID

- En conjunto, ser tan pocas como sea posible 


\section{DE LA EVALUACIÓN DEL DESEMPEÑO A LA MEJORA}

\subsection{Indicadores de desempeño como base del benchmarking}

En 2011, se publicó el Manual de Buenas Prácticas de la IWA "Benchmarking para servicios de agua" (Cabrera Jr. et al., 2011) como un seguimiento lógico a las primeras ediciones de este manual. Al ser parte de la misma serie, los contenidos de este capítulo son totalmente coherentes con los del otro manual y a veces incluso son coincidentes. En cualquier caso, para una visión completa del benchmarking y su aplicación a los servicios de agua, el lector debe consultar el manual original.

Aunque el término benchmarking se ha utilizado de muchas maneras diferentes en la industria del agua durante casi dos décadas, la verdad es que, en todas esas concepciones, los indicadores de desempeño fueron una parte clave del proceso.

Tal y como se ha explicado previamente, los indicadores de desempeño pueden utilizarse de diferentes maneras, pero en esencia proporcionan una excelente herramienta para evaluar el estado actual de una organización, proporcionando una instantánea detallada de las áreas clave de rendimiento.

Esta capacidad ha demostrado ser esencial para los esfuerzos de benchmarking. Después de todo, el benchmarking requiere la identificación del mejor desempeño de una forma u otra, y los indicadores son las herramientas perfectas para esta tarea.

Es importante señalar que los términos "benchmarking métrico" y "benchmarking de procesos" deben ser evitados como se recomienda en el manual antes mencionado:

"El Grupo Especialista en Benchmarking y Evaluación del Desempeño de la IWA recomienda encarecidamente abandonar el uso de los términos "benchmarking métrico" y "benchmarking de procesos". En su lugar, "evaluación del desempeño" y "mejora del desempeño" deben considerarse como los componentes naturales del benchmarking (Cabrera Jr. et al., 2011). 
Esto puede sorprender a los lectores de la segunda edición de este manual, donde estos términos fueron utilizados para describir las diferentes funciones de los indicadores de desempeño. Sin embargo, aunque los conceptos siguen siendo perfectamente válidos hoy en día, es cierto que los diferentes actores de la industria a menudo usaban los nombres de una forma contradictoria en el pasado. Es por ello que esta recomendación busca proporcionar un lenguaje común e inconfundible.

Detalles y referencias históricas sobre este tema se pueden encontrar en el manual de benchmarking, mientras que la definición formal de benchmarking se encuentra en este capítulo.

En cualquier caso, y para resumir las recomendaciones del Grupo Especialista en Benchmarking y Evaluación del Desempeño de la IWA, se recomienda el uso de los siguientes términos:

- Evaluación del desempeño: Uso de indicadores de desempeño para determinar el estado actual y la evolución del desempeño de un servicio de agua o saneamiento.

- Evaluación comparativa del desempeño: Uso de indicadores de desempeño para determinar el desempeño relativo de un servicio de agua o de saneamiento con respecto a otros participantes (anteriormente denominado benchmarking métrico).

- Mejora del desempeño: Segunda parte del proceso de benchmarking en el cual se identifican y adaptan las mejores prácticas para mejorar el desempeño de un servicio de agua o saneamiento.

Todas estas herramientas (con su denominación) pueden utilizarse en diferentes niveles de detalle, como se muestra en la Figura 3 (Cabrera Jr. et al., 2011) 


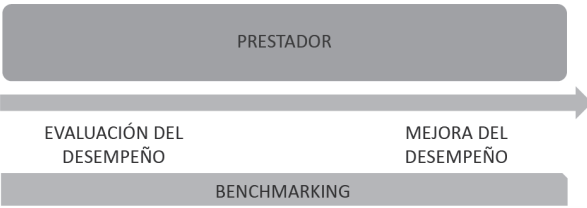

Figura 3. El modelo de evaluación y mejora del desempeño

\section{2 ¿Qué es el benchmarking?}

Hay muchas definiciones de benchmarking en la literatura. La mayoría de esas referencias no son específicas del sector del agua, hecho que debería tener poca o ninguna influencia en la adecuación de esas definiciones. Sin embargo, hasta la publicación del Manual de Buenas Prácticas (MBP) sobre benchmarking (Cabrera Jr. et al., 2011), había muchas definiciones contradictorias sobre lo que es el benchmarking dentro de la industria del agua.

La definición que se proporciona en dicho manual del 2011 de la IWA es clásica y abarca en una sola frase la esencia del benchmarking:

"El benchmarking es una herramienta ${ }^{3}$ para mejorar el desempeño mediante la búsqueda sistemática y uso de prácticas pioneras.”

La cuidadosa elección de estas palabras busca englobar en una única frase un concepto muy amplio. La clave de dicho concepto reside en la idea de que el benchmarking es, sencillamente, una herramienta. Una herramienta poderosa

3 El Benchmarking debería considerarse más un proceso que una herramienta. Sin embargo, por motivos que luego se explican, los autores han evitado utilizar el término proceso en esta definición. 
que es especialmente apta para el sector del agua, pero que de ninguna manera constituye un fin en sí misma. El benchmarking, cuando no se tiene un objetivo claro, a menudo conducirá a la decepción y al gasto innecesario de recursos.

Otra piedra angular del concepto de benchmarking queda incluida en el término sistemático. Las técnicas de benchmarking deberían estar siempre dirigidas a la mejora continua. Es más, el benchmarking encaja especialmente bien en el círculo de Deming (Planificar, Hacer, Verificar, Actuar) y debería ser abordado teniendo presentes esas cuatro etapas en todo momento. Como consecuencia, el benchmarking debería derivar en una tendencia natural hacia la mejora continua para cualquier organización.

Sin embargo, el benchmarking es todo menos un proceso de "hágalo usted mismo". La búsqueda de buenas práctica implica que hay lecciones que deben ser aprendidas de terceros ${ }^{4}$, con suerte, de los mejores de la clase. En cualquier caso, por mucho que el benchmarking consista en mirar hacia fuera, también es un ejercicio de mirar hacia dentro y aprender sobre cómo se hacen las cosas internamente. Es solo a partir del conocimiento interior y de entender cómo otros hacen las cosas que es posible lograr esa mejora.

Un factor clave de éxito es comprender los conceptos de buenas prácticas y mejores de la clase. Esas palabras son a menudo citadas en la literatura señalando casos de estudio emblemáticos y empresas de talla mundial como referencias en ciertos procesos. Si bien es cierto que dichas empresas constituyen una clara referencia, el benchmarking no está limitado a los líderes de la industria y a las grandes organizaciones. Es más, algunos de los proyectos realizados recientemente por prestadores de servicios demuestran que hay lecciones que pueden ser aprendidas de prácticamente cualquiera y que ser capaces de identificar las buenas prácticas y aquellos que las han desarrollado es un factor clave de éxito.

Lo cierto es que para distinguir al mejor de la clase se han de tomar mediciones. Sin embargo, y en contra de la noción vastamente extendida de que el benchmarking se logra comparando métricas, conviene aclarar que

${ }^{4}$ Estos otros pueden incluir otros prestadores del mismo grupo de empresas. 
crear un gráfico de barras con una comparación de distintos prestadores de servicios no es benchmarking. Incluso la definición original de benchmarking métrico (Kingdom et al., 1996) lo considera algo más que la comparación de unos pocos prestadores. El concepto de benchmarking ha englobado siempre un proceso sistemático y la voluntad por la mejora continua.

Las consecuencias de un benchmarking continuo en los prestadores de servicios se plasman en organizaciones mucho más maduras, más transparentes, que entienden mejor cómo se hacen las cosas, cómo mejorar y qué se necesita para mejorarlas.

\section{3 ¿Por qué hacer benchmarking?}

Los indicadores de desempeño han sido y serán utilizados como una herramienta independiente sin necesidad de desembocar en benchmarking. Sin embargo, el simple uso de indicadores (individualmente o en comparación con otros) no mejora el desempeño de prestador de servicios. Los ID son una excelente herramienta para evaluar el desempeño y compararlo con valores anteriores del mismo indicador, metas o valores obtenidos por otros prestadores, pero las soluciones a los posibles defectos y mejoras deben lograrse con herramientas complementarias. El benchmarking es una de esas herramientas.

La historia demuestra que muchos de los proyectos que comenzaron como proyectos de evaluación de desempeño han evolucionado hasta convertirse en benchmarking. Esto es debido a que sus participantes solicitaban aprovechar las oportunidades de mejora que mostraban los indicadores. El proyecto de las 6 ciudades en Escandinavia o el proyecto European Benchmarking Cooperation son un claro ejemplo de ello.

En muchas ocasiones, la motivación para hacer benchmarking empezaba de manera ajena al prestador y se valoraba como una opción lógica cuando ocurría alguna de las siguientes situaciones:

Debate público sobre liberalización o privatización de servicios públicos; demanda por unos servicios públicos más transparentes y eficientes; presión política por la recuperación de costes, o requisitos de grandes inversiones para mejorar el servicio en términos de cobertura y calidad, que en contrapartida requerían innovaciones 
inteligentes en el sector del agua para mantener los costes en niveles razonables.

Sin embargo, las motivaciones externas no son habitualmente suficientes para iniciarse en el benchmarking (excluyendo las obligaciones con reguladores). Normalmente, los gestores del servicio, por su responsabilidad operacional, tienen sus propias motivaciones. La necesidad de la mejora continua de la organización y sus productos puede facilitarse con proyectos de benchmarking que proporcionen una visión detallada del desempeño e identifique aéreas y formas de mejora. La posición relativa del prestador con sus análogos puede ayudar a determinar la urgencia en la toma de medidas en las áreas analizadas.

No obstante, si hay algo que se ha demostrado en los últimos años, es que muchos prestadores son reacios a entrar en el mundo del benchmarking. Por tanto, también deberíamos reconocer que hay muchas razones por las que un prestador puede no querer unirse a un proyecto de benchmarking:

El prestador se considera único y no comparable; la compañía está siendo reestructurada o fusionada, por lo que la situación no es. suficientemente estable como para evaluar el desempeño; no hay información de confianza que utilizar; no hay suficientes recursos disponibles (presupuesto, recursos humanos); hay dudas sobre el valor añadido del proyecto; la metodología sugerida es muy complicada; no hay garantía de confidencialidad de la información individual del desempeño.

Por tanto, todos estos puntos deben tenerse en cuenta cuando se prepara un proyecto de benchmarking.

El mundo del benchmarking no se limita a prestadores de servicios. Es más, el sector en sí mismo ha estado a menudo menos interesado en el benchmarking que otros agentes, que se citan a continuación.

\section{Gobiernos / reguladores}

Los gobiernos son políticamente responsables de los servicios de agua. Los reguladores, cuando existen, se centran más en los prestadores individuales. En cualquier caso, la evaluación comparativa del desempeño puede ayudar a ambos a introducir una competencia artificial en un sector que constituye un 
monopolio natural y a transferir cierta presión a los prestadores para mejorar la eficiencia y la transparencia.

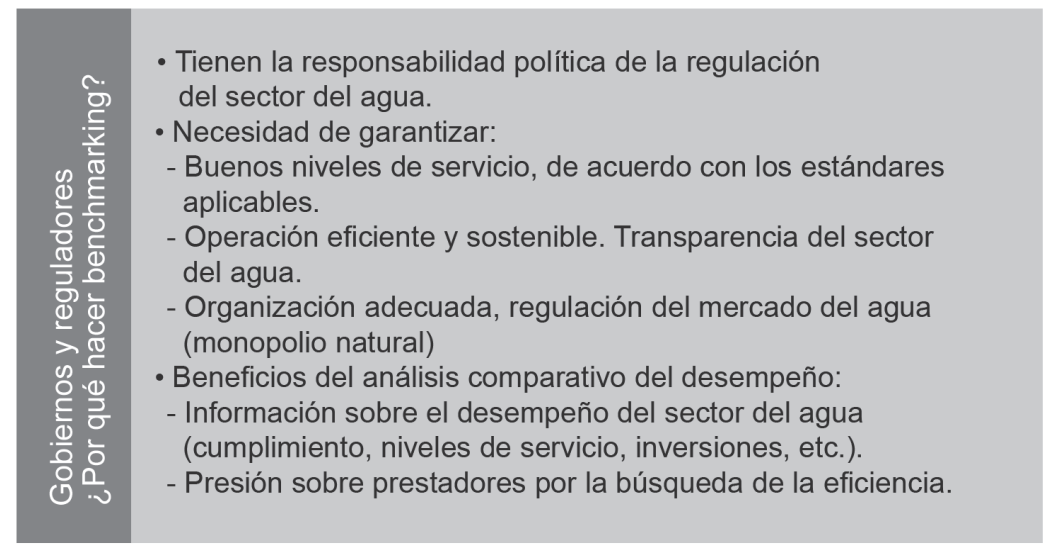

Figura 4. Gobiernos y reguladores: ¿Por qué evaluar el desempeño?

\section{Consumidores}

Los consumidores y organizaciones de consumidores se centran habitualmente en obtener un buen servicio y un buen producto a un precio justo. Además, las preguntas sobre la accesibilidad de aquellos con menores recursos son también una preocupación primordial.

El benchmarking es una herramienta excelente para consumidores, como también lo es la evaluación comparativa el desempeño (no es difícil encontrar informes de consumidores comparando varios prestadores).

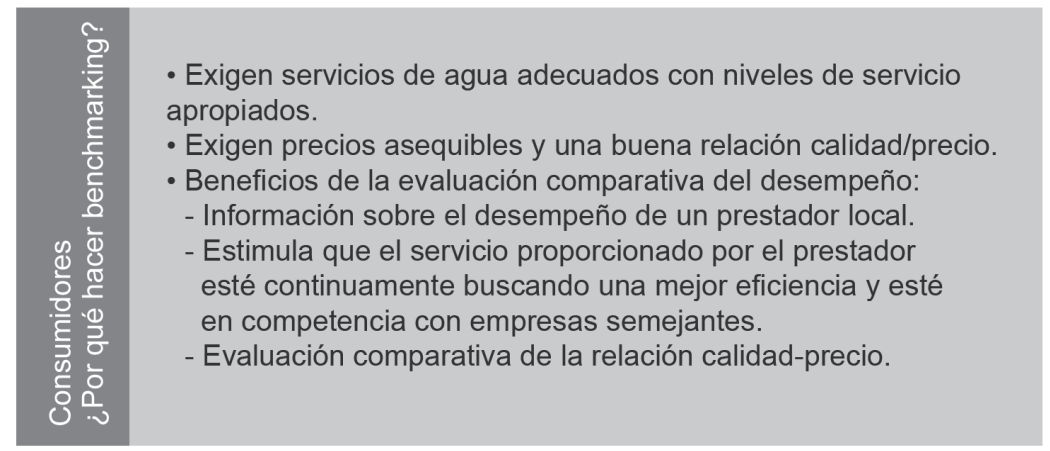

Figura 5. Consumidores: ¿Por qué hacer benchmarking? 


\section{Dueños/accionistas}

Los dueños y accionistas son legalmente responsables del prestador. Como resultado de esta responsabilidad y, para cumplir con las regulaciones aplicables, necesitan una visión del desempeño del prestador, su eficiencia y la magnitud de los riesgos financieros o de cualquier otro tipo a los que está sujeto el prestador.

El benchmarking y la evaluación comparativa del desempeño son herramientas excelentes para evaluar dichas magnitudes y colocarlas en perspectiva cuando se comparan con otros. Además, el benchmarking demuestra que hay una cultura dentro de la organización para mejorar de forma continua y volverse más eficientes.

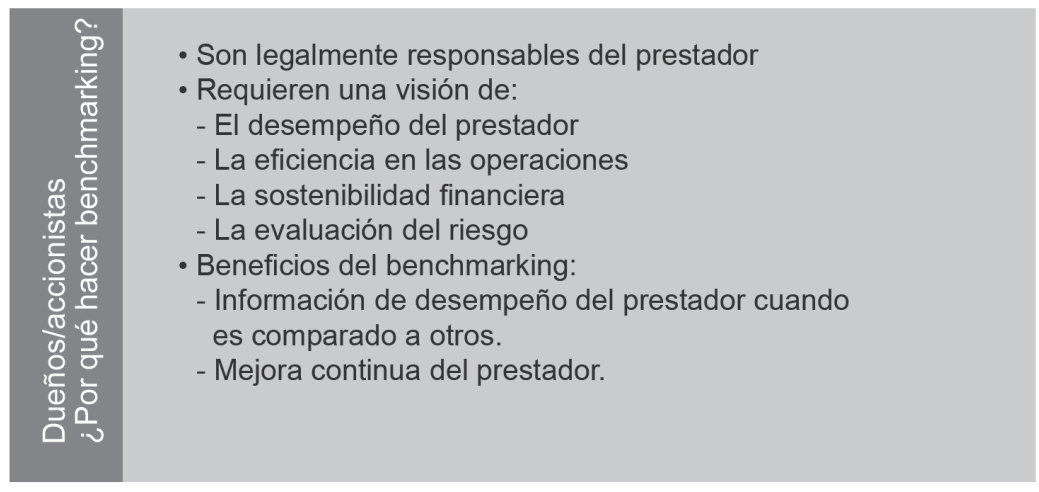

Figura 6. Dueños/accionistas: ¿Por qué hacer benchmarking?

\subsection{El Marco de Benchmarking de la IWA}

Un vistazo rápido al Marco de Benchmarking de la IWA (Figura 7) puede proporcionar una estimación de la complejidad y el trabajo requerido para ejecutar un proyecto exitoso de benchmarking. Este marco no sólo es relevante para las personas involucradas en este proyecto, sino también para las organizaciones y personas que se ocupan de proyectos de indicadores de desempeño.

Son muchas las similitudes entre la evaluación comparativa del desempeño (comparación de ID) y los proyectos de benchmarking. De hecho, un proyecto de benchmarking siempre incluirá un mini-proyecto en el que se comparará el desempeño de los prestadores. 


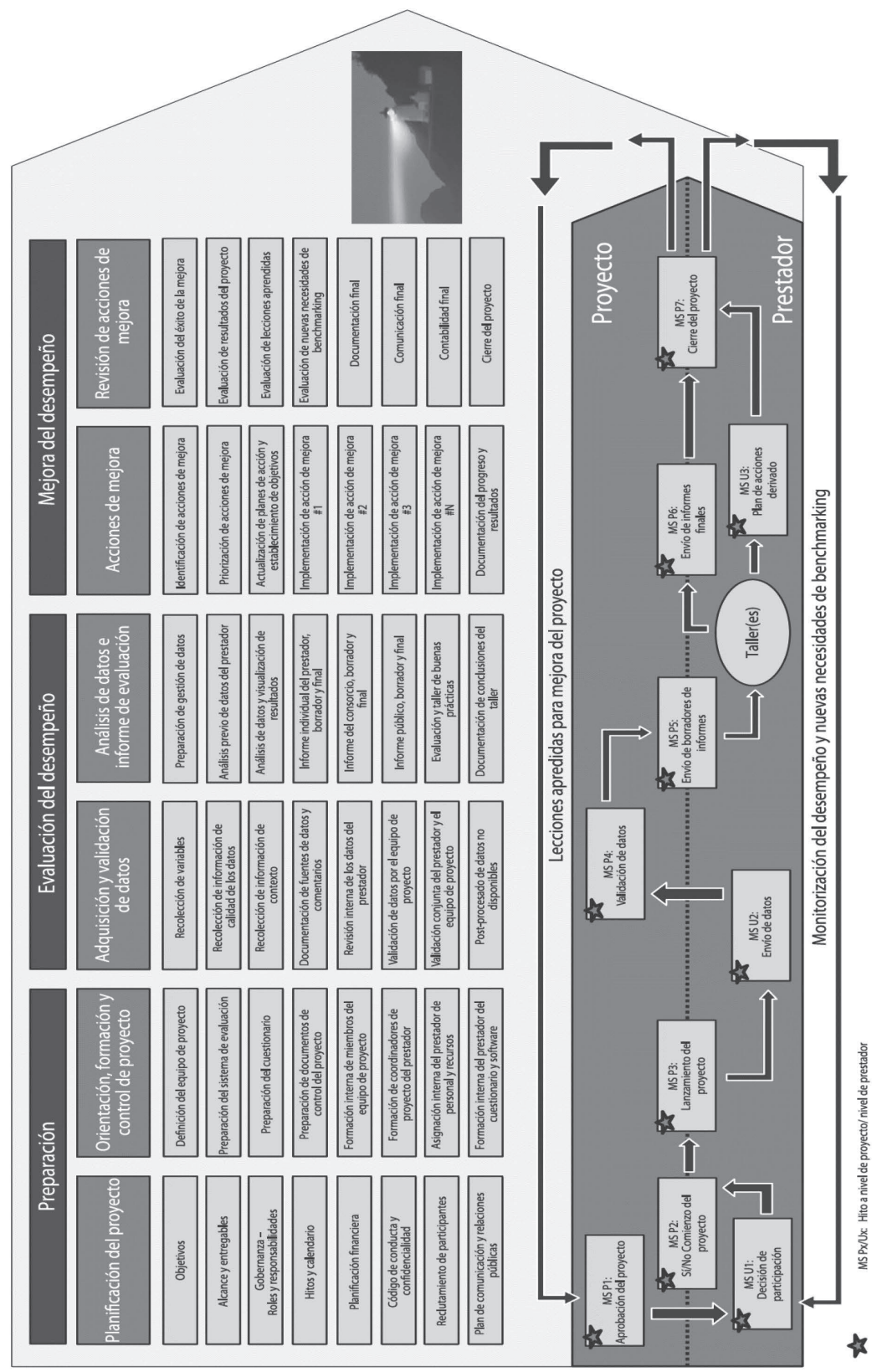

Figura 7. Marco de benchmarking de la IWA (Cabrera Jr. et al., 2011) 
El marco de benchmarking de la IWA está formado por tres etapas:

[1] Preparación: El proyecto se planifica, estableciendo los objetivos y los recursos necesarios para su desarrollo. El sistema de evaluación del desempeño se diseña e implementa, incluyendo la recopilación de datos. Se establecen las reglas internas del proyecto.

[2] Evaluación del desempeño: Se recopilan las variables, información de contexto y la calidad de los datos. Una vez se han validado los datos, se calculan los indicadores del desempeño. Se analizan los resultados y se redactan los informes.

[3] Mejora del desempeño: Se identifican las acciones de mejora y se establecen objetivos alcanzables. Los indicadores de desempeño se utilizan para monitorizar el éxito del proyecto. Se redactan informes y se evalúan nuevas necesidades de benchmarking.

Todos los proyectos relacionados con indicadores de desempeño pueden compartir tanto etapas individuales como la naturaleza éstas con el proceso de benchmarking de la IWA. La Tabla 1 muestra el grado de correlación entre tres proyectos típicos que implican el uso de indicadores de desempeño en relación con el marco de referencia de la IWA.

Tabla 1. Grado de correlación entre las etapas del marco de benchmarking de la IWA y proyectos típicos de indicadores de desempeño

\begin{tabular}{|l|c|c|c|}
\hline & Preparación & $\begin{array}{c}\text { Evaluación del } \\
\text { desempeño }\end{array}$ & $\begin{array}{c}\text { Mejora del } \\
\text { desempeño }\end{array}$ \\
\hline $\begin{array}{l}\text { Evaluación } \\
\text { interna del } \\
\text { desempeño }\end{array}$ & Medio & Alto & Ninguno \\
\hline $\begin{array}{l}\text { Evaluación } \\
\text { comparativa del } \\
\text { desempeño }\end{array}$ & Alto & Alto & Ninguno \\
\hline Benchmarking & Alto & Alto & Alto \\
\hline
\end{tabular}




\section{EL SISTEMA IWA DE INDICADORES DE DESEMPEÑO}

\subsection{Objetivo}

Para entender correctamente el sistema de indicadores de desempeño (ID) de la IWA en su concepción, es necesario conocer el objetivo original de la obra.

Este manual se originó como resultado de la creencia de que los indicadores de desempeño podrían ser utilizados en la industria del agua y que se deberían definir algunas directrices sobre cómo definirlos y utilizarlos.

Cualquier persona con un poco de experiencia en el campo de los indicadores de desempeño sabe que hay casi un número infinito de posibilidades en términos de seleccionar las ratios de desempeño y definir un sistema de indicadores de desempeño. En consecuencia, este trabajo debe entenderse como el resultado de la aplicación de una serie de restricciones, la definición de objetivos claros y el consenso entre las muchas personas que han participado en el proyecto a través de los años. Los principales objetivos que se perseguían originalmente eran:

- Con el fin de proporcionar una herramienta útil, el manual no sólo debía contener las directrices y los principios teóricos para el uso de indicadores. La creación de un conjunto sólido, consistente y coherente de indicadores de desempeño se estableció como una prioridad máxima y se consideró como una herramienta útil para la industria desde el principio.

- El sistema debía ser lo más universal posible. Las condiciones de la prestación del servicio de saneamiento en todo el mundo son variadas y muy diferentes. En algunos casos, las diferencias son tan grandes que la compatibilidad para algunos indicadores es imposible. Esto tiene una reflexión sobre el sistema final, que es redundante para algunos conceptos con soluciones para ambos extremos del espectro.

- El sistema debería ser útil para todas las partes interesadas que desempeñan un papel en el contexto de prestadores del servicio de saneamiento como se describió anteriormente. Esto obviamente presentó una amplia gama de usuarios y usos diferentes que tuvieron que ser considerados en el sistema. Aunque el uso y el usuario final de un sistema de ID 
ciertamente pueden determinar muchos aspectos del sistema en sí, una solución común era el objetivo.

- A pesar de que el sistema se desarrolló teniendo en cuenta las numerosas partes interesadas y usos en la industria del agua, estaba dirigido principalmente los propios prestadores. Como herramienta de gestión, el principal usuario en mente fue siempre el propio prestador, y la meta, la mejora del servicio. Otras aplicaciones extendidas del Sistema demostraron que puede representar una excelente herramienta común y generalmente aceptada para evaluar el desempeño del prestador, adecuada para proyectos internacionales de benchmarking.

- Por razones obvias, aspectos que se consideraban particulares a cada prestador quedaron fuera del sistema. Éstas incluían características de contexto como la particularidad geográfica, el marco institucional o la organización interna, pero también partes del propio negocio, como el tratamiento del agua.

- Por último, pero no menos importante, el número de indicadores de desempeño tuvo que ser limitado. A través de los años, el número de indicadores y la variación de los indicadores existentes probablemente alcanzó el millar. Desde el conjunto original, el número de indicadores ha sido constantemente considerado demasiado grande por casi todos lo ven por primera vez. Sin embargo, cuando a la mayoría de estas personas se les pidió que presentaran propuestas de mejora, éstas a menudo consistían en agregar más indicadores o en sustituirlos, y casi nunca mencionaban la eliminación o la disminución del número total de ID.

\subsection{Estructura}

\section{Indicadores de desempeño}

Los ID se agrupan en una estructura que tiene sentido para cada prestador y para todo tipo de usos del sistema. Los indicadores de desempeño se organizaron en los siguientes grupos:

- Medioambientales (wEn)

- Personal (wPe) 
- Físicos (wPh)

- Operacionales (wOp)

- Calidad del servicio (wQS)

- Económicos y financieros $(\mathrm{wFi})$

Las abreviaciones se han mantenido de acuerdo a las siglas originales en inglés para no alterar los códigos universalmente utilizados de los indicadores.

Estos grupos principales tienen la intención de ayudar a identificar el propósito de un determinado indicador y el usuario final dentro del prestador. El código de indicador, que es único, consiste en el código de dos letras mostrado arriba y un número que muestra el orden del indicador dentro del grupo.

Cada uno de estos grupos también se divide en subgrupos. La división en subgrupos también tiene como objetivo ayudar a identificar el uso y el usuario de un determinado indicador o indicadores (en algunos casos especiales, los subgrupos también se dividen en unidades más pequeñas). Por ejemplo, estos son los subgrupos incluidos en el grupo Operacionales:

- Indicadores operacionales

- Inspección y mantenimiento de colectores

- Inspección y mantenimiento de depósitos de retención y DSUs

- Inspección de bombas y estaciones de bombeo

- Calibración de equipos

- Inspección de equipos eléctricos y transmisión de señales

- Consumo de energía

- Rehabilitación de colectores

- Rehabilitación de bombas

- Entrada / Infiltración / Exfiltración (E/I/E)

- Averías

- Control de tanques de tormenta

- Monitorización de la calidad de aguas residuales y lodos

- Disponibilidad de vehículos

- Equipamiento de seguridad 
Por último, algunos de los indicadores se desglosan en subindicadores. Normalmente, los subindicadores son partes del indicador superior que pueden o no evaluarse por separado. Por ejemplo, el indicador " Ensayos realizados de calidad del agua residual " que explica el número de ensayos que se realizan de calidad de las aguas residuales puede desglosarse de la siguiente manera:

wOp44 -Ensayos realizados de calidad del agua residual (-/año)

- wOp45 -Ensayos de DBO (-/año)

- wOp46-Ensayos DQO (-/año)

- wOp47 -Ensayo de sólidos suspendidos (-/año)

- wOp48-Ensayos de fósforo (-/año)

- wOp49-Ensayos de nitrógeno (-/año)

- wOp50 -Ensayos de e. coli fecales (-/año)

- wOp51 -Otros ensayos (-/año)

\section{Variables}

Las variables se organizan en el sistema de ID de la IWA de manera similar a los indicadores. Es importante recordar que las variables son, de hecho, las entradas de un sistema de ID y, por consiguiente, tienen que ser medidas u obtenidas a partir de instancias reales en el prestador. Los grupos de variables se establecieron de acuerdo con el posible origen de los datos, e independientemente de los indicadores para los que se utilizaron. De hecho, una variable puede utilizarse para calcular varios indicadores de diferentes grupos. Las variables del sistema IWA PI se dividen en los siguientes grupos:

- A - Datos medioambientales

- B - Datos de personal

- C - Datos de activos físicos

- D - Datos operacionales

- E - Datos sobre demografía y clientes

- F - Datos de calidad del servicio

- G - Datos financieros

- H - Datos de tiempo

A veces, las variables también se pueden dividir en partes y, en consecuencia, calcularse utilizando otras variables. Por ejemplo, puede ser conveniente 
considerar la longitud total del colector para cada material utilizado en el prestador (acero, fundición dúctil, polietileno, etc.) aunque algunos indicadores usarán solamente la longitud total de colectores (que se puede calcular sumando todas las longitudes parciales).

Atendiendo a esta consideración, es posible hacer una clasificación entre variables primarias y secundarias. Las variables primarias son aquellas directamente involucradas en el cálculo de los indicadores de desempeño seleccionados. Las variables secundarias se utilizan para calcular variables primarias. En consecuencia, esta clasificación no es permanente y depende de los indicadores seleccionados. Sin embargo, es útil para determinar el número total de datos necesarios para evaluar los indicadores de desempeño. También es importante resaltar que las variables primarias también son medidas como cualquier otra variable, y, aunque pueden ser calculadas a través de variables secundarias, esto es sólo una alternativa.

\section{Información de contexto y otros datos del Sistema}

La información de contexto (IC) es una parte crucial del sistema de ID de la IWA. Sin embargo, tiene una enorme dependencia de las condiciones locales del prestador en estudio. Un dato que es relevante para entender el contexto y su influencia en el desempeño de un prestador es puede ser insignificante en otro.

Por consiguiente, los elementos de información de contexto proporcionados con el sistema IWA deben ser considerados sólo como referencia y un punto de partida para evaluar todos los factores explicativos posibles debido al contexto en un sistema.

La Información de Contexto proporcionada en el sistema de ID de la IWA se clasifican en las siguientes categorías:

- Perfil del prestador

- Datos del servicio

- Nivel de tratamiento de agua residual

- Servicio al usuario

- Cuenca 
- Activos físicos

- Red de alcantarillado

- Pozos de registro e imbornales

- Aliviaderos y tanques de tormenta

- Puntos de vertido

- Acometidas

- Almacenamiento de aguas residuales

- Almacenamiento de aguas pluviales

- Estaciones de bombeo

- Estaciones Depuradoras de Aguas Residuales (EDAR)

- Recursos tecnológicos

- Demografía y economía

- Demografía

- Economía

- Medioambiente

- Precipitación anual

- Precipitaciones de corta duración

- Temperatura del aire

- Topografía

- Medio receptor

\subsection{Utilización del sistema de indicadores de desempeño}

\section{de la IWA}

Contrariamente a la creencia general, el sistema IWA de indicadores de desempeño debe ser considerado como una herramienta muy flexible y adaptable. Después de la publicación de la Primera Edición del manual para servicios de abastecimiento de agua, muchos usuarios expresaron su opinión acerca de que el número de indicadores era demasiado alto, las definiciones no servían para sus propósitos o el marco de tiempo no era apropiado para su negocio. Sin embargo, la intención de los autores nunca fue imponer esos criterios a los usuarios, sino simplemente convertir un proceso largo en uno más fácil y corto.

Aunque los indicadores, las variables y la información de contexto del sistema IWA han sido elegidos para tratar de representar conceptos universales que pueden aplicarse casi en cualquier parte del mundo, los autores saben que pueden ser insuficientes, incompletos o inapropiados en determinadas 
situaciones particulares. No es posible definir un sistema de ID que cubra todas las necesidades, puntos de vista y circunstancias. Sin embargo, es posible definir un punto de partida lo más amplio y general posible que permita a los usuarios desarrollar sus propios sistemas compatibles.

Estos son algunos de los conceptos erróneos más comunes que se tienen sobre el sistema de indicadores de la IWA que no deben influir en su uso:

- El Sistema IWA tiene demasiados indicadores de desempeño: Como se explica más adelante en el capítulo de implementación, uno de los primeros pasos a seguir al implementar un sistema de ID es seleccionar aquellos ID más relevantes para la evaluación. El sistema IWA debe ser visto como un gran supermercado donde los usuarios pueden comprar indicadores de "calidad" (con definiciones completas, consistentes en su naturaleza, y con el valor añadido de ser usadas potencialmente por muchos otros usuarios). En cualquier caso, las aplicaciones prácticas del sistema IWA ya han visto en los últimos años aplicaciones con el uso exclusivo de indicadores IWA, soluciones mixtas con indicadores de la IWA e indicadores propios definidos y soluciones que sólo aplican la estructura IWA sin ninguno de sus indicadores.

- E1 Sistema IWA es demasiado complicado de usar: Por sí solo, el sistema IWA no es más complejo ni más simple que cualquier otro sistema de ID. Lo que típicamente caracteriza al sistema IWA es la estructura coherente de sus elementos, una definición completa de éstos y un conjunto completo de herramientas de apoyo y bibliografía. Si se despoja de todos estos elementos adicionales, el sistema IWA podría considerarse simplemente como una estructura (basada en ID, variables, IC y otros elementos de datos) y un conjunto de elementos coherentes de muestra (ID, variables y IC) que pueden usarse para configurar un sistema de indicadores orientado a cualquier meta dentro del sistema de saneamiento.

- E1 Sistema IWA es demasiado general y mi prestador tiene necesidades muy específicas: Como ya se ha mencionado anteriormente, el sistema IWA no puede cubrir todos los casos y condiciones particulares de todos los prestadores del mundo. Sin embargo, es difícilmente imaginable que algún prestador no encuentre útil al menos algunos de los indicadores propuestos por la IWA. El sistema de ID para 
cualquier prestador debe definirse de acuerdo a sus necesidades y condiciones locales. La propuesta de la IWA representa un excelente punto de partida para desarrollar un sistema específico. Lo mismo se puede decir sobre el desarrollo de sistemas ID a nivel departamental.

- E1 sistema IWA sólo se evalúa anualmente y necesito retroalimentación más a menudo: El período de evaluación que se cita en los elementos del sistema IWA es sólo una referencia. Dependiendo de las necesidades de gestión de cada prestador, el uso de indicadores de desempeño cambiará. La evaluación puede ser desde anual hasta diaria dependiendo de la actividad y de los indicadores. Cambiar el período de evaluación es una opción permitida para proporcionar flexibilidad al sistema.

- Si el sistema IWA es tan general, no hay ninguna ventaja real en su uso: El uso de los conceptos desarrollados para el sistema IWA garantiza que el sistema será consistente y coherente. Además, los elementos del sistema serán compatibles con los de otros sistemas en términos de estructura y definiciones (permitiendo así el uso de las plataformas de software desarrolladas, la integración en conjuntos de benchmarking combinados, etc.).

- Ya tengo mis sistemas de información y no quiero usar ningún otro software: La gestión de datos en el sistema IWA puede mejorarse mucho mediante el uso de herramientas informáticas. SIGMA es sólo una ejemplo de herramienta con fines educativos y no tiene la intención de proporcionar una evaluación profesional de desempeño. Por otra parte, SIGMA no es necesario para utilizar el sistema de indicadores de la IWA. Cada proyecto debe considerar la necesidad de herramientas de gestión de datos por separado. 


\subsection{Indicadores de desempeño}

\section{Suposiciones subyacentes}

Los indicadores de desempeño contenidos en el sistema ID de la IWA han sido cuidadosamente seleccionados para ser lo más generales posible, teniendo en cuenta los requisitos enumerados en la sección I-2.2. En este capítulo se enumeran y describen los indicadores.

Todos los indicadores están referidos al servicio de saneamiento. Aquellos prestadores con más servicios deberán evaluar únicamente la parte de recursos e ingresos correspondiente a este servicio. Lo mismo se aplica a aquellos prestadores con servicios complementarios, como son, por ejemplo, aquellos que proveen servicios relacionados con el muestreo y obtención de pruebas de calidad del agua residual o de reparación de las instalaciones interiores privadas.

Las definiciones completas de cada indicador se pueden encontrar en la sección II-2, incluyendo reglas de cálculo y la especificación de variables. Para facilitar su uso, el número de la página inicial donde se pueden encontrar los detalles de los indicadores de cada grupo se muestra entre paréntesis en el título de las tablas presentadas en esta sección.

A continuación, realizaremos una visita guiada a través de cada grupo de ID.

\section{Indicadores medioambientales}

Los indicadores medioambientales evalúan el desempeño del prestador del servicio con respecto a los impactos medioambientales, incluyendo el cumplimiento de los requisitos de vertido de las aguas residuales, las descargas intermitentes por reboses y disposición final de desechos sólidos (lodos, sedimentos y tamices). 
Los ID de Recursos Hídricos de la IWA son:

Tabla 2. ID Medioambientales de aguas residuales (II \#172)5

\begin{tabular}{|ll|}
\hline wEn1- & Cumplimiento de la EDAR con los requisitos de vertido (\%/año) \\
\hline & $\begin{array}{l}\text { porcentaje de población equivalente servida por la EDAR que } \\
\text { cumple con los requisitos de vertido. }\end{array}$ \\
\hline wEn2- & Reutilización de aguas residuales (\%) \\
\hline wEn3- & $\begin{array}{l}\text { Frecuencia de descargas intermitentes por reboses } \\
\text { (No./dispositivo de desbordamiento/año) }\end{array}$ \\
\hline & $\begin{array}{l}\text { Ratio entre el número de descargas por reboses (alivios) y el } \\
\text { número de dispositivos de desbordamiento. }\end{array}$ \\
\hline wEn4- & $\begin{array}{l}\text { Volumen de descargas intermitentes por reboses ( } \mathrm{m}^{3} / \text { dispositivo } \\
\text { de desbordamiento/año) }\end{array}$ \\
\hline & $\begin{array}{l}\text { Volumen total de descargas por reboses. } \\
\text { REn5- } \\
\text { Ratio entre el volumen de las descargas intermitentes por reboses y } \\
\text { el volumen de lluvia (\%/año) }\end{array}$ \\
\hline $\begin{array}{l}\text { Volumen total de descargas intermitentes por reboses y el volumen } \\
\text { de lluvia. }\end{array}$ \\
\hline
\end{tabular}

5 Leyenda (II \#151) = (Ver información detallada en la Parte II, página 151). 
Tabla 3. ID Medioambientales de aguas residuales (II \#175)

\begin{tabular}{|c|c|}
\hline wEn6- & Producción de lodos en la EDAR (kg DS/p.e./año) \\
\hline & $\begin{array}{l}\text { Ratio entre el peso seco del lodo utilizado y el peso seco del lodo } \\
\text { tratado. }\end{array}$ \\
\hline \multirow[t]{2}{*}{ wEn7- } & Utilización de lodos (\%) \\
\hline & $\begin{array}{l}\text { Ratio entre el peso seco del lodo utilizado y el peso seco del lodo } \\
\text { tratado. }\end{array}$ \\
\hline \multirow[t]{8}{*}{ wEn8- } & Desecho de lodos $(\%)$ \\
\hline & $\begin{array}{l}\text { Ratio entre el peso seco del lodo destinado a vertedero y el peso } \\
\text { seco del lodo tratado. }\end{array}$ \\
\hline & wEn9- Lodos destinados a vertedero (\%) \\
\hline & $\begin{array}{l}\text { Ratio entre el peso seco del lodo destinado a vertedero y el peso } \\
\text { seco del lodo tratado. }\end{array}$ \\
\hline & wEn10- Lodos procesados térmicamente (\%) \\
\hline & $\begin{array}{l}\text { Ratio entre el peso en seco del lodo procesado térmicamente y el } \\
\text { peso seco del lodo tratado. }\end{array}$ \\
\hline & wEn11- Otro tipo de disposición de lodos (\%) \\
\hline & $\begin{array}{l}\text { Ratio entre el peso en seco del lodo desechado por otros medios } \\
\text { distintos a los expuestos en wEn } 9 \text { y wEn } 10 \text { y el peso seco del lodo } \\
\text { tratado. }\end{array}$ \\
\hline \multirow[t]{2}{*}{ wEn12- } & Sedimentos de colectores (ton $/ \mathrm{km}$ colector $/ \mathrm{año}$ ) \\
\hline & $\begin{array}{l}\text { Peso drenado de los sedimentos extraídos de los elementos } \\
\text { auxiliares de la red de alcantarillado. }\end{array}$ \\
\hline \multirow[t]{2}{*}{ wEn13- } & Sedimentos de elementos auxiliares (ton/ $\mathrm{km}$ colector/año) \\
\hline & $\begin{array}{l}\text { Peso drenado de los sedimentos extraídos de los elementos } \\
\text { auxiliares de la red de alcantarillado. }\end{array}$ \\
\hline \multirow[t]{2}{*}{ wEn14- } & Sedimentos de filtros (ton/km colector/ año) \\
\hline & $\begin{array}{l}\text { Peso drenado del film y arenilla extraídos en los filtros y tamices de } \\
\text { las estaciones de depuración de aguas residuales y estaciones de } \\
\text { bombeo. }\end{array}$ \\
\hline \multirow[t]{2}{*}{ wEn15- } & Sedimentos de sistemas in-situ (ton/p.e./año) \\
\hline & $\begin{array}{l}\text { Peso drenado de los sedimentos extraídos de los sistemas in-situ } \\
\text { durante el periodo de evaluación. }\end{array}$ \\
\hline
\end{tabular}




\section{Indicadores de Personal}

Los indicadores de personal abordan los puntos de vista de la eficiencia de los recursos humanos (personal total, personal por función principal y actividades del personal de servicios técnicos), calificación y capacitación, salud y seguridad y horas extraordinarias.

Los indicadores de personal deben ser evaluados en términos de empleados equivalentes a tiempo completo y su interpretación debe ser completada analizando paralelamente el nivel correspondiente de externalización.

El número de empleados necesarios en un sistema depende en gran medida de las características del propio sistema. Sin embargo, también depende importantemente del desempeño en su gestión y, por lo tanto, el sistema de ID de la IWA incluye ID relacionados con el personal total, como un indicador bastante agregado, e indicadores más detallados que permiten un análisis más profundo de cómo el personal es repartido. La comparación de este tipo de indicadores entre prestadores de características similares ayuda a identificar aquellas áreas donde hay margen de mejora.

Los ID de personal son:

Tabla 4. ID de personal total (II \#180)

\begin{tabular}{|ll|}
\hline wPe1- & $\begin{array}{l}\text { Personal en tratamiento de aguas residuales por población } \\
\text { equivalente (No./ } 1000 \text { p.e.) }\end{array}$ \\
\hline & $\begin{array}{l}\text { Número equivalente de empleados que trabajan en el tratamiento } \\
\text { de aguas residuales por cada } 1000 \text { personas equivalentes. }\end{array}$ \\
\hline wPe2- & Personal de la red de alcantarillado por longitud (No./100 km red) \\
\hline & $\begin{array}{l}\text { Número equivalente de empleados que trabajan en la red de } \\
\text { alcantarillado por cada } 100 \mathrm{~km} \text { de red }\end{array}$ \\
\hline
\end{tabular}


El siguiente grupo de ID permite identificar el peso de la mano de obra (en términos de número de empleados) en cada función principal:

Tabla 5. ID de personal por función principal (II \#181)

\begin{tabular}{|c|c|}
\hline wPe3- & Personal de administración general (\%) \\
\hline & $\begin{array}{l}\text { Porcentaje de empleados dedicados a dirección, } \\
\text { administración central, planificación estratégica, relaciones } \\
\text { públicas, relaciones con otros interesados, asuntos legales, } \\
\text { auditorías internas, gestión ambiental, desarrollo de nuevos } \\
\text { negocios y soporte informático general. }\end{array}$ \\
\hline \multirow[t]{2}{*}{ wPe4- } & $\begin{array}{l}\text { Personal encargado de la gestión de los recursos humanos } \\
(\%)\end{array}$ \\
\hline & $\begin{array}{l}\text { Porcentaje de empleados encargados de la administración, } \\
\text { educación y formación del personal, la seguridad en el } \\
\text { trabajo, los servicios médicos y las actividades sociales. }\end{array}$ \\
\hline \multirow[t]{2}{*}{ wPe5- } & Personal de finanzas y comercial $(\%)$ \\
\hline & $\begin{array}{l}\text { Porcentaje de empleados encargados de la planificación } \\
\text { económica y financiera, la administración financiera, el } \\
\text { control económico y la gestión de materiales. }\end{array}$ \\
\hline \multirow[t]{2}{*}{ wPe6- } & Personal de atención al cliente $(\%)$ \\
\hline & $\begin{array}{l}\text { Porcentaje de empleados encargados de la contabilidad, } \\
\text { control y gestión de las relaciones con los clientes. }\end{array}$ \\
\hline \multirow[t]{6}{*}{ wPe7- } & Personal de servicios técnicos $(\%)$ \\
\hline & $\begin{array}{l}\text { Porcentaje de empleados encargados de la planificación, la } \\
\text { construcción y las actividades de mantenimiento. }\end{array}$ \\
\hline & wPe8- Personal de planificación, diseño y construcción (\%) \\
\hline & $\begin{array}{l}\text { Porcentaje de empleados del servicio técnico encargados de } \\
\text { la planificación y la construcción. }\end{array}$ \\
\hline & wPe9- Personal de operaciones y mantenimiento (\%) \\
\hline & $\begin{array}{l}\text { Porcentaje de empleados del servicio técnico encargados de } \\
\text { las funciones de operaciones y mantenimiento. }\end{array}$ \\
\hline
\end{tabular}

Teniendo en cuenta que el personal técnico es el que se ocupa del núcleo del negocio y que, en general, su labor se corresponde con la mayoría de funciones principales, los siguientes ID permiten un análisis más profundo, identificando el personal asignado a cada actividad técnica. En este caso, los indicadores se expresan en términos de una cantidad directamente relacionada con el tipo de actividad. 
Tabla 6. ID Personal de servicios técnicos por actividad (II \#183)

\begin{tabular}{|c|c|}
\hline wPe10- & $\begin{array}{l}\text { Personal técnico de tratamiento de aguas residuales (No./1000 } \\
\text { p.e.) }\end{array}$ \\
\hline & $\begin{array}{l}\text { Número de empleados encargados de la planificación, diseño, } \\
\text { construcción, operaciones y mantenimiento de del tratamiento } \\
\text { de aguas residuales, por población equivalente servida por } \\
\text { sistemas de tratamiento de aguas residuales. }\end{array}$ \\
\hline \multirow[t]{2}{*}{ wPe11- } & $\begin{array}{l}\text { Personal técnico del sistema de alcantarillado (No./100 km } \\
\text { colector) }\end{array}$ \\
\hline & $\begin{array}{l}\text { Número equivalente de empleados trabajando en actividades de } \\
\text { planificación, diseño, construcción, operación, mantenimiento y } \\
\text { reparación del sistema de alcantarillado, por la longitud total de } \\
\text { la red de alcantarillado. }\end{array}$ \\
\hline \multirow[t]{2}{*}{ wPe12- } & $\begin{array}{l}\text { Personal de monitorización de la calidad del agua residual (No./ } \\
\text { (1000 ensayos/año)) }\end{array}$ \\
\hline & $\begin{array}{l}\text { Número equivalente de empleados trabajando en el muestreo y } \\
\text { testeo de la calidad del agua residual por el número total de } \\
\text { ensayos de calidad de aguas residuales realizados anualmente. }\end{array}$ \\
\hline \multirow[t]{2}{*}{ wPe13- } & Personal de servicios de apoyo (\%) \\
\hline & Porcentaje de empleados encargados de los servicios de apoyo. \\
\hline
\end{tabular}

Un objetivo de gestión importante es tener un equilibrio adecuado en la calificación de personal, evaluado por los siguientes indicadores:

Tabla 7. ID de cualificación del personal (II \#185)

\begin{tabular}{|ll|}
\hline wPe14- & Personal con titulación universitaria (\%) \\
\hline wPe15- & Porcentaje de empleados con titulación universitaria. \\
\hline & Porcentaje de empleados con nivel de estudios básicos. \\
\hline wPe16- & Personal con otra cualificación (\%) \\
\hline & Porcentaje de empleados sin nivel de estudios básicos. \\
\hline
\end{tabular}

Tan importante como la cualificación académica es la cualificación profesional. Sin embargo, el análisis de los criterios utilizados para definir las categorías de cualificaciones demostró que existen diferencias importantes de un país a otro que impiden establecer definiciones generales de uso internacional. Todas las alternativas analizadas resultaron en interpretaciones engañosas y fueron eliminadas. Este problema se puede superar a nivel de empresa o incluso de país. Siempre que sea factible y pertinente, los 
indicadores anteriores deben complementarse con (o reemplazarse por) indicadores de cualificación profesional.

Uno de los objetivos del área de gestión de los prestadores es mantener a los empleados bien capacitados para el trabajo que deben realizar. El sistema de ID de la IWA incluye los siguientes indicadores para evaluar esta área:

Tabla 8. ID de formación de personal (II \#186)

wPe7 Formación total del personal (horas/empleado/año)

Número de horas de formación por empleado y año.

Los siguientes ID se incluyen en el Sistema de ID de la IWA para tratar el tema de la seguridad y salud del personal:

Tabla 9. ID de seguridad y salud del personal (II \#187)

\begin{tabular}{|ll|}
\hline wPe18- & Vacunación (\%) \\
\hline wPe19- & $\begin{array}{l}\text { Porcentaje de empleados con certificación de vacunas actualizada } \\
\text { para enfermedades relacionadas con las aguas residuales. }\end{array}$ \\
\hline & $\begin{array}{l}\text { Porcentaje de empleados con formación adecuada y autorizada en } \\
\text { espacios confinados. }\end{array}$ \\
\hline wPe20- & Accidentes laborales (No./100 empleados/año) \\
\hline & $\begin{array}{l}\text { Número de accidentes laborales que han requerido atención } \\
\text { médica por cada } 100 \text { empleados. }\end{array}$ \\
\hline & $\begin{array}{l}\text { wPe21- Víctimas de incidentes fatales en el trabajo (No./100 } \\
\text { empleados/año) }\end{array}$ \\
\cline { 2 - 2 } $\begin{array}{l}\text { Número de accidentes laborales que resultan en muerte o } \\
\text { enfermedad permanente por cada } 100 \text { empleados. }\end{array}$ \\
\hline
\end{tabular}


El absentismo laboral es también un elemento importante a monitorizar:

Tabla 10. ID de horas extraordinarias (II \#188)

\begin{tabular}{|l|l|}
\hline wPe22- & Absentismo (días/100 empleados/año) \\
\hline & Número de días de absentismo por empleado y año. \\
\hline & $\begin{array}{l}\text { wPe23- Absentismo debido a accedentes o enfermedades } \\
\text { laborales (días /100 empleados/año) }\end{array}$ \\
\cline { 2 - 2 } & $\begin{array}{l}\text { Número de días de absentismo debido a accidentes laborales o } \\
\text { enfermedades provocadas en el trabajo por empleado y año. }\end{array}$ \\
\hline & $\begin{array}{l}\text { wPe24- Absentismo debido a otros motivos (días/100 } \\
\text { empleados/año) }\end{array}$ \\
\cline { 2 - 2 } & $\begin{array}{l}\text { Número de días de absentismo no debido a accidentes laborales } \\
\text { o enfermedades provocadas en el trabajo por empleado y año. }\end{array}$ \\
\hline
\end{tabular}

Las tareas imprevistas y la falta de personal ocasionan la necesidad de trabajar horas extras. Por lo tanto, es un punto de vista importante a considerar:

Tabla 11. ID de horas extraordinarias (II \#190)

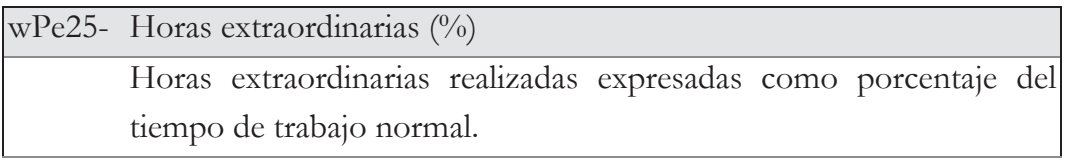

\section{Indicadores físicos}

Los indicadores físicos tienen como objetivo evaluar si el tratamiento de aguas residuales y los activos del prestador del servicio de saneamiento aún tienen la capacidad suficiente (margen de maniobra) para operar de manera correcta y segura, asegurando que se puedan alcanzar sus objetivos de servicio. Aunque de naturaleza diferente, los elementos de automatización y control también se incluyen debido a su importancia.

Se presentan indicadores para evaluar la capacidad de tratamiento preliminar, primario, secundario y terciario de aguas residuales. 
Tabla 12. ID de capacidad de tratamiento de aguas residuales (II \#190)

\begin{tabular}{|ll|}
\hline wPh1- & Utilización de pretratamientos $(\%)$ \\
\hline & $\begin{array}{l}\text { Porcentaje máximo de la capacidad diaria de la EDAR para } \\
\text { pretratar las aguas residuales. }\end{array}$ \\
\hline wPh2- & Utilización de tratamientos primarios (\%) \\
\hline & $\begin{array}{l}\text { Porcentaje máximo de la capacidad diaria de la EDAR para } \\
\text { realizar el tratamiento primario. }\end{array}$ \\
\hline wPh3- & Utilización de tratamientos secundarios (\%) \\
\hline & $\begin{array}{l}\text { Porcentaje máximo de la capacidad diaria de la EDAR para } \\
\text { realizar el tratamiento secundario. }\end{array}$ \\
\hline wPh4- & Utilización de tratamientos terciarios (\%) \\
\hline & $\begin{array}{l}\text { Porcentaje máximo de la capacidad diaria de la EDAR para } \\
\text { realizar el tratamiento terciario. }\end{array}$ \\
\end{tabular}

También se evalúa la capacidad de los colectores, supervisando su entrada en carga, tanto en tiempo seco como en tiempo de lluvia.

Tabla 13. ID de capacidad de los colectores (II \#192)

\begin{tabular}{|ll|}
\hline wPh5- & Entrada en carga de colectores por gravedad en tiempo seco (\%) \\
\hline Porcentaje de la longitud de colectores que han entrado en carga \\
en tiempo seco.
\end{tabular}

De modo similar a los elementos de tratamiento, en el caso de bombeo, los indicadores de bombeo se refieren a la capacidad de respuesta en términos de capacidad de bombeo tanto para la red de alcantarillado como en la EDAR. 
Tabla 14. ID de bombeo (II \#194)

\begin{tabular}{|c|c|}
\hline & $\begin{array}{l}\text { Porcentaje de la capacidad máxima de bombeo en la red de } \\
\text { alcantarillado (que puede utilizarse simultáneamente) por la que } \\
\text { se utiliza realmente. }\end{array}$ \\
\hline \multirow[t]{2}{*}{ wPh9- } & Energía de bombeo utilizada en la EDAR (\%) \\
\hline & $\begin{array}{l}\text { Porcentaje de la capacidad máxima de bombeo en la EDAR (que } \\
\text { puede utilizarse simultáneamente) por la que se utiliza realmente. }\end{array}$ \\
\hline \multirow[t]{2}{*}{ wPh10- } & Altura de bombeo en la red de alcantarillado (\%) \\
\hline & $\begin{array}{l}\text { Porcentaje de estaciones de bombeo en la red de alcantarillado } \\
\text { donde las bombas operaron más del } 75 \% \text { del tiempo. }\end{array}$ \\
\hline
\end{tabular}

Uno de los objetivos de gestión puede ser aumentar el nivel de automatización y control remoto. Dos indicadores se refieren a este asunto:

Tabla 15. ID de automatización y control remoto (II \# 195)

\begin{tabular}{|c|}
\hline wPh11- Grado de automatización (\%) \\
\hline Porcentaje de unidades de control automatizadas. \\
\hline Ph12- Grado de control remoto $(\%)$ \\
\hline Porcentaje de unidades de control controladas de forma remota. \\
\hline
\end{tabular}

\section{Indicadores operacionales}

Gran parte de la eficiencia de un prestador se puede perder o mejorar en las actividades de operación y mantenimiento. Los gerentes deben monitorizar las actividades planificadas de inspección, el mantenimiento y la rehabilitación preventivas, así como las actividades no planificadas causadas por el fallo de elementos del sistema.

Con respecto a la inspección y el mantenimiento de los activos físicos, el sistema ID de la IWA contempla los siguientes ID: 
Tabla 16. ID de inspección y mantenimiento de activos físicos (II \#196)

\begin{tabular}{|c|c|}
\hline wOp1- & 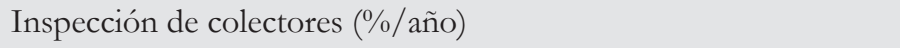 \\
\hline & $\begin{array}{l}\text { Porcentaje de colectores inspeccionados por año, evaluado en } \\
\text { términos de longitud. }\end{array}$ \\
\hline \multirow[t]{2}{*}{ wOp2- } & Limpieza de colectores ( $\% /$ año) \\
\hline & $\begin{array}{l}\text { Porcentaje de colectores limpiados por año, evaluado en términos } \\
\text { de longitud. }\end{array}$ \\
\hline \multirow[t]{2}{*}{ wOp3- } & Inspección de pozos de registro (-/año) \\
\hline & Ratio de pozos de registro inspeccionados. \\
\hline \multirow[t]{2}{*}{ wOp4- } & Inspección de imbornales (-/año) \\
\hline & Ratio de imbornales inspeccionados. \\
\hline \multirow[t]{2}{*}{ wOp5- } & Limpieza de imbornales (-/año) \\
\hline & Ratio de imbornales limpiados. \\
\hline \multirow[t]{2}{*}{ wOp6- } & $\begin{array}{l}\text { Frecuencia de inspección de depósitos de retención y tanques de } \\
\text { tormenta (No./depósitos de retención y tanques de tormenta } \\
\text { /año) }\end{array}$ \\
\hline & $\begin{array}{l}\text { Frecuencia de inspecciones a depósitos de retención y tanques de } \\
\text { tormenta llevadas a cabo. }\end{array}$ \\
\hline \multirow[t]{2}{*}{ wOp7- } & $\begin{array}{l}\text { Volumen inspeccionado de depósitos de retención y tanques de } \\
\text { tormenta (-/año) }\end{array}$ \\
\hline & $\begin{array}{l}\text { Ratio de depósitos de retención y tanques de tormenta } \\
\text { inspeccionados, evaluado en términos de volumen. }\end{array}$ \\
\hline \multirow[t]{2}{*}{ wOp8- } & Limpieza de depósitos de retención y tanques de tormenta (-/año) \\
\hline & $\begin{array}{l}\text { Ratio de depósitos de retención y tanques de tormenta limpiados, } \\
\text { evaluado en términos de volumen. }\end{array}$ \\
\hline \multirow[t]{2}{*}{ wOp9- } & Inspección de filtros (-/año) \\
\hline & Ratio de filtros inspeccionados. \\
\hline \multirow[t]{2}{*}{ wOp10- } & Frecuencia de inspección de estaciones de bombeo (-/año) \\
\hline & Frecuencia de inspecciones a estaciones de bombeo realizadas. \\
\hline wOp11- & Inspección de bombas por potencia (-/año) \\
\hline & $\begin{array}{l}\text { Ratio de bombas inspeccionadas por año, evaluado en términos } \\
\text { de potencia nominal. }\end{array}$ \\
\hline
\end{tabular}

Para monitorizar de forma fiable, la información obtenida debe basarse en datos precisos. Para ello, la calibración de los instrumentos es un aspecto clave: 
Tabla 17. ID de calibración de instrumentos (II \#204)

\begin{tabular}{|c|c|}
\hline \multirow[t]{2}{*}{ wOp12- } & Calibración de caudalímetros en la red de alcantarillado (-/año) \\
\hline & $\begin{array}{l}\text { Ratio de caudalímetros en la red de alcantarillado calibrados por } \\
\text { año. }\end{array}$ \\
\hline \multirow[t]{2}{*}{ wOp13- } & Calibración de caudalímetros en la EDAR (-/año) \\
\hline & Ratio de caudalímetros en la EDAR calibrados por año. \\
\hline \multirow[t]{2}{*}{ wOp14- } & $\begin{array}{l}\text { Calibración de equipos de monitorización de la calidad del agua } \\
\text { residual (-/año) }\end{array}$ \\
\hline & $\begin{array}{l}\text { Ratio de equipos de monitorización de la calidad del agua } \\
\text { residual calibrados por año. }\end{array}$ \\
\hline
\end{tabular}

Los procedimientos de inspección y mantenimiento deben incluir equipo eléctrico y de transmisión de señales:

Tabla 18. ID de inspección de equipos eléctricos y transmisión de señales (II \#205)

\begin{tabular}{|ll|}
\hline wOp15- & Inspección de los sistemas eléctricos de emergencia (-/año) \\
\hline $\begin{array}{l}\text { Ratio de inspección de sistemas eléctricos de emergencia por año, } \\
\text { evaluado en términos de potencia nominal. }\end{array}$ \\
\hline wOp16- & Inspección de equipamiento de transmisión de señales (-/año) \\
\hline $\begin{array}{l}\text { Ratio de inspección de equipamiento de transmisión de señales por } \\
\text { año. }\end{array}$ \\
\hline wOp17- & Inspección de los equipos eléctricos (-/año) \\
\hline & Ratio de inspección de los equipos eléctricos por año. \\
\hline
\end{tabular}

Los siguientes indicadores se refieren a la eficiencia del uso de la energía energía, tanto en la red de alcantarillado como en el tratamiento de las aguas residuales. No se incluye el indicador tradicional "Consumo de energía por $\mathrm{m}^{3 \prime}$ porque no permite comparaciones entre sistemas, aunque puede ser útil evaluar la evolución de un sistema dado. El indicador "recuperación de energía" es relevante cuando existen procesos de cogeneración en las plantas de tratamiento de aguas residuales. 
Tabla 19. ID de consumo de energía (II \#207)

\begin{tabular}{|l}
\hline wOp18- $\begin{array}{l}\text { Consumo de energía en el tratamiento de aguas residuales } \\
(\mathrm{kWh} / \mathrm{p} . \mathrm{e} . / \mathrm{año})\end{array}$ \\
\hline $\begin{array}{l}\text { Ratio de la energía consumida en los tratamientos de aguas } \\
\text { residuales, evaluado por población equivalente servida por } \\
\text { EDAR. }\end{array}$ \\
\hline wOp19- $\begin{array}{l}\text { Recuperación de energía en el tratamiento de aguas residuales } \\
\text { través de procesos de cogeneración }(\%)\end{array}$ \\
\hline $\begin{array}{l}\text { Porcentaje del consumo total de energía utilizada en el } \\
\text { tratamiento de aguas residuales que se recupera mediante } \\
\text { procesos de cogeneración. }\end{array}$ \\
\hline wOp20- \\
\hline $\begin{array}{l}\text { Consumo de energía estándar }\left(\mathrm{kWh} / \mathrm{m}^{3} / \mathrm{m}\right) \\
\text { Promedio del consumo de energía de bombeo en el sistema de }\end{array}$ \\
\hline
\end{tabular}

El desempeño a largo plazo y la evaluación de sostenibilidad están estrechamente relacionados con las prácticas de rehabilitación. Los siguientes indicadores se refierena la rehabilitación de la red y estaciones de bombeo. Véase el capítulo de definiciones para aclarar los conceptos relacionados con la rehabilitación, la renovación, la sustitución y la restauración que se deberán adoptarán al utilizar el sistema de ID de la IWA.

Tabla 20. ID de rehabilitación (II \#208)

\begin{tabular}{|l|l|}
\hline Rehabilitación de colectores, pozos de registro y acometidas \\
\hline wOp21- & Rehabilitación de colectores (\%/año) \\
\hline & Porcentaje de longitud de la red rehabilitada por año. \\
\hline & wOp22- Restauración de colectores (\%/año) \\
& Porcentaje de longitud de la red restaurada por año. \\
\hline & \begin{tabular}{l} 
wOp23- Sustitución de colectores (\%/año) \\
\hline
\end{tabular} $\begin{array}{l}\text { Porcentaje de longitud de la red sustituida por año. } \\
\text { red/año) }\end{array}$ \\
\hline $\begin{array}{l}\text { Ratio de colectores y juntas reparados al año, evaluado por } \\
\text { longitud. }\end{array}$ \\
\hline $\begin{array}{l}\text { Sustitución, renovación o rehabilitación de pozos de registro } \\
\text { (\%)/año) }\end{array}$ \\
$\begin{array}{l}\text { Porcentaje de pozos de registro sustituidos, renovadas o } \\
\text { rehabilitados por año. }\end{array}$ \\
\hline
\end{tabular}


Tabla 20a. ID de rehabilitación (II \#208)(cont.)

\begin{tabular}{|ll|}
\hline wOp26- & Sustitución de tapas de pozos de registro (\%/año) \\
\hline & Porcentaje de tapas de pozos de registro sustituidas por año. \\
\hline wOp27- & Rehabilitación de acometidas (\%/año) \\
\hline & Porcentaje de acometidas rehabilitadas por año. \\
\hline Rehabilitación de bombas \\
\hline wOp28- & Rehabilitación de bombas (\%/año) \\
\hline & $\begin{array}{l}\text { Porcentaje de bombas revisadas por año, evaluadas en términos } \\
\text { de potencia nominal. }\end{array}$ \\
\hline wOp29- & Sustitución de bombas (\%/año) \\
& $\begin{array}{l}\text { Porcentaje de bombas sustituidas por año, evaluadas en } \\
\text { términos de potencia nominal. }\end{array}$ \\
\hline
\end{tabular}

El siguiente grupo de indicadores mide la entrada, infliltración y exfiltración de agua en los colectores.

Tabla 21. ID de entrada, infliltración y exfiltración de agua (II 213)

\begin{tabular}{|ll|}
\hline wOp30- & Entrada / Infiltración / Exfiltración (E/I/E) (\%) \\
\hline & $\begin{array}{l}\text { Porcentaje del volumen de agua que entra en la red de } \\
\text { alcantarillado (incluyendo agua subterránea infiltrada, } \\
\text { conexiones erróneas y restando las fugas) por el volumen de } \\
\text { agna residual recolectada (incluyendo el volumen infiltrado y de } \\
\text { entrada y restando el exfiltrado). }\end{array}$ \\
\hline wOp31- & Entrada $\left(\mathrm{m}^{3} / \mathrm{km} /\right.$ año) \\
\hline & $\begin{array}{l}\text { Ratio del volumen de agua que entra en el sistema de } \\
\text { alcantarillado debido a conexiones erróneas, evaluado en } \\
\text { términos de longitud total de la red de alcantarillado. }\end{array}$ \\
\hline wOp32- & Infiltración ( $\mathrm{m}^{3} / \mathrm{km} /$ año) \\
\hline $\begin{array}{l}\text { Ratio del volumen de agua subterránea que entra en el sistema } \\
\text { de alcantarillado, evaluado en términos de longitud total de la } \\
\text { red de alcantarillado. }\end{array}$ \\
\hline EOp3iltración (m $\mathrm{m}^{3} / \mathrm{km} /$ año) \\
\hline $\begin{array}{l}\text { Ratio del volumen de aguas residuales fugadas desde la red de } \\
\text { alcantarillado al exterior, evaluado en términos de longitud total } \\
\text { de la red de alcantarillado. }\end{array}$ \\
\hline
\end{tabular}

El siguiente grupo de indicadores mide las averías, que son particularmente relevantes para la gestión patrimonial. 
Tabla 22. ID de averías (II \#215)

\begin{tabular}{|l|l|}
\hline wOp34- & Atascos de colectores (No./100 km red/año) \\
\hline & Número de atascos en colectores por $100 \mathrm{~km}$ de red y por año. \\
\hline & $\begin{array}{l}\text { wOp35- Puntos de atasco de colectores (No./100 km red/año) } \\
\text { colectores por } 100 \mathrm{~km} \text { de red y por año. }\end{array}$ \\
\hline wOp36- & $\begin{array}{l}\text { Atascos en estaciones de bombeo } \\
\text { bombeo/año) }\end{array}$ \\
\hline & $\begin{array}{l}\text { Número de atascos en estaciones de bombeo por el número } \\
\text { total de estaciones de bombeo en la red de alcantarillado y por } \\
\text { año. }\end{array}$ \\
\hline wOp37- & $\begin{array}{l}\text { Inundaciones de colectores de aguas negras (No./100 km } \\
\text { red/año) }\end{array}$ \\
\hline $\begin{array}{l}\text { Número de inundaciones producidas por colectores de aguas } \\
\text { negras, por 100km de red y año. }\end{array}$ \\
\hline Inundaciones de colectores unitarios (No./100 km red/año) \\
\hline Número de inundaciones producidas por colectores unitarios \\
de aguas residuales, por 100km de red y año.
\end{tabular}

La frecuencia de los fallos en los activos afecta directamente la calidad del servicio prestado y los costes de mantenimiento. En cambio - y esto es un aspecto relevante desde el punto de vista operacional - son una medida indirecta de la condición física de los activos.

El siguiente grupo de indicadores se ocupa del desempeño del control de los tanques de tormenta: 
Tabla 23. ID de averías (II \#219)

wOp43- Control de tanques de tormenta (\%)

Porcentaje de tanques de tormenta controlados por reguladores de caudal dinámicos o estáticos.

El siguiente grupo de indicadores aborda el desempeño de la monitorización de la calidad de las aguas residuales.

Tabla 24. ID de supervisión de calidad del agua residual y lodos (II \#220)

\begin{tabular}{|c|c|}
\hline & $\begin{array}{l}\text { Ratio de ensayos de calidad del agua residual requeridos por las } \\
\text { normas o leyes aplicables llevados a cabo. }\end{array}$ \\
\hline & wOp45- Ensayos de DBO (-/año) \\
\hline & $\begin{array}{l}\text { Ratio de ensayos de DBO requeridos por las normas o leyes } \\
\text { aplicables llevados a cabo. }\end{array}$ \\
\hline & wOp46- Ensayos DQO (-/año) \\
\hline & $\begin{array}{l}\text { Ratio de ensayos de DQO requeridos por las normas o leyes } \\
\text { aplicables llevados a cabo. }\end{array}$ \\
\hline & wOp47- Ensayo de sólidos suspendidos (-/año) \\
\hline & $\begin{array}{l}\text { Ratio de ensayos de sólidos suspendidos requeridos por las } \\
\text { normas o leyes aplicables llevados a cabo. }\end{array}$ \\
\hline & wOp48- Ensayos de fósforo (-/año) \\
\hline & $\begin{array}{l}\text { Ratio de ensayos de fósforo requeridos por las normas o leyes } \\
\text { aplicables llevados a cabo. }\end{array}$ \\
\hline & wOp49- Ensayos de nitrógeno (-/año) \\
\hline & $\begin{array}{l}\text { Ratio de ensayos de nitrógeno requeridos por las normas o } \\
\text { leyes aplicables llevados a cabo. }\end{array}$ \\
\hline & wOp50- Ensayos de e. coli fecales (-/año) \\
\hline & $\begin{array}{l}\text { Ratio de ensayos de e.coli fecales requeridos por las normas o } \\
\text { leyes aplicables llevados a cabo. }\end{array}$ \\
\hline & wOp51- Otros ensayos (-/año) \\
\hline & $\begin{array}{l}\text { Ratio de otros ensayos requeridos por las normas o leyes } \\
\text { aplicables llevados a cabo. }\end{array}$ \\
\hline wOp52- & Ensayos realizados de lodos (-/año) \\
\hline & $\begin{array}{l}\text { Ratio de ensayos de lodos requeridos por las normas o leyes } \\
\text { aplicables llevados a cabo. }\end{array}$ \\
\hline wOp53- & Ensayos realizados de vertidos industriales (-/año) \\
\hline & $\begin{array}{l}\text { Ratio de ensayos en los vertidos industriales en la red de } \\
\text { alcantarillado requeridos por las normas o leyes aplicables } \\
\text { llevados a cabo. }\end{array}$ \\
\hline
\end{tabular}


Estos indicadores se organizan en función de la naturaleza de los parámetros del agua. Esta clasificación puede no coincidir con la clasificación de la legislación aplicable. Sin embargo, había que adoptar una clasificación coherente y general que pudiera ser adoptada por cualquier país, no necesariamente la más fácil de aplicar para casos particulares.

Estos indicadores evalúan la cantidad de ensayos realizados. Sus resultados, como, por ejemplo, el cumplimiento de los ensayos de DQO, se considera en la sección de calidad de servicio.

La movilidad es un aspecto importante para el funcionamiento y mantenimiento de los servicios de agua. Se puede evaluar en términos de disponibilidad de vehículos:

Tabla 25. ID de disponibilidad de vehículos (II \#229)

wOp54 Disponibilidad de vehículos (No./100 km)

Promedio del número de vehículos disponibles diariamente, de manera permanente, para trabajos de operación y mantenimiento en campo por cada $100 \mathrm{~km}$ de tuberías.

Finalmente, el equipamiento de seguridad de los trabajadores se debe evaluar para prevenir accidentes laborales:

Tabla 26. ID de equipamiento de seguridad (II \#229)

\begin{tabular}{|ll|}
\hline wOp55- & Detectores de gas (No./empleado) \\
\hline & $\begin{array}{l}\text { Ratio entre el número de detectores de gas (incluyendo: O2, H2S, } \\
\text { CH4 y CO2) y el personal de operaciones y mantenimiento. }\end{array}$ \\
\hline wOp56- & Detectores de gas instalados permanentemente $(\%)$ \\
\hline & $\begin{array}{l}\text { Porcentaje de detectores de gas permanentemente instalados } \\
\text { (incluyendo: O2, H2S, CH4 y CO2) por el número total de } \\
\text { detectores de gas. }\end{array}$ \\
\hline
\end{tabular}

\section{Indicadores de calidad del servicio}

Los indicadores de calidad de servicio miden el nivel de servicio prestado a los usuarios. Las áreas a evaluar incluyen el nivel de cobertura del servicio, inundaciones, interrupciones y relaciones con los usuarios, como son la respuesta a solicitudes y quejas, daños a terceros y la interrupción del tráfico 
causada por la realización de actividades relacionadas con el servicio de saneamiento.

Los indicadores de cobertura de servicios evalúan la cobertura de los distintos servicios de saneamiento. Todos ellos proporcionan el resultado de la cobertura del servicio en porcentaje.

Tabla 27. ID de cobertura del servicio (II \#230)

\begin{tabular}{|c|c|}
\hline & $\begin{array}{l}\text { Porcentaje de población residente conectada a la red de } \\
\text { alcantarillado. }\end{array}$ \\
\hline \multirow[t]{2}{*}{ wQS2- } & Población residente servida por la EDAR (\%) \\
\hline & $\begin{array}{l}\text { Porcentaje de población residente servida por la Estación } \\
\text { Depuradora de Aguas Residuales. }\end{array}$ \\
\hline \multirow[t]{2}{*}{ wQS3- } & Población residente servida por sistemas in-situ (\%) \\
\hline & Porcentaje de población residente servida por sistemas in-situ. \\
\hline \multirow[t]{2}{*}{ wQS4- } & Población residente no servida (\%) \\
\hline & $\begin{array}{l}\text { Porcentaje de población residente cuya agua residual no es ni } \\
\text { recogida ni tratada. }\end{array}$ \\
\hline
\end{tabular}

Una buena calidad de servicio comprende un correcto tratamiento de las aguas residuales que minimice el impacto medioambiental de su vertido:

Tabla 28. ID de tratamiento de aguas residuales (II \#231)

\begin{tabular}{|c|c|}
\hline & $\begin{array}{l}\text { Porcentaje de agua residual tratada en las estaciones depuradoras de } \\
\text { aguas residuales. }\end{array}$ \\
\hline & wQS6- Pretratamiento (\%) \\
\hline & $\begin{array}{l}\text { Porcentaje de agua residual que recibe únicamente pretratamiento } \\
\text { en las EDAR. }\end{array}$ \\
\hline & wQS7- Tratamiento primario (\%) \\
\hline & $\begin{array}{l}\text { Porcentaje de agua residual que recibe únicamente tratamiento } \\
\text { primario en las EDAR. }\end{array}$ \\
\hline & wQS8- Tratamiento secundario (\%) \\
\hline & $\begin{array}{l}\text { Porcentaje de agua residual que recibe únicamente tratamiento } \\
\text { secundario en las EDAR. }\end{array}$ \\
\hline & wQS9- Tratamiento terciario (\%) \\
\hline & $\begin{array}{l}\text { Porcentaje de agua residual que recibe únicamente tratamiento } \\
\text { terciario en las EDAR. }\end{array}$ \\
\hline
\end{tabular}


Otro aspecto fundamental de la calidad del servicio es la minimización de las inundaciones:

Tabla 29. ID de inundaciones (II \#233)

\begin{tabular}{|l}
\hline wQS10- $\begin{array}{l}\text { Inundación de propiedades por colectores de aguas negras en } \\
\text { tiempo seco (n. } / 1000 \text { propiedades/año) }\end{array}$ \\
\hline $\begin{array}{l}\text { Número de propiedades afectadas por la inundación de } \\
\text { colectores de aguas negras en tiempo seco. }\end{array}$ \\
\hline wQS11- $\begin{array}{l}\text { Inundación de propiedades por colectores de aguas negras en } \\
\text { tiempo de lluvia (n. } / 1000 \text { propiedades/año) }\end{array}$ \\
\hline $\begin{array}{l}\text { Número de propiedades afectadas por la inundación de } \\
\text { colectores de negras residuales en tiempo de lluvia. }\end{array}$ \\
\hline wQS12- $\begin{array}{l}\text { Inundación de propiedades por colectores unitarios en tiempo } \\
\text { seco (n. } / 1000 \text { propiedades/año) }\end{array}$ \\
\hline $\begin{array}{l}\text { Número de propiedades afectadas por la inundación de } \\
\text { colectores unitarios en tiempo seco. }\end{array}$ \\
\hline wQS13- $\begin{array}{l}\text { Inundación de propiedades por colectores unitarios en tiempo de } \\
\text { lluvia (n. } / 1000 \text { propiedades/año) }\end{array}$ \\
\hline $\begin{array}{l}\text { Número de propiedades afectadas por la inundación de } \\
\text { colectores unitarios en tiempo de lluvia. }\end{array}$ \\
\hline $\begin{array}{l}\text { Inundación de la superficie de propiedades en tiempo de lluvia } \\
\text { (n. }{ }^{\circ} / 1000 \text { propiedades/año) } \\
\text { Número de propiedades afectadas por inundaciones de la } \\
\text { superficie en tiempo de lluvia. }\end{array}$ \\
\hline wQS14 \\
\hline
\end{tabular}

Las interrupciones del servicio son un aspecto clave en la calidad del servicio:

Tabla 30. ID de instalación y reparación de acometidas y contadores (II \#237)

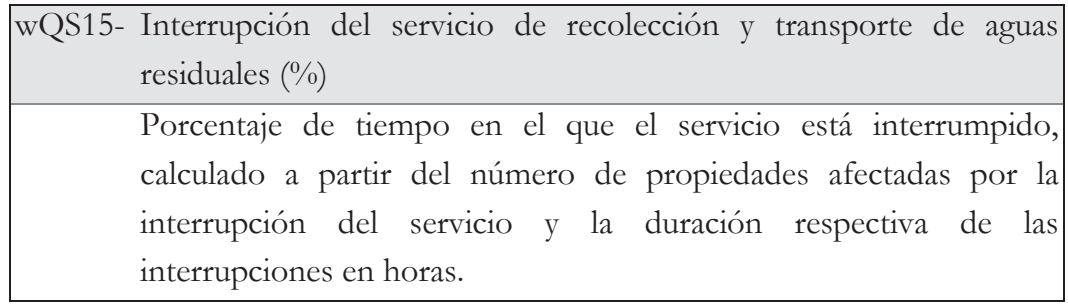


La instalación y reparación de acometidas, así como el tiempo de respuesta para vaciar fosas sépticas también aspectos relevantes de la calidad del servicio prestado a los clientes:

Tabla 31. ID de instalación y reparación de acometidas (II \#238)

\begin{tabular}{|ll|}
\hline wQS16- & Eficiencia de alta de nuevas acometidas (días/nueva acometida) \\
\hline & $\begin{array}{l}\text { Tiempo promedio desde que el usuario solicita el servicio hasta } \\
\text { que éste está disponible, para las acometidas existentes. }\end{array}$ \\
\hline wQS17- & Tiempo de reparación de acometidas (días/acometida reparada) \\
\hline wQS18- & $\begin{array}{l}\text { Tiempo promedio de reparación de acometidas. } \\
\text { (días/solicitud) }\end{array}$ \\
\hline & $\begin{array}{l}\text { Tiempo promedio desde que el usuario solicita el servicio para } \\
\text { vaciar fosas sépticas o letrinas hasta que éste está disponible. }\end{array}$ \\
\hline
\end{tabular}

Todos los ID anteriores son medidas de la calidad del servicio prestado, pero no reflejan las opiniones de los usuarios. El análisis de las quejas de los usuarios también es muy importante:

Tabla 32. ID de quejas de los usuarios (II \#239)

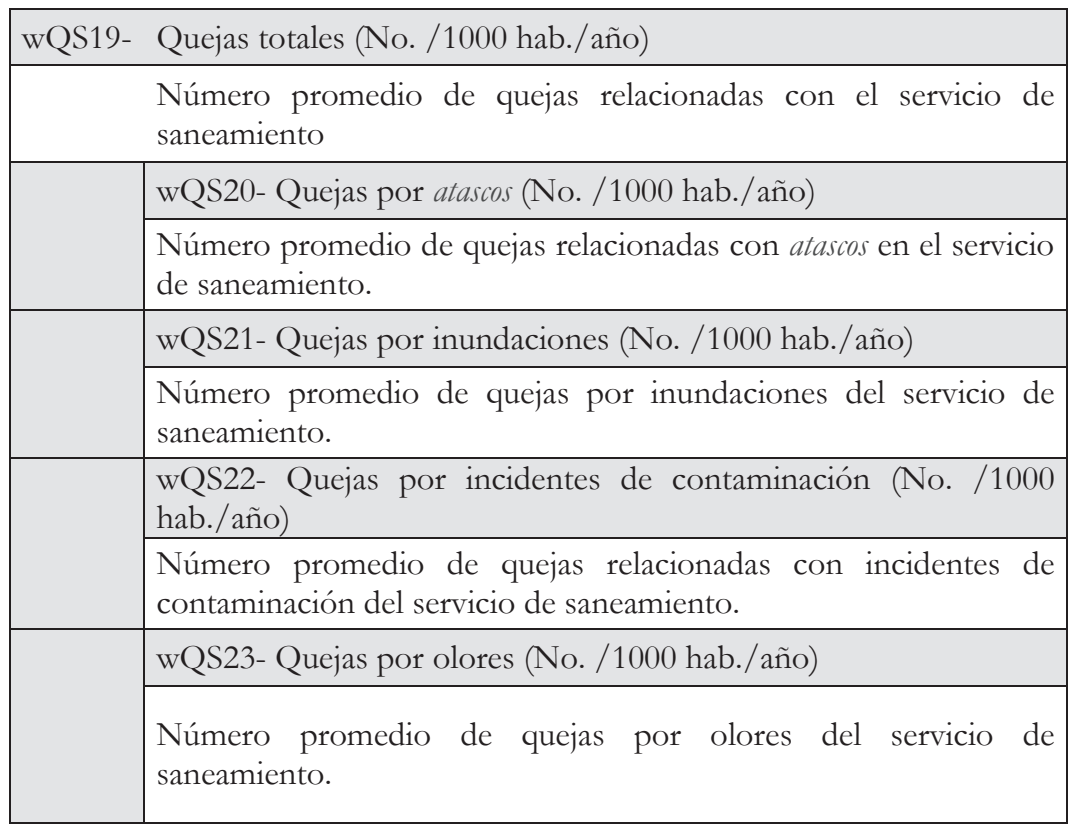


Tabla 32a. ID de quejas de los usuarios (II \#239) (cont.)

\begin{tabular}{|l|l|}
\hline \multirow{2}{*}{$\begin{array}{l}\text { wQS24- Quejas relacionadas con roedores (No./1000 hab./año) } \\
\text { servicio de saneamiento. }\end{array}$} \\
\hline $\begin{array}{l}\text { wQS25- Quejas relacionadas con la facturación (No. /1000 } \\
\text { hab./año) }\end{array}$ \\
$\begin{array}{l}\text { Número promedio de quejas relacionadas con la facturación del } \\
\text { servicio de saneamiento. }\end{array}$ \\
\hline & $\begin{array}{l}\text { Número promedio de otras quejas relacionadas con el servicio de } \\
\text { saneamiento. }\end{array}$ \\
\hline wQS27- & Respuesta a quejas (\%) \\
\hline $\begin{array}{l}\text { Porcentaje de quejas respondidas dentro del tiempo objetivo } \\
\text { fijado. }\end{array}$ \\
\hline
\end{tabular}

Los indicadores de quejas son válidos y relevantes, pero deben ser interpretados con cuidado. De hecho, no son medidas de desempeño directo. Mientras que en la mayoría de los casos la evolución de un ID con el tiempo permite una comprensión directa de si el desempeño, para ese aspecto específico, está empeorando o mejorando, esto puede no aplicarse a los ID de quejas sobre servicio si se producen cambios del servicio al cliente al mismo tiempo. Los clientes no se quejan si no tienen acceso fácil a su proveedor de servicios o si saben que su queja no se tiene en cuenta. Por lo tanto, una evolución natural de las quejas en los servicios con una creciente calidad de servicio es un aumento de las quejas cuando los clientes se dan cuenta de que pueden ser escuchados, seguido por un período de disminución de las quejas cuando se resuelven los problemas de servicio. Finalmente, se suele observar una fase de estabilización.

Si el análisis individual de un ID, aislado y fuera de contexto, es en general peligroso y potencialmente engañoso, para este grupo de ID esto es particularmente el caso. Por un lado, se necesitan factores explicativos sobre las razones que afectan el número de quejas; por otro lado, estos indicadores deben ser observados con otros ID relacionados, como las interrupciones, inundaciones o averías.

Finalmente, los ID de responsabilidad por daños a terceros y perturbaciones en el tráfico con también relevantes para evaluar la calidad del servicio. 
Tabla 33. ID de responsabilidad por daños a terceros y perturbaciones en el tráfico (II \#244)

\begin{tabular}{|c|c|}
\hline & $\begin{array}{l}\text { Porcentaje de incidentes relacionados con accidentes, bien de } \\
\text { personas que no trabajan para el servicio, o que han causado } \\
\text { daños a bienes, activos, vehículos o pertenencias de terceros. }\end{array}$ \\
\hline wQS29- & Perturbaciones en el tráfico (km/ interrupción de tráfico) \\
\hline & $\begin{array}{l}\text { Dimensión de las perturbaciones de tráfico debidas a actividades } \\
\text { relacionadas con el servicio de alcantarillado, evaluado como la } \\
\text { longitud del carril de tráfico no disponible x duración de la } \\
\text { interrupción y el número de perturbaciones de tráfico debidas a las } \\
\text { actividades de la red de alcantarillado. }\end{array}$ \\
\hline
\end{tabular}

\section{Indicadores económicos y financieros}

El último grupo de ID se ocupa del desempeño económico y financiero del prestador de servicios de saneamiento. En primer lugar, los ingresos, los costes, la inversión, las tarifas y los indicadores económicos y financieros más descriptivos $y$, en segundo lugar, los indicadores de eficiencia, apalancamiento y rentabilidad.

La evaluación de estos indicadores requiere el cumplimiento de las definiciones financieras de la sección II-1.3, establecidas de acuerdo con las normas internacionales de contabilidad. La reciente adopción de las Normas Internacionales de Información Financiera (NIIF) puede tener impactos potenciales tanto en la calidad de las variables de entrada como en los valores del ID evaluado. Por lo tanto, cualquier comparación entre pares necesita atención extra. Puede ser necesaria una armonización previa, en particular si algunos de ellos no han adoptado todavía los principios de las NIIF.

La implementación en algunos países puede requerir algún grado de adaptación, pero los prestadores que realmente intentaron evaluar estos indicadores durante la prueba de campo lo lograron sin grandes dificultades.

Las tablas siguientes presentan los indicadores recomendados, comenzando con los indicadores clásicos de ingresos: 
Tabla 34. ID de ingresos (II \#246)

\begin{tabular}{|l|l|}
\hline wFi1- & Ingresos unitarios (EUR/p.e./año) \\
\hline & Ingresos por población equivalente total servida. \\
\hline & wFi2- Ingresos por servicios (\%) \\
\cline { 2 - 2 } & Porcentaje de ingresos provenientes del servicio de saneamiento. \\
\hline \multirow{2}{*}{ wFi3- Otros ingresos (\%) } \\
\cline { 2 - 2 } & Porcentaje de ingresos no provenientes del servicio de saneamiento. \\
\hline \multirow{2}{*}{ wFi4- } & Ingresos por servicios industriales (\%) \\
\hline & Porcentaje de ingresos por servicios industriales. \\
\hline
\end{tabular}

La fortaleza particular de estos indicadores es la especificación detallada de las variables de entrada. Los ingresos totales no deben incluir los costes capitalizados de los activos autoconstruidos.

Los indicadores básicos de costes son también los tradicionales:

Tabla 35. ID de Costes (II \#248)

\begin{tabular}{|ll|}
\hline wFi5- & Costes totales unitarios por población equivalente (EUR/p.e./año) \\
\hline & $\begin{array}{l}\text { Costes totales (de explotación y capitales) por población } \\
\text { equivalente total servida. }\end{array}$ \\
\hline wFi6- & $\begin{array}{l}\text { Costes totales unitarios por longitud de colector (EUR/km } \\
\text { red/año) }\end{array}$ \\
\hline & $\begin{array}{l}\text { Costes totales (de explotación y capitales) por longitud total de la } \\
\text { red de alcantarillado. }\end{array}$ \\
\hline & $\begin{array}{l}\text { wFi7- Costes de explotación unitarios por población equivalente } \\
\text { (EUR/p.e./año) }\end{array}$ \\
\hline $\begin{array}{l}\text { Costes de explotación relacionados con la recogida y tratamiento de } \\
\text { aguas residuales por población equivalente total servida. }\end{array}$ \\
\hline $\begin{array}{l}\text { wFi8- Costes de explotación unitarios por longitud de colector } \\
\text { (EUR/km red/año) }\end{array}$ \\
\hline $\begin{array}{l}\text { Costes de explotación relacionados con el servicio de alcantarillado } \\
\text { por longitud total de la red de alcantarillado. }\end{array}$ \\
\hline $\begin{array}{l}\text { wFi9- Costes de capital unitarios por población equivalente } \\
\text { (EUR/p.e./año) }\end{array}$ \\
$\begin{array}{l}\text { Costes capitales relacionados con la recogida y tratamiento de aguas } \\
\text { residuales por población equivalente total servida. }\end{array}$ \\
$\begin{array}{l}\text { wFi10- Costes de capital unitarios por longitud de colector } \\
\text { (EUR/km red/año) }\end{array}$ \\
\hline $\begin{array}{l}\text { Costes capitales relacionados con el servicio de alcantarillado por } \\
\text { longitud total de la red de alcantarillado. }\end{array}$ \\
\hline
\end{tabular}


Los costes de explotación deben expresarse a su valor neto (obtenido mediante la distribución negativa de los costes capitalizados relacionados con los activos construidos por la empresa). En cualquier caso, la interpretación de los costes unitarios obtenidos puede requerir un análisis en profundidad de la composición de los costes de explotación por tipo principal de costes:

Tabla 36. ID de composición de costes de explotación por tipo de coste (II \#251)

\begin{tabular}{|ll|}
\hline wFi11- & Coste de personal interno $(\%)$ \\
\hline & $\begin{array}{l}\text { Porcentaje de los gastos de explotación correspondientes a la } \\
\text { mano de obra interna. }\end{array}$ \\
\hline wFi12- & Coste de servicios externos $(\%)$ \\
\hline & $\begin{array}{l}\text { Porcentaje de los gastos de explotación correspondientes a } \\
\text { servicios externos. }\end{array}$ \\
\hline wFi13- & Coste de la energía eléctrica (\%) \\
\hline & $\begin{array}{l}\text { Porcentaje de los gastos de explotación correspondientes a la } \\
\text { energía eléctrica. }\end{array}$ \\
\hline wFi14- & Coste del material comprado (\%) \\
\hline & $\begin{array}{l}\text { Porcentaje de los gastos de explotación correspondientes al } \\
\text { material comprado. }\end{array}$ \\
\hline wFi15- & Otros costes de explotación (\%) \\
\hline & $\begin{array}{l}\text { Porcentaje de los gastos de explotación correspondientes a otros } \\
\text { costes no considerados en los indicadores wFi11 a wFi14. }\end{array}$ \\
\hline
\end{tabular}

En una versión anterior del sistema ID, una categoría era "Costes de energía", ya que parecía ser la solución más lógica. Sin embargo - y esto es sólo un ejemplo de equilibrios y decisiones tomadas durante el proceso de construcción del sistema ID - la práctica demostró que la evaluación de este indicador consumía demasiado tiempo. La razón es que las normas contables separan los costos de electricidad de los de combustible, que se incluye en las "mercancías compradas". La conclusión fue encontrar categorías pertinentes que fueran compatibles con las normas contables.

Los indicadores anteriores permiten la identificación de "grandes cifras" y la comparación con valores de organizaciones homólogas (teniendo en cuenta el contexto), y por lo tanto permiten tratar de identificar dónde se encuentra el ahorro potencial. 
Otra dimensión complementaria del mismo tipo de análisis es la observación de los costes de explotación por función principal, en las categorías adoptadas por los indicadores de personal:

Tabla 37. ID sobre la composición de costes de explotación por función principal del prestador (II \#253)

\begin{tabular}{|ll|}
\hline wFi16- & Coste de la dirección general $(\%)$ \\
\hline & $\begin{array}{l}\text { Porcentaje de los costes de explotación correspondientes a los } \\
\text { costes de explotación de dirección general. }\end{array}$ \\
\hline wFi17- & Coste del área de gestión de recursos humanos $(\%)$ \\
\hline & $\begin{array}{l}\text { Porcentaje de los costes de explotación correspondientes a los } \\
\text { costes de explotación de la gestión de recursos humanos. }\end{array}$ \\
\hline wFi18- & Coste del área financiera y comercial (\%) \\
\hline $\begin{array}{l}\text { Porcentaje de los costes de explotación correspondientes a los } \\
\text { costes de explotación del área financiera y comercial. }\end{array}$ \\
\hline $\begin{array}{l}\text { Porcentaje de los costes de explotación correspondientes a los } \\
\text { costes de explotación del servicio de atención al cliente. }\end{array}$ \\
\hline wFi20- & Coste del área servicio técnico (\%) \\
\hline & $\begin{array}{l}\text { Porcentaje de los costes de explotación correspondientes a los } \\
\text { costes de explotación del servicio técnico. }\end{array}$ \\
\hline
\end{tabular}

El siguiente grupo se extiende más detalladamente con respecto a las funciones técnicas.

Tabla 38. ID de composición de costes de explotación por la función técnica (II \#255)

\begin{tabular}{|ll|}
\hline wFi21- & Costes de explotación del tratamiento de aguas residuales (\%) \\
\hline $\begin{array}{l}\text { Porcentaje de costes de explotación del tratamiento de aguas } \\
\text { residuales. }\end{array}$ \\
\hline wFi22- & Costes de explotación de la red de alcantarillado (\%) \\
\hline wFi23- & $\begin{array}{l}\text { Costes de explotación de la monitorización de la calidad del agua } \\
\text { residual (\%) }\end{array}$ \\
\hline & $\begin{array}{l}\text { Porcentaje de costes de explotación de la monitorización de la } \\
\text { calidad del agua residual. }\end{array}$ \\
\hline wFi24- & Costes de explotación de servicios de apoyo (\%) \\
\hline & Porcentaje de costes de explotación de servicios de apoyo \\
\hline
\end{tabular}


La descomposición de los costes capitales sigue una estructura diferente, mucho más simple:

Tabla 39. ID de la composición de los costes de capital (II \#256)

\begin{tabular}{|ll|}
\hline wFi25- & Costes por depreciación (\%) \\
\hline $\begin{array}{l}\text { Porcentaje de los costes capitales correspondientes a los costes } \\
\text { por depreciación. }\end{array}$ \\
\hline wFi26- & Coste por intereses netos (\%) \\
\hline $\begin{array}{l}\text { Porcentaje de los costes capitales correspondientes a los costes } \\
\text { por intereses netos (es decir, la diferencia entre los costes de los } \\
\text { intereses a cargo menos los ingresos por intereses). }\end{array}$ \\
\hline
\end{tabular}

Lo importante es diferenciar la inversión en nuevos activos y refuerzo de los activos existentes (por ejemplo, la expansión) de la inversión para sustituir y renovar activos. El análisis de estos indicadores es más relevante en el ámbito de la gestión de infraestructuras.

Tabla 40. ID de Inversión (II \#257)

\begin{tabular}{|l|l|}
\hline wFi27- & Inversión unitaria (EUR/p.e.) \\
\hline $\begin{array}{l}\text { Costes de inversión (gastos en la red de alcantarillado, plantas de } \\
\text { tratamiento y equipo) por población equivalente. }\end{array}$ \\
\hline $\begin{array}{l}\text { wFi28- Inversión en nuevos activos y refuerzo de activos } \\
\text { existentes (\%) }\end{array}$ \\
$\begin{array}{l}\text { Porcentaje del coste de inversiones correspondiente a inversiones } \\
\text { en nuevos activos y refuerzo de activos existentes. }\end{array}$ \\
\hline & $\begin{array}{l}\text { PFi29- Inversión en sustitución y restauración de activos (\%) } \\
\text { inversiones para sustitución y renovación de activos. }\end{array}$ \\
\hline
\end{tabular}

Cuando existan concesiones, las Normas Internacionales de Información Financiera, NIIF, contabilizan los activos construidos o mejorados según el acuerdo de concesión entre los Activos Intangibles y los deprecian, de forma sistemática, durante el período de concesión (como se detalla en la sección II1.3). Dado que en muchos casos los prestadores del servicio de saneamiento tradicionalmente contabilizaban, y algunos aún lo hacen, los activos construidos o mejorados según el acuerdo de concesión como activos del servicio de saneamiento y depreciados según diferentes conceptos de vidas útiles, se recomienda una cuidadosa atención al comparar los prestadores. 
El siguiente conjunto de indicadores permite el análisis de la eficiencia del prestador:

Tabla 41. ID de eficiencia (II \#259)

\begin{tabular}{|ll|}
\hline wFi30- & Ratio de cobertura de costes totales (-) \\
& Ratio entre los ingresos y costes totales. \\
\hline wFi31- & Ratio de cobertura de costes operacionales (-) \\
\hline & Ratio entre los ingresos y los costes de explotación totales. \\
\hline wFi32- & Retraso en el pago de recibos (días equivalentes) \\
\hline & $\begin{array}{l}\text { Ratio entre las cuentas por cobrar provenientes del servicio de } \\
\text { saneamiento y los ingresos por ventas. }\end{array}$ \\
\hline wFi33- & Ratio de inversión (-) \\
\hline Ratio entre las inversiones sujetas a depreciación y los costes de \\
depreciación.
\end{tabular}


El siguiente conjunto trata del apalancamiento:

Tabla 42. ID de apalancamiento (II \#261)

\begin{tabular}{|ll|}
\hline wFi39- & Ratio de cobertura de deuda $=$ DSC $(\%)$ \\
\hline $\begin{array}{l}\text { Porcentaje de la deuda financiera del servicio que se corresponde } \\
\text { al flujo de caja. }\end{array}$ \\
\hline wFi40- & Ratio de apalancamiento (-/año) \\
\hline & Relación entre la deuda total y el capital social. \\
\hline
\end{tabular}

Se debe de tener en cuenta que en algunos países el ratio de apalancamiento se evalúa como la inversa de wFi40, es decir, como la relación entre el capital social y la deuda total. Se debe tener cuidado al realizar comparaciones entre los diferentes países.

La evaluación e interpretación de estos indicadores resultó ser a veces problemática en situaciones en que existen subvenciones externas para la inversión (por ejemplo, donaciones internacionales en regiones en desarrollo, fondos de cohesión dentro de la Unión Europea). Se requiere un análisis bien informado, e incluso puede ser necesaria alguna adaptación de las fórmulas de cálculo de los indicadores.

La liquidez puede evaluarse utilizando el ratio de circulante:

Tabla 43. ID de liquidez (II \#262)

\begin{tabular}{|ll|}
\hline wFi41- & Ratio de circulante (-) \\
\hline Ratio entre el activo circulante y el pasivo circulante. \\
\hline
\end{tabular}

Se recomienda un conjunto de cuatro indicadores para evaluar la rentabilidad: 
Tabla 44. ID de rentabilidad (II \#262)

\begin{tabular}{|ll|}
\hline wFi42- & Retorno de activos no corrientes (\%/año) \\
\hline & $\begin{array}{l}\text { Porcentaje del valor histórico de los activos tangibles del prestador, } \\
\text { deducido del valor histórico depreciado de los activos tangibles } \\
\text { del prestador, que corresponden a los ingresos de operación. }\end{array}$ \\
\hline wFi43- & Rendimiento sobre el capital (\%) \\
\hline & $\begin{array}{l}\text { Porcentaje del capital social que corresponde al ingreso neto (tras } \\
\text { el pago de intereses e impuestos). }\end{array}$ \\
\hline wFi44- & Rendimiento del capital invertido (\%) \\
\hline & $\begin{array}{l}\text { Porcentaje de los activos totales que corresponden a los ingresos } \\
\text { de operación (BAII) (deducido de los } \\
\text { correspondientes). }\end{array}$ \\
\hline wFi45- & Indice de rotación de activos (-/año) \\
\hline & Relación entre ingresos por ventas y activos totales. \\
\hline
\end{tabular}

\subsection{Variables}

Como se explica en la sección I-2.1, las variables son los datos que son necesarios para evaluar los ID, de acuerdo con los requisitos enumerados en el apartado I-2.2.

Las variables se organizan en grupos y subgrupos, como se indica en la sección I-4.2. En el apartado II-3 se pueden encontrar junto con su definición detallada.

Es muy importante tener en cuenta que sólo una selección de las variables es necesaria para la implementación específica de un sistema de ID. Sólo después de la preselección de los ID relevantes, los usuarios deben identificar el subconjunto de variables que se necesitan. Durante la prueba de campo, algunos participantes hicieron lo contrario: llenaron tantas variables como pudieron, y luego se dieron cuenta de que ID podrían calcular. Este procedimiento es aceptable para probar el sistema, pero no debe ser adoptado como una práctica normal. El procedimiento de implementación recomendado se describe en el capítulo I-6.

Hay variables que se utilizan para un solo indicador específico, y otras que se utilizan para muchos. En las tablas de las variables del capítulo II-3 se enumeran para cada variable los indicadores que se las requieren. 
Casi todas las variables se utilizan directamente en, al menos un ID, como variables primarias. Hay algunas que también se utilizan para evaluar otras variables, jugando el rol de variables secundarias.

En cuanto a los ID, todas las variables se refieren al servicio de saneamiento. Los prestadores de servicios múltiples deben evaluar la parte de los recursos e ingresos relacionados con la parte de alcantarillado y tratamiento de aguas residuales. Lo mismo se aplica a los prestadores con empresas complementarias, como, por ejemplo, aquellos que proveen servicios relacionados con el muestreo y obtención de pruebas de calidad de las aguas residuales o de reparación de las instalaciones interiores privadas.

Independientemente del software que los usuarios puedan adoptar para la introducir datos y evaluar los ID, debe estar preparado para manejar los tres elementos fundamentales de información para cada variable que el sistema de ID de la IWA requiere: el valor de la variable, la banda de precisión y la fiabilidad de la fuente de datos (véanse I-5 y II-5):

Tabla 45. Ejemplo de tabla de datos de entrada para variables

\begin{tabular}{|l|c|c|c|}
\hline \multicolumn{1}{|c|}{ Variable } & Valor & $\begin{array}{c}\text { Banda de } \\
\text { precisión }\end{array}$ & $\begin{array}{c}\text { Fiabilidad de } \\
\text { la fuente de } \\
\text { datos }\end{array}$ \\
\hline $\begin{array}{l}\text { wC1 - Longitud de la red de } \\
\text { alcantarillado (km) }\end{array}$ & 1398 & $0-5 \%$ & $* * *$ \\
\hline wC21- Pozos de registro (No.) & 10027 & $0-5 \%$ & $* * *$ \\
\hline wC22- Imbornales (No.) & 93000 & $5-20 \%$ & $* *$ \\
\hline
\end{tabular}

Esta es una característica del sistema de ID de la IWA que otros sistemas existentes de ID no tienen. Al utilizar el sistema en diferentes contextos la experiencia ha demostrado la importancia de ser consciente de la calidad de la información manejada y de la necesidad de invertir en el control de la calidad de los datos. Los prestadores que participaron en la prueba de campo consideraron que vale la pena el esfuerzo, siempre que no haya demasiadas categorías de precisión y fiabilidad entre las que elegir. Esta es la razón por la que el número de categorías en la Primera Edición se redujo.

Uno de los mayores desafíos en la creación del sistema de ID de la IWA fue encontrar consenso sobre las definiciones de las variables para que fueran 
claras puesto que es muy fácil interpretar de distinta forma el mismo texto para diferentes personas.

Para algunas variables, esto es un objetivo fácilmente alcanzable, sin embargo, no lo es para otras. Para hacer frente a estos casos más complejos, se estableció el siguiente esquema de definición:

- Las funciones y subfunciones de un servicio de saneamiento se definen de la manera en que deben ser adoptadas para la evaluación estandarizada del personal, las variables económicas y financieras e indicadores. En general, el organograma de la organización no coincide totalmente con esta agregación. Sin embargo, esto no es ni el objetivo ni un problema, como demostró la prueba de campo. Algunos ajustes se hicieron con respecto a la Primera Edición del manual, según la experiencia en campo (II-1.2).

- Una definición detallada de conceptos económicos y financieros, establecida de acuerdo con las normas internacionales de contabilidad. La prueba de campo resultó ser la más útil para la mejora de estas definiciones (II-1.3)

- Un glosario de definiciones complementarias, compartido por varias variables e ID (II-1.4)

- Una lista de definiciones y comentarios específicos de cada variable, contenida en las tablas de cada variable (II-3).

\subsection{Factores explicativos}

\section{Tipos de factores explicativos}

Tal y como se vio en el apartado I-2.1, un factor explicativo es cualquier elemento del sistema de indicadores de desempeño que pueda ser utilizado para explicar los valores de los ID, en la etapa de análisis. Esto incluye ID, variables, información de contexto y otros datos que no desempeñan un papel activo antes de la etapa de análisis.

Existen factores explicativos que dependen de las opciones de gestión a corto y medio plazo. Su identificación y análisis es crucial para la identificación y priorización de las medidas de mejora. Este tipo de factor explicativo también se conoce como un "factor impulsor". Hay otros factores 
explicativos que son contextuales, y no pueden ser cambiados por el prestador, al menos a corto o medio plazo. En algunos casos, las diferencias de contexto son tan relevantes que impiden cualquier comparación válida de ID.

Debe tenerse en cuenta que los factores explicativos dependen del ID considerado, es decir, un factor explicativo que es relevante para un ID o un conjunto de ID puede ser irrelevante para otros. La consecuencia principal de este hecho es que dos prestadores diferentes pueden ser comparables para algunos indicadores y no para otros.

En el establecimiento del sistema de ID de la IWA, uno de los objetivos subyacentes fue minimizar la dependencia de cada ID del contexto. Por ejemplo, no se incluyeron en el sistema indicadores potencialmente relevantes para el uso dentro de un prestador pero que dependen demasiado del contexto (por ejemplo, consumo de energía por metro cúbico). Sin embargo, la independencia total del contexto no es un objetivo factible para ningún sistema de ID.

Las siguientes secciones tratan acerca de los distintos tipos de factores explicativos:

- Información de contexto

- Indicadores de desempeño y variables

- Otros factores explicativos

\section{Información de contexto}

La información de contexto es especialmente útil en las iniciativas de benchmarking. En una etapa preliminar, apoya el establecimiento de grupos de prestadores comparables. En la etapa de análisis, debe tenerse en cuenta para determinar si las diferencias en los valores de desempeño corresponden a diferencias en los procedimientos de gestión o al contexto.

Internamente, la información de contexto es importante para entender las variaciones del desempeño en el tiempo.

La información de contexto también puede usarse para probar hipótesis dadas para la explicación del desempeño. Preguntas tales como "¿Cómo influye el tipo de propiedad o el tipo de operaciones en el desempeño?", "¿Cuál es la influencia del tamaño del sistema y del prestador en el 
desempeño?" O "Los prestadores multiservicio tienden a ser más eficientes que los que cuentan con un único servicio?" requieren mucho cuidado al ser probadas. No hay dos prestadores que tengan idéntica información de contexto, y por lo tanto los enfoques independientes y sólidos son fundamentales.

En general, la información de contexto es relativamente estable. Demografía, clima, economía, características del sistema, etc. no cambian de la noche a la mañana. Ésta es una característica general de la información de contexto. Sin embargo, también hay algunos tipos de información de contexto que pueden tener una naturaleza mucho más dinámica. Este es el caso de eventos especiales que pueden afectar temporalmente el desempeño de un sistema. Ejemplos típicos son el tiempo (por ejemplo, inundaciones o sequías excepcionales), situaciones de crisis o concentraciones excepcionales de personas (por ejemplo, el entierro del Papa Juan Pablo II, en Roma).

Dado que la prueba de campo del sistema de ID de la IWA no era una iniciativa de evaluación comparativa, existían limitaciones prácticas para una comprobación exhaustiva y sistemática de la información de contexto recomendada. Sin embargo, se tuvieron en cuenta las sugerencias de mejora. Un punto importante es el nivel de detalle y cantidad de información de contexto que debería especificarse. El sistema de ID de la IWA contiene especificaciones detalladas y cuantificadas.

La lista completa de información de contexto del sistema de ID de la IWA se presenta y define en II-4. Está estructurado en cinco grupos principales, como se muestra en la Tabla 46.

Tabla 46. Tipos de información de contexto del sistema de ID IWA

\begin{tabular}{|l|l|}
\hline \multicolumn{2}{|l|}{ Perfil del prestador (página II-358) } \\
\hline Datos del servicio (página II-362) \\
\hline & Nivel de tratamiento de agua residual \\
\hline & Servicio al usuario \\
\hline & Cuenca \\
\hline
\end{tabular}


Tabla 46a. Tipos de información de contexto del sistema de ID IWA (cont.)

\begin{tabular}{|l|l|}
\hline Activos físicos (página II-367) \\
\hline & Red de alcantarillado \\
\hline & Pozos de registro e imbornales \\
\hline & Aliviaderos y tanques de tormenta \\
\hline & Puntos de vertido \\
\hline & Acometidas \\
\hline & Almacenamiento de aguas residuales \\
\hline & Almacenamiento de aguas pluviales \\
\hline & Estaciones de bombeo \\
\hline & Estaciones Depuradoras de Aguas Residuales (EDAR) \\
\hline & Recursos tecnológicos \\
\hline Demografía y economía (página II-382) \\
\hline & Demografía \\
\hline & Economía \\
\hline Medioambiente (página II-384) \\
\hline & Precipitación anual \\
\hline & Precipitaciones de corta duración \\
\hline & Temperatura del aire \\
\hline & Topografía \\
\hline & Medio receptor \\
\hline
\end{tabular}

Algunos de los tipos de información de contexto mencionados anteriormente son externos y totalmente independientes de las decisiones de gestión del prestador, como la información sobre el medioambiente. Otros, como la demografía y la economía, son casi independientes; aunque la provisión del servicio de saneamiento es muy importante para la economía de una región, y se podría aceptar que el propio prestador tiene una capacidad limitada para cambiar significativamente la demografía y la economía.

Otros tipos de información del contexto son una combinación de factores externos y de gestión. Este es el caso, por ejemplo, del consumo y de los factores punta, teniendo en cuenta que el prestador tiene un potencial significativo para gestionar la demanda. Este es también el caso de la información de contexto de servicio. 
La información de contexto de los activos del sistema depende de las políticas a largo plazo del prestador. La situación evaluada hoy se ve afectada por las políticas pasadas del prestador. Los cambios en las políticas tampoco tienen efectos inmediatos. Sin embargo, las medidas de mejora deberían incluir esta perspectiva a largo plazo.

El perfil del prestador depende de decisiones políticas. El propietario de los activos puede o no tener la capacidad de modificarlos dependiendo del caso.

\section{Indicadores de desempeño y variables como factores explicativos}

El análisis del desempeño de un prestador como un todo, o de un proceso dado, necesita estar basado en un conjunto de ID interrelacionados, algunos de los cuales actúan como factores explicativos de los otros. Por ejemplo, es probable que los prestadores que inviertan en el mantenimiento, la inspección y la rehabilitación preventivos del sistema tengan menores tasas de avería e interrupciones de servicio. También existe una interrelación entre un ID y su ID padre o hijo (por ejemplo, si el ID para el número total de empleados es muy alto, sería racional averiguar si esto se debe a alguna función específica).

También hay casos en los que la interpretación de los valores de desempeño se puede explicar con datos que también son variables (es decir, se usan para evaluar ID). Por ejemplo, puede compararse el desempeño entre un prestador grande y otro pequeño, pero la interpretación debe tener en cuenta estas diferencias, ya que pueden explicar diferencias en los resultados. De manera similar, la adopción de los principios de las NIC (Normas Internacionales Contables) influye fuertemente en las variables e informes financieros clave; comparando los ID de diferentes prestadores, donde sólo algunos de ellos están adoptando sistemas de contabilidad que cumplen con las NIC. Estas comparaciones pueden ser engañosas debido a la falta de conceptos y definiciones comunes. La Tabla 47 presenta ejemplos de variables que reflejan el tamaño del prestador y del sistema, que a veces son relevantes como factores explicativos. 
Tabla 47. Ejemplos de variables que pueden ser relevantes como factores explicativos

\begin{tabular}{|c|c|}
\hline Tamañ & el prestador \\
\hline wG5 - & stes totales (EUR/año) \\
\hline wG1 - & gresos totales (EUR/año) \\
\hline wG30 - & $\begin{array}{l}\text { versión en activos tangibles del servicio de saneamiento } \\
\text { UR/año) (se debe utilizar una media móvil de los últimos 3-5 } \\
\text { os) }\end{array}$ \\
\hline wB1 - & rsonal total (No.) \\
\hline Tamañ & el sistema \\
\hline wC1 - & Longitud de la red de alcantarillado $(\mathrm{km})$ \\
\hline wC27 - & Caudalímetros de agua de la red de alcantarillado (No.) \\
\hline wD22- & Imbornales (No.) \\
\hline $\mathrm{wC21}-$ & Pozos de registro (No.) \\
\hline wC23 - & Número de depósitos de retención (No.) \\
\hline wC24 - & Volumen de depósitos de retención y tanques de tormenta $\left(\mathrm{m}^{3}\right)$ \\
\hline
\end{tabular}

\section{Otros factores explicativos}

Puede haber otros factores que afectan los valores de los ID de una manera significativa que no son parte del contexto, ya que pueden ser cambiados por los gerentes en el corto plazo, tampoco son ni variables ni ID. Algunos pueden explicar un rendimiento mejor o peor, otros simplemente pueden explicar las diferencias en los valores, no significando que el desempeño real es diferente.

El sistema de ID de la IWA no especifica una lista de otros factores explicativos, porque dependen de cada caso. Sin embargo, esta sección proporciona algunos ejemplos.

Uno de los más relevantes y fundamentales para la comparación del ID de personal, es el nivel de externalización. Un prestador que externaliza una parte significativa de la actividad tendrá naturalmente una tasa de personal más baja para la misma eficiencia. El Tabla 48 contiene algunas recomendaciones sobre cómo expresar la externalización. 
Tabla 48. Otros factores explicativos: nivel de externalización

\begin{tabular}{|c|}
\hline Funciones generales de gestión $(\%)$ \\
\hline $\begin{array}{l}\text { Porcentaje estimado de los costes de la función general de gestión (del } \\
\text { servicio de saneamiento) que se subcontrata. }\end{array}$ \\
\hline Gestión de recursos humanos (\%) \\
\hline $\begin{array}{l}\text { Porcentaje estimado de los costes de la gestión de recursos humanos } \\
\text { (del servicio de saneamiento) que se subcontrata. }\end{array}$ \\
\hline Funciones financieras y comerciales $(\%)$ \\
\hline $\begin{array}{l}\text { Porcentaje estimado de los costes de las funciones financieras y } \\
\text { comerciales (del servicio de saneamiento) que se subcontratan. }\end{array}$ \\
\hline Servicio al cliente $(\%)$ \\
\hline $\begin{array}{l}\text { Porcentaje estimado de los costes del servicio al cliente (del servicio de } \\
\text { saneamiento) que se subcontrata. }\end{array}$ \\
\hline Planificación y construcción (\%) \\
\hline $\begin{array}{l}\text { Porcentaje estimado de los costes de la planificación y construcción } \\
\text { (del servicio de saneamiento) que se subcontrata (por ejemplo, } \\
\text { contratar consultores). }\end{array}$ \\
\hline Construcción (\%) \\
\hline $\begin{array}{l}\text { Porcentaje estimado de los costes de la función de construcción (del } \\
\text { servicio de saneamiento) que se subcontrata (proporción por valor de } \\
\text { nuevas obras y renovación de activos realizada por contratistas } \\
\text { externos, incluyendo nuevas conexiones de servicio y extensiones de } \\
\text { red). }\end{array}$ \\
\hline Operaciones y mantenimiento $(\%)$ \\
\hline $\begin{array}{l}\text { Porcentaje estimado de los costes de operaciones y mantenimiento (del } \\
\text { servicio de saneamiento) que se subcontrata. }\end{array}$ \\
\hline Servicios de monitorización del agua (\%) \\
\hline $\begin{array}{l}\text { Porcentaje estimado de los costes del servicio de monitorización de } \\
\text { aguas residuales que se subcontrata. }\end{array}$ \\
\hline
\end{tabular}

El nivel de sofisticación de la gestión es también otro tipo de factor explicativo que puede ser relevante para la comprensión de los resultados o para comprobar cuánto desempeño se logra y "explica" por ellos. Las características del servicio al cliente (muy importante para interpretar los ID de quejas, por ejemplo) y los recursos tecnológicos existentes son dos de los ejemplos más significativos, expresados respectivamente en la Tabla 49 y Tabla 50. 
Tabla 49. Otros factores explicativos: servicio al cliente

\begin{tabular}{|c|}
\hline $\begin{array}{l}\text { Existencia de un sistema para registrar todas las quejas de los } \\
\text { clientes }\end{array}$ \\
\hline $\begin{array}{l}\text { Existencia de registros que muestran el número total de } \\
\text { reclamaciones verbales y escritas de los clientes, permitiendo } \\
\text { determinar la naturaleza de las quejas mediante el escrutinio de } \\
\text { las entradas individuales. }\end{array}$ \\
\hline $\begin{array}{l}\text { Existencia de un sistema formal de registro de quejas de los } \\
\text { clientes para el monitorizar la calidad del servicio y la gestión de } \\
\text { infraestructuras }\end{array}$ \\
\hline $\begin{array}{l}\text { Existencia de un sistema de registro y procesamiento de datos de } \\
\text { reclamaciones de clientes que se utiliza para resolver quejas de } \\
\text { clientes, monitorizar la calidad y desempeño de servicio y } \\
\text { planificación de la gestión de infraestructuras. }\end{array}$ \\
\hline Existencia de un sistema de normas garantizadas \\
\hline $\begin{array}{l}\text { Existencia de un sistema de normas garantizadas que establezca } \\
\text { los derechos de los clientes, como: el tiempo máximo para } \\
\text { obtener una nueva acometida y para reparar una existente; } \\
\text { tiempo máximo de respuestas escritas; horarios para asistir a las } \\
\text { instalaciones de los clientes. Se deben especificar los tiempos establecidos } \\
\text { en el sistema de normas garantizadas. }\end{array}$ \\
\hline Tiempo establecido para una nueva acometida \\
\hline $\begin{array}{l}\text { Tiempo máximo de establecimiento de una nueva acometida, } \\
\text { desde la solicitud del cliente hasta la disponibilidad del servicio } \\
\text { (en los casos en que existe la acometida). }\end{array}$ \\
\hline
\end{tabular}


Tabla 50. Otros factores explicativos: recursos tecnológicos

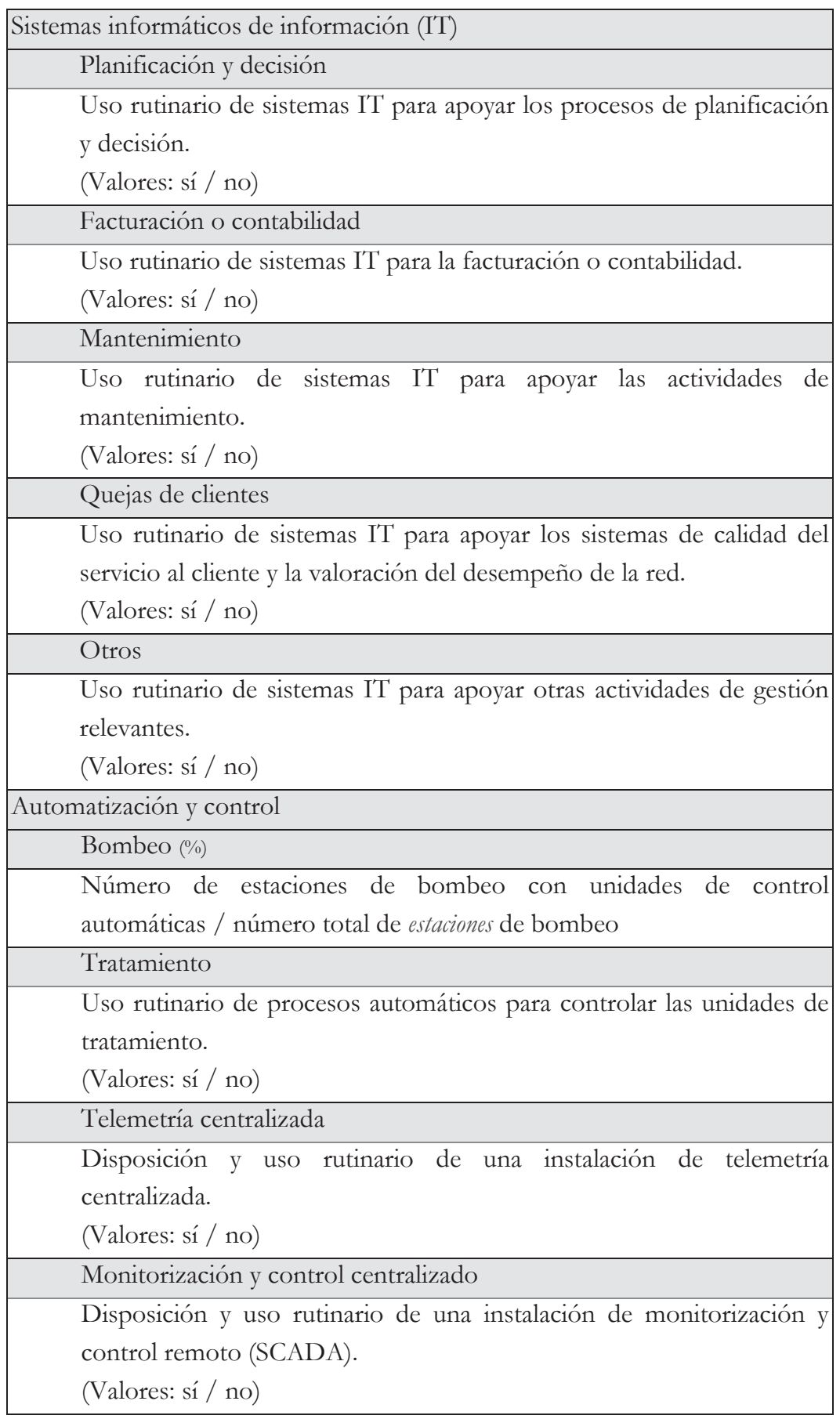


Tabla 50a. Otros factores explicativos: recursos tecnológicos (cont.)

\begin{tabular}{|c|c|}
\hline & Control integrado (\%) \\
\hline & $\begin{array}{l}\text { Número de estaciones integradas / número total de estaciones x } 100 . \\
\text { (Valores: sí / no) }\end{array}$ \\
\hline \multicolumn{2}{|c|}{ Mapeo } \\
\hline & Mapeo actualizado (\%) \\
\hline & $\begin{array}{l}\text { Longitud de la red mapeada con una tolerancia de captura compatible } \\
\text { con una escala de } 400 \text { p.p.m. / longitud total de la red x } 100 . \\
(400 \text { p.p.m. }=1: 2500)\end{array}$ \\
\hline \multicolumn{2}{|r|}{ Mapeo digital (\%) } \\
\hline & $\begin{array}{l}\text { Longitud de la red digitalizada con una tolerancia de captura } \\
\text { compatible con una escala de } 400 \text { p.p.m. / longitud total de la red x } \\
100 . \\
(400 \text { p.p.m. }=1: 2500)\end{array}$ \\
\hline
\end{tabular}




\section{CALIDAD DE LOS DATOS}

\subsection{Introducción}

Si hay un concepto incluido en el marco de indicadores de desempeño de la IWA que no ha logrado ser ampliamente aceptado y aplicado, es la integración real de la calidad de los datos en los sistemas de evaluación del desempeño. Incluso hoy en día, muy pocos sistemas en el mundo consideran la calidad de los datos o la gestionan según su importancia. Y, sin embargo, la comprensión, la recogida y la consideración durante el período de evaluación de la calidad de las variables recogidas es fundamental para tomar decisiones coherentes y bien informadas.

La industria del agua es notablemente propensa a tratar con información de mala calidad. Con algunas excepciones, la naturaleza enterrada de la mayoría de infraestructuras y el largo período de tiempo desde que los servicios de saneamiento iniciaron sus actividades, a menudo conducen a incógnitas e incertidumbres. Los sistemas de información a menudo no están completamente actualizados o no están adecuadamente conectados entre sí. Además, los volúmenes medidos son a menudo inexactos debido a caudalímetros antiguos o no calibrados. Esta realidad a menudo se hace evidente cuando un prestador elige participar en un proyecto de evaluación de desempeño, dándose cuenta de que los datos a menudo no están disponibles o no tienen calidad suficiente (y esto suele ser una sorpresa).

Los indicadores de desempeño son más útiles cuando se comparan con algún valor (ya sea con metas, desempeño previo o resultados entre pares). Sin embargo, tomar decisiones basadas en tales comparaciones cuando la calidad de los datos es deficiente es un ejercicio arriesgado que debe llevarse a cabo con extremo cuidado.

Sin embargo, la mayoría de los usos de los indicadores de desempeño de la IWA encontrados en la práctica presentan el valor numérico del indicador sin información sobre la calidad de los datos utilizados para lograr tal valor. Esto puede crear situaciones en las que los indicadores desinformen en lugar de ayudar a toma buenas decisiones. Esto es particularmente cierto en la evaluación comparativa del desempeño o en el benchmarking, donde se comparan los valores de los indicadores de varios prestadores (por ejemplo, 
cuando se utilizan en la regulación por comparación o "yardstick competition" por parte de algunos reguladores).

Un buen ejemplo de este problema ha sido dado a menudo por algunos de los autores de este manual en algunas presentaciones públicas ${ }^{6}$. Imagine dos prestadores hipotéticos comparando su desempeño de pérdidas de agua reales. La Tabla 51 resume la información necesaria para obtener el indicador de pérdidas reales de cada prestador. Como se muestra en la tabla, la diferencia en la calidad de los datos utilizados por cada prestador para el cálculo del indicador es elevada.

Tabla 51. Ejemplo de diferencias en la calidad de los datos en dos prestadores hipotéticos

\begin{tabular}{|c|c|c|}
\hline Variable / Indicador & Prestador A & Prestador B \\
\hline Volumen de entrada & $\begin{array}{l}\text { Hay caudalímetros } \\
\text { presentes en la entrada del } \\
\text { sistema y están } \\
\text { mantenidos. }\end{array}$ & $\begin{array}{l}\text { No hay caudalímetros. } \\
\text { Los valores de entrada se } \\
\text { calculan a partir de los } \\
\text { tiempos de bombeo y } \\
\text { eficiencia estimada de las } \\
\text { bombas. }\end{array}$ \\
\hline Consumo autorizado & $\begin{array}{l}\text { Todos los usuarios tienen } \\
\text { contador, incluyendo los } \\
\text { residenciales. Se tiene un } \\
\text { programa de } \\
\text { mantenimiento de } \\
\text { contadores. }\end{array}$ & $\begin{array}{l}\text { No se utilizan contadores } \\
\text { para la facturación. } \\
\text { Todos los volúmenes son } \\
\text { estimados }\end{array}$ \\
\hline $\begin{array}{l}\text { Número de } \\
\text { acometidas }\end{array}$ & $\begin{array}{l}\text { Cada cliente con contrato } \\
\text { tiene su propia acometida. } \\
\text { La certeza es elevada. }\end{array}$ & $\begin{array}{l}\text { Se desconoce el número } \\
\text { de acometidas. El } \\
\text { crecimiento ha llevado a } \\
\text { casos de varias } \\
\text { acometidas por cliente, y } \\
\text { el valor total es } \\
\text { desconocido. }\end{array}$ \\
\hline ID de pérdidas reales & 260 1/acometida/día & 215 l/ acometida/día \\
\hline
\end{tabular}

${ }^{6}$ NdelT: Aunque se trata de un ejemplo acerca de la prestación del servicio de agua, es completamente válido para comprender la relevancia del problema. 
Sin embargo, en la mayoría de los proyectos observados hasta la fecha los resultados se presentarán como:

- Prestador A: 260 1/acometida/día

- Prestador B: 215 1/acometida/día

La mayoría de los profesionales del agua cuando se enfrentan a este ejemplo comprenden inmediatamente la necesidad de un enfoque sistemático de la calidad de los datos en el sistema de indicadores de desempeño. Un enfoque que siempre ha sido parte del marco de la IWA para la evaluación del desempeño, pero desafortunadamente sigue siendo ignorado.

Si bien los conceptos fundamentales introducidos en la primera edición de este manual siguen siendo válidos y completamente aplicables, es cierto que el sistema propuesto ha demostrado ser demasiado complejo para ser aplicado en muchas circunstancias.

\subsection{Gestión completa de la calidad de los datos: exactitud y fiabilidad}

El marco original para gestionar la calidad de los datos publicado con el primer manual sobre indicadores de desempeño de la IWA se basó en el sistema desarrollado por OFWAT para su esquema de regulación.

Este sistema sigue siendo completamente válido hoy en día y proporciona información detallada sobre cuán buenos son los datos utilizados para calcular los indicadores de desempeño. Sin embargo, como se mencionó anteriormente, los usuarios del sistema han encontrado a menudo esta opción demasiado compleja.

Para realizar una evaluación completa de la calidad de los datos de entrada, ésta se debe evaluar en términos de la fiabilidad de la fuente y de la exactitud de los datos.

La fiabilidad de la fuente explica la incertidumbre asociada a fuente de datos. Por ejemplo, hasta qué punto la fuente de datos proporciona información consistente, estable y resultados uniformes para observaciones repetidas o mediciones en condiciones similares a lo largo del tiempo. Además, los datos 
en el sector del agua a menudo son obsoletos y se basan en registros incompletos, lo que hace aconsejable registrar la fiabilidad de la fuente de información.

La exactitud engloba errores de medida en la adquisición de los datos; la cercanía de los valores observados, computados o estimados a los valores reales. La exactitud se relaciona con la fidelidad del resultado y se distingue de la precisión en que ésta se relaciona con la fidelidad de la operación utilizada para obtener el resultado.

La práctica demuestra que, en general, los suministradores de datos no tienen información detallada sobre la fiabilidad y exactitud de los datos, pero son capaces de realizar estimaciones si se utilizan amplias bandas de confianza.

La prueba de campo del sistema de ID de la IWA demostró que el uso de cuatro categorías de exactitud de los datos y tres de fiabilidad es factible y un resulta en un buen equilibrio entre "un mundo ideal" y no utilizar este tipo de información.

Las bandas de exactitud recomendadas son:

Tabla 52. Bandas de exactitud recomendadas

\begin{tabular}{|cl|}
\hline $\begin{array}{c}\text { Banda de } \\
\text { confianza }\end{array}$ & \multicolumn{1}{c|}{ Incertidumbre asociada } \\
\hline $0-5 \%$ & Mejor que o igual a $+/-5 \%$ \\
\hline $5-20 \%$ & Peor que $\pm 5 \%$, pero mejor que o igual a $+/-20 \%$ \\
\hline $20-50 \%$ & Peor que $\pm 20 \%$, pero mejor que o igual a $+/-50 \%$ \\
\hline$>50$ & Peor que $\pm 50 \%$ \\
\hline
\end{tabular}

Las bandas recomendadas para la fiabilidad de los datos son: 
Tabla 53. Bandas de confianza recomendadas para la fiabilidad de los datos

\begin{tabular}{|ll|}
\hline $\begin{array}{c}\text { Banda de } \\
\text { confianza }\end{array}$ & \multicolumn{1}{c|}{ Definición } \\
\hline & $\begin{array}{l}\text { Fuente de datos altamente fiable: datos basados en } \\
\text { registros sólidos, procedimientos, investigaciones o análisis } \\
\text { apropiadamente documentados y reconocidos como los } \\
\text { mejores métodos de evaluación disponibles. }\end{array}$ \\
\hline$\star \star$ & $\begin{array}{l}\text { Fuente de datos moderadamente fiable: pero que } \star \star \star \\
\text { pero mejor que } \star\end{array}$ \\
\hline$\star$ & $\begin{array}{l}\text { Fuente de datos poco fiable: datos basados en la } \\
\text { extrapolación de un número limitado de muestras o en } \\
\text { inferencias. }\end{array}$ \\
\hline
\end{tabular}

Se recomienda que las implementaciones específicas definan criterios para evaluar las bandas de fiabilidad para cada variable de entrada (por ejemplo, *** - variable evaluada con base en la medición que contribuye al menos al $95 \%$ del valor total)

La fiabilidad de la fuente de datos y la precisión de los datos deben evaluarse para cada dato de entrada. La exactitud de los cálculos también debe evaluarse, preferiblemente de forma cuantitativa, de acuerdo con la Guía ISO para la expresión de la incertidumbre en la medición ${ }^{7}$. Véase II-5 para detalles sobre cómo se puede evaluar la exactitud de los valores resultantes de las operaciones algebraicas.

\subsection{Un nuevo enfoque en la calidad de los datos}

El enfoque completo de la gestión de la calidad de los datos, descrito anteriormente, ha demostrado ser fundamental para la toma de decisiones cuando se aplica adecuadamente, pero sigue siendo demasiado complejo para muchos proyectos. Especialmente aquellos donde la calidad de los datos es bastante pobre.

7 GUM (1995) - Guía para la expresión de la incertidumbre en la medición, "Guide to the expression of uncertainty in measurement", “'ISO, ISBN 92-67-10188-9. 
Como consecuencia, algunas de las aplicaciones del sistema IWA que han aparecido en los últimos años han implementado sistemas simplificados de calidad de datos. La mayoría de estos sistemas comparten dos características básicas:

[1] Una sola escala para la calidad de los datos. La fiabilidad y la exactitud se sustituyen por términos más genéricos y los datos se califican con términos como "bueno", "regular" o "malo".

[2] Cada nivel de calidad de datos se define para todas las variables. Dado que los datos están calificados en términos más genéricos, es necesario definir para cada variable lo que se entiende como datos de calidad "buena", "regular" o "mala".

Este nuevo enfoque requiere un mayor esfuerzo al definir el sistema de evaluación del desempeño, ya que se requiere una definición para cada nivel de calidad de datos. Estas definiciones deben adaptarse a las necesidades específicas del proyecto y a la realidad de los participantes en el proyecto. Sin embargo, una vez definidos los niveles, es mucho más fácil para los prestadores proporcionar una evaluación de la calidad de los datos. 


\section{IMPLEMENTACIÓN DE UN SISTEMA DE ID}

\subsection{Introducción}

Los indicadores de desempeño son una poderosa herramienta de gestión, como se ha demostrado a través de su uso sistemático en muchas industrias durante décadas. Pueden proporcionar medidas de cuántos recursos se están utilizando en relación con los disponibles, pueden utilizarse para evaluar la medida en que se cumplen los objetivos de gestión e incluso para evaluar el impacto general de las estrategias de gestión.

Sin embargo, los indicadores de desempeño no pueden convertirse en una meta en sí mismos. La implementación de un sistema de indicadores de desempeño debe ser el resultado de un enfoque más amplio en la gestión dentro de un prestador de servicios de saneamiento. De lo contrario, los resultados obtenidos a través de indicadores de desempeño pueden no ser adecuados o útiles. Una consecuencia típica de los indicadores de desempeño utilizados como fin y no como medio se describe por Neely (2002) en la llamada "crisis de medición":

\section{La crisis de medición}

- Las medidas no están relacionadas con la estrategia de la organización

- Se miden cosas las equivocadas

- Las únicas medidas a las que se les da importancia son las financieras

- Las únicos datos a los que se les da importancia es a los financieros

- Se recogen datos, pero no se analizan, sin utilizarlos para tomar decisiones

- El nivel operativo se pasa por alto

- Los sistemas de medición son tan complejos que las prioridades no están claras

- Hay una buena síntesis del desempeño pasado, pero un pronóstico deficiente de futuro

- Se mide todo lo que se puede medir, pero no aquello que es importante

Algunos de los problemas descritos anteriormente son bastante comunes en muchos prestadores de servicios de saneamiento, incluyendo algunos que disponen de un sistema de indicadores de desempeño. Es posible que la 
Primera Edición de este manual hubiera confundido a algunos lectores en el uso de indicadores de desempeño, sugiriendo que todos los indicadores en el manual debían a ser utilizados.

Sin embargo, la intención de los autores de este manual no es proporcionar un solo conjunto único de indicadores de desempeño, sino más bien un amplio conjunto que cubra muchas de las necesidades de un prestador típico en la mayor parte del mundo. Un estudio detallado de los indicadores de desempeño contenidos en la propuesta de la IWA muestra claramente que algunos de ellos han sido creados para ser utilizados sólo en ciertas partes del planeta y bajo condiciones específicas. En consecuencia, un uso apropiado del sistema requiere una selección de un subconjunto de indicadores y una correcta implementación del sistema. Este capítulo está dedicado a proporcionar algunas pautas básicas para el uso correcto de un sistema de indicadores de desempeño basado en la propuesta de la IWA.

\subsection{Uso de los indicadores de la IWA en un sistema de evaluación del desempeño}

Un sistema de evaluación del desempeño es una herramienta necesaria en cualquier empresa y por lo tanto en cualquier prestador de servicios de saneamiento. Un buen sistema proporcionará información sobre el desempeño actual de la empresa e incluso puede anticipar eventos futuros. El objetivo último de cualquier sistema de evaluación del desempeño es proporcionar información en lugar de datos (podemos definir la información como cualquier dato que sea útil en un proceso de toma de decisiones). En consecuencia, los datos recopilados y procesados dentro de un sistema de evaluación del desempeño deben estar relacionados con los objetivos e intereses de la empresa y de sus administradores.

Un sistema adecuado de indicadores de desempeño debe entenderse como parte de un ente más amplio que vincula objetivos, estrategias, factores críticos de éxito dentro de la empresa y de los mismos indicadores. Esta integración de la evaluación del desempeño en todas las actividades de gestión es uno de los fundamentos de sistemas como el "Cuadro de mandos integral" o Balance Scorecard (Kaplan \& Norton, 1996) que pretende mostrar que las principales perspectivas dentro de una empresa (financiera, cliente, 
procesos y desarrollo y aprendizaje) están interconectados y, por consiguiente, deben considerarse como un todo.

El sistema de indicadores de desempeño de la IWA proporciona una herramienta muy valiosa cuando se adoptan sistemas de evaluación del desempeño como el Cuadro de mandos integral, y ambas herramientas pueden ser totalmente compatibles. Lograr una integración exitosa de un sistema tan equilibrado con indicadores de la IWA depende principalmente de la correcta filosofía y enfoque, y de una implementación cuidadosa y metódica.

El proceso de implementación descrito en este capítulo es genérico y no corresponde a ningún sistema específico de evaluación del desempeño. Sin embargo, un conocimiento adecuado de cualquier otro sistema y la propuesta de indicadores de desempeño de la IWA debería permitir una integración relativamente fácil de esta propuesta en cualquier sistema.

\subsection{Definición de los objetivos}

La implementación de cualquier sistema de ID debe estar orientada a los objetivos. Los indicadores de desempeño son el último paso de una estrategia de gestión más amplia que debe vincular los objetivos del prestador con las estrategias, definir factores críticos de éxito y luego seleccionar indicadores de desempeño como medio para evaluar el éxito de estas estrategias y como mecanismo de control para detectar problemas con antelación .

Los objetivos deben ser precisos y claros. Necesitan ser exigentes y realistas y, lo más importante, deben reflejar la misión y la visión de la empresa. Los objetivos a corto plazo deben ser parte de una estrategia de planificación a largo plazo, lo que es especialmente importante en un negocio basado en activos, como es el servicio de saneamiento. Los objetivos de un prestador de servicios de saneamiento deben tener en cuenta no sólo los aspectos puramente gerenciales de una empresa, sino también las necesidades y objetivos de las diferentes partes interesadas.

La definición de objetivos debe ser siempre el primer paso de un sistema de evaluación del desempeño bien definido. Una definición clara de los objetivos a alcanzar será útil para obtener una perspectiva del proyecto y responder a algunas preguntas complicadas: ¿Cuánto se debe invertir en el 
sistema de evaluación del desempeño? ¿Quién y qué departamentos deben ser incluidos en el equipo del proyecto? ¿Cuáles serán los beneficios de este proyecto?

No conseguir una definición adecuada de los objetivos sólo conducirá a la incertidumbre en la utilidad de todo el sistema y la falta de implicación en todos los niveles. La definición de estos objetivos puede abarcar desde los objetivos prioritarios de la compañía hasta objetivos periódicos a nivel departamental. Dependiendo de la importancia de los objetivos, el personal directivo responsable de estos objetivos debe promover, estimular y respaldar claramente todo el proyecto. En los prestadores con estrategias de gestión de la calidad total ya desarrolladas, el sistema de evaluación del desempeño debe ser integrado y adoptado como una herramienta adicional.

El servicio de saneamiento es un servicio público y presenta algunas diferencias en comparación con otras industrias. La presencia de partes interesadas externas (además de las internas) puede afectar la definición de los objetivos y, en última instancia, la elección de los indicadores de desempeño. En cualquier caso, la metodología aplicable seguiría siendo la misma y los únicos cambios serían la naturaleza de los objetivos y los actores que juegan un papel en el proceso.

Una lista de motivos para utilizar un sistema ID (y, como consecuencia de posibles objetivos) se presenta en I-1.3, y está ilustrada en la Figura 1.

\subsection{Definición de estrategias}

Las estrategias que deben aplicarse para alcanzar los objetivos en un prestador son una decisión clave de la gerencia. Esta decisión depende de muchos factores, especialmente en el sector del servicio de saneamiento, donde entran en juego variables no directamente relacionadas con los criterios empresariales (generalmente corresponden a la necesidad de cumplir los objetivos de las partes interesadas externas).

Este manual no tiene la intención de proporcionar estrategias potenciales para la gestión de los servicios de saneamiento. Sin embargo, e independientemente de las estrategias elegidas, deben vincularse directamente a uno de los objetivos establecidos en el paso anterior. Todos los objetivos definidos deben ser abordados por al menos una estrategia específica y todas 
las estrategias desarrolladas deben ser el resultado de tratar de lograr al menos uno de los objetivos.

\subsection{Establecimiento de factores críticos de éxito}

No siempre es posible alcanzar los objetivos utilizando todas las estrategias. Muy a menudo los directivos se enfrentan a restricciones que pueden ser tan simples como económicas, o incluso pueden presentar un carácter político. Además, según el contexto, se puede considerar una estrategia exitosa inadecuada para un caso particular. Como resultado, la selección de la estrategia óptima para alcanzar los objetivos del prestador dependerá del contexto y las restricciones existentes en cada situación.

Los factores críticos de éxito son, en consecuencia, entidades dinámicas. Mientras que la fase anterior se basa en la identificación de todas las estrategias posibles que pueden dirigir hacia la consecución de los objetivos, la selección de los factores de éxito críticos dependerá del tiempo, el lugar y la situación. Un cambio en las restricciones o un contexto diferente, pueden conducir a un factor de éxito crítico diferente. Por lo tanto, es de vital importancia seguir la evolución de todas las limitaciones actuales (algo bastante obvio para cualquier prestador) y ser consciente del contexto en el que se toma la decisión. Por tanto, una estrategia elegida para un determinado prestador puede no ser la mejor para otro con un contexto diferente).

\subsection{Establecimiento de un sistema de indicadores del desempeño}

Los indicadores de desempeño son el principal objetivo de este manual. Sin embargo, deben formar parte siempre de un marco más amplio. Los indicadores de desempeño monitorizan, evalúan el desempeño, identifican el éxito obtenido de las metas propuestas y suministran información valiosa para pronosticar las tendencias futuras e identificar necesidades de planificación.

Hay muchas definiciones de conjuntos de indicadores de desempeño en la industria del agua, así como fuera de ésta. Todos ellos pueden ser una fuente útil y un punto de partida para una adecuada selección de ID en un sistema. 
Sin embargo, no todos estos conjuntos se han definido con el mismo nivel de detalle o los mismos objetivos en mente.

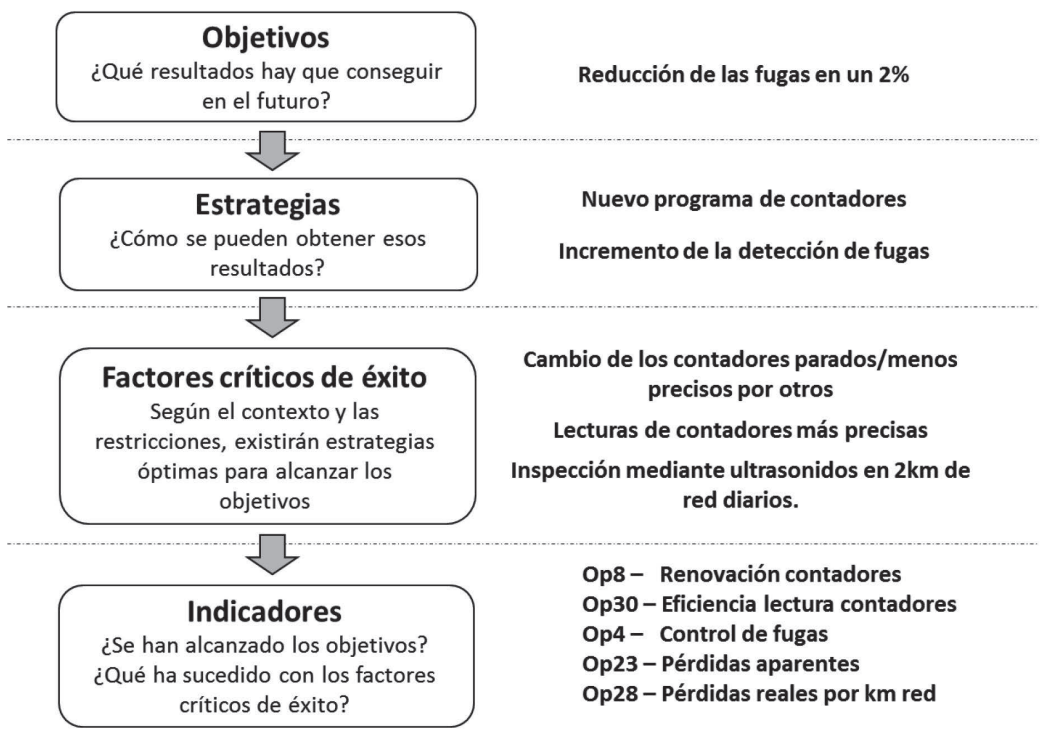

Figura 8. ID como parte de un sistema de evaluación del desempeño ${ }^{8}$

El sistema de indicadores de desempeño de la IWA para servicios de saneamiento se desarrolló teniendo en cuenta tres factores clave:

- Fue desarrollado para la industria con objetivos de gestión interna en mente;

- Se desarrolló tratando de tener en cuenta las diferentes realidades del servicio en todo el mundo, y con el objetivo de proporcionar indicadores válidos para todas esas realidades;

- Fue diseñado para permitir comparaciones más verídicas siempre que sea posible, con el fin de ser útil para la evaluación comparativa del desempeño.

8 NdelT: Aunque se trata de un ejemplo acerca de la prestación del servicio de agua, del Manual de Buenas Prácticas de Indicadores de Desempeño para Servicios de Abastecimiento de Agua, es completamente válido para comprender la función de los indicadores dentro del enfoque estratégico. 
Como consecuencia, el sistema de ID de la IWA para servicios de saneamiento es un gran conjunto de indicadores que deben ser entendidos en su contexto. Presenta un gran número de ventajas sobre otros sistemas existentes, y algunas desventajas. Los usuarios deben tener en cuenta estas fortalezas y debilidades cuando usen el sistema.

Ventajas:

- Estructura sólida - Como se define en el capítulo I-3, el sistema de ID de la IWA se ha construido sistemáticamente en torno a una estructura coherente, clara y sólida que permite modificaciones, adaptaciones y ampliaciones

- Sistema bien definido - Las sólidas definiciones de los diferentes elementos (indicadores, variables, información de contexto) son un punto de partida muy valioso para el usuario. El sistema ha sido probado en cientos de situaciones y en todas partes del mundo. El resultado es un conjunto de definiciones que tienen en cuenta la mayoría de los problemas que pueden surgir en el uso del sistema.

- Conjunto bien equilibrado - El sistema de la IWA fue desarrollado teniendo en cuenta todos los aspectos del prestador en conjunto. Como consecuencia, el número de indicadores dedicados a cada parte del servicio ha sido diseñado para mantenerse en equilibrio con el resto. El uso del sistema IWA como un todo debe proporcionar la misma cantidad de información sobre cada aspecto del prestador.

- Definiciones estándar - El sistema IWA ya se considera el sistema estándar en la industria del agua, y se ha utilizado alrededor de todo el mundo en la definición de nuevos sistemas de evaluación del desempeño. Usando los indicadores definidos en este manual, lo más probable es que alguien, en algún lugar, esté usando las mismas definiciones.

Desventajas:

- Demasiado superficial - El conjunto de indicadores IWA fue diseñado sin una necesidad específica en mente, sino más bien para evaluar de 
forma global el servicio. Es por ello que algunos indicadores necesarios para funciones y procesos más específicos pueden no estar contemplados en este sistema.

- Demasiado amplio de alcance - Los indicadores de la IWA se fueron seleccionados con el fin de evaluar el desempeño de los servicios de saneamiento independientemente del área dónde se encuentren. Dado que la realidad de los servicios de saneamiento es tan diferente en las distintas partes del planeta, algunas partes del sistema pueden parecer inservibles cuando se consideran para determinados prestadores.

- Demasiados indicadores - Como consecuencia directa de los dos puntos anteriores, el número de indicadores de desempeño presentados en la propuesta de la IWA parece demasiado grande, y ciertamente lo es para las aplicaciones y prestadores normalmente considerados. Sin embargo, el gran número de indicadores también ofrece más posibilidades de elegir los más adecuados para cada caso y circunstancia.

Como se muestra arriba, en el sistema IWA no son todo ventajas. Sin embargo, todos los problemas mencionados anteriormente pueden superarse fácilmente estableciendo adecuadamente el sistema. Las necesidades específicas de cada caso se pueden abordar ya sea añadiendo o modificando indicadores, y un proceso de selección adecuado descartará los ID inservibles o sin sentido para las necesidades reales del usuario. Independientemente de los cambios realizados en el sistema, el proceso será mucho más fácil y resultará en un conjunto más sólido que el que se podría obtener si se construyese desde cero.

Por lo tanto, es de gran importancia seguir una implementación metódica de un Sistema de Indicadores de Desempeño. Tales pasos se describen en este punto.

\section{Definición de los principios estratégicos de la evaluación del desempeño}

La definición de unos principios de evaluación del desempeño como tal es el resultado de la aplicación de los conceptos definidos anteriormente para cualquier sistema de evaluación del desempeño. En cualquier caso, deben ser considerados a cualquier nivel, y son el primer paso para cualquier sistema de 
indicadores de desempeño. Será más fácil abordar una política clara con objetivos y estrategias definidas y con factores críticos de éxito específicos que temas o nociones más amplios. Estas decisiones son responsabilidad de la alta dirección, y un equipo estratégico debe estar a cargo de establecer la dirección estratégica que la empresa debe tomar en el futuro.

En esta fase, la empresa debe asegurarse de que los objetivos incluyen a todas las partes interesadas, tanto las internas como las externas. De esta manera se logra comprometer de una forma efectiva a los encargados e impulsores del proyecto, los que lo llevan a cabo, los que proporcionan los datos clave y los interesados en los resultados.

Esto ha demostrado ser un buen punto de partida para determinar las características y componentes del equipo de ID. Este equipo debe estar a cargo del proyecto actual de ID y de su consistencia dentro de las decisiones estratégicas tomadas previamente. Como resultado, la implementación exitosa de un sistema de ID dentro de una organización normalmente requiere que el líder del equipo de ID sea un miembro del personal de nivel superior, de ser necesario asistido por colegas menos experimentados. La implicación y participación activa del personal directivo, por lo general los encargados de tomar decisiones que van a utilizar la información proporcionada por los ID, es esencial. También se recomienda encarecidamente que los representantes de los departamentos o secciones que necesiten proporcionar los datos de los ID sean miembros principales del equipo de ID, a fin de asegurar su compromiso con todas las etapas del proceso.

La experiencia recabada en los ensayos piloto del sistema de ID de la IWA demostraron que la implicación del personal puede reportar un importante beneficio en la implementación de un sistema de ID. Los participantes presentan una gama más amplia de opiniones y puntos de vista alternativos a las de otros miembros del personal con diferentes responsabilidades y antecedentes. Es esencial en esta etapa informar adecuadamente al equipo de ID sobre el propósito, los objetivos y los resultados esperados del establecimiento del sistema de evaluación del desempeño dentro del prestador.

La siguiente etapa del proceso es revisar los sistemas de ID disponibles y seleccionar el más apropiado para los factores críticos de éxito especificados. Aunque este manual puede usarse en general para asistir a los usuarios en la 
aplicación de un rango amplio de sistemas de indicadores, los usuarios que requieran implementar un sistema de ID para abastecimiento de agua se presupone que normalmente adoptarán el Manual de Indicadores de Desempeño de la IW A para servicios de Abastecimiento de Agua. Es por ello, que las directrices subsiguientes en este manual pueden no ser aplicables a otros sistemas ID.

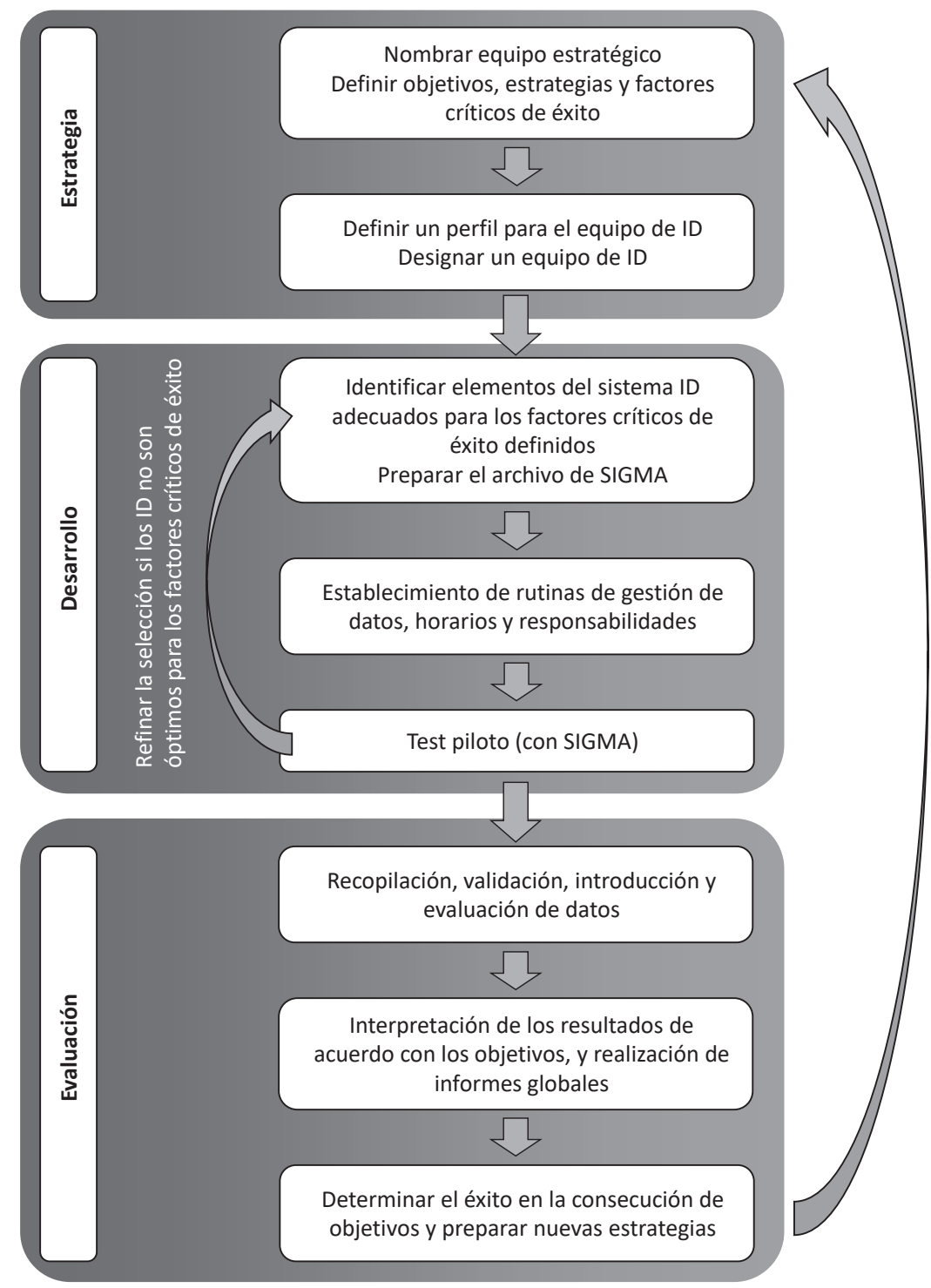

Figura 9. Fases del proceso de implementación de un Sistema de ID 


\section{Selección de los ID a evaluar}

El siguiente paso en el proceso de establecer un sistema de ID adecuado consiste en seleccionar y definir adecuadamente los indicadores de desempeño que se utilizarán y la Información de Contexto (IC) necesaria en caso de que sea preciso. La etapa de selección es relevante por varias razones:

- El número total de indicadores de desempeño puede ser un factor clave en el éxito del proyecto. Si hay demasiados indicadores, los costes y dificultades de implementar el sistema aumentarán significativamente. Si por el contrario son muy pocos, el sistema no será capaz de proporcionar una evaluación adecuada del desempeño del prestador en los términos definidos por los objetivos y las estrategias seleccionadas.

- Los indicadores seleccionados deben de formar un grupo equilibrado que estudie el desempeño de las diferentes áreas de la empresa. Seleccionar un pequeño número de indicadores no es de gran utilidad si todos se refieren a la misma área del negocio (y los objetivos y estrategias se refieren a un ámbito más amplio).

- La naturaleza de los indicadores seleccionados puede influir en la interpretación de los resultados. Aunque un indicador bien definido proporcionará poco o ningún sesgo a la interpretación de sus resultados, hay muchos ejemplos de la vida real que nos muestran que esto es un peligro real.

- Los indicadores deben ser consistentes en su construcción. Un sistema de ID bien definido consistirá en indicadores de desempeño que comparten la misma estructura y nivel de detalle en sus definiciones, período de evaluación y unidades. Adicionalmente, el sistema debe ser construido de tal manera que las variables comunes sean compartidas por indicadores y tengan definiciones únicas, los mismos períodos de evaluación y unidades.

Teniendo en cuenta todos estos factores, no es difícil ver por qué la propuesta de la IWA es una herramienta poderosa para la construcción de un sistema de ID. Cuando se usa la propuesta IWA, la única dificultad que hay que superar es seleccionar un número reducido de ID dependiendo de las necesidades del proyecto. Todas las demás condiciones, que consumen 
mucho tiempo y requieren experiencia en la medición del rendimiento, ya se han tenido en cuenta.

Sin embargo, esto no significa que no se puedan usar indicadores adicionales. De hecho, en un buen número de casos será necesario crear y agregar más indicadores al subconjunto seleccionado de indicadores de la IWA. Estos nuevos indicadores contemplarán las peculiaridades de la región, el negocio, las partes interesadas o el propio prestador. Sin embargo, todos los nuevos indicadores deben construirse de tal manera que los haga totalmente coherentes y compatibles con los indicadores de la IWA.

Con el fin de seleccionar los indicadores y la información de contexto apropiados del conjunto IWA, se presentan los cinco pasos siguientes:

[1] - Preselección de los ID considerados importantes para la evaluación (junto con los objetivos, estrategias y factores críticos de éxito relevantes seleccionados).

[2] - Selección de los ID e IC utilizados en la evaluación inicial.

[3] - Desarrollo de ID e IC adicionales si se considera necesario. Comprobar su consistencia.

[4] - Realización de una prueba piloto con los ID seleccionados inicialmente.

[5] - Selección final de los ID a utilizar, que serán aquellos considerados como importantes en la evaluación.

Estos procesos se ilustran en la Figura 10.

El primer paso es clasificar los indicadores en función de su importancia para la evaluación. Esta clasificación debe tener en cuenta las opiniones y necesidades de las diversas partes implicadas. Una clasificación de tres niveles (alta, media y baja) puede ser apropiado para esta etapa. Esta clasificación debe llevarse a cabo independientemente de la disponibilidad o calidad de los datos necesarios para calcular el ID. Una vez que se han identificado los ID importantes, puede ser necesario modificar los procesos de recopilación y gestión de datos, y estas mejoras deben hacerse teniendo en cuenta la importancia de los indicadores que se han de calcular a partir de estos datos. 
La selección inicial de ID debe hacerse a nivel de la alta dirección (equipo estratégico) dentro del prestador en consulta con el equipo de ID, que interactuaría con los encargados de proveer los datos (a nivel de departamento). Pueden requerirse consultas adicionales fuera del prestador, por ejemplo, cuando la evaluación del desempeño se realice con fines regulatorios o externos. En la Tabla 54 se muestra los participantes que podrían ser necesarios para asignar niveles de significación y seleccionar los ID relevantes. Las partes interesadas externas pueden no ser tenidas en cuenta cuando la evaluación es para uso interno.

En caso de que exista un ID al que se le ha asignado una importancia elevada, pero con variables no disponibles o difíciles de obtener, el ID debe seguir siendo incluido en la selección y deben tomarse medidas para obtener los datos para futuras evaluaciones de los indicadores de desempeño.

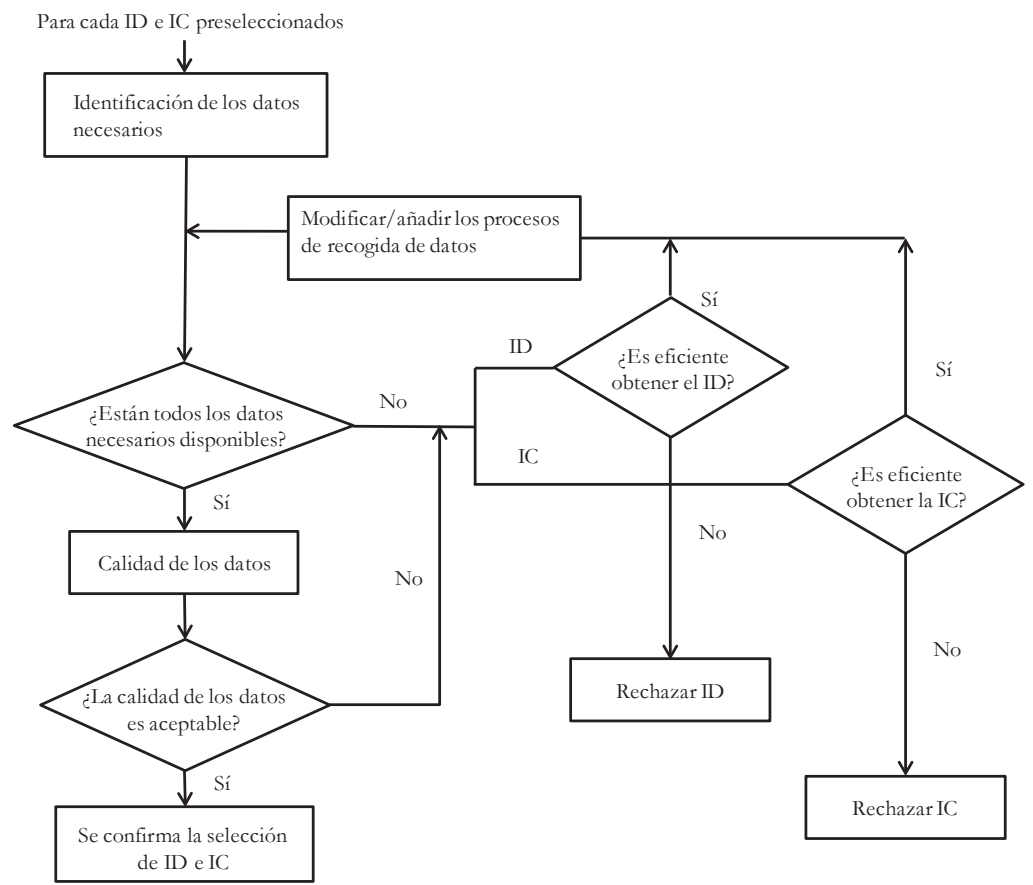

Figura 10. Proceso de selección de ID e IC

En algunos proyectos de evaluación puede ser necesario personalizar los ID principales. Puede ser necesario complementarlos con subíndices ampliados o más detallados. La selección de estos otros indicadores debe seguir el mismo procedimiento. Después de la preselección de ID, se recomienda 
asignar a una persona, departamento o subgrupo responsable de la provisión, validación y confirmación de datos para cada ID.

Tras la asignación de niveles de importancia a cada uno de los ID, la siguiente etapa consiste en preseleccionar los ID que se utilizarán en una prueba piloto. La selección debe incluir aquellos clasificados como los más importantes. La selección final de indicadores que se utilizarán después de la implementación completa será el resultado de un proceso iterativo. En cualquier caso, la selección debe tener como objetivo incluir los indicadores que son óptimos para monitorizar los factores críticos de éxito. Sin embargo, a veces los datos requeridos no están disponibles o no son lo suficientemente buenos. En tales casos, debe considerarse si es eficiente recolectar dichos datos antes de proceder a recogerlos o seleccionar otro indicador con datos más asequibles.

La experiencia del personal de la alta dirección del equipo estratégico debe proporcionar la selección inicial, dando una lista preliminar basada en el nivel de importancia. A continuación, se debe tener en cuenta la definición de los datos requeridos y su calidad al evaluar la idoneidad de cada ID.

Es importante señalar que, en el caso de la preparación de un proyecto de evaluación del desempeño, la información de contexto también debe seleccionarse en esta etapa. La selección de IC depende no sólo de las características locales de todas los prestadores participantes, sino también de las diferencias reales entre ellos. Cualquier elemento de contexto sospechoso de que pueda afectar significativamente a los valores de los ID debe tenerse en cuenta al seleccionar la IC apropiada. Los mismos principios descritos en la introducción de esta sección para los indicadores del sistema IWA se aplican a la información de contexto. En este caso, la necesidad de nuevos elementos de IC no incluidos en la propuesta IWA puede ser aún mayor. En cualquier caso, la propuesta de la IWA debe ser adoptada si es posible para permitir futuras comparaciones eligiendo el "estándar". 
Tabla 54. Ilustración de los tipos de participantes e implicaciones de los datos para la asignación de niveles de importancia relativos al conjunto de ID que se dan en este manual

\begin{tabular}{|c|c|c|}
\hline $\begin{array}{l}\text { Ejemplo del } \\
\text { propósito } \\
\text { (contexto) para } \\
\text { usar el sistema } \\
\text { de ID }\end{array}$ & $\begin{array}{l}\text { Partes interesadas } \\
\text { involucradas en la asignación } \\
\text { de la importancia de cada ID }\end{array}$ & Implicaciones de los datos \\
\hline $\begin{array}{l}\text { Para propósitos } \\
\text { de revisión } \\
\text { interna } \\
\text { únicamente por } \\
\text { el prestador }\end{array}$ & $\begin{array}{l}\text { La Alta Dirección y todos los } \\
\text { niveles dentro del prestador } \\
\text { que están involucrados en la } \\
\text { administración u operación } \\
\text { del sistema a ser revisado. } \\
\text { Muchos o pocos de los ID } \\
\text { pueden ser asignados al nivel } \\
\text { más alto (prioritario) que se } \\
\text { considere apropiado para la } \\
\text { revisión interna. }\end{array}$ & $\begin{array}{l}\text { El prestador puede o no tener } \\
\text { ya implementados sistemas } \\
\text { para la recogida, procesado y } \\
\text { registro de los datos } \\
\text { requeridos. }\end{array}$ \\
\hline $\begin{array}{l}\text { Para el uso } \\
\text { requerido por un } \\
\text { regulador } \\
\text { medioambiental }\end{array}$ & $\begin{array}{l}\text { Como el anterior, pero también } \\
\text { incluye al regulador y } \\
\text { posiblemente a usuarios } \\
\text { proactivos, tales como grupos de } \\
\text { interés medioambiental (ONGs). } \\
\text { Es probable que haya alguna } \\
\text { negociación en cuanto a los ID a } \\
\text { ser considerados en el nivel más } \\
\text { alto de importancia. }\end{array}$ & $\begin{array}{l}\text { Es probable que los } \\
\text { reguladores requieran que se } \\
\text { evalúen solo aquellos ID } \\
\text { relevantes para su área de } \\
\text { interés (p.ej. económicos o } \\
\text { ambientales). Es probable } \\
\text { que el prestador ya esté } \\
\text { registrando los datos } \\
\text { requeridos.. }\end{array}$ \\
\hline $\begin{array}{l}\text { Para la } \\
\text { interacción con } \\
\text { una amplia gama } \\
\text { de grupos de } \\
\text { clientes }\end{array}$ & $\begin{array}{l}\text { Una gama tan amplia de partes } \\
\text { interesadas como sea posible. El } \\
\text { prestador tendrá primero que } \\
\text { convencer a las otras partes } \\
\text { interesadas de la necesidad de } \\
\text { priorizar los ID y de informar } \\
\text { sólo sobre los más significativos, } \\
\text { pero puede ser necesario } \\
\text { aumentar eventualmente el } \\
\text { número de ID reportados. }\end{array}$ & $\begin{array}{l}\text { Es poco probable que el } \\
\text { prestador disponga de todos } \\
\text { los datos necesarios para } \\
\text { evaluar los ID percibidos } \\
\text { como importantes por las } \\
\text { partes interesadas. Puede que } \\
\text { ya exista un conjunto más } \\
\text { limitado de ID como parte } \\
\text { de un consejo de clientes u } \\
\text { otra forma de representación. }\end{array}$ \\
\hline
\end{tabular}


Trabajando sucesivamente a través de los indicadores preseleccionados, cada uno puede ser considerado para su inclusión o rechazo en la lista final de los ID más importantes según los criterios previamente establecidos. La prueba piloto puede proporcionar información adicional sobre la idoneidad de los indicadores para monitorizar los factores críticos de éxito y si estos indicadores son eficientes para evaluar el desempeño de éstos. En consecuencia, es posible que ID inicialmente clasificados como de importancia media o baja, puedan resultar de mayor importancia debido a las circunstancias.

El equipo de implementación de los ID debe identificar todos los datos requeridos y trabajar con los encargados de proveer los datos para evaluar la disponibilidad, fiabilidad y exactitud de los datos. Siempre que los datos de un ID no estén disponibles o no sean precisos, los equipos estratégicos y de ID y los encargados de proveer los datos deberán decidir si deben o no mejorar los datos o seleccionar otro indicador adecuado. Un elemento importante de la decisión será la posibilidad de vincular los sistemas de información actuales con el sistema de evaluación del desempeño. De manera óptima, los datos de todos los sistemas de información dentro del prestador deben ser definidos, recopilados y gestionados de manera coherente para maximizar los beneficios derivados de su gestión.

La Figura 11 muestra cómo interactúan los distintos participantes en el proceso de implementación de ID, junto con los flujos de datos. 


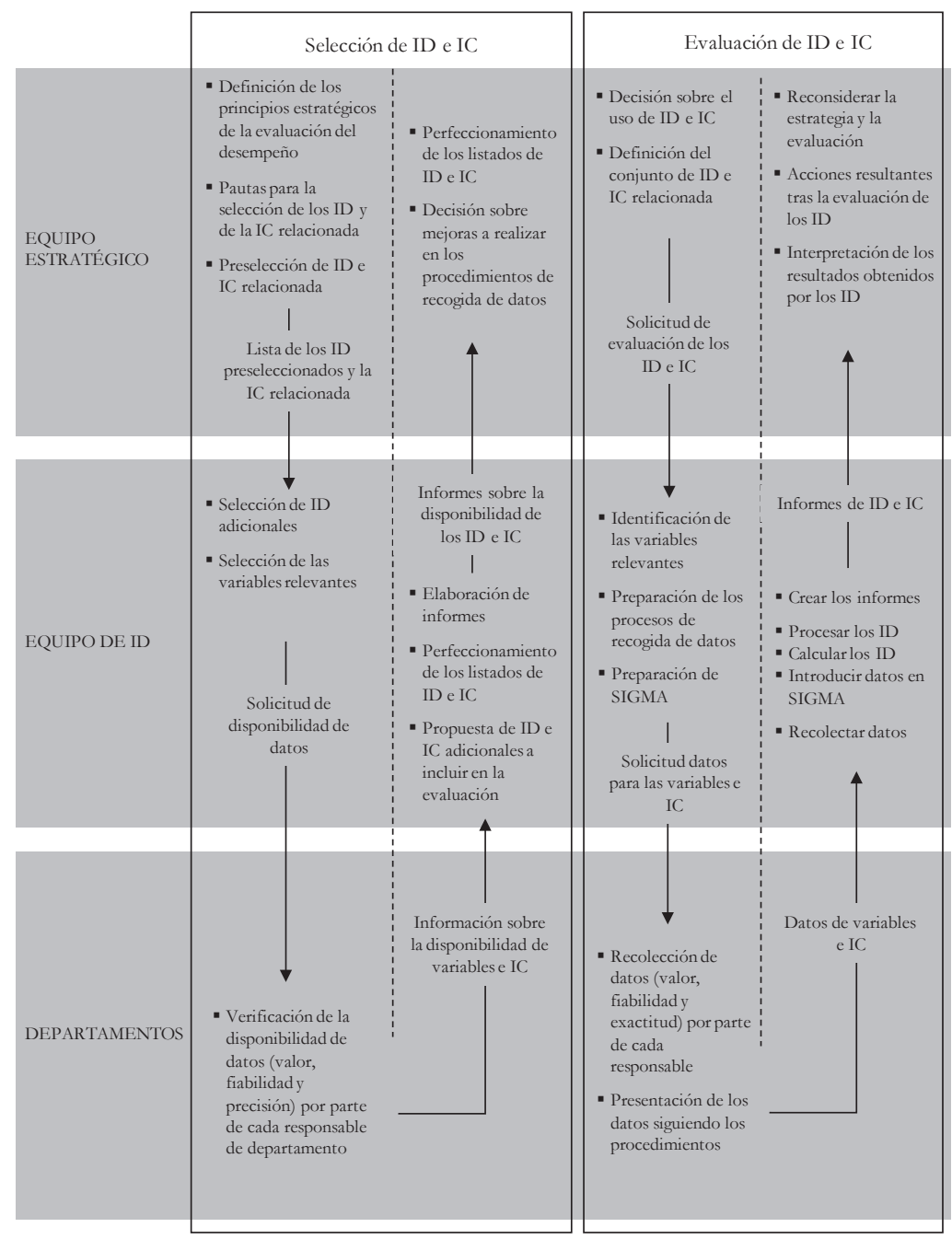

Figura 11. Ejemplo del flujo de datos sobre ID e IC y responsabilidades del equipo 


\subsection{Evaluación de los indicadores de desempeño}

La evaluación de los valores obtenidos del sistema de indicadores de desempeño debe hacerse de acuerdo a los objetivos, estrategias y factores críticos de éxito establecidos de antemano. Un indicador de desempeño no puede evaluarse a menos que se compare con un valor de referencia. Estos valores de referencia pueden ser metas predefinidas, valores pasados del mismo indicador de desempeño o valores externos del indicador (obtenidos de proyectos de benchmarking o referencias externas). El proceso de interpretación de resultados, más que un indicador individual, usualmente requiere la comparación con un valor de referencia o un umbral de referencia, teniendo en cuenta la información de contexto, y analizando un grupo de ID relacionado.

Para aprovechar al máximo los beneficios de la evaluación, debe utilizarse un enfoque sistematizado. Los equipos de estrategias e indicadores deben definir los procedimientos de evaluación, y todos los participantes en el proceso deben recibir algún tipo de retroalimentación de la evaluación de ID para mantener la motivación en el proyecto (desde los recopiladores de datos a la alta dirección).

Los resultados de la evaluación de los ID se pueden obtener utilizando el software SIGMA que se puede descargar en www.sigmalite.com/sigmaes.php, en combinación con otros paquetes de software de hojas de cálculo. Asimismo, los usuarios también pueden utilizar bases de datos individuales. Los informes finales deben ser personalizados para considerar la información provista por los ID. Es importante que se incluya la información de contexto pertinente, así como la de los ID.

La consecuencia inmediata de la evaluación de los resultados proporcionados por los ID debería ser un proceso mejorado de toma de decisiones. En la primera etapa, los indicadores de desempeño deben proporcionar información sobre la adecuación y el éxito de las estrategias definidas como factores críticos de éxito para lograr los objetivos. Como resultado, los resultados de los indicadores de desempeño pueden utilizarse para tomar decisiones inmediatas o para definir estrategias a largo plazo.

Finalmente, se recomienda que, al finalizar la evaluación de los indicadores del desempeño, el equipo de ID y los altos directivos revisen el proceso, con 
el objetivo de mejorar tanto el procedimiento general como las etapas detalladas. En muchos casos, un prestador puede desear personalizar el proceso para que se corresponda más estrechamente con otros procedimientos de auditoría. Cuando se vayan a hacer comparaciones externas para fines de evaluación comparativa, esto también puede requerir una reconsideración del ID incluido en la evaluación.

Cuando se piensa utilizar ID en la evaluación comparativa del desempeño, puede ser necesario comparar los indicadores con los de otras partes del prestador que desempeñan funciones similares, con otras organizaciones, con objetivos preestablecidos para cumplimiento financiero o ambiental u otros estándares de referencia. En muchos casos el ejercicio ID servirá para más de uno de estos propósitos.

Cuando se lleva a cabo un benchmarking entre organizaciones, los prestadores pueden desear salvaguardar la confidencialidad de algunos de sus ID. Bajo estas circunstancias, las comparaciones de ID pueden hacerse anónimamente dentro de subgrupos cuidadosamente seleccionados, o ser gestionadas por una entidad externa independiente que recolecta los datos para los ID en nombre de los diversos prestadores, y luego procesa e informa de los resultados de una forma que asegura que la identificación del prestador no es posible.

\subsection{Mejora continua}

Todos los procesos presentados en este capítulo están destinados a ser parte de un proceso de mejora continua dentro de un prestador. Es obvio que definir objetivos y estrategias para alcanzarlos es una tarea periódica en la gestión de cualquier organización a cualquier nivel.

Los indicadores de desempeño no son una meta en sí mismos, aunque pueden desempeñar un papel clave en liderar con éxito a un prestador de servicios de saneamiento hacia una gestión más eficiente y hacia un enfoque sistemático que le permita afrontar y alcanzar sus objetivos. Sin embargo, los beneficios de la implementación de un sistema de evaluación del desempeño usando indicadores aumentarán con el tiempo a medida que el sistema sea refinado y asimilado en la organización. Muy a menudo, los prestadores renuncian a continuar con un proyecto de ID debido a los resultados iniciales obtenidos, sin lograr alcanzar los resultados deseados. 
Por estas razones, la implementación de un sistema de ID en un prestador de servicios de saneamiento debe considerarse como un proyecto a medio plazo. Si sólo se pueden asignar recursos limitados al proyecto, podría resultar más interesante reducir el tamaño del sistema y ampliar la vida del proyecto, en lugar de buscar un sistema de ID de tamaño completo que sólo se utilizará una vez. La experiencia hace la diferencia, y los indicadores de desempeño son un claro ejemplo. 


\section{REFERENCIAS Y BIBLIOGRAFÍA SELECCIONADA}

Alegre, H. (2002a). Implementation of a performance indicators system. Retrieved June 2002, from the workshop Views and Experience Gained Through Implementing the IWA Performance Indicators Project (Melbourne, Australia)

Alegre, H. (2002b). Performance indicators as a management support tool. in Mays, L.W., Urban Water Supply Handbook, MacGraw-Hill, ISBN 0-07-137160-5.

Alegre, H., Almeida, M. C. (2009). Strategic asset management of water and wastewater infrastructures. IWA Publishing, ISBN 97843391869 .

Alegre, H., Baptista, J.M., Lobato de Faria, A. (1997). A general framework of performance indicators in the scope of water supply. Workshop Performance indicators for transmission and distribution systems, Lisboa, Portugal.

Alegre, H., Hirner, W., Baptista, J.M., Parena, R. (2000). Performance indicators for water supply services. Manual of Best Practice Series, IWA Publishing, London, ISBN 1900222272.

Alegre, H., Hirner, W., Baptista, J.M., Parena, R. (2002a). Highlights of the IWA system of performance indicators for water supply services. Retrieved June 2002, from the workshop Views and Experience Gained Through Implementing the IWA Performance Indicators Project (Melbourne, Australia)

Alegre, H., Hirner, W., Baptista, J.M., Parena, R., Cubillo, F., Cabrera, E., Matos, R. (2002b). The IWA Systems of Performance Indicators for Urban Water Services. Retrieved June 2002, from the workshop Views and Experience Gained Through Implementing the IWA Performance Indicators Project (Melbourne, Australia) 
Ashley, R M., Hopkinson, P. (2002). Sewer systems and Performance indicators - into the $21^{\text {st }}$ Century. Journal of Urban Water 4 (2) pp. 123-136.

Ashley, R. M., Smith, H., Jowitt, P. H., Butler, D., Blackwood, D. J., Davies, J. W., Gilmour, D., Foxon, T. (2002). Making More Sustainable Decisions For Asset Investment In The Water Industry - Sustainable Water Industry Asset Resource Decisions - The SWARD Project. Proceedings of the $9^{\text {th }}$ ICUD - International Conference on Urban Drainage, Portland; Oregon, USA.

Ashley, R. M., Souter, N., Butler, D., Davies, J., Dunkerley, J., Hendry, S.(1999). Assessment of the sustainability of alternatives for the disposal of domestic sanitary waste. Water Science and Technology 39 (5) pp. 251- 258.

Audit Commission (UK) (2000). On-target - the practice of performance indicators. The Audit Commission, 1 Vincent Square, London SW1P 2PN, ISBN 186240228 0, retrieved from the Audit Commission Web site: www.audit-commission.gov.uk

Brown, R. E., Humphrey, B. G. (2005). Asset management for transmission and distribution. Power and Energy Magazine, IEEE, 3(3,39).

Cabrera, E. (2001). Diseño de un sistema para la evaluación de la gestión de abastecimientos urbanos. PhD Thesis, Polytechnic University of Valencia, Spain.

Cabrera Jr., E., Dane, P., Haskins, S. and Theuretzbacher-Fritz, H. (2011). Benchmarking water services. IWA Publishing, London, ISBN: 1843391988

Deb A., Cesario L. (1997). Water Distribution Systems Performance Assessment. IWSA Workshop on Performance Indicators for Transmission and Distribution Systems. Lisbon, Portugal. Project funded by the AWWA Research Foundation.

Duarte, P., Alegre, H., Matos, R. (2003). About the two IWA performance indicators systems for urban water management, in PEDS 2003 - Pumps, Electromechanical Devices and Systems Applied to Urban $W$ ater Management Conference Proceedings, Valencia, Spain. 
Ewan Associates Ltd / Mott MacDonald Ltd (2001). Development of Enhanced Serviceability Indicators For Sewerage Assets. Report ref. 01-G003/02/Ofwat/od/dg/002/63452.

Foxon, T. J., McIlkenny, G., Gilmour, D., Oltean-Dumbrava, C., Souter, N., Ashley, R., Butler, D., Pearson, P., Jowitt, P., Moir, J. (2001). Sustainability Criteria For Decision Support In The UK Water Industry. J.Env. Planning \& Management. 45 (2) pp. 285-301, March.

Hopkinson, P., Whitaker, M. (1999). The relationship between company environmental reports and their environmental performance: a study of the UK Water industry. In: Bennet M., James P. (Eds.). Sustainable Measures. Evaluating and reporting of environmental and social performance. Sheffield: Greenleaf pub.

IAS/IFRS (International Accounting Standards / International Financial Reporting Standards enacted by the International Accounting Standard Board - IASB).

ISO/TC 224 (2003). Service activities relating to drinking water supply systems and wastewater systems - quality criteria of the service and performance indicators, Business Plan, Version: Draft 4, February 2003.

Larsson M., Parena R., Smeets E., Troquet I. (2002). Process Benchmarking in the Water Industry. Manual of Best Practice Series, IWA Publishing, London, ISBN 1843390108.

Lobato de Faria, A., Alegre, H. (1996). Paving the way to excellence in water supply systems: a national framework for levels-ofservice assessment based on consumer satisfaction, The Maarten Schalekamp Award - 1995, AQUA, Vol. 45, n. 1, February 1996, IWSA, London, UK (pp. 1-12).

Matos, M.R., Cardoso, M.A, Duarte, P., Ashley, R., Molinari, A., Shulz, A. (2002a). Performance Indicators for Wastewaters Services Towards a Manual of Best Practice, IWA $3^{\text {rd }}$ World Water Congress, Melbourne, Australia. 
Matos, M.R., Cardoso, M.A, Duarte, P., Ashley, R., Molinari, A., Shulz, A. (2002b). The IWA performance indicator manual for wastewater service provision, in International Conference on Sewer Operation and Maintenance Proceedings (SOM2002), Bradford, UK.

Matos, M.R., Cardoso, M.A, Duarte, P., Ashley, R., Molinari, A., Shulz, A. (2003). Performance Indicators for Wastewaters Services Towards a Manual of Best Practice, Water Science and Technology: Water Supply 3 (1-2) pp. 365-371, IWA Publishing, London.

Merkel, W. (2002). International Report: Performance assessment in the water industry, Water Science and Technology: Water Supply 2 (4) pp. 151-162, IWA Publishing, London.

Neely A.; Adams C.; Kennerley M. (2002). Performance Prism: The Scorecard for Measuring and Managing Stakeholder Relationships. Financial Times Prentice Hall.

OFWAT (2002). June return reporting requirements and definitions manual. Retrieved March 2003, from the Office of Water Services (OFWAT)

Oxford (2002). Oxford Advanced Learner's Dictionary of Current English, $6^{\text {th }}$ edition, 2002 ( $8^{\text {th }}$ impression), Oxford University Press, Oxford, UK. ISBN 019431 585-1.

PBM SIG - Performance-Based Management Special Interest Group (2001). The Performance-Based Management Handbook - Vol. 1. Retrieved February 5, 2003, from Oak Ridge Institute for Science and Education

Reynolds J H. (2000). Maintenance of sewers and water mains within the concept of serviceability to customers. Pipes \& Pipelines International. March-April.

Schulz, A., Schön, J. (2001). A benchmarking system in the watermanagement industry from an operator's point of view Requirements, using the example of treatment plants. $I W A$ $2^{\text {nd }}$ World Water Congress Proceedings, Berlin, Germany. 
Stahre P., Adamsson J. (2002). Performance benchmarking: A Powerful Management Tool For Water And Wastewater Utilities. Presented at AFNOR Atelier Assurer la qualité de la gestion des services d'eau potable et d'assainissement: les bonnes pratiques - un enjeu, une méthodologie, un partage d'expériences, Paris, France.

Turrell, R. (1995). Levels of Service for the Municipal Services Sector. Consultant report for the project Sustainable development strategies for the water supply and wastewater sectors in Portugal, developed for the General Directorate for the Environment (DGA, Portugal), funded by the Cohesion Fund of the European Commission.

UKWIR Ltd (2002). Capital Maintenance Planning: A common framework. Vol. 1 - Overview. 02/RG/05/3 ISBN 1-840572655.

WERF (1997). Benchmarking wastewater operations - collection, treatment, and biosolids management, Final Report Project 96-CTS-5. Water Environment Research Foundation, Alexandria, USA. ISBN 1-57278-121-1.

World Bank (2002). Benchmarking Water \& Sanitation Utilities: Network of Core Indicator Values. Retrieved April 5, 2002, from World Bank 



\section{PARTE II}

\section{ESPECIFICACIONES \\ DEL SISTEMA DE ID \\ DE LA IWA}





\section{DEFINICIONES}

\subsection{Definiciones del balance de aguas residuales}

Un sistema de recogida y tratamiento de aguas residuales puede definirse desde distintas perspectivas. La Figura 12 muestra los principales componentes y enlaces desde la perspectiva de la infraestructura. En la Figura 13 se muestra una representación alternativa, donde el caudal, los sólidos transportados y otras sustancias transportadas por el agua son representadas como un balance de aguas residuales. Es decir, la suma de los componentes de entrada y las pérdidas del sistema es igual a las salidas del sistema. Las definiciones de los términos en estas Figuras se encuentran en el apartado II-1.4.

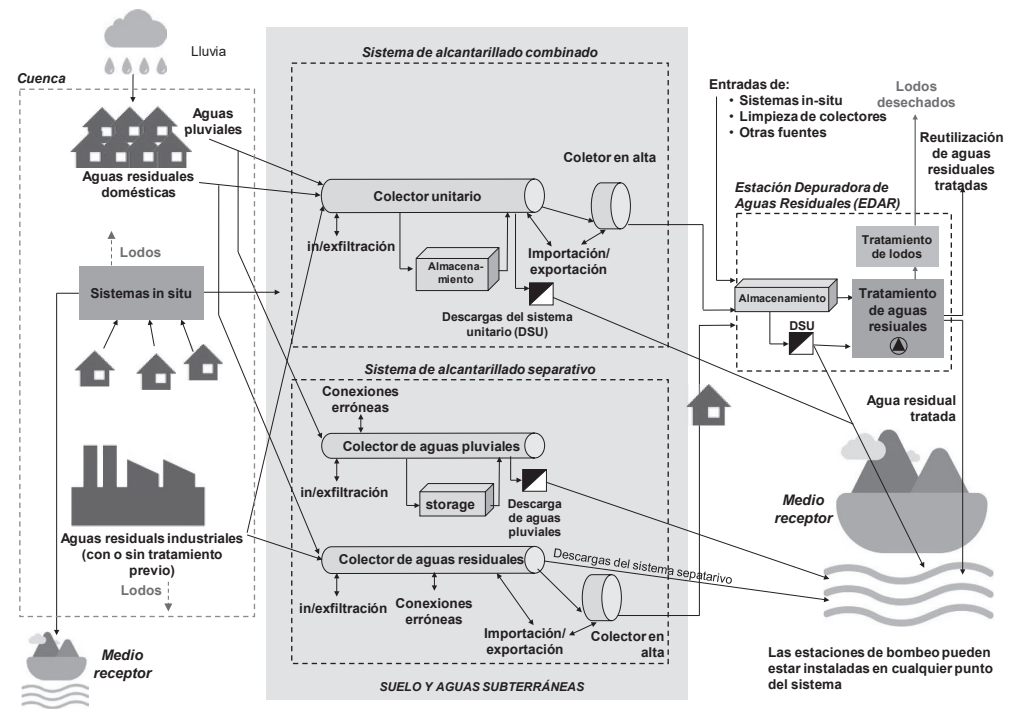

Figura 12. Sistema de saneamiento 


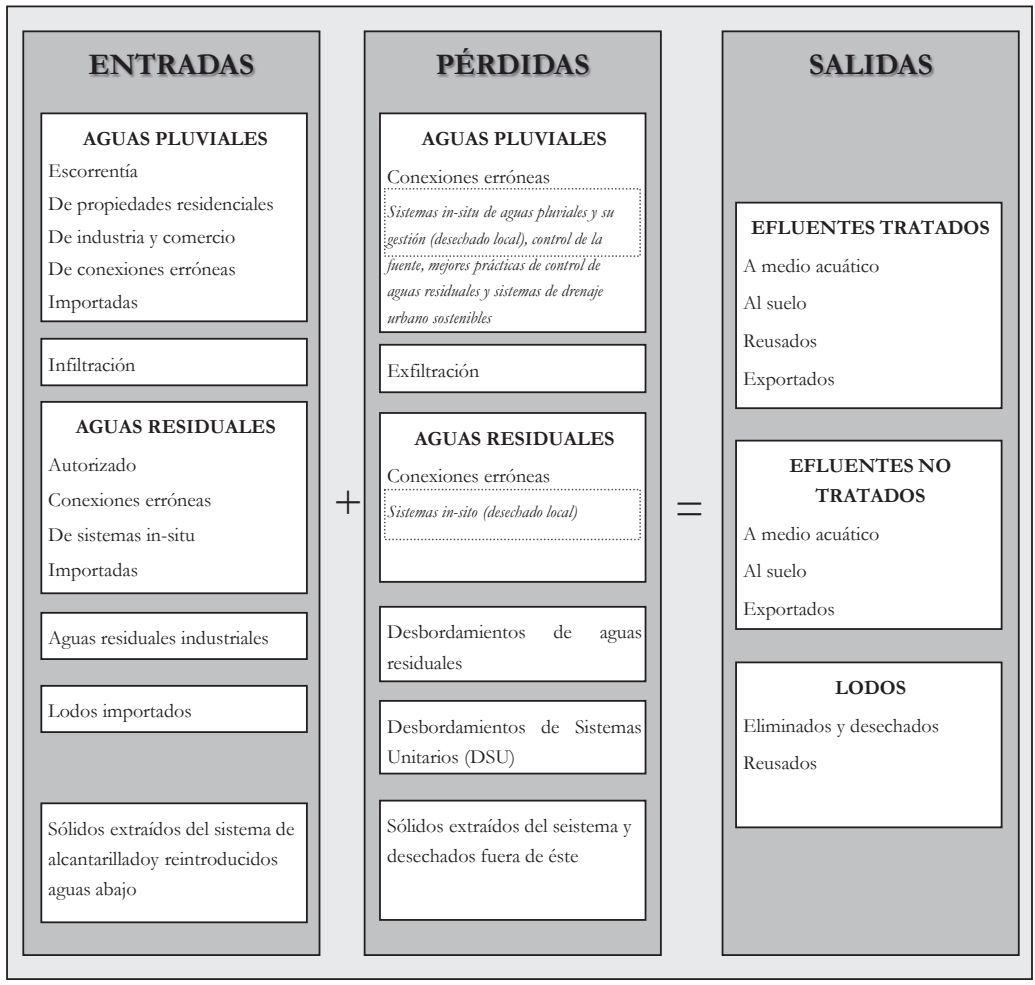

Estos Servicios no están en general bajo la responsabilidad del servicio de saneamiento.

Figura 13. Balance de aguas residuales

(Véase el apartado II-1.4 para las definiciones).

Los servicios proporcionados por el prestador deben estar relacionados con los usuarios de esos servicios, por lo tanto, la interrelación entre los usuarios atendidos por el servicio de saneamiento y los impactos directos derivados de esos servicios se ilustran en la Figura 14. Las definiciones de los términos se encuentran en el apartado II-1.4. La Figura 14 muestra cómo los diversos usuarios utilizan los servicios: residentes, comercios, industrias, servicios, así como otros usuarios como los temporales (visitantes). También muestra qué partes de la población y otros usuarios potenciales pueden administrar sus propios servicios de aguas residuales in-situ o de otra manera. Los no usuarios de los servicios están representados como "no servidos". 


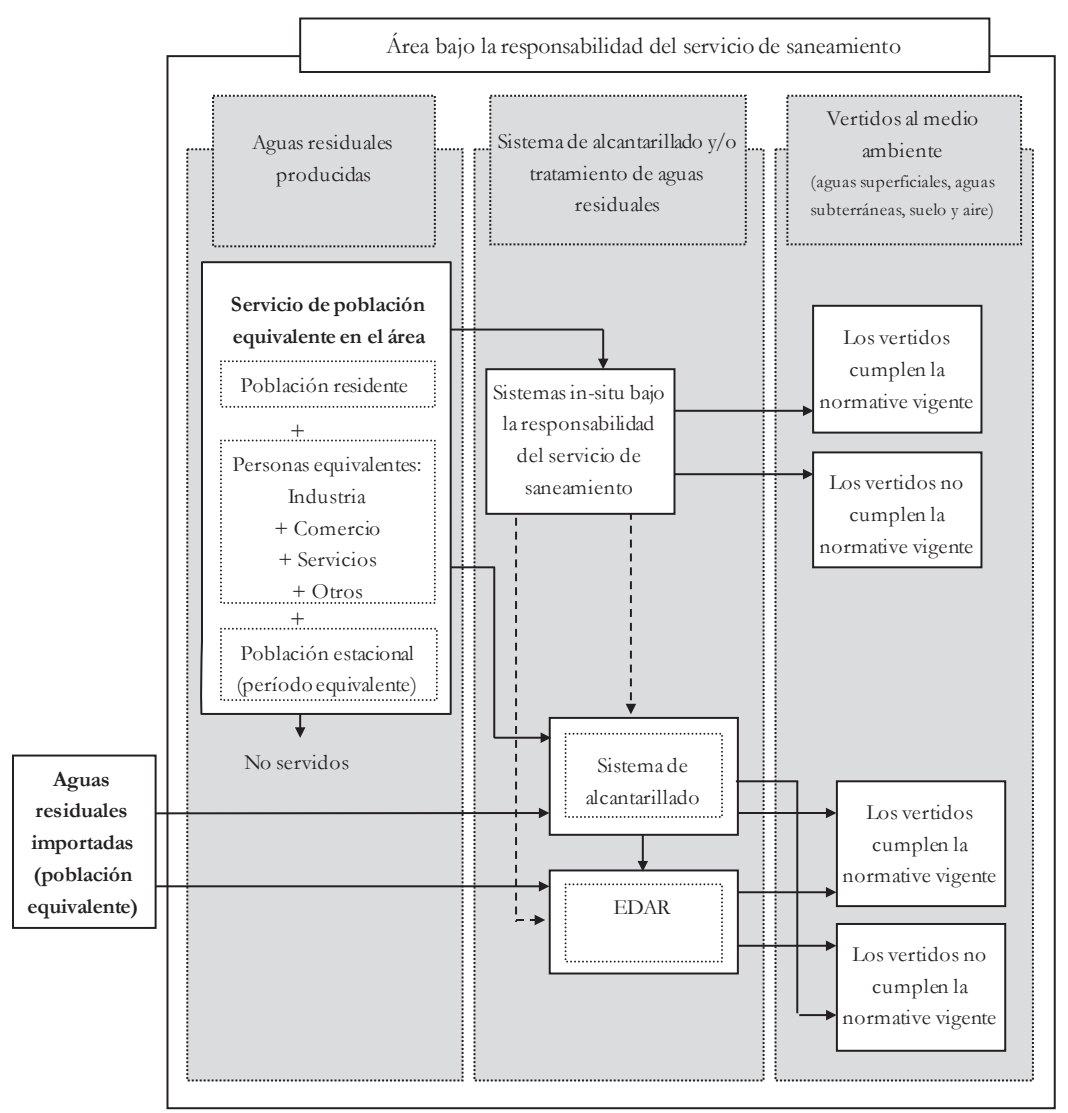

Figura 14. Prestación del servicio en términos de clientes y principales impactos

\subsection{Funciones de organización}

Esta sección define las funciones de organización incluidas en:

- administración general;

- administración de recursos humanos;

- financieros y comerciales;

- servicio al cliente;

- servicios técnicos:

- planificación y construcción;

- operaciones y mantenimiento;

que se utilizan en varias subsecciones del capítulo II- 2 - Indicadores de Desempeño. 
El objetivo de las siguientes tablas y figuras es apoyar la definición de los indicadores de personal y financieros relacionados con las funciones de la organización y se refieren exclusivamente a las actividades principales de la empresa.

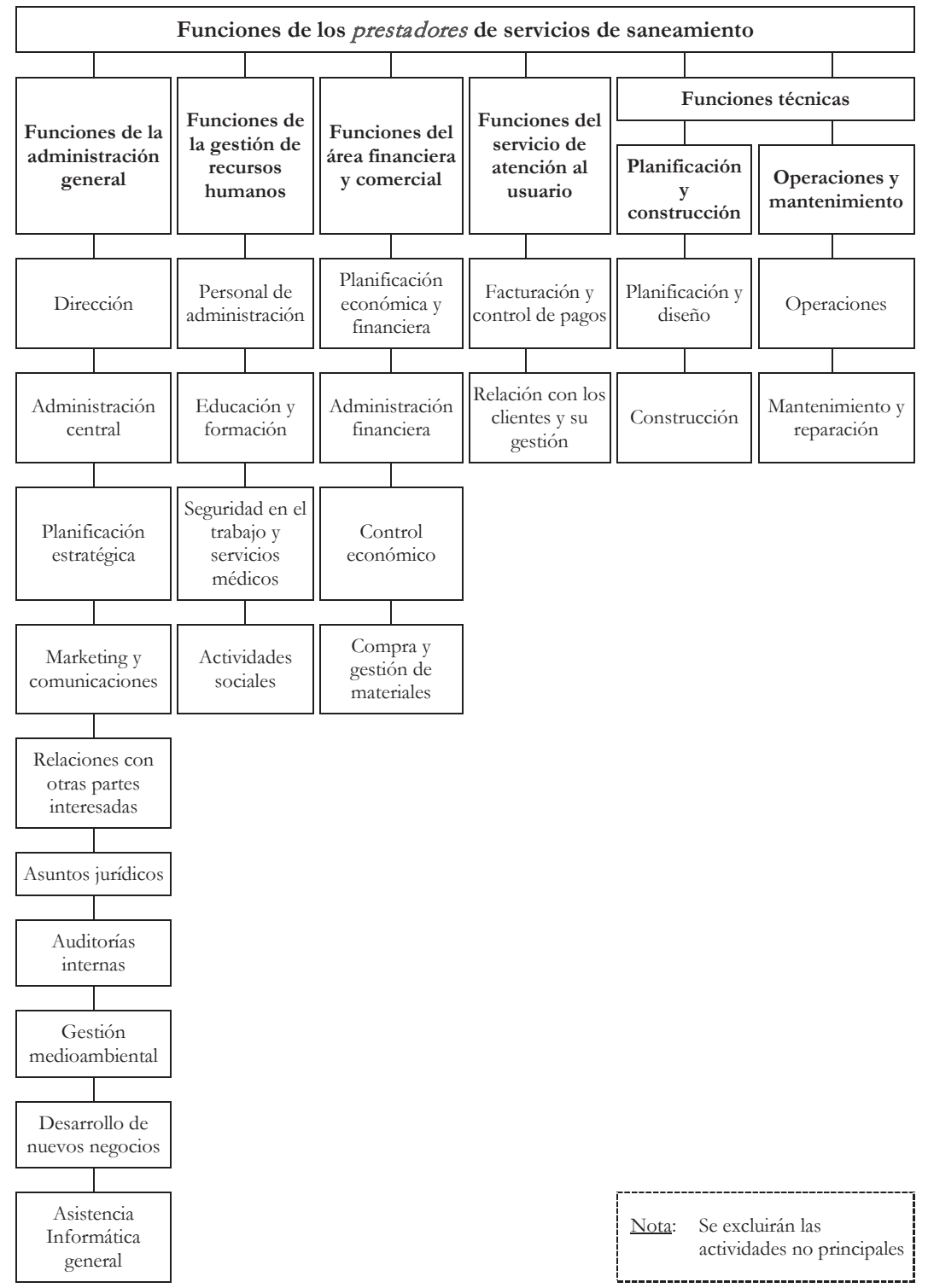

Figura 15. Funciones de los prestadores de agua 
Las tablas a continuación especifican las subfunciones de cada función parcial indicada en la Figura 15.

Tabla 55. Funciones de organización - Administración general

\begin{tabular}{|c|c|c|c|}
\hline $\begin{array}{l}\text { FUNCIONES } \\
\text { PRINCIPALES }\end{array}$ & $\begin{array}{l}\text { FUNCIONES } \\
\text { PARCIALES }\end{array}$ & & SUBFUNCIONES \\
\hline \multirow[t]{8}{*}{$\begin{array}{l}\text { Funciones de la } \\
\text { administración } \\
\text { general }\end{array}$} & Dirección & $\begin{array}{l}\square \\
\square\end{array}$ & $\begin{array}{l}\text { Políticas estratégicas } \\
\text { Representación y Relaciones } \\
\text { externas } \\
\text { Nuevos negocios } 9\end{array}$ \\
\hline & $\begin{array}{l}\text { Administración } \\
\text { central }\end{array}$ & $\begin{array}{l}\square \\
\square\end{array}$ & $\begin{array}{l}\text { Secretaría general } \\
\text { Archivos }\end{array}$ \\
\hline & $\begin{array}{l}\text { Planificación } \\
\text { estratégica }\end{array}$ & $\begin{array}{l}\square \\
\square \\
\square \\
\square\end{array}$ & $\begin{array}{l}\text { Definición de objetivos } \\
\text { Organización } \\
\text { Sistemas de planificación } \\
\text { informáticos } \\
\text { Evaluación del desempeño }\end{array}$ \\
\hline & $\begin{array}{c}\text { Marketing y } \\
\text { comunicaciones }\end{array}$ & $\begin{array}{l}\square \\
\square \\
0 \\
0 \\
\end{array}$ & $\begin{array}{l}\text { Servicio de prensa y noticias } \\
\text { Comunicación e imagen } \\
\text { Encuestas a clientes } \\
\text { Campañas de concientización } \\
\text { pública } \\
\text { marketing } \\
\text { Publicaciones e información } \\
\text { Informes de la empresa }\end{array}$ \\
\hline & $\begin{array}{l}\text { Relaciones con } \\
\text { Otras partes } \\
\text { interesadas }\end{array}$ & $\begin{array}{l}0 \\
\square \\
\square \\
\square\end{array}$ & $\begin{array}{l}\text { Asuntos de accionistas } \\
\text { Asuntos de los órganos normativos } \\
\text { Asuntos regulatorios } \\
\text { Otros asuntos de las partes } \\
\text { interesadas }\end{array}$ \\
\hline & $\begin{array}{l}\text { Asuntos } \\
\text { jurídicos }\end{array}$ & $\begin{array}{l}\square \\
\square \\
\square \\
\square \\
\square\end{array}$ & $\begin{array}{l}\text { Contratos legales } \\
\text { Documentación de las licitaciones } \\
\text { Protección jurídica y seguros } \\
\text { Administración de parcelas } \\
\text { Asuntos contenciosos y litigios }\end{array}$ \\
\hline & $\begin{array}{l}\text { Auditorías } \\
\text { internas }\end{array}$ & ם & $\begin{array}{l}\text { Comprobación de los } \\
\text { procedimientos financieros } \\
\text { Comprobación de los } \\
\text { procedimientos administrativos } \\
\text { Comprobación de los } \\
\text { procedimientos técnicos } \\
\text { Controles de calidad }\end{array}$ \\
\hline & $\begin{array}{c}\text { Gestión } \\
\text { medioambiental }\end{array}$ & $\begin{array}{l}\square \\
\square \\
\square\end{array}$ & $\begin{array}{l}\text { Políticas ambientales } \\
\text { Gestión ambiental y auditorías } \\
\text { Control de la gestión de residuos }\end{array}$ \\
\hline
\end{tabular}




\begin{tabular}{|c|c|c|c|}
\hline $\begin{array}{l}\text { FUNCIONES } \\
\text { PRINCIPALES }\end{array}$ & $\begin{array}{c}\text { FUNCIONES } \\
\text { PARCIALES }\end{array}$ & & SUBFUNCIONES \\
\hline & $\begin{array}{l}\text { Desarrollo de } \\
\text { nuevos } \\
\text { negocios } 9\end{array}$ & 口 & $\begin{array}{l}\text { Expansión de los servicios } \\
\text { prestados } \\
\text { Expansión de la base de clientes } \\
\text { existente }\end{array}$ \\
\hline & $\begin{array}{l}\text { Asistencia } \\
\text { Informática } \\
\text { general }\end{array}$ & 口 & $\begin{array}{l}\text { Gestión y operación de recursos } \\
\text { informáticos centrales y redes } \\
\text { internas } \\
\text { Gestión general de los recursos } \\
\text { informáticos descentralizados } \\
\text { Gestión de software, incluyendo } \\
\text { intranet e internet } \\
\text { Diseño, implementación y gestión } \\
\text { de sistemas de información, } \\
\text { excluyendo aplicaciones específicas } \\
\text { para funciones técnicas } \\
\text { Capacitación y apoyo técnico a los } \\
\text { usuarios del prestador }\end{array}$ \\
\hline
\end{tabular}

9 El coste y la mano de obra para nuevos negocios pueden ser incluidos mientras están en desarrollo. Se excluirán todas las actividades no principales ya existentes. 
Tabla 56. Funciones de organización - Gestión de recursos humanos

\begin{tabular}{|c|c|c|}
\hline $\begin{array}{c}\text { FUNCIONES } \\
\text { PRINCIPALES }\end{array}$ & $\begin{array}{l}\text { FUNCIONES } \\
\text { PARCIALES }\end{array}$ & SUBFUNCIONES \\
\hline \multirow[t]{4}{*}{$\begin{array}{c}\text { Funciones de la } \\
\text { gestión de recursos } \\
\text { humanos }\end{array}$} & $\begin{array}{c}\text { Personal de } \\
\text { administración }\end{array}$ & $\begin{array}{ll} & \text { Planificación y desarrollo del } \\
& \text { personal } \\
\square & \text { Reclutamiento } \\
\square & \text { Gestión de personal } \\
\square & \text { Evaluación del trabajo } \\
\square & \text { Contabilidad y pago de nómina }\end{array}$ \\
\hline & $\begin{array}{l}\text { Educación y } \\
\text { formación }\end{array}$ & $\begin{array}{ll}\text { alanificación de la formación } \\
\text { Implementación y control de la } \\
\text { formación } \\
\end{array}$ \\
\hline & $\begin{array}{l}\text { Seguridad en el } \\
\text { trabajo y servicios } \\
\text { médicos }\end{array}$ & $\begin{array}{ll} & \text { Chequeos médicos } \\
\square & \text { Evaluación de la incapacidad } \\
\text { para el trabajo } \\
\text { Políticas de seguridad en el } \\
\text { trabajo, implementación y } \\
\text { control } \\
\end{array}$ \\
\hline & Actividades sociales & $\begin{array}{ll}\text { 口 } & \text { Integración de personal nuevo } \\
\square & \text { Asistencia social } \\
\square & \text { Actividades socioculturales }\end{array}$ \\
\hline
\end{tabular}


Tabla 57. Funciones de organización - Financiera y comercial

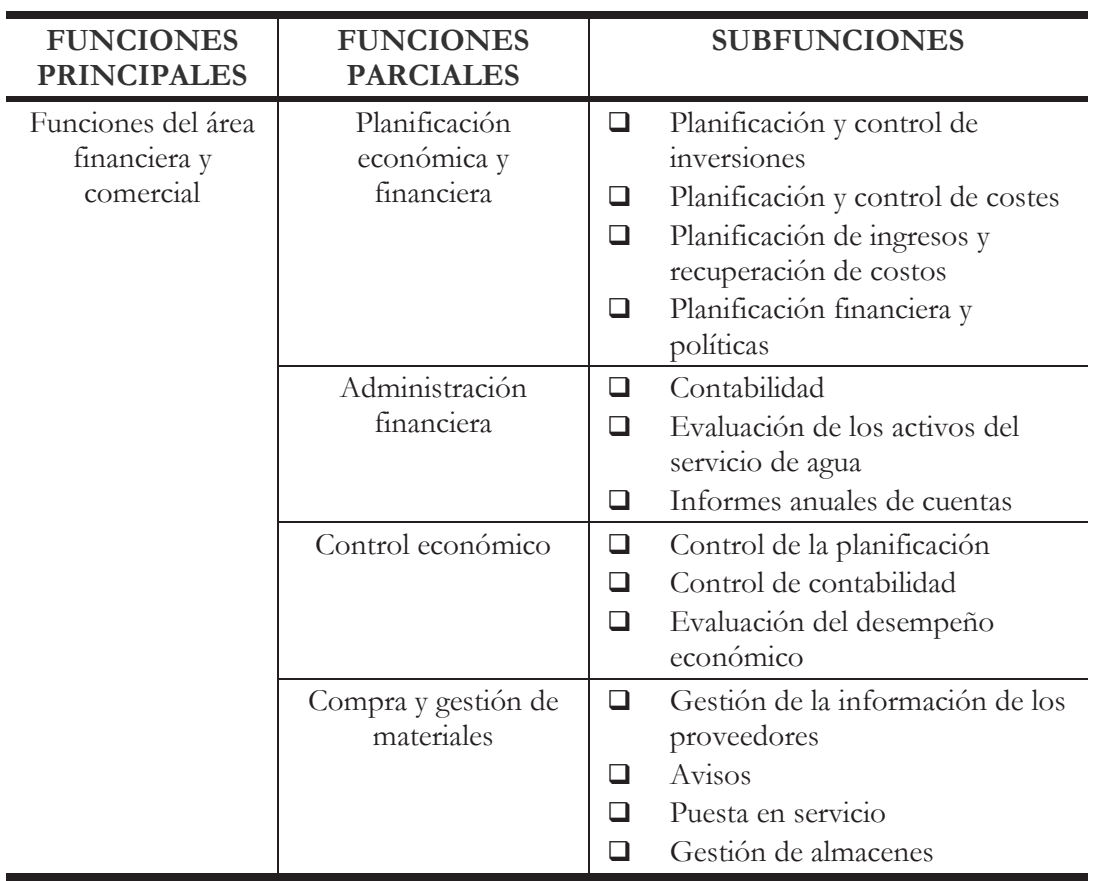

Tabla 58. Funciones de organización - Servicio de atención al usuario

\begin{tabular}{l|c|cl}
\hline \multicolumn{1}{c|}{ FUNCIONES } & FUNCIONES & & \multicolumn{2}{c}{ SUBFUNCIONES } \\
PRINCIPALES & PARCIALES & & \\
\hline Funciones del & Lectura, control y & $\square$ & Facturación \\
servicio de & facturación & $\square$ & Control de pagos \\
atención al usuario & Relación con los & $\square$ & Gestión de pedidos entrantes \\
& clientes y su gestión & $\square$ & Consultas de los clientes \\
& & $\square$ & Gestión de quejas \\
& & $\square$ & Difusión de información \\
\hline
\end{tabular}


Tabla 59. Funciones de organización - Planificación y construcción 10

\begin{tabular}{|c|c|c|c|}
\hline $\begin{array}{l}\text { FUNCIONES } \\
\text { PRINCIPALES }\end{array}$ & $\begin{array}{l}\text { FUNCIONES } \\
\text { PARCIALES }\end{array}$ & & SUBFUNCIONES \\
\hline \multirow[t]{2}{*}{$\begin{array}{l}\text { Funciones de } \\
\text { planificación y } \\
\text { construcción }\end{array}$} & Planificación y diseño & $\begin{array}{l} \\
\square \\
\square \\
\square\end{array}$ & $\begin{array}{l}\text { Gestión de vertidos y protección } \\
\text { de los medios receptores } \\
\text { Plan maestro del servicio de } \\
\text { saneamiento para la recolección, } \\
\text { transporte y tratamiento de } \\
\text { aguas residuales, con los } \\
\text { objetivos a medio y largo plazo } \\
\text { de demanda } \\
\text { Programas de planificación de } \\
\text { gestión de activos y } \\
\text { rehabilitación } \\
\text { Planificación, diseño y cálculo de } \\
\text { plantas, redes y equipos } \\
\text { Especificación de plantas, } \\
\text { construcción y selección de } \\
\text { materiales } \\
\text { Planificación y diseño de } \\
\text { tecnologías, p.ej. tecnologías de } \\
\text { la información } \\
\text { Contratación de servicios } \\
\text { externalizados de diseño en } \\
\text { relación con los puntos } \\
\text { anteriores } \\
\text { Estadísticas } \\
\text { Investigación y Desarrollo } \\
\text { Evaluación de la seguridad y el } \\
\text { riesgo }\end{array}$ \\
\hline & Construcción & $\begin{array}{l}\square \\
\square \\
\square \\
\square \\
\square\end{array}$ & $\begin{array}{l}\text { Adquisición de obras mediante } \\
\text { contratos externos } \\
\text { Dirección de obras realizadas } \\
\text { por mano de obra directa } \\
\text { Supervisión, control de calidad y } \\
\text { aceptación de la obra } \\
\text { Puesta en marcha de nuevas } \\
\text { instalaciones, redes y equipos } \\
\text { Pagos y control financiero }\end{array}$ \\
\hline
\end{tabular}

10 Planificación y construcción es el conjunto de tareas relacionadas con la planificación y provisión de nuevos activos y refuerzo, reemplazo y sustitución de los activos existentes. 
Tabla 60. Funciones de organización - Operaciones y mantenimiento

\begin{tabular}{|c|c|c|c|}
\hline $\begin{array}{l}\text { FUNCIONES } \\
\text { PRINCIPALES }\end{array}$ & $\begin{array}{c}\text { FUNCIONES } \\
\text { PARCIALES }\end{array}$ & & SUBFUNCIONES \\
\hline \multirow[t]{2}{*}{$\begin{array}{l}\text { Funciones de } \\
\text { operaciones y } \\
\text { mantenimiento }\end{array}$} & Operaciones & 口 & $\begin{array}{l}\text { Supervisión de las zonas de } \\
\text { protección } \\
\text { Supervisión y control general del } \\
\text { sistema } \\
\text { Trabajos en espera y gestión de } \\
\text { riesgos } \\
\text { Documentación, recopilación de } \\
\text { datos, mantenimiento de registros y } \\
\text { procesado de datos (incluida la } \\
\text { gestión y el funcionamiento de los } \\
\text { sistemas de información) } \\
\text { Monitorización, muestreo y análisis } \\
\text { de la calidad de las aguas residuales } \\
\text { Descargas del Sistema Unitario } \\
\text { (DSU) y gestión de los efluentes } \\
\text { Aceptación operacional de nuevas } \\
\text { instalaciones, redes y equipos } \\
\text { Volver a poner en marcha los } \\
\text { sistemas después de la parada }\end{array}$ \\
\hline & $\begin{array}{l}\text { Mantenimiento } \\
\text { y reparación }\end{array}$ & $\begin{array}{l}\square \\
\square \\
\square \\
\square \\
\square\end{array}$ & $\begin{array}{l}\text { Inspección de sistemas } \\
\text { Controles regulares de } \\
\text { mantenimiento o actividades de } \\
\text { servicio } \\
\text { reparación de fallos y otros defectos } \\
\text { Limpieza } \\
\text { remodelación } \\
\text { Reemplazo y mantenimiento de } \\
\text { caudalímetros } \\
\text { Mantenimiento y reparación de los } \\
\text { equipos de extinción de incendios } \\
\text { (siempre que sea responsabilidad del } \\
\text { prestador) }\end{array}$ \\
\hline
\end{tabular}

Las principales funciones técnicas - planificación, construcción, operaciones y mantenimiento- también pueden dividirse desde la perspectiva de la asignación típica de recursos humanos:

- Tratamiento de aguas residuales

- Sistema de alcantarillado

- Monitorización de la calidad de las aguas residuales

- Recursos hídricos y gestión de cuencas;

- Servicios de apoyo (almacén central de stock, talleres centrales y flota central de vehículos). 


\subsection{Definiciones financieras}

\section{(Véase también la Parte I, sección 4.4, indicadores económicos y financieros)}

Esta sección presenta las definiciones financieras de la estructura de Ganancias y Pérdidas anuales, las definiciones de inversión, los cambios anuales en la situación financiera y el Balance General al final del año.

Las definiciones de ganancias y pérdidas anuales presentadas en la Tabla 61 y Tabla 62 se refieren a los principios de contabilidad financiera. En el caso de los prestadores con más de un servicio, las ganancias y pérdidas relacionadas con el servicio de saneamiento (incluidas las actividades técnicas y no técnicas) están específicamente identificadas en la contabilidad.

Anteriormente, se utilizaban principios de contabilidad financiera ampliamente aceptados, a pesar de haber algunas variaciones entre países. Más recientemente, ha aumentado la comparación de metodologías a nivel internacional, como consecuencia de la creciente internacionalización del comercio y accionistas. Existe una necesidad real de que las Normas Internacionales de Información Financiera (NIIF), diseñadas como un lenguaje global común para negocios, hagan que las cuentas de las empresas sean comprensibles y comparables a través de las fronteras internacionales. Los estados financieros deben reflejar una visión verdadera y justa de la posición financiera de una organización y son utilizados por diversos profesionales y reguladores. Estas declaraciones les permiten verificar la posición financiera de una empresa durante un período específico.

En la actualidad, la mayoría de los países del mundo requieren o permiten las informar de acuerdo a las NIIF. La Junta de Normas Internacionales de Contabilidad (NIC) ha reemplazado progresivamente muchos estándares nacionales de contabilidad y ha establecido las reglas que los contables deben seguir para mantener cuentas comparables, comprensibles, confiables y relevantes para usuarios internos o externos.

En todo el mundo existen prestadores que operan servicios públicos bajo de contratos de concesión. Para armonizar adecuadamente diversos aspectos contables de esta situación particular, el Comité de Interpretación de la Información Financiera Internacional emitió, en noviembre de 2006 y bajo el paraguas de la Junta de Normas Internacionales de Contabilidad, la interpretación oficial "CINIIF 12 - Arreglos de concesión de servicios" que entró en vigencia el 1 de enero de 2008. 
Las experiencias pasadas y recientes demuestran que los sistemas de ID de la IWA se han adoptado en todo el mundo. Dada la tendencia actual, se espera que la adopción aumente en el futuro cercano. Puesto que la adopción de sistemas contables que cumplen con las NIC influye de manera importante en las principales variables financieras e ID, la comparación de los ID de diferentes abastecimientos puede volverse menos significativa si no todos cumplen con estas normas ya que es preciso que todos los indicadores estén basados en los mismos conceptos y definiciones si se quieren obtener comparaciones válidas.

Por lo tanto, esta sección del Manual se centrará en cómo la adopción de las NIC puede modificar (tanto en concepto como en valor) algunas variables asignadas a la estructura tanto del Ganancias y Pérdidas como del Balance General al final del año fiscal.

Por lo tanto, los arreglos se identificarán para "ajustar" adecuadamente las variables económicas y financieras que se considerarán a fin de preservar la validez y los beneficios del Sistema ID de la IWA y se proporcionarán definiciones detalladas coherentes. 
Tabla 61. Estructura de ganancias y pérdidas anuales

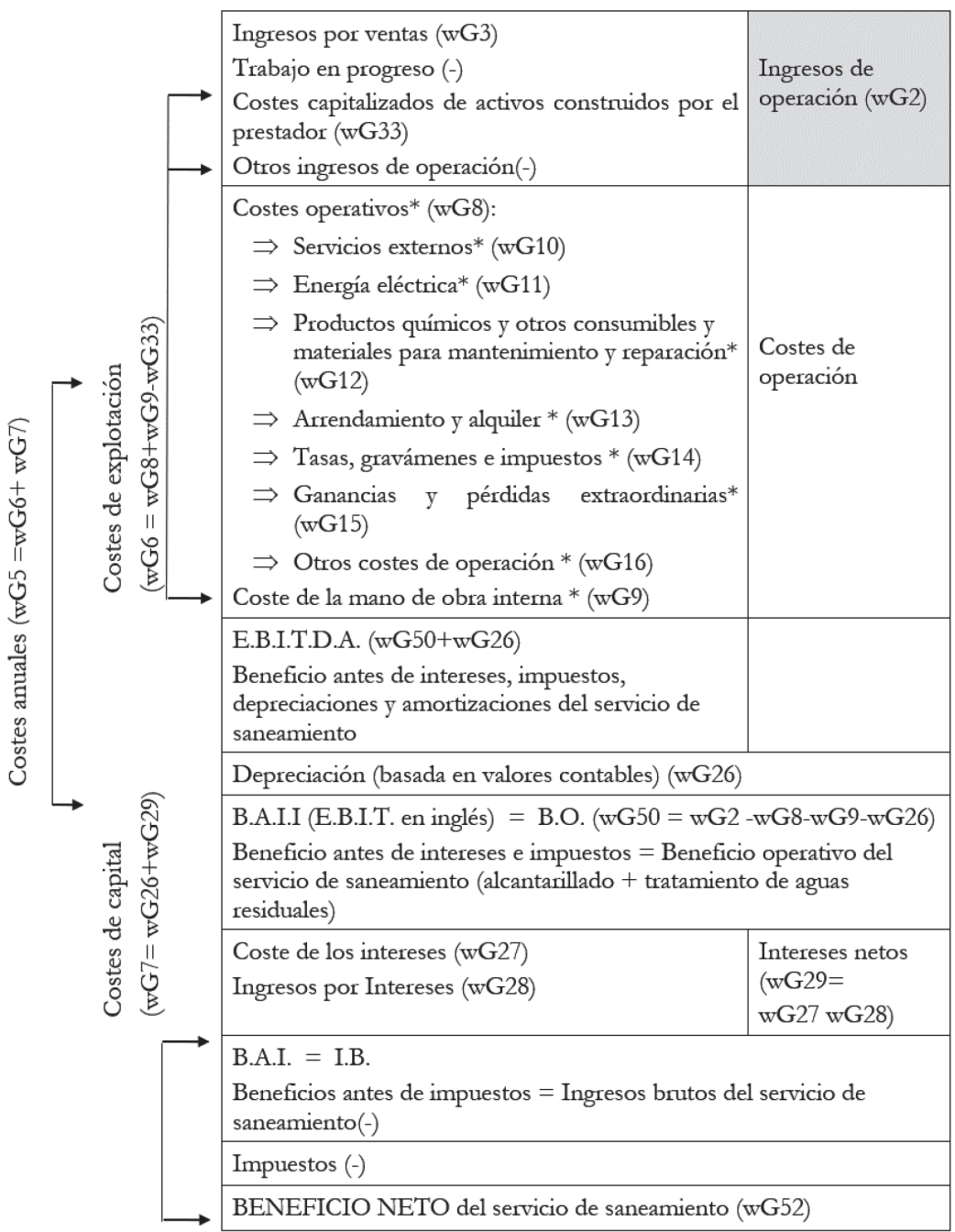

* Valor bruto; la variable entre paréntesis es el valor neto correspondiente, es decir, sin incluir la contribución para el costo capitalizado de los activos construidos por el prestación.

Algunas de estas variables son relevantes por sí mismas para respaldar la gestión, aunque no se definan como indicadores de desempeño en este Manual de buenas prácticas de ID de la IWA. 
Las definiciones detalladas relacionadas con la Tabla 61 se detallan a continuación:

Tabla 62. Definiciones detalladas relacionadas con la Tabla 61

\begin{tabular}{|c|c|}
\hline $\begin{array}{l}\text { TÉRMINO EN } \\
\text { Tabla } 61\end{array}$ & INCLUYE \\
\hline ENERGÍA ELÉCTRICA & $\begin{array}{l}\text { Coste total de la energía eléctrica relacionada con el Servicio } \\
\text { de saneamiento, incluyendo la energía para el bombeo y } \\
\text { tratamiento de aguas residuales - electricidad y combustibles } \\
\text { para la maquinaria. }\end{array}$ \\
\hline \multirow[t]{4}{*}{$\begin{array}{l}\text { SERVICIOS } \\
\text { EXTERNOS }\end{array}$} & $\begin{array}{l}\text { EXTERNALIZACIÓN: subcontratación de servicios técnicos o } \\
\text { administrativos, tales como consultores, contratistas, } \\
\text { tareas operacionales del prestador. }\end{array}$ \\
\hline & $\begin{array}{l}\text { LICENCIAS DE SOFTWARE Y SERVICIOS DE ASISTENCIA } \\
\text { INFORMÁTICA: pagos de las licencias de software y } \\
\text { soporte técnico por parte de compañías de software. }\end{array}$ \\
\hline & $\begin{array}{l}\text { EMPRESAS ASOCIADAS: costes de las empresas asociadas que } \\
\text { no están incluidas en otras partidas. }\end{array}$ \\
\hline & $\begin{array}{l}\text { SERVICIOS DE TERCEROS: costes de operación de proporcionar } \\
\text { servicios de agua a terceros (que no sean la función } \\
\text { encomendada de tratamiento de aguas residuales) que no } \\
\text { están incluidos en otras partidas. }\end{array}$ \\
\hline $\begin{array}{l}\text { ARRENDAMIENTO Y } \\
\text { ALQUILER }\end{array}$ & $\begin{array}{l}\text { Pagos por arrendamiento o alquiler de locales, vehículos, } \\
\text { instalaciones y equipos móviles y fijos. }\end{array}$ \\
\hline COMPRAS & $\begin{array}{l}\text { MATERIALES, PRODUCTOS QUímICOS Y OTROS CONSUMIBLES: } \\
\text { todos los materiales, productos químicos y otros } \\
\text { consumibles, aparte de la energía eléctrica, que no están } \\
\text { en incluidos en la partida de SERVICIOS CONTRATADOS y } \\
\text { que son necesarios para la operación del sistema de } \\
\text { alcantarillado y tratamiento de aguas residuales o para } \\
\text { funciones no técnicas (p.ej. material de oficina). }\end{array}$ \\
\hline
\end{tabular}


Tabla 62. Definiciones detalladas relacionadas con la Tabla 61 (cont.)

\begin{tabular}{|c|c|}
\hline $\begin{array}{l}\text { TÉRMINO EN } \\
\text { Tabla } 61\end{array}$ & INCLUYE \\
\hline $\begin{array}{l}\text { TASAS, } \\
\text { GRAVÁMENES E } \\
\text { IMPUESTOS }\end{array}$ & $\begin{array}{l}\text { Cualquier tasa y licencia relacionada con la operación del } \\
\text { sistema pagada a una autoridad gubernamental o municipal } \\
\text { distinta de los impuestos directos. }\end{array}$ \\
\hline $\begin{array}{l}\text { GANANCIAS Y } \\
\text { PÉRDIDAS } \\
\text { EXTRAORDINARIAS }\end{array}$ & $\begin{array}{l}\text { Cualquier ingreso o gasto extraordinario por donaciones, } \\
\text { subsidios de inversión, compensaciones o ajustes } \\
\text { relacionados con ventas / cancelación de activos fijos. }\end{array}$ \\
\hline \multirow[t]{6}{*}{$\begin{array}{l}\text { OTROS COSTES DE } \\
\text { OPERACIÓN }\end{array}$} & $\begin{array}{l}\text { OTROS COSTES DIRECTOS: cualquier otro coste operativo } \\
\text { (excluyendo intereses e impuestos, sobre una base } \\
\text { agregada). }\end{array}$ \\
\hline & $\begin{array}{l}\text { GASTOS GENERALES Y DE APOYO: el coste directo agregado de } \\
\text { las ACTIVIDADES GENERALES Y DE APOYO } \\
\text { (excluyendo los costes de mano de obra) (véase la } \\
\text { sección II- } 1.2 \text { para definiciones). }\end{array}$ \\
\hline & $\begin{array}{l}\text { SERVICIO AL CLIENTE: los costes directamente asociados con } \\
\text { servicios al cliente que no están incluidos en partidas } \\
\text { anteriores, relacionados con la contabilidad del } \\
\text { cliente, lectura de medidores de caudal de aguas } \\
\text { residuales, cobro de deudas, costes de desconexiones } \\
\text { de la red, consultas de clientes y gestión de quejas. }\end{array}$ \\
\hline & $\begin{array}{l}\text { SERVICIOS CIENTífICOS: costes asociados directamente con } \\
\text { los servicios científicos y de laboratorio y con la } \\
\text { monitorización de la calidad que no están incluidos en } \\
\text { partidas anteriores. }\end{array}$ \\
\hline & $\begin{array}{l}\text { OTRAS ACTIVIDADES COMERCIALES: costes directamente } \\
\text { asociados con otras actividades comerciales que no } \\
\text { están incluidas en partidas anteriores, excepto por la } \\
\text { depreciación de costos. }\end{array}$ \\
\hline & $\begin{array}{l}\text { DEUDAS INCIERTAS: cargo / atribución a la cuenta de } \\
\text { Ganancias y Pérdidas por deudas incobrables y } \\
\text { dudosas. }\end{array}$ \\
\hline $\begin{array}{l}\text { COSTE DE LA MANO } \\
\text { DE OBRA INTERNA }\end{array}$ & $\begin{array}{l}\text { COSTES DE EMPLEO: suma de los costos totales de mano de } \\
\text { obra del personal permanente y temporal empleados } \\
\text { directamente por el prestador, incluidos los costes y } \\
\text { beneficios sociales relacionados con el empleo } \\
\text { pagados por el empleador. }\end{array}$ \\
\hline
\end{tabular}


Tabla 62. Definiciones detalladas relacionadas con la Tabla 61 (cont.)

\begin{tabular}{|c|c|}
\hline $\begin{array}{l}\text { TÉRMINO EN } \\
\text { Tabla } 61\end{array}$ & INCLUYE \\
\hline $\begin{array}{l}\text { COSTES } \\
\text { CAPITALIZADOS DE } \\
\text { ACTIVOS } \\
\text { CONSTRUIDOS POR } \\
\text { EL PRESTADOR } \\
\text { (asignación negativa) }\end{array}$ & $\begin{array}{l}\text { La suma de los montos en cada una de las categorías de costes } \\
\text { anteriores que se han contraído en la construcción de activos } \\
\text { nuevos o rehabilitados (incluyendo, en el caso de las } \\
\text { concesiones, los activos construidos, mejorados o } \\
\text { rehabilitados de acuerdo con el acuerdo de concesión). } \\
\text { Para propósitos de cálculo de ID de costes de explotación, los costes } \\
\text { capitalizados de los activos construidos por el prestador se deben repartir } \\
\text { negativamente con cada uno de los elementos de coste corriente anteriores } \\
\text { teniendo en cuenta la estricta observancia de la signiente relación: } \\
\text { Costes de explotación de la Estructura de Ganancias y } \\
\text { Pérdidas anual } \\
= \\
\text { Costes de operación y mantenimiento + Costes de la mano de } \\
\text { obra interna - Costes capitalizados de activos construidos por } \\
\text { el prestador } \\
= \\
\text { Valor neto de: (Energía eléctrica + Servicios externos }+ \\
\text { Mercancías compradas + Arrendamiento y alquiler + Gastos } \\
\text { de operación + Costes de mano de obra interna) }\end{array}$ \\
\hline $\begin{array}{l}\text { DEPRECIACIÓN } \\
\text { (BASADOS EN } \\
\text { VALORES } \\
\text { CONTABLES) }\end{array}$ & $\begin{array}{l}\text { DEPRECIACIÓN DE COSTES: cargo por depreciación del coste } \\
\text { sobre los activos fijos del servicio de saneamiento. } \\
\text { AMORTIZACIÓN DE ACTIVOS INTANGIBLES: Cualquier } \\
\text { amortización u otra reducción en el valor de los } \\
\text { activos intangibles en Balance General. } \\
\text { SERVICIOS DE TERCEROS: la depreciación de los costes de los } \\
\text { activos relacionados con servicios de terceros, junto } \\
\text { con cualquier cargo de renovación de infraestructura } \\
\text { para los activos de la infraestructura relacionados con } \\
\text { servicios de terceros. }\end{array}$ \\
\hline INTERESES NETOS & $\begin{array}{l}\text { INTERESES NETOS: Coste neto del capital en préstamos a } \\
\text { corto, medio y largo plazo (COSTE DE LOS INTERESES } \\
\text { - INGRESOS POR INTERESES). }\end{array}$ \\
\hline $\begin{array}{l}\text { IMPUESTOS } \\
\text { DIRECTOS }\end{array}$ & $\begin{array}{l}\text { IMPUESTOS: Todos los impuestos y gravámenes sobre los } \\
\text { ingresos brutos relacionados con las actividades del } \\
\text { servicio de saneamiento. } \\
\text { Los costes de los impuestos y gravámenes fiscales estrictamente } \\
\text { relacionados con las operaciones en las plantas de tratamiento (como las } \\
\text { tarifas de alcantarillado en los residuos de tratamiento, las tarifas por } \\
\text { extracción de agua, las tarifas sobre tuberías y concesiones, los } \\
\text { gravámenes medioambientales, los cargos de la autoridad de control del } \\
\text { agua, etc.) deben considerarse costos de explotación e incluirse en TASAS, } \\
\text { GRAVÁMENES E IMPUESTOS (COSTES DE EXPLOTACIÓN). }\end{array}$ \\
\hline
\end{tabular}


Tabla 63. Definiciones de inversiones

\begin{tabular}{l|l}
\hline TÉRMINO & \multicolumn{1}{|c}{ DEFINICIÓN } \\
\hline $\begin{array}{l}\text { INVERSIONES SUJETAS A } \\
\text { DEPRECIACIÓN }\end{array}$ & $\begin{array}{l}\text { Las inversiones que deben estar sujetas a depreciación } \\
\text { como se enumera en detalle por los principios } \\
\text { contables generalmente aceptados. }\end{array}$ \\
\hline $\begin{array}{l}\text { VALOR HISTÓRICO } \\
\text { DEPRECIADO DE ACTIVOS } \\
\text { DEL SERVICIO DE AGUA }\end{array}$ & $\begin{array}{l}\text { Suma, sobre todos los activos del servicio de } \\
\text { saneamiento, del valor de depreciación aplicado desde } \\
\text { la fecha de compra. }\end{array}$ \\
\hline $\begin{array}{l}\text { VALOR HISTÓRICO DE } \\
\text { ACTIVOS DEL SERVICIO DE } \\
\text { AGUA }\end{array}$ & $\begin{array}{l}\text { Se refiere al valor contable bruto de los gastos totales } \\
\text { (que aparecen como valor neto en la Tabla 65) tanto } \\
\text { en infraestructuras como en activos del servicios de } \\
\text { saneamiento que no son de infraestructura. }\end{array}$ \\
\hline
\end{tabular}

Tabla 64. Cargos anuales en la situación financiera

\begin{tabular}{|c|c|}
\hline APLICACIÓN DE FONDOS & FUENTES DE FONDOS \\
\hline 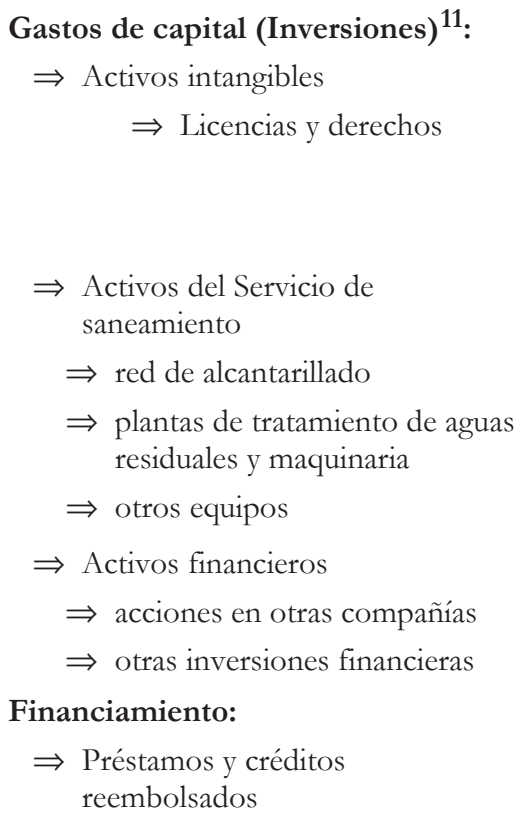 & $\begin{array}{l}\text { Fuentes internas provenientes del } \\
\text { FLUJO DE CAJA (CASH FLOW): } \\
\qquad \begin{aligned} \Rightarrow & \text { Ganancias retenidas (tras } \\
& \text { dividendos y otros pagos fura } \\
& \text { del ingreso neto) } \\
\Rightarrow & \text { depreciación }\end{aligned} \\
\text { Fuentes externas: } \\
\Rightarrow \text { recibos de capital } \\
\Rightarrow \text { préstamos y créditos otorgados } \\
\Rightarrow \text { venta de activos fijos } \\
\Rightarrow \text { subsidios de las inversiones }\end{array}$ \\
\hline & \\
\hline Aumento del capital de trabajo ${ }^{12}$ & Disminución del capital de trabajo ${ }^{12}$ \\
\hline
\end{tabular}

11 El gasto de capital anual (inversión en activos tangibles, intangibles y financieros) es el mismo que "inversión anual total".

$12 \mathrm{El}$ aumento o la disminución es el equilibrio entre la aplicación y las fuentes. La transición hacia las NIIF crea cambios significativos en la información financiera de las empresas, incluidos los cambios en la medición, la divulgación y la presentación 
Tabla 65. Estructura del Balance General al final del año

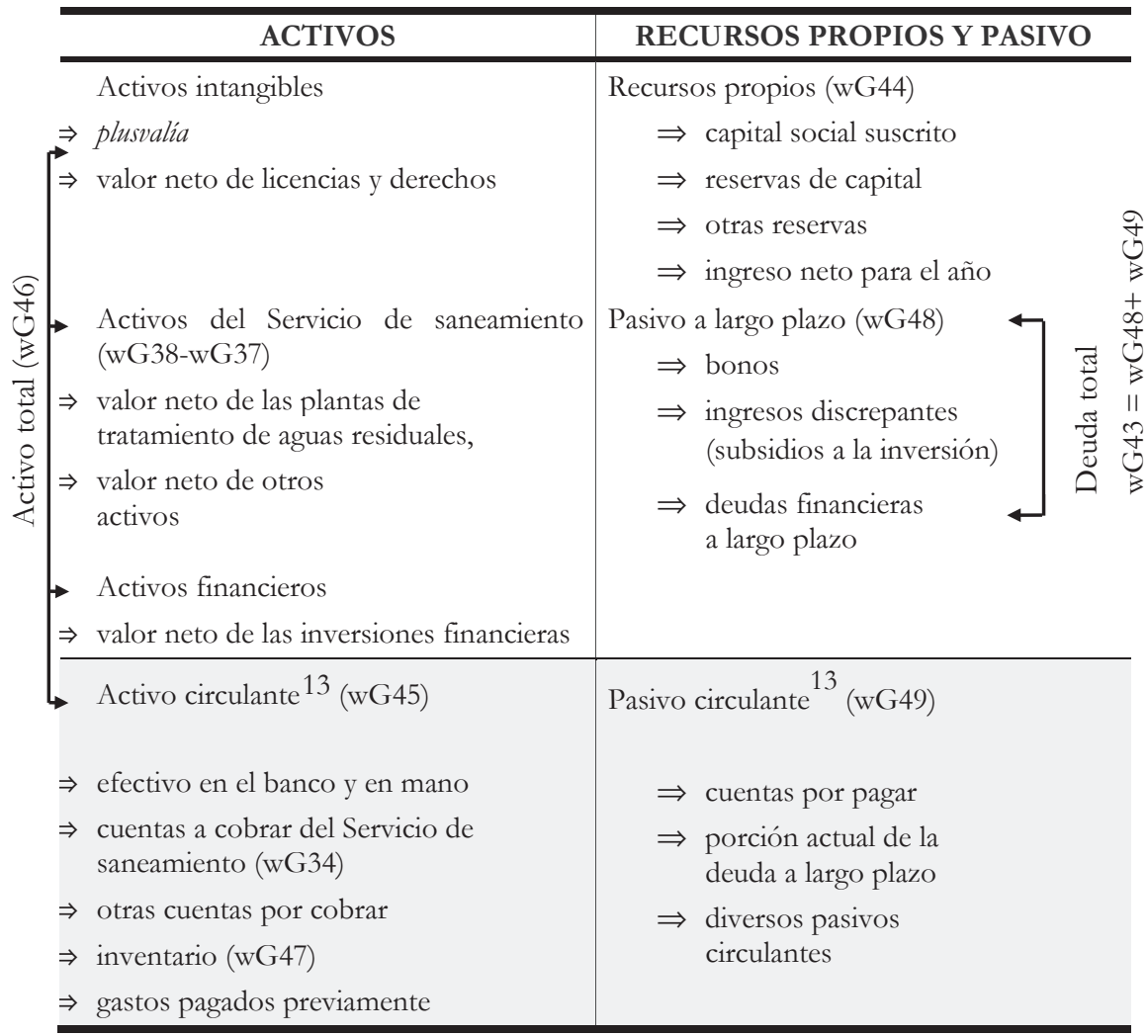

Las tablas anteriores se refieren a los principios de contabilidad financiera definidos en la doctrina general y generalmente aceptados, aunque con algunas diferencias entre países (GAAP por sus siglas en inglés).

La transición hacia las NIIF provoca cambios significativos en la información financiera de las empresas, incluidos cambios en la medición, divulgación y presentación de los datos.

La adopción de los estándares mostró que los cambios en la medición de los elementos financieros afectaban significativamente las valoraciones y los valores obtenidos, con especial atención a la divulgación del valor de mercado, el uso de provisiones y las pérdidas de valor de activos.

La adopción de los principios de las NIIF tiene una gran influencia en las principales variables financieras e informes. Por ello, los analistas deben

13 Activo circulante - Pasivo circulante $=$ Capital de trabajo 
distinguir los cambios en el desempeño debidos a la transición a las NIIF de los causados por los cambios en el negocio.

Es importante señalar que los cambios que provienen de la adopción de las NIIF no influyen en los componentes de los ratios involucrados ni en las justificaciones en las que se basan dichos ratios.

\section{Los cambios de las NIIF}

La actual bibliografía cubre exhaustivamente las NIIF y puede consultarse para un análisis más profundo. El principal interés, en este Manual, es observar en detalle el impacto de las NIIF sobre los indicadores financieros y las variables que se consideran en el Sistema de ID de IWA.

En primer lugar, es útil identificar los impactos y cambios más relevantes en las estructuras de Ganancias y Pérdidas y en el Balance General en los que se basan los indicadores de desempeño.

Dado que un enfoque "esquemático" parece ser el mejor ajuste para tal fin, el cumplimiento del Informe Financiero de las NIIF en comparación con los informes tradicionales nacionales (GAAP) muestra que los posibles cambios se aplican de manera diferente a los servicios de agua. Esto se puede observar en la Tabla 66 y Tabla 67.

La estructura de las Ganancias y Pérdidas y Balances Generales anuales sigue el mismo esquema presentado anteriormente en la Tabla 65 y Tabla 61. Los valores se asignan en términos de proporciones normales en el servicio de saneamiento. 
Tabla 66. Comparación de las Ganancias y Pérdidas

\begin{tabular}{|c|c|c|c|}
\hline$K €$ & NIIF & GAAP $* *$ & Cambios \\
\hline Ingresos por ventas (wG3) & 10,000 & 10,000 & $\begin{array}{l}\text { Cambios en el reconocimiento de ingresos, } \\
\text { p.ej. la marca en el mercado de "uso propio" } \\
\text { no puede generalmente aplicarse a los } \\
\text { prestadores de servicios de saneamiento }\end{array}$ \\
\hline \multicolumn{4}{|l|}{ Trabajo en progreso (-) } \\
\hline $\begin{array}{l}\text { Costes capitalizados de } \\
\text { activos construidos por el } \\
\text { prestador (wG33 }\end{array}$ & 2,150 & 6,150 & $\begin{array}{l}\text { Cambios en la capitalización de costes, } \\
\text { adquisición, mantenimiento y construcción de } \\
\text { infraestructuras en concesión }\end{array}$ \\
\hline $\begin{array}{l}\text { Otros ingresos de operación } \\
(-)\end{array}$ & 1,990 & 1,990 & $\begin{array}{l}\text { Los cambios en el reconocimiento de ingresos } \\
\text { generalmente no se aplican a los prestadores de } \\
\text { servicios de saneamiento }\end{array}$ \\
\hline Costes operativos (wG8): & 2,500 & 6,500 & $\begin{array}{l}\text { Cambios en la capitalización de costes, } \\
\text { adquisición, mantenimiento y construcción de } \\
\text { infraestructuras en concesión }\end{array}$ \\
\hline Energía eléctrica (wG11) & 1,350 & 1,350 & \\
\hline $\begin{array}{r}\text { Productos químicos y } \\
\text { otros consumibles y } \\
\text { materiales (wG12) }\end{array}$ & 3,390 & 3,390 & \\
\hline $\begin{array}{r}\text { Arrendamiento y alquiler } \\
\text { (wG13) }\end{array}$ & 650 & 650 & \\
\hline $\begin{array}{r}\text { Tasas, gravámenes e } \\
\text { impuestos (wG14) }\end{array}$ & $\square$ & $\square$ & \\
\hline $\begin{array}{r}\text { Ganancias y pérdidas } \\
\text { extraordinarias (wG15) }\end{array}$ & (30) & $(30)$ & \\
\hline $\begin{array}{r}\text { Otros costes de operación } \\
\text { (wG16) }\end{array}$ & 1,140 & 1,120 & $\begin{array}{l}\text { Cambios en el reconocimiento de ingresos que } \\
\text { generalmente no se pueden aplicar a los } \\
\text { prestadores de servicios de saneamiento debido } \\
\text { a una definición más estricta de provisión }\end{array}$ \\
\hline $\begin{array}{r}\text { Coste de la mano de obra } \\
\text { interna (wG9) }\end{array}$ & 2,540 & 2,580 & $\begin{array}{l}\text { Cambios en la capitalización de costes, cargos } \\
\text { por reestructuración (valor de mercado de la } \\
\text { indemnización por rescisión de contrato y } \\
\text { otros beneficios para el personal) }\end{array}$ \\
\hline $\begin{array}{l}\text { E.B.I.T.D.A. (wG50+wG26) } \\
\text { Beneficio antes de intereses, } \\
\text { impuestos, depreciaciones y } \\
\text { amortizaciones }\end{array}$ & 2,450 & 2,430 & $\begin{array}{l}\text { Mayor volatilidad debido a la contabilidad del } \\
\text { valor de mercado. Algunos cargos pasan de } \\
\text { depreciación a gastos }\end{array}$ \\
\hline $\begin{array}{l}\text { Depreciación (basada en } \\
\text { valores contables) (wG26) }\end{array}$ & 1,970 & 1,980 & $\begin{array}{l}\text { Cambios en las vidas útiles y la estimación de } \\
\text { su valor, la amortización de la plusvalía } \\
\text { desapareció en 2004, sustituyéndose por } \\
\text { degradaciones anuales }\end{array}$ \\
\hline
\end{tabular}


Tabla 66a. Comparación de las Ganancias y Pérdidas (cont.)

\begin{tabular}{|c|c|c|c|}
\hline$K €$ & IFRS & GAAP $* *$ & Cambios \\
\hline $\begin{array}{l}\text { Beneficio operativo } \\
(\mathrm{wG} 50= \\
\text { wG2-wG8-wG9-wG26) } \\
\text { Beneficio antes de intereses e } \\
\text { impuestos = Beneficio operativo }\end{array}$ & & & $\begin{array}{l}\text { Aumento de la volatilidad debido a la } \\
\text { contabilización y depreciación del valor de } \\
\text { mercado }\end{array}$ \\
\hline Coste de los intereses (wG27) & 320 & 290 & $\begin{array}{l}\text { Impacto por la contabilidad del valor de } \\
\text { mercado y la amortización de los costes de } \\
\text { aumento de la deuda. Definición de } \\
\text { deuda. Valor de mercado de los derivados }\end{array}$ \\
\hline Ingresos por Intereses (wG28) & 10 & 30 & $\begin{array}{l}\text { Impacto de la contabilidad del valor de } \\
\text { mercado, definición de crédito. }\end{array}$ \\
\hline $\begin{array}{l}\text { B.A.I. = I.B. } \\
\text { Beneficios antes de impuestos }= \\
\text { Ingresos brutos }\end{array}$ & 170 & 190 & Incremento de la volatilidad \\
\hline Impuestos (-) & 150 & 140 & $\begin{array}{l}\text { Cambios en las estimaciones impositivas, } \\
\text { incluido el impuesto diferido. Posibles } \\
\text { impactos impositivos de la contabilidad } \\
\text { del valor de mercado }\end{array}$ \\
\hline BENEFICIO NETO (wG52) & 170 & 200 & Volatilidad significante \\
\hline
\end{tabular}

* Los valores no reflejan la situación de ningún prestador real 
Tabla 67. Balance General comparativo al final del año

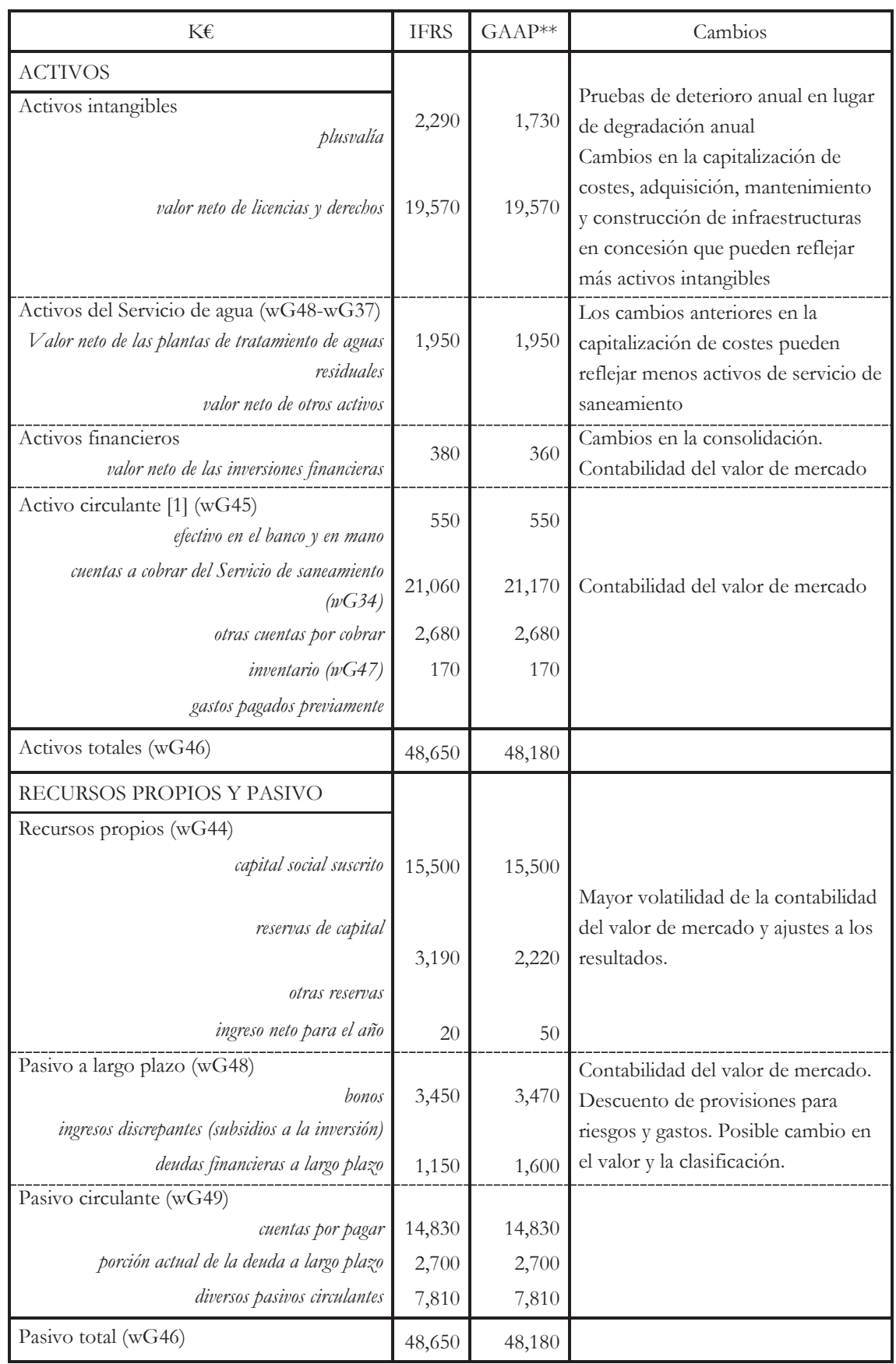

* Los valores no reflejan la situación de ningún prestador real

**GAAP refleja la interpretación del Sistema de ID de IWA de los principios de contabilidad nacional comúnmente aceptados. 


\section{Perspectiva general}

Desde una perspectiva teórica, un cambio en la contabilidad no debe cambiar el valor de una empresa, aparte de los posibles cambios en el comportamiento que pueden provocar los cambios. Por ejemplo, la contabilidad del valor de mercado podría conducir a estrategias de riesgo potencialmente subóptimas para reducir la volatilidad de las Ganancias y Pérdidas.

Sin embargo, en la práctica, la adopción de las NIIF, y en particular las posibles nuevas divulgaciones y el cambio en las mediciones, pueden afectar en última instancia la forma en que los accionistas interesados valoran a las empresas:

- Medición: los elementos contables a menudo pueden estar sujetos a nuevas medidas; por ejemplo, los ingresos deben reconocerse de manera diferente o el valor de ciertos activos o pasivos debe marcarse para comercializarse.

- Divulgación: se requiere información adicional para ser divulgada, o para ser divulgada de una manera diferente.

- Presentación: la información se presenta de manera diferente; por ejemplo, las partidas extraordinarias pueden no existir, a pesar de que las compañías pueden haber elegido mostrar su impacto por separado.

Los cambios anteriores se pueden resumir, para una mejor comprensión, en la siguiente Tabla 68 . 
Tabla 68. Cuestiones clave de las NIC/NIIF

\begin{tabular}{|l|l|}
\hline NIC/NIIF & Cuestiones clave \\
\hline (normas NIC 39 y NIC 32): & La NIC 39 (Instrumentos Financieros: Reconocimiento y \\
Medición) describe los requisitos para el reconocimiento y \\
la medición de activos y pasivos financieros y algunos \\
contratos para comprar o vender artículos no financieros. \\
La NIC 32 (Instrumentos financieros: Presentación) \\
describe los requisitos contables para la presentación de \\
los instrumentos financieros, en particular en cuanto a su \\
clasificación en activos financieros, pasivos financieros e \\
instrumentos de recursos propios. \\
Las normas anteriores se aplican a todos los tipos de \\
instrumentos financieros, excepto aquellos que están en el \\
ámbito específicamente. \\
Los instrumentos financieros se reconocen inicialmente \\
cuando una entidad se convierte en parte de las \\
disposiciones contractuales del instrumento, y se clasifican \\
en diversas categorías según el tipo de instrumento, que \\
luego determina la metodología de medición posterior. \\
El valor de mercado es el monto por el cual un activo \\
puede ser canjeado, o un pasivo liquidado, entre partes \\
informadas y dispuestas en una transacción \\
independiente. Los cambios de valor conectados se \\
reconocen en ganancias o pérdidas. \\
Un ejemplo común de instrumentos financieros dentro \\
del alcance de la NIC 39 son: efectivo, demanda y tiempo \\
de depósito, papel comercial, cuentas por cobrar y por \\
pagar, valores de deuda y capital, derivados, etc. \\
Es probable que la contabilidad de valor de mercado \\
trajera una volatilidad significativa a las Ganancias y \\
Pérdidas (y al Balance General). Sin embargo, la \\
bibliografía muestra que esta volatilidad es más probable \\
que afecte a los prestadores con una exposición sustancial \\
a los servicios básicos y, por lo tanto, a negocios no \\
regulados como la generación y el suministro de \\
electricidad o la importación y el suministro de gas, que a \\
los negocios regulados completamente como son la \\
transmisión de gas, suministro de agua y saneamiento. \\
\hline
\end{tabular}


Tabla 68a. Cuestiones clave de las NIC/NIIF

\begin{tabular}{|c|c|}
\hline$N I C / N I I F$ & Cuestiones clave \\
\hline $\begin{array}{l}\text { Pensiones y beneficios para empleados } \\
\text { (norma NIC 19): }\end{array}$ & $\begin{array}{l}\text { La NIC } 19 \text { (Beneficios para empleados) describe los } \\
\text { requisitos de contabilidad para los beneficios de los } \\
\text { empleados, incluidos los beneficios a corto plazo (por } \\
\text { ejemplo, sueldos y salarios, vacaciones anuales), beneficios } \\
\text { posteriores al empleo tales como beneficios de jubilación, } \\
\text { otros beneficios a largo plazo (por ejemplo, beneficios por } \\
\text { finalización de contrato. La norma establece el principio de } \\
\text { que el costo de proporcionar beneficios a los empleados } \\
\text { debe ser reconocido en el período en que el beneficio es } \\
\text { obtenido por el empleado, en lugar de cuando se paga o es } \\
\text { pagadero, y describe cómo se mide cada categoría de } \\
\text { beneficios de los empleados, proporcionando información } \\
\text { detallada en particular sobre los beneficios post-empleo. } \\
\text { La norma rige por separado los beneficios a corto y a largo } \\
\text { plazo o planes de contribución, pero en términos generales, } \\
\text { cuando las obligaciones de pago vayan a vencer dentro de } \\
\text { los } 12 \text { meses después del final del período en el cual el } \\
\text { empleado presta el servicio, debe ser descontadas a su } \\
\text { presente valor. } \\
\text { De este modo, el monto reconocido en el balance general } \\
\text { debe representar el valor actual de los pagos futuros } \\
\text { esperados necesarios para liquidar la obligación resultante } \\
\text { del servicio prestado por el empleado en los períodos } \\
\text { actuales y anteriores ajustados por ganancias y pérdidas } \\
\text { actuariales no reconocidas y costo de servicio pasado no } \\
\text { reconocido y reducido por el valor razonable de los activos } \\
\text { del plan a la fecha del balance. } \\
\text { El valor de mercado de los activos de pensiones y los } \\
\text { pasivos actuariales representados en el balance general } \\
\text { puede aumentar la volatilidad para la cuenta de resultados } \\
\text { estas obligaciones. }\end{array}$ \\
\hline
\end{tabular}


Tabla 68b. Cuestiones clave de las NIC/NIIF

\begin{tabular}{|l|l|}
\hline NIC/NIIF & \multicolumn{1}{|c|}{ Cuestiones clave } \\
\hline Norma NIC 23) & La NIC 23 (Costes de endeudamiento) requiere que los \\
& costes por préstamos directamente atribuibles a la \\
adquisición, construcción o producción de un "activo \\
calificado" (que necesariamente toma un período sustancial \\
de tiempo para prepararse para su uso o venta) estén \\
incluidos (capitalizados) en el coste del activo. Otros costes \\
por préstamos se reconocen como un gasto. \\
Los activos elegibles pueden ser propiedades, plantas y \\
equipos e inversiones inmobiliarias durante el período de \\
construcción, activos intangibles durante el período de \\
desarrollo, o incluso inventarios. \\
Los costos de endeudamiento incluyen intereses sobre \\
descubiertos y préstamos bancarios, amortización de \\
descuentos o primas sobre préstamos, cargos financieros \\
por arrendamientos financieros y diferencias de cambio en \\
préstamos en moneda extranjera cuando se consideran \\
como un ajuste a los costes de intereses. \\
La NIIF 23 implica, por lo tanto, cierto cambio (aumento) \\
en el valor contable de los activos y una mayor \\
depreciación correspondiente que refleja el aumento de la \\
volatilidad de las Ganancias y la Pérdidas.
\end{tabular}


Tabla 68c. Cuestiones clave de las NIC/NIIF

\begin{tabular}{|c|c|}
\hline$N I C / N I I F$ & Cuestiones clave \\
\hline $\begin{array}{l}\text { Valor decreciente de los activos } \\
\text { (normas NIC 36): }\end{array}$ & 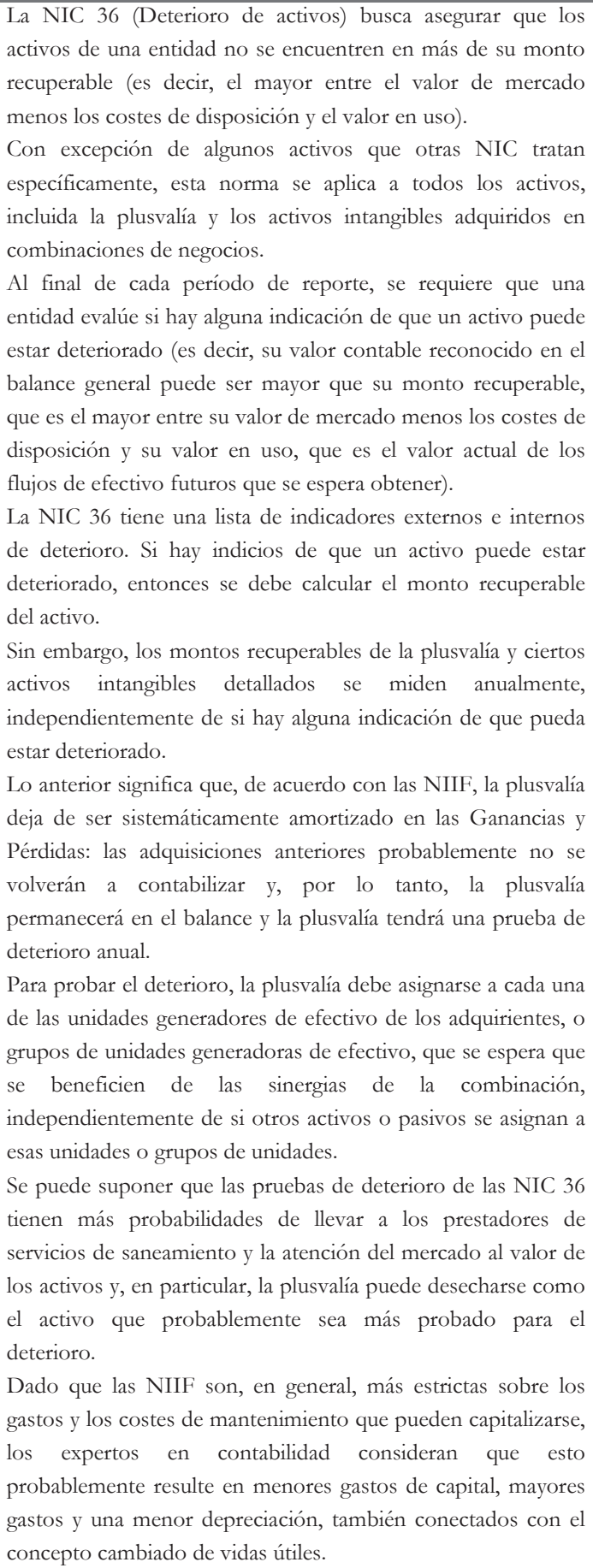 \\
\hline
\end{tabular}


Tabla 68d. Cuestiones clave de las NIC/NIIF

\begin{tabular}{|c|c|}
\hline NIC/NIIF & Cuestiones clave \\
\hline $\begin{array}{l}\text { Contabilidad de activos intangibles } \\
\text { (normas NIC } 38 \text { y CINIIF 12) }\end{array}$ & $\begin{array}{l}\text { La NIC } 38 \text { (Activos Intangibles) describe los requisitos } \\
\text { contables para los activos intangibles, que son activos no } \\
\text { monetarios identificables sin sustancia física (ya sea } \\
\text { separables o derivados de derechos contractuales u otros } \\
\text { derechos legales) que son controlados por la entidad como } \\
\text { resultado de eventos pasados (por ejemplo, compra o } \\
\text { creación propia) y de los cuales se esperan beneficios } \\
\text { económicos futuros. } \\
\text { El patrón de beneficio esperado refleja directamente la vida } \\
\text { útil del activo, cambiando notablemente el concepto } \\
\text { GAAP de vida útil e impactando consistentemente en la } \\
\text { depreciación de los activos. } \\
\text { Los activos intangibles que cumplen con los criterios de } \\
\text { reconocimiento relevantes se miden inicialmente al coste y } \\
\text { posteriormente se miden al coste (menos la amortización } \\
\text { acumulada y las pérdidas por deterioro) o utilizando el } \\
\text { modelo de revalorización (basado en el valor de mercado), } \\
\text { y se amortizan de manera sistemática sobre sus vidas útiles } \\
\text { finitas. En caso de vida útil indefinida, el intangible no debe } \\
\text { amortizarse. } \\
\text { En cualquier caso, el activo también debe ser evaluado por } \\
\text { deterioro de acuerdo con la NIC } 36 \text {. }\end{array}$ \\
\hline $\begin{array}{r}\text { Contabilidad de activos intangibles } \\
\text { (normas CINIIF 12) }\end{array}$ & $\begin{array}{l}\text { En todo el mundo, existen prestadores que operan } \\
\text { servicios públicos en virtud de contratos de concesión. } \\
\text { Para armonizar adecuadamente diversos aspectos contables } \\
\text { de esta situación particular, el Comité de Interpretación de } \\
\text { la Información Financiera Internacional emitió, en } \\
\text { noviembre de } 2006 \text { y bajo el paraguas del Junta de Normas } \\
\text { Internacionales de Contabilidad, la interpretación oficial } \\
\text { "CINIIF } 12 \text { - Arreglos de concesión de servicios" que } \\
\text { entró en vigencia el } 1 \text { de enero de } 2008 \text {. } \\
\text { La CINIIF } 12 \text { define un acuerdo de concesión de servicios } \\
\text { como un acuerdo mediante el cual un gobierno u otro } \\
\text { organismo del sector público contrata con un operador } \\
\text { privado para desarrollar (o actualizar), operar y mantener } \\
\text { activos de infraestructura del otorgante tales como } \\
\text { carreteras, puentes, túneles, aeropuertos, energía, agua y } \\
\text { redes de distribución de gas, prisiones u hospitales. El } \\
\text { otorgante controla o regula qué servicios debe } \\
\text { proporcionar el operador utilizando los activos, a quién y a } \\
\text { qué precio, y también controla cualquier interés residual } \\
\text { significativo en los activos al final del plazo del acuerdo. } \\
\text { La CINIIF } 12 \text { también establece una distinción entre dos } \\
\text { tipos de acuerdos de concesión de servicios. }\end{array}$ \\
\hline
\end{tabular}


Tabla 68e. Cuestiones clave de las NIC/NIIF

\begin{tabular}{|c|c|}
\hline$N I C / N I I F$ & Cuestiones clave \\
\hline $\begin{array}{r}\text { Contabilidad de activos intangibles } \\
\text { (normas CINIIF 12) }\end{array}$ & 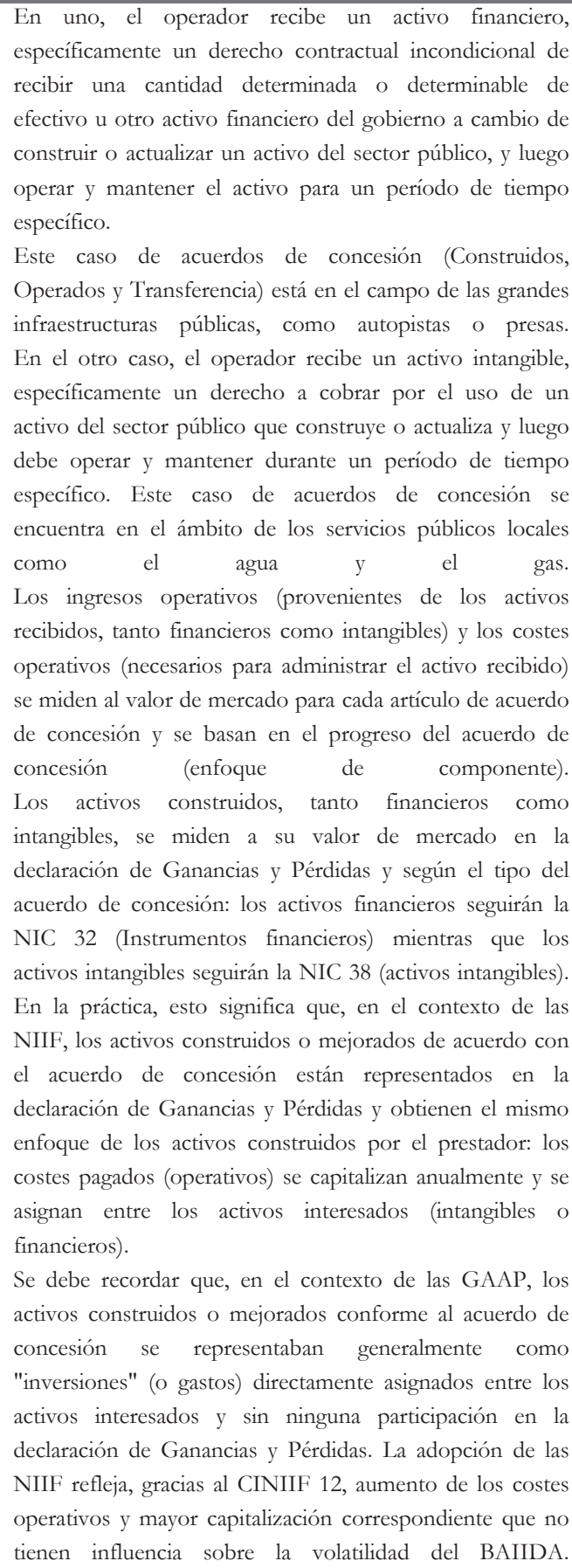 \\
\hline
\end{tabular}




\begin{tabular}{|l|l|}
\hline NIC/NIIF & \multicolumn{1}{|c|}{ Cuestiones clave } \\
\hline & $\begin{array}{l}\text { Los activos intangibles recibidos e incrementados se } \\
\text { amortizarán de manera sistemática durante la duración de } \\
\text { la concesión }\end{array}$ \\
\hline
\end{tabular}

Tabla 68f. Cuestiones clave de las NIC/NIIF

\begin{tabular}{|c|c|}
\hline NIC/NIIF & Cuestiones clave \\
\hline Impuesto diferido (norma NIC 12) & $\begin{array}{l}\text { La NIC } 12 \text { (Impuesto sobre la Renta) implementa el } \\
\text { llamado "método integral del Balance General" para } \\
\text { contabilizar los impuestos sobre la renta que reconoce las } \\
\text { consecuencias fiscales actuales y futuras de la recuperación } \\
\text { o liquidación futura del valor contable de los activos y } \\
\text { pasivos de una entidad. Las diferencias entre el importe en } \\
\text { valor contable y la base imponible de los activos y pasivos, } \\
\text { y las pérdidas y créditos fiscales acumulados, se reconocen, } \\
\text { con excepciones limitadas, como pasivos por impuestos } \\
\text { diferidos o activos por impuestos diferidos, y este último } \\
\text { también está sujeto a una prueba de "ganancias probables". } \\
\text { El principio general es, por un lado, que los pasivos por } \\
\text { impuestos diferidos deben ser reconocidos por todas las } \\
\text { diferencias temporales imponibles (que son la diferencia } \\
\text { entre el valor contable de un activo o pasivo y su base } \\
\text { impositiva) mientras, por otro lado, un activo por } \\
\text { impuestos diferidos debe ser reconocido por las diferencias } \\
\text { temporales deducibles, pérdidas fiscales no utilizadas y } \\
\text { créditos fiscales no utilizados en la medida en que sea } \\
\text { probable que se disponga de ganancias fiscales contra las } \\
\text { cuales se puedan utilizar las diferencias temporales } \\
\text { deducibles, a menos que surja del activo por impuestos } \\
\text { diferidos. } \\
\text { El enfoque de diferencias temporales utilizado en el } \\
\text { contexto de las NIIF es, sin ninguna duda, más amplio que } \\
\text { el enfoque temporal adoptado generalmente en el contexto } \\
\text { GAAP y puede dar lugar a aumentos tanto en los activos y } \\
\text { pasivos por impuestos diferidos, particularmente cuando la } \\
\text { contabilidad del valor de mercado y las metodologías } \\
\text { afectadas tienen un impacto significativo las Ganancias y } \\
\text { Pérdidas. }\end{array}$ \\
\hline
\end{tabular}




\section{Impacto en los Ratios Financieros}

La Tabla 66 y Tabla 67 anteriores muestran los cambios potenciales que la adopción de las NIIF está llevando a los estados financieros de los prestadores de servicios de saneamiento, de acuerdo con los cuestiones clave de los principios relacionados con las NIIF descritos en la Tabla 68, por lo que resalta el problema para establecer el nivel de comparabilidad entre pares cuando algunos aplican NIIF y otros continúan usando estándares nacionales.

Los casos de estudios y la bibliografía indican que los valores de las empresas difieren significativamente cuando se aplican NIIF y no las GAAP en la preparación de la información financiera. Esta es la razón por la cual es importante comprender las razones de tales diferencias para evaluar el impacto de las NIIF en el cálculo y la volatilidad de los ratios financieros.

Se ha visto que los cambios son más significativos para aquellos conceptos que son más relevantes para la evaluación de una estructura financiera como son deudores, efectivo y equivalentes de efectivo, capital, pasivos a largo plazo y totales. Por ello, al analizar los principales ajustes significativos para adaptar los estados financieros a los estándares internacionales, los principales motivos de la variación, se pueden resumir de la siguiente manera:

- la aplicación de valor de mercado a los instrumentos financieros, la reclasificación de cuentas y los cambios en el alcance del impacto de la consolidación en los activos corrientes;

- el cambio en las reglas para la valoración de deudas y los cambios en el perímetro de consolidación influyen directamente en los pasivos, mientras que los ajustes directos y el efecto indirecto de los ajustes a los resultados afectan las cifras de patrimonio;

- los activos fijos globales y los inventarios no parecen variar significativamente: el primero gracias a la opción generalmente adoptada de no cambiar el criterio de valuación de los activos fijos aplicado (coste de adquisición) mientras que el último depende del método de evaluación adoptado anteriormente. Sin embargo, se pueden observar variaciones significativas al analizar por separado el servicio de saneamiento y los activos fijos intangibles debido a los cambios en la capitalización de costes y en la valoración de la plusvalía;

- en la declaración de ingresos, se pueden observar variaciones significativas en los ingresos operativos, que reflejan una mayor 
volatilidad del resultado final, dependiendo de las posibles diferencias en el tratamiento de los ingresos y gastos (capitalización de costos, deterioro del activo, contabilidad de valor de mercado, etc.).

Dichas diferencias en la medición de las cifras contables bajo las NIIF en lugar de las GAAP tradicionales pueden afectar directamente al cálculo de ratios influyendo en el numerador, el denominador o ambos.

Cuando la diferencia en la medición afecta solo al numerador o solo al denominador, el efecto de los cambios es sencillo, fácil de identificar e interpretar. Por ejemplo, el ratio de circulante es mayor según las NIIF (manteniéndose todo lo demás igual) si los activos actuales son más altos, pero los pasivos actuales permanecen sin cambios.

La identificación y la interpretación son menos evidentes en los casos en los que se encuentran numerosos efectos divergentes en los ratios. Por ejemplo, una ganancia menor bajo las NIIF reducirá el retorno de los activos al reducir el numerador, pero, al mismo tiempo, lo aumentará reduciendo el denominador.

Además, puede haber distintas diferencias contables entre las NIIF y las GAAP tradicionales que tienen efectos opuestos en un ratio particular. Un ejemplo es el impacto en el ratio de circulante de los activos corrientes más altos según las NIIF debido a la contabilización del valor de mercado de los ingresos por cobrar simultáneamente con mayores pasivos debido, por ejemplo, al reconocimiento de un pasivo de arrendamiento financiero.

Sin embargo y en términos generales, se puede deducir que los índices de solvencia y de endeudamiento, así como el retorno de los activos y del patrimonio, pueden variar significativamente como resultado de los cambios en el balance general y la declaración de ingresos.

Las variables financieras operativas siguen siendo aportes útiles para el efectivo, pero la adopción de metodologías de actualización está trayendo nuevos conceptos de ganancias; las cifras clave como la deuda, las pensiones, las provisiones o las minorías, cambian sustancialmente y los cambios en las cifras mismas (ya sean beneficios antes de intereses, impuestos, depreciaciones y amortizaciones (BAIIDA) o deuda neta como resultado de la contabilidad del coste del valor de mercado y las políticas de capitalización), junto con el probable aumento en la volatilidad de las 
Ganancias y Pérdidas, pueden afectar la percepción general del valor relativo y absoluto de la compañía.

La mayor volatilidad del ingreso neto hace que los ratios relacionados con las Ganancias por Acción, de uso poco frecuente, sean comparables para grandes prestadores (incluyendo el Índice de Rentabilidad o el crecimiento de la Ganancia por Acción).

Se puede concluir que las posiciones económicas y financieras de las empresas de servicios de saneamiento reflejadas de conformidad con las NIIF parecen ser significativamente diferentes de la imagen presentada por las normas contables locales, y en un marco de comparación general caracterizado por una mayor divulgación proporcionando más información. Esto puede permitir una pronta identificación de las fuentes potenciales de bajo desempeño (por ejemplo, en el caso de normas de deterioro potencialmente más estrictas).

El número de ratios financieros afectados por la adopción de las NIIF es considerable, sin lugar a dudas, pero de todos modos es importante remarcar una vez más que dicho impacto no influye ni en los componentes de los ratios involucrados ni en la lógica en las que se basan los dichos ratios.

Lo que cambia es el resultado obtenido en los ratios, es decir, la calidad de la información provista $\mathrm{y}$, por lo tanto, el resultado final de la comparación entre pares, particularmente cuando algunos de los pares del panel no adoptan los principios NIIF.

Si esta última opción es inevitable, es igualmente inevitable unificar la base de datos de los panelistas reconvirtiendo los valores representados en las estructuras de Ganancias y Pérdidas y el Balance General de las NIIF en los criterios GAAP. Por ejemplo, en la práctica, las propiedades que aún no cumplen con las NIIF deben consolidar los resultados de las NIIF subsidiarias en el Informe Financiero del Grupo.

Este procedimiento hacia atrás consistirá básicamente en la aplicación del valor de mercado a los instrumentos financieros y los beneficios para el personal, las normas adoptadas para la valoración de las deudas, las diferencias en la capitalización de costes, la depreciación y el deterioro del activo (con referencia al tratamiento de la plusvalía) tal y como se detalla en la Tabla 71. 
Tabla 69. Impacto en los Indicadores Financieros (Ganancias y pérdidas)

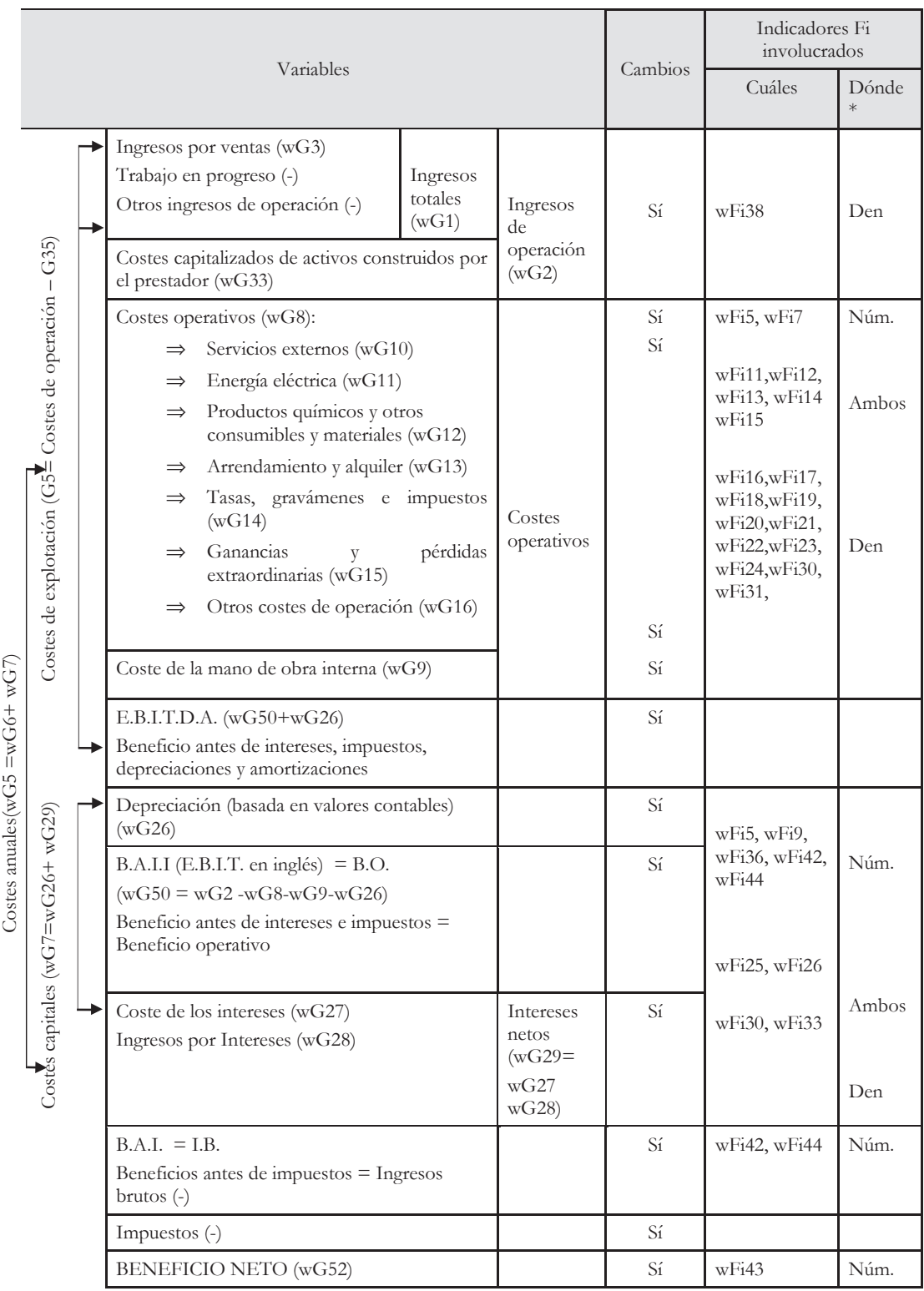

* Cuando los cambios impactan en el cálculo de los ID (Den: Denominador, Núm.: Numerador, Ambos) 
Tabla 70. Impacto en los Indicadores financieros (Balance General)

\begin{tabular}{|c|c|c|c|}
\hline \multirow{2}{*}{ Variables } & \multirow{2}{*}{ Cambios } & \multicolumn{2}{|c|}{ Indicadores Fi involucrados } \\
\hline & & Cuáles & Dónde* \\
\hline ACTIVOS & & \multirow{3}{*}{$\begin{array}{l}\text { wFi27 (wG30), wFi28 } \\
\text { (wG30, wG31), wFi29 } \\
\text { (wG30, wG32), wFi34 } \\
\text { (wG30) }\end{array}$} & \multirow[b]{3}{*}{ Ambos } \\
\hline $\begin{array}{l}\text { Activos intangibles } \\
\qquad \text { plusvalia } \\
\text { valor neto de licencias y derechos }\end{array}$ & Sí & & \\
\hline $\begin{array}{l}\text { Activos del Servicio de } \\
\text { saneamiento } \\
\text { (wG38-wG37) } \\
\text { valor neto de las plantas de tratamiento de } \\
\text { aguas residuales } \\
\text { valor neto de otros activos s }\end{array}$ & & & \\
\hline $\begin{array}{l}\text { Activos financieros } \\
\text { valor neto de las inversiones financieras }\end{array}$ & Sí & & \\
\hline $\begin{array}{r}\text { Activo circulante [1] (wG } 45) \text { ) } \\
\text { efectivo en el banco y en mano } \\
\text { cuentas a cobrar del Servicio de } \\
\text { saneamiento (w } G 34) \\
\text { otras cuentas por cobrar } \\
\text { inventario ( } w G 47) \\
\text { gastos pagados previamente }\end{array}$ & Sí & $\begin{aligned} & \text { wFi32 } \text { (wG34), wFi38 } \\
& \text { (wG47) } \\
& \text { wFi41 (wG45, wG49) }\end{aligned}$ & $\begin{array}{l}\text { Núm. } \\
\text { Ambos }\end{array}$ \\
\hline Activos totales (wG46) & Sí & wFi44, wFi45 & Den \\
\hline $\begin{array}{l}\text { RECURSOS PROPIOS Y } \\
\text { PASIVO }\end{array}$ & & \multirow{4}{*}{$\begin{array}{l}\text { wFi40 (wG43, wG44), } \\
\text { wFi43 (wG44) }\end{array}$} & \multirow{4}{*}{$\begin{array}{l}\text { Ambos } \\
\text { Den }\end{array}$} \\
\hline $\begin{array}{r}\text { Recursos propios (wG44) } \\
\text { capital social suscrito } \\
\text { reservas de capital } \\
\text { otras reservas } \\
\text { ingreso neto para el año }\end{array}$ & Sí & & \\
\hline $\begin{array}{r}\text { Pasivo a largo plazo (wG48) } \\
\text { ingresos discrepantes (subsidios a la } \\
\text { inversión) } \\
\text { deudas financieras a largo plazo }\end{array}$ & Sí & & \\
\hline Deuda total (wG43) & & & \\
\hline \multicolumn{4}{|l|}{$\begin{array}{r}\text { Pasivo circulante (wG49) } \\
\text { cuentas por pagar } \\
\text { porción actual de la deuda a largo plazo } \\
\text { diversos pasivos circulantes }\end{array}$} \\
\hline Pasivo total (wG46) & Sí & & \\
\hline
\end{tabular}

* Cuando los cambios impactan en el cálculo de los FI (Den: Denominador, Núm.: Numerador, Ambos) 
Tabla 71. De NIIC a GAAP: Ajustes

\begin{tabular}{|c|c|c|}
\hline Criterios & $\begin{array}{c}\text { Variables involucradas } \\
\text { en las Ganancias y } \\
\text { Pérdidas y el Balance } \\
\text { General }\end{array}$ & $\begin{array}{c}\text { Ajustes } \\
\text { NIIF vs/ GAAP }\end{array}$ \\
\hline $\begin{array}{l}\text { Aplicación del valor de } \\
\text { mercado }\end{array}$ & $\begin{array}{l}\text { Ingreso por intereses } \\
\text { Activos financieros } \\
\text { Cuentas por cobrar } \\
\text { Pasivos a largo plazo }\end{array}$ & $\begin{array}{l}\text { Descuento vs / Valor nominal } \\
\text { Descuento vs / Valor nominal } \\
\text { Descuento vs / Valor nominal } \\
\text { Capitalización de los intereses de la } \\
\text { deuda principal y provisiones para el } \\
\text { descuento de personal vs/ aumento de } \\
\text { la deuda }\end{array}$ \\
\hline $\begin{array}{l}\text { Beneficios para el } \\
\text { personal }\end{array}$ & $\begin{array}{l}\text { Costes de mano de obra } \\
\text { interna }\end{array}$ & $\begin{array}{l}\text { Beneficios e indemnización por } \\
\text { terminación para el descuento del año } \\
\text { vs / coste nominal }\end{array}$ \\
\hline $\begin{array}{l}\text { Capitalización } \\
\text { costes }\end{array}$ & $\begin{array}{l}\text { Gastos por intereses } \\
\text { Plusvalía }\end{array}$ & $\begin{array}{l}\text { Capitalización vs/ asignación de } \\
\text { Ganancias y Pérdidas } \\
\text { Deterioro vs / Depreciación }\end{array}$ \\
\hline Depreciación & $\begin{array}{l}\text { Vida útil de los activos } \\
\text { Plusvalía }\end{array}$ & $\begin{array}{l}\text { Servicio de agua vs / intangible } \\
\text { Deterioro vs / Depreciación }\end{array}$ \\
\hline Recursos & $\begin{array}{l}\text { Reservas } \\
\text { Ingreso neto para el año }\end{array}$ & $\begin{array}{l}\text { ajustes directos y el efecto indirecto de } \\
\text { los ajustes en los resultados }\end{array}$ \\
\hline Impuestos & Impuestos diferidos & $\begin{array}{l}\text { enfoque de diferencia temporal vs } \\
\text { enfoque de tiempo }\end{array}$ \\
\hline
\end{tabular}

En cuanto a los Activos Fijos, es importante recordar que en el contexto de las NIIF (como se define mejor en la interpretación anterior del CINIIF 12, ver Tabla 68), las prestadores de servicios de saneamiento representan los activos construidos o mejorados según el acuerdo de concesión en la declaración de Ganancias y Pérdidas, al igual que los activos construidos por el prestador, y capitalizan anualmente los costes pagados (operativos) a través de la asignación entre los activos intangibles a depreciar, de manera sistemática, sobre su vida útil finita, es decir, la duración de la concesión.

Sin embargo, en el contexto GAAP, los activos construidos o mejorados de acuerdo con el acuerdo de concesión generalmente se representan como "inversiones" (o gasto de capital) asignados directamente entre los activos interesados (normalmente tangibles) sin ninguna implicación de la declaración de Ganancias y Pérdidas.

De lo anterior se desprende que la adopción de las NIIF refleja un aumento de los costos operativos y una mayor capitalización correspondiente, pero esto resulta de forma neutral en el resultado final. 
Por otro lado, el Sistema de ID de la IWA excluye explícitamente los activos construidos por el prestador de los indicadores (véase los capítulos 2 y 3 de la Parte II de este Manual, Definiciones de indicadores de desempeño y variables), por lo tanto, un aumento tanto de los costos operativos como de los ingresos correspondientes es relevante para el análisis de inversiones (wFI27, wFi28, wFi29, wFi34, wFi35, wFi36, wFi42) que en el contexto de las NIIF revela un predominio de activos intangibles.

Sin embargo, en algunos contextos de las GAAP, se debe observar un reposicionamiento similar entre los activos intangibles de los activos subyacentes del contrato de concesión, por lo que los indicadores de desempeño anteriores con las variables respectivas se han ajustado adecuadamente en las secciones 2.8 y 3.7 de la Parte II del manual.

Finalmente, menos evidente, pero relacionado directamente, es el impacto que se observa en la depreciación y en la relación con diferentes conceptos (NIIF vs GAAP) de la vida útil entre los activos tangibles e intangibles.

En conclusión, se puede evaluar que la adopción de las NIIF en los prestadores de servicios de saneamiento tiene un impacto considerable en los valores tal como se representa en el Informe Financiero, por lo que se inducen muchos cambios tanto en la calidad como en los fundamentos de la información financiera proporcionada.

En el marco de las comparaciones de desempeño, este impacto no interviene, sin embargo, en el caso de una comparación interna a lo largo del tiempo, dado que los procedimientos de Adopción por Primera Vez (definidos en la interpretación SIC8) regulan la aplicación de disposiciones transitorias en el período de primera aplicación de las NIC para que los estados financieros proforma se preparen y presenten, como siempre se han preparado, de acuerdo con las NIC.

Por el contrario, una investigación previa de los principios de contabilidad adoptados y, de ser el caso, una armonización previa de la base de datos de los panelistas es altamente recomendable, como pasos fundamentales en cualquier proceso de comparación entre prestadores tanto nacionales como internacionales. 


\subsection{Definiciones complementarias}

En esta sección, se presentan una serie de definiciones para expresiones clave que generalmente se usan en el texto y cuyo significado preciso debe aclararse.

\section{Definiciones relacionadas con el servicio de saneamiento}

accesorios complementarios: estructuras y elementos del sistema que no son los colectores del sistema de alcantarillado (estaciones de bombeo, tanques de tormenta, depósitos de retención, etc.).

accionista: propietario de las acciones de una empresa o negocio, en este caso de un servicio de aguas residuales u otro proveedor de servicios (adaptado de Oxford, 2002).

acometida: parte del sistema de alcantarillado cuya función es transportar las aguas residuales desde un edificio al sistema de alcantarillado. Las acometidas están gestionadas por el prestador del servicio.

agua cloacal: Véase aguas negras.

agua residual: agua cuyas características han sido alteradas debido a su uso y son vertidas en un desagüe o red de alcantarillado (EN 753-1, 1995).

agua residual exportada: aguas residuales que son recogidas del sistema de alcantarillado o de la estación depuradora de aguas residuales por el prestador del servicio e introducidas en un sistema externo que no es responsabilidad del prestador.

agua residual importada: aguas residuales introducidas en el sistema de alcantarillado o en las estaciones depuradoras de aguas residuales, con una autorización previa, provenientes de fuentes externas que no son responsabilidad del prestador.

agua residual industrial: se trata principalmente desechos líquidos específicos, que provienen de procesos industriales y no tienen ningún otro uso de recuperación de productos. Puede contener contaminantes y sustancias tóxicas, dependiendo del tipo de industria. También puede contener pequeñas cantidades de aguas residuales domésticas procedentes de las instalaciones de saneamiento de la planta industrial (Ellis et al., 2003).

agua residual municipal: agua residual de las áreas municipales que consisten predominantemente en aguas residuales domésticas. Además, también puede contener aguas pluviales, aguas de infiltración, aguas de comercios o industrias situadas en el área urbana. Véase también aguas negras.

agua residual recolectada: todos los efluentes provenientes de propiedades y otras fuentes de producción de aguas residuales (como industrias) 
transportadas por la red de alcantarillado en tiempo seco (se excluye en tiempo de lluvia).

agua residual reutilizada: agua residual que es utilizada sin ser primero vertida al medio acuático receptor.

agua residual tratada en la EDAR: agua residual que ha recibido tratamiento primario, secundario o terciario para reducir su contaminación o los peligros para la salud, y que posteriormente se vierten como efluente de una EDAR después de su tratamiento (Horton, 2000).

aguas negras: aguas contaminadas por el uso procedentes de propiedades domésticas: cocinas, lavaderos, lavabos, baños, inodoros e instalaciones similares (adaptado de EN 752-1, 1995). También se consideran aguas negras las aguas procedentes de instalaciones médicas como hospitales. Puede incluir sólidos de gran tamaño que son depositados en inodoros u otras entradas. También se conocen como aguas residuales domésticas o aguas cloacales.

aguas pluviales: (1) agua resultante de las precipitaciones que percola en el suelo, se desplaza por la superficie o es recogida por un sistema de alcantarillado de aguas pluviales o de aguas residuales combinado y, de forma limitada, en sistemas de alcantarillado de aguas negras. (2) agua que se encuentra en la superficie procedente de la lluvia, la nieve o del deshielo y se convierte en escorrentía hasta un área de drenaje. A menudo se recoge en sistemas de alcantarillado unitario para aguas pluviales, y típicamente recibe un tratamiento mínimo antes de su descarga en el medio acuático receptor (James, 1996).

aguas residuales domésticas: Véase aguas negras.

alcantarillado: tubería u otra construcción, generalmente subterránea, diseñada para transportar aguas residuales o pluviales de más de una fuente.

alcantarillado en alta: colector de grandes dimensiones que, en un sistema combinado, transporta el caudal de aguas residuales a la estación depuradora de aguas residuales o a otro punto de descarga. También puede utilizarse en sistemas separativos o combinados para recoger los caudales de los colectores principales y troncales y llevarlos a los puntos de tratamiento (adaptado de EPA, 2003). Los colectores de alcantarillado en alta suelen ser los más grandes y tener pocas conexiones.

alcantarillado simplificado: alcantarillas de pequeño calibre que transportan aguas residuales sin sólidos, generalmente de una fosa séptica o similar.

alcantarillas de pequeño calibre: alcantarillas cuyo diámetro típicamente es hasta $150 \mathrm{~mm}$, utilizadas para transportar aguas residuales. 
alivio: normalmente relacionado con el exceso de caudal descargado desde un sistema de DSU. Los alivios también pueden ocurrir debido al mal funcionamiento de los reguladores de flujo del sistema de alcantarillado. También se conoce como desbordamiento.

alivio de aguas negras: estructuras diseñadas para permitir el desbordamiento de los sistemas de alcantarillado de aguas negras cuando el sistema aguas abajo alcanza su capacidad máxima. Similar a las estructuras de DSU, excepto que se encuentran en las redes de alcantarillado separativas (en los colectores de aguas negras), mientras que los DSU ocurren en sistemas de alcantarillado combinados.

almacenamiento (en línea o en derivación): utilización de una parte del volumen del sistema de alcantarillado de aguas pluviales, de aguas residuales o un colector de alta, que no se está utilizando, para transportar agua residual o pluvial, con el fin de almacenar el volumen adicional. Este término también se aplica a una instalación de almacenamiento, como un tanque, embalse u otro depósito que esté conectado a un sistema de alcantarillado de forma que todo el caudal del sistema pase por la instalación de almacenamiento. En este caso, el almacenamiento en línea se diferencia del almacenamiento en derivación en que este último está conectado de tal manera que el exceso de caudal se puede desviar a la instalación de almacenamiento, pero los caudales normales no pasan por dicha instalación (Ellis, et al., 2003).

atasco: causado por una obstrucción que interfiere con el movimiento de las aguas residuales. La expresión atasco se utiliza principalmente para describir el efecto de una obstrucción no deseada del flujo (parcial o total) en una tubería, canal colector combinado, regulador de desbordamientos o reboses u otro regulador de flujo, desagüe, compuerta, orificio, filtro o cualquier otro lugar en el que circule flujo (Ellis et al., 2003).

calibración: es un conjunto de operaciones que establecen, bajo determinadas condiciones, la relación entre los valores obtenidos mediante un instrumento de medida (o valores representados por una medida material) y los correspondientes valores obtenidos de acuerdo a las normas.

El resultado de una calibración se puede registrar en un documento, p.ej. un certificado de calibración. El resultado se puede expresar como correcciones con respecto a las medidas del instrumento.

La calibración en sí misma no significa necesariamente que un instrumento esté funcionando de acuerdo con su especificación. 
caudal en tiempo seco: Caudal en un sistema de alcantarillado en condiciones de tiempo seco (EN 752 1, 1995). En general, es el caudal que circula por los colectores cuando el periodo de tiempo seco anterior ha sido de al menos 24 horas. Tiene en cuenta tanto el caudal de aguas residuales como el infiltrado dentro del colector en tiempo seco (White et al., 1997). IVEM, 1993 especifica que es el caudal medio durante siete días consecutivos sin lluvias (excluyendo periodos de vacaciones y días festivos) después de siete días durante los cuales la lluvia no excedió los $0,25 \mathrm{~mm}$ en un solo día.

cloacas: Véase sistema de alcantarillado

colapso: fallo crítico de un colector debido a la desintegración estructural del material que lo conforma (NASTT, 2001).

colector troncal: colector al que se conectar al menos dos ramas de colectores (de aguas negras, pluviales o un sistema combinado). Transporta el caudal al sistema de alcantarillado en alta (NAST'T, 2001). Véase también sistema de alcantarillado.

conexión errónea: una conexión a un colector de aguas pluviales, u otro sistema de transporte de aguas pluviales, como un canal abierto, desde un colector de aguas residuales (ya sea de aguas negras o combinado). Una conexión en un colector de aguas negras desde una fuente de aguas pluviales (como, por ejemplo, un colector de aguas pluviales).

control de la fuente: diversos enfoques y técnicas para la gestión y el control local e in situ de la escorrentía de aguas pluviales en el punto de precipitación. Incluye procedimientos de mantenimiento (no estructurales), controles estructurales en el terreno y controles estructurales tanto en el área como en la región (adaptado de Ellis et al., 2003). También puede aplicarse a los sistemas in-situ.

depósito o tanque de almacenamiento: depósito destinado a contener aguas pluviales, aguas residuales, aguas negras o industriales cuando se necesita un almacenamiento temporal del flujo, normalmente cuando el caudal o volumen del agua excede la capacidad del transporte de las tuberías, canales o sistemas o plantas de tratamiento, o cuando el caudal o volumen total vertido en el medio acuático receptor excede la cantidad permitida (Ellis et al., 2003). Véase también almacenamiento (en línea o en derivación).

desbordamiento: Véase alivio.

desbordamiento del sistema de aguas pluviales: Véase Desbordamiento del sistema unitario (DSU). En algunas definiciones, los colectores de aguas pluviales pueden contener únicamente escorrentía o también aguas residuales, como en un DSU (NetRegs, 2003). 
Desbordamiento del Sistema Unitario (DSU): dispositivo instalado en un sistema de alcantarillado combinado o parcialmente separado, o en una planta de tratamiento de agua residual cuya función es aliviar el exceso de caudal (EN752-1, 1995). Las estructuras de DSU pueden ser alivios directamente al medio receptor o incluir o estar asociadas a un tanque de tormenta, también llamado depósito anti-DSU. (Véase también desbordamiento).

descarga intermitente por reboses: desbordamiento o alivio diseñado desde un DSU, para proteger los colectores aguas abajo de un exceso de caudal. Es aplicable estrictamente en tiempo de llwvia en sistemas de alcantarillado unitarios, pero estas descargas pueden ocurrir en tiempo seco debido a una capacidad reducida de los colectores aguas abajo.

dispositivo de desbordamiento de aguas pluviales: estructura que se construye en un sistema de alcantarillado separativo de aguas pluviales para verter en el medio acuático receptor o a un sistema de alivio, aquellos caudales excesitos, que no pueden ser transportados por el sistema (Ellis et al., 2003). Véase también desbordamiento del sistema unitario y alivio de aguas negras.

drenaje: tubería, generalmente subterránea, diseñada para transportar aguas residuales y/o aguas superficiales desde una fuente hasta una alcantarilla u otro punto de descarga

eliminación de lodos: proceso por el cual los lodos se recogen de una planta de tratamiento y se tratan en otro lugar, ya sea mediante un tratamiento adicional en otro lugar, el esparcimiento en el terreno, la incineración, el vertido, etc. En algunos países esto puede suponer el vertido en el mar. emisario submarino: lugar en la costa o mar adentro, donde se descargan aguas residuales, aguas residuales parcialmente tratadas o aguas residuales tratadas, y donde hay movimientos de agua debido a las mareas.

en carga: condición en la que las aguas residuales se encuentran a presión dentro de un sistema de alcantarillado diseñado para funcionar por gravedad, pero no llegan a salir a la superficie ni causan inundaciones (adaptado de EN 752-1, 1995).

entrada: ingreso de agua superficial directamente al sistema de alcantarillado (White et al., 1997). En los EE.UU. el agua de lluvia no está destinada a ser transportada por la red de alcantarillado de aguas negras, ya que el sistema es separativo.

escorrentia: Agua procedente de la lluvia que fluye por una superficie para llegar a un sistema de drenaje, alcantarillado o al medio acuático receptor (EN 752-1, 1995). estabilización de lodos: proceso que generalmente contempla la digestión anaeróbica de lodos, un tratamiento que estabiliza los lodos sin procesar. 
Los lodos totalmente digeridos tienen poca materia orgánica fácilmente biodegradable. No tiene olor y alrededor del 50\% de los sólidos son inorgánicos. Los lodos también pueden ser digeridos aeróbicamente (EPA, 2003).

estación: estación de bombeo, plantas de tratamiento y otros puntos de control y monitorización de los sistemas de aguas residuales (adaptado de Alegre et al., 2000).

estación de bombeo: edificio, estructuras y equipos utilizados para impulsar aguas residuales a presión para elevarlas a una cota superior o aumentar su altura piezométrica (adaptado de EN 752-7, 1995).

estación depuradora de aguas residuales (EDAR): serie de procesos de tratamiento, incluyendo, entre otros, uno o más de los siguientes procesos: desarenado, tamizado, sedimentación, coagulación-floculación, biooxidación, biofiltración, adsorción de carbono y desinfección, mediante los cuales se transforman y eliminan los contaminantes de las aguas residuales. Los niveles de tratamiento pueden clasificarse como pretratamiento, tratamiento primario, secundario y terciario, dependiendo del grado de procesamiento. El tratamiento de las aguas residuales es la eliminación de los contaminantes o las sustancias contaminantes de éstas (incluyendo las aguas negras, combinadas y pluviales) para la protección de la salud pública y el medio ambiente (adaptado de Ellis et al., 2003). A menudo de abrevia como EDAR.

exfiltración: fuga de aguas residuales hacia el suelo circundante en acometidas o en un sistema de alcantarillado (EN752-1, 1995). La fuga hacia abajo o hacia afuera de escorrentía hacia las capas de suelo subyacentes o envolventes, a través de la periferia de un colector o dispositivo de infiltración. El término también se utiliza para referirse al rebose de la escorrentía desde un canal elevado con un caudal marginal hacia un área de almacenamiento adyacente, como en el diseño de una cuenca de infiltración. Fuga o descarga de los caudales transportados por la red de alcantarillado hacia el suelo a través de fugas en los colectores, juntas, pozos de registro u otras estructuras del sistema de alcantarillado (NASTT, 2001).

\section{fango: véase lodo.}

filtro: rejilla metálica (normalmente de acero) destinada a capturar los sólidos gruesos, materia de tamaño grueso, desechos y escombros de las aguas pluviales y las aguas residuales antes de su descarga en el medio acuático receptor, estructura de DSU o en la entrada de la EDAR. Su funcionamiento puede ser mecánico o estático (adaptado de Ellis et al., 2003). 
fosa séptica: tipo de tanque de sedimentación destinado a proporcionar condiciones de reposo para la sedimentación de lodos y el desarrollo de condiciones anaeróbicas para la descomposición de la materia orgánica. Las aguas residuales sin tratar se descargan en el tanque y las aguas residuales ya sedimentadas se devuelven al terreno mediante un sistema de drenaje tras la salida del tanque. El lodo se acumula en el fondo del tanque y debe ser retirado periódicamente Un sistema de fosa séptica consiste en el propio tanque y, si descarga en el terreno, en un campo de drenaje (Payne et al., 1993). Véase también sistema in-situ.

imbornal: cámara diseñada para captar aguas pluviales lavadas de una calzada $\mathrm{u}$ otra superficie pavimentada. Generalmente, situada al lado de la carretera y diseñada para atrapar la arena y otros sólidos antes de su entrada en la red de alcantarillado (Ellis et al., 2003).

impulsión: tubería a través de la cual se bombea agua residual (EN 752-1, 1995).

infiltración: ingreso de aguas subterráneas en el sistema de alcantarillado (EN 7521, 1995).

inspección: implementación de un procedimiento formal, por regla general escrito, cuyos resultados se registran posteriormente de una forma que permite al prestador evaluar la capacidad de servicio de los activos y adoptar las medidas correctivas oportunas (alegre et al., 2000).

interrupción del servicio: suspensión del servicio ya sea planificada, no planificada (incluso se si ha notificado), o no notificada a los clientes, con una duración medida desde el inicio de la suspensión hasta el pleno restablecimiento del servicio. Puede estar causada por roturas, colapsos, paradas o fallos en el sistema de alcantarillado, mantenimiento planificado, construcción, reparaciones o renovaciones, o cualquier otra causa. Incluye las interrupciones planificadas incluso cuando se notifican previamente a los clientes (adaptado de Alegre et al., 2000).

inundación: condición en la que las aguas negras, otras aguas residuales y/o aguas superficiales se salen o no pueden entrar en un sistema de alcantarillado. De este modo, permanecen en la superficie o entran en los edificios (adaptado de EN 752-1, 1995). Véase también inundación de la superficie.

inundación de aguas negras: inundación producida por cualquier caudal desde un sistema separativo de alcantarillado de aguas negras.

inundación superficial: condición en la que las aguas residuales y/o el agua de superficie se salen o no pueden entrar en un sistema de alcantarillado y se encuentran en la superficie o entran en los edificios desde la superficie (EN 752-1, 1995). Véase también inundación. 
limpieza: se trata de una serie de técnicas que incluyen limpiar con agua, excavación manual, esponjas, aire a presión e inyectar presión con la intención de eliminar los depósitos sueltos o blandos que se encuentran en los colectores, y otras áreas de almacenamiento, como los pozos de aspiración de las estaciones de bombeo. Limpieza significa la aplicación de un procedimiento formal, por regla general escrito, cuyos resultados se registran posteriormente. (Alegre et al., 2014).

lodo: residuo semisólido producido en varios procesos de tratamiento de aguas residuales. Muchos tipos de lodos están clasificados como residuos peligrosos y deben ser eliminados en un sitio designado (Ellis et al., 2003). Los lodos no incluyen las arenas y los sedimentos recogidos durante el tratamiento preliminar de aguas residuales domésticas en las plantas de tratamiento (EPA, 2003). También conocido como fango.

medio acuático receptor: cualquier cuerpo de agua como el mar, río, arroyo o lago, así como un acuífero en el que se vierten las aguas residuales (EN 752-7, 1995). Cuerpo de agua superficial o subterránea que proporciona una capacidad de dilución suficiente para verter los contaminantes directamente. Ejemplos de medio acuático receptor superficial, ya sean aguas corrientes o estacionarias, son los ríos, arroyos, lagos, lagunas, o aguas de marea, como los estuarios o el mar (véase también emisario submarino). La distribución, dispersión y asimilación espacial y temporal de los contaminantes dentro de los medios acuáticos receptores es fundamental para determinar su impacto resultante (Ellis et al., 2003).

mejores prácticas de control de aguas residuales: medidas estructurales utilizadas para almacenar o tratar la escorrentía de aguas pluviales urbanas con el fin de reducir las inundaciones, reducir los contaminantes y proporcionar otros servicios. Algunos ejemplos son instalaciones de detención o retención de aguas pluviales, instalaciones de infiltración, humedales, franjas de vegetación, filtros verdes (Véase también control de fuente) (Ellis et al., 2003).

partes interesadas: cualquier grupo o individuo que puede afectar o es afectado por el cumplimiento de los objetivos de una organización. Ejemplos de partes interesadas son los empleados, los clientes, los proveedores, las comunidades, los individuos e incluso los competidores (atribuido a Edward Freeman, 1984 en Andriof et al., 2002).

prestador del servicio de saneamiento: prestador de los servicios que opera y gestiona el sistema de aguas residuales en cuestión.

pretratamiento: tratamiento de las aguas residuales antes de su descarga en los sistemas de recogida municipal (Metcalf, 1991). 
propiedad: vivienda, otro edificio o parte de un edificio utilizada como vivienda, lugar de trabajo o recreación, por propietarios, inquilino o visitantes (si la propiedad se visita con cualquier propósito). En bloques de apartamentos, es cada vivienda separada, en propiedades comerciales, es el espacio utilizado por una empresa individual (Alegre et al., 2000).

queja: cualquier queja del usuario expresada a los servicios, ya sea personalmente (verbal o escrita), por teléfono, fax, correo, correo electrónico o cualquier otro formato escrito (Alegre et al., 2000).

refuerzo: construcción de una instalación adicional que complementa la capacidad de una existente o que ofrece una alternativa a ella (WRC, 2001).

regulador de flujo (dinámico/estático): dispositivo de control de flujo que se utiliza para regular el flujo hacia o desde una estructura o sistema. Los tipos de regulador pueden clasificarse como estáticos o dinámicos. Cada tipo de regulador de flujo tiene una relación característica (no lineal) entre la altura (nivel del agua) y la descarga regulada por el flujo (salida). Esta relación es una función de las condiciones de flujo aguas arriba y aguas abajo del dispositivo de control y de si el regulador funciona con una descarga libre o en condiciones de inmersión (Ellis et al., 2003).

rehabilitación: cualquier intervención física que prolongue la vida del sistema y/o mejore su desempeño estructural o hidráulico e implica el cambio de su condición o especificación (EN 752-1, 1995).

La rehabilitación estructural incluye la sustitución, renovación y restauración. La rehabilitación hidráulica incluye la sustitución, el refuerzo, la reducción o atenuación de caudal y, ocasionalmente, la renovación (WRc, 2001).

remodelación: todos los métodos para restaurar los activos existentes con el fin de lograr el desempeño necesario (Alegre et al., 2000). Véase también rehabilitación.

renovación: construcción de un nuevo colector, en el mismo lugar o no que el existente, siendo la función y capacidad del nuevo colector similares a las del antiguo (WRc, 2001).

reparación: rectificación de daños locales (EN 752-5, 1997). Comprende la rectificación de daños estructurales de corta longitud, pero no la reconstrucción del conducto completo (WRc, 2001).

restauración: intervención que mantiene todo o parte del colector original mediante el cual se mejora su desempeño actual (EN 752-5, 1997).

revestimiento: eliminación de todos los depósitos del interior de una tubería existente, seguida de la aplicación in situ de un revestimiento no estructural para proporcionar protección contra la corrosión, como el cemento o el mortero epoxi (el revestimiento se denomina a veces 
raspado y revestimiento, renovación o reacondicionamiento). El revestimiento es una forma particular de restauración (Alegre et al., 2000). sedimento: material sólido que es transportado desde la superficie, propiedades, industria, en el agua infiltrada u otras fuentes, se transporta en el caudal de agua residual o pluvial circulante y se acumula en zonas de los colectores o elementos auxiliares en las que el agua circula a baja velocidad.

sistema de alcantarillado: red de colectores o tuberías y accesorios complementarios que transportan aguas negras y/o pluviales desde los drenajes hasta las plantas de tratamiento u otros lugares de vertido (adaptado de EN 7521, 1995). Incluye las alcantarillas en alta.

sistema de alcantarillado combinado o sistema unitario: Sistema de alcantarillado diseñado para transportar en las mismas conducciones tanto aguas negras como aguas pluviales (EN 752-1, 1995).

sistema de alcantarillado de aguas negras: sistema de alcantarillado diseñado para transportar únicamente aguas negras, generalmente a las plantas de tratamiento de aguas residuales. La capacidad de estos sistemas está diseñada en función de las aportaciones de los usuarios al sistema, sin tener en cuenta las aguas pluviales (salvo la entrada e infiltración). Los caudales circulantes por dichos colectores suelen incluir tanto caudales de aguas de entrada e infiltración. Estos sistemas también se conocen como sistemas de alcantarillado de aguas residuales domésticas.

sistema de alcantarillado de aguas residuales domésticas: Véase sistema de alcantarillado de aguas negras.

sistema de alcantarillado separativo: sistema de alcantarillado compuesto normalmente por dos redes de colectores. Una transporta aguas negras y la otra aguas pluviales provenientes de la superficie (adaptado de EN 7521, 1995).

sistema in-situ: sistema por el cual todos los desechos y aguas residuales producidas se gestionan localmente en un lugar cercano al punto de origen, mediante fosas sépticas, pozos de absorción, letrinas, lechos de evaporación, cañaverales, etc. Los residuos pueden utilizarse posteriormente directamente como fertilizantes y/o en procesos de recuperación de energía. La materia sólida puede ser transportada a otro lugar y los efluentes líquidos pueden descargarse en el sistema de alcantarillado principal. El término incluye tanto los sistemas húmedos como secos.

sistema urbano de drenaje sostenible (SUDS): prácticas de gestión y estructuras de control diseñadas para drenar las aguas superficiales de manera más sostenible que las técnicas tradicionales (CIRIA, 2003). 
sustitución: construcción de un nuevo colector, en el mismo lugar o no que el existente, siendo su función similar a la del antiguo (EN 752-5, 1997). La renovación es un caso particular de sustitución cuando se mantiene también su capacidad. En la práctica esto suele significar que es del mismo diámetro nominal (para tuberías), potencia (para sistemas de bombeo), etc. (adaptado de Alegre et al., 2000).

tiempo de lluvia: periodo en el que hay lluvias. Normalmente se refiere a aquellas lluvias que producen escorrentía. Véase también tiempo seco.

tiempo seco: periodo durante el cual no ha habido lluvias en la cuenca.

tratamiento adecuado: tratamiento de las aguas residuales municipales mediante cualquier proceso y/o sistema de eliminación o desechado que se considere adecuado para un objetivo específico.

tratamiento de lodos: procesado de lodos de aguas residuales para hacerlos inocuos. Esto puede hacerse mediante digestión aeróbica o anaeróbica seguida de secado en lechos de secado, filtrado e incineración, filtrado y secado, u oxidación del aire húmedo (EPA, 2003).

tratamiento preliminar: proceso del tratamiento de las aguas residuales que suele comprender de un desarenado y un tamizado fino con el fin de eliminar la arena, grasas y materia flotante de tamaño grueso (Ellis et al., 2003).

tratamiento primario: tratamiento de las aguas residuales que utiliza la sedimentación, desespumado y la cloración (opcional) para eliminar los sólidos en suspensión, flotantes y los patógenos de las aguas residuales (negras, combinadas, pluviales e industriales). El tratamiento primario normalmente elimina sobre el 35\% y el 65\% de la demanda biológica de oxígeno (DBO5) y sólidos en suspensión, respectivamente. Para eliminar un mayor porcentaje de sólidos en suspensión, se agregan productos químicos (coagulantes y floculantes) en una cámara de coagulación y luego el agua residual es floculada en otra cámara, antes de los tanques de sedimentación (adaptado de Ellis et al., 2003).

tratamiento secundario: paso en el tratamiento del agua residual para eliminar las partículas finas, coloidales y orgánicas disueltas (e inorgánicas) mediante el uso de procesos biológicos, incluidos el lecho bacteriano y fangos activos. Recientemente, se está utilizando un sistema secuencial que proporciona entornos aeróbicos, anóxicos y anaeróbicos en lugar del proceso convencional de aireación de fangos activos para transformar de forma biológica y efectiva contaminantes tóxicos orgánicos en componentes menos o nada tóxicos. El líquido mezclado fluye desde el tanque de aireación hasta el tanque de sedimentación secundario para eliminar los sólidos en suspensión de la mezcla. En varios países la 
desinfección del efluente antes de su descarga en el medio acuático receptor completa el tratamiento secundario (adaptado de Ellis et al., 2003).

tratamiento terciario: tratamiento avanzado de aguas residuales que va más allá del proceso de tratamiento biológico que se lleva a cabo en el secundario. Elimina un alto porcentaje de sólidos suspendidos $(>95 \%)$, demanda biológica de oxígeno conocida como DBO5 (>90\%) y nutrientes como el fósforo y el nitrógeno. Los procesos terciarios incluyen, entre otros, los siguientes: nitrificación y desnitrificación, filtración con arena y carbón activo, y desinfección (Ellis et al., 2003).

utilización de lodos: reutilización de los lodos de aguas residuales generalmente después de algún proceso de acondicionamiento, estabilización o tratamiento. Véase también eliminación de lodos.

vivienda: casa, piso o apartamento, donde vive una persona (Oxford, 2002).

\section{Definiciones relacionadas con la población}

otra población equivalente: parte de la población equivalente en el área que está relacionada con las aguas residuales producidas por otras fuentes que no son residenciales, comerciales, industriales ni de servicios.

población: número de habitantes de un área de asentamiento que residen normalmente en dicha área (se excluyen los residentes de segundas viviendas).

población equivalente (p.e.): expresión cuantitativa de la carga de contaminación de las aguas residuales comerciales o industriales en términos del número de personas "equivalentes" que crearían un residuo de la misma fuerza. 1 p.e. corresponde a la carga de contaminación de las aguas residuales generadas por un habitante. Normalmente corresponde a las cargas de $\mathrm{DBO}_{5}$, pero también puede ser estimada a partir de los sólidos suspendidos totales (SST), demanda química de oxigeno (DQO) $\mathrm{u}$ otros valores per cápita. En este documento, 1 p.e. $=60 \mathrm{~g}$ de equivalencia de $\mathrm{DBO}_{5} /$ día se utiliza por defecto al evaluar las variables, los indicadores de desempeño y la información de contexto, excepto en los casos en que se definan explícitamente otras equivalencias.

población equivalente comercial: parte de la población equivalente en el área que está relacionada con las aguas residuales producidas por el comercio y los restaurantes que operan en el área que es responsabilidad del servicio de saneamiento.

población equivalente con sistemas de tratamiento de aguas residuales satisfactorios: población equivalente que es servida por estaciones depuradoras de aguas residuales que cumplen con los requisitos de vertido establecidos. 
población equivalente de agua importada: población equivalente a todas las aguas residuales importadas, que comprende las aguas residuales producidas por cualquier fuente (población, industria, comercio, servicios y otros) situada fuera del área de responsabilidad del servicio de saneamiento.

población equivalente de servicios: parte de la población equivalente en el área que está relacionada con las aguas residuales producidas por servicios como oficinas, hospitales, escuelas y otros servicios disponibles en el área que es responsabilidad del servicio de saneamiento.

población equivalente en el área: población equivalente a todas las aguas residuales producidas en la zona geográfica de la que es responsable el prestador del servicio de saneamiento y para la que debe prestar un servicio de recogida y/o tratamiento. No se contabilizarán las aguas residuales que sean tratadas por otras soluciones autónomas (como las estaciones privadas de tratamiento de aguas residuales en las industrias y soluciones in-situ, por ejemplo, las fosas sépticas existentes en zonas aisladas).

población equivalente estacional: parte de la población equivalente en el área relacionada con la producción de aguas residuales durante sólo una parte del periodo, por ejemplo, una población estacional o una industria con una actividad estacional. Corresponde a la siguiente suma: población estacional (número de personas x duración de la estancia/ periodo de evaluación) + industrias estacionales (p.e. x duración de la actividad /periodo de evaluación).

población equivalente industrial: parte de la población equivalente en el área que está relacionada con las aguas residuales producidas por las industrias que trabajan en el área que es responsabilidad del servicio de saneamiento, excluyendo aquellas con estaciones depuradoras autónomas que descargan sus aguas residuales tratadas directamente al medio receptor.

población equivalente no servida en el área: parte de la población equivalente en el área cuyas aguas residuales no son recogidas ni tratadas en instalaciones que son responsabilidad del servicio de saneamiento. No incluye las aguas residuales tratadas por sistemas in-situ ni locales (como las estaciones depuradoras de aguas residuales privadas de las industrias o las fosas sépticas en las zonas aisladas) que no son responsabilidad del servicio de saneamiento.

población equivalente servida en el área: parte de la población equivalente en el área en el área que es atendida por instalaciones de recogida o tratamiento gestionadas por el servicio de saneamiento.

población equivalente servida por ED AR: parte de la población equivalente en el área y la porción de la población equivalente de agua importada para la que se 
tratan las aguas residuales en las estaciones depuradoras de aguas residuales (EDAR) que son responsabilidad del servicio de saneamiento.

población equivalente servida por el servicio de saneamiento: parte de la población equivalente en el área cuyas aguas residuales son recogidas o tratadas mediante instalaciones que son responsabilidad del servicio de saneamiento, así como la población equivalente de agua importada.

población equivalente servida por el sistema de alcantarillado y el sistema de alcantarillado en alta: parte de la población equivalente en el área y la porción de la población equivalente de agua importada para la que se recogen las aguas residuales mediante los sistemas de alcantarillado y el alcantarillado en alta que son responsabilidad del servicio de saneamiento.

población equivalente servida por servicios in-situ: parte de la población equivalente en el área cuyas aguas residuales son tratadas por sistemas in-situ (como fosas sépticas o letrinas). Algunos de estos sistemas proporcionan soluciones de tratamiento de aguas residuales de acuerdo a los criterios de desempeño, mientras que otros pueden no satisfacerlos. Aunque los vertidos de las instalaciones de tratamiento de aguas residuales in-situ pueden entrar en la red de alcantarillado, alcantarillado en alta o en $E D A R$, esto no se considera una buena práctica. Sin embargo, como puede ocurrir, está representado en el esquema de la Figura 14 por flechas punteadas.

población punta: números máximos en la población residente y no residente en el área que es responsabilidad del servicio de saneamiento.

población residente: parte de la población equivalente en el área relacionada con la población que vive permanentemente en la zona que es responsabilidad del servicio de saneamiento. 



\section{INDICADORES DE DESEMPEÑO}

\subsection{Introducción}

Este capítulo contiene la definición detallada de los indicadores de desempeño de la IWA para los servicios de saneamiento. Cada prestador seleccionará exclusivamente el subconjunto pertinente para su caso específico y objetivos, de acuerdo con el procedimiento de implementación recomendado en I-6.

Si el prestador del servicio es responsable de otras actividades productivas más allá de la recogida de aguas residuales y su tratamiento, sólo se considerará el componente básico del suministro de agua para la evaluación de los indicadores.

El sistema de ID de la IWA tiene como objetivo ser utilizado anualmente, por lo que se recomienda encarecidamente que el año se utilice como período de evaluación de referencia. Sin embargo, dado que los prestadores pueden necesitar monitorizar la evolución de su desempeño a lo largo del año, el sistema de ID está preparado para acomodar otros períodos de evaluación para la mayoría de los indicadores. En este caso, y para asegurar la coherencia de las unidades y permitir la comparación de indicadores, todos los ID expresados en términos de tiempo se formulan de tal manera que los valores calculados para otros períodos de evaluación se convierten en valores anuales.

Se debe tener en cuenta que el comportamiento de la mayoría de las variables no es uniforme durante el año, debido a efectos aleatorios o estacionales o a la planificación de actividades. Todas las comparaciones basadas en ID evaluadas a partir de datos no anuales deben tener en cuenta este hecho, a fin de evitar sesgos.

La sección II-2.2 contiene una lista de referencia rápida de los indicadores. Las secciones II-2.3 hasta II-2.8 contienen toda la información detallada. 


\subsection{Listado de referencia rápida de los ID de la IWA}

\begin{tabular}{|c|c|}
\hline \multicolumn{2}{|c|}{ Indicadores medioambientales (página II-172) } \\
\hline \multicolumn{2}{|c|}{ Aguas residuales (página II-172) } \\
\hline wEn1 - & $\begin{array}{l}\text { Cumplimiento de la EDAR con los requisitos de vertido } \\
(\% / \text { año })\end{array}$ \\
\hline wEn2 - & Reutilización de aguas residuales $(\%)$ \\
\hline wEn3 - & $\begin{array}{l}\text { Frecuencia de descargas intermitentes por reboses } \\
\text { (No./dispositivo de desbordamiento/año) }\end{array}$ \\
\hline wEn4 - & $\begin{array}{l}\begin{array}{l}\text { Volumen de descargas intermitentes por reboses } \\
\left(\mathrm{m}^{3} / \text { dispositivo de desbordamiento/año) }\right.\end{array} \\
\end{array}$ \\
\hline wEn5 - & $\begin{array}{l}\text { Ratio entre el volumen de las descargas intermitentes por } \\
\text { reboses y el volumen de lluvia ( } \% / \text { año) }\end{array}$ \\
\hline \multicolumn{2}{|c|}{ Residuos sólidos (página II-175) } \\
\hline wEn6 - & Producción de lodos en la EDAR (kg DS/p.e./año) \\
\hline wEn7 - & Utilización de lodos $(\%)$ \\
\hline \multirow[t]{4}{*}{ wEn8 - } & Desecho de lodos $(\%)$ \\
\hline & wEn9 -Lodos destinados a vertedero (\%) \\
\hline & wEn10 Lodos procesados térmicamente (\%) \\
\hline & wEn11 -Otro tipo de disposición de lodos (\%) \\
\hline wEn12 - & Sedimentos de colectores (ton/km colector/año) \\
\hline wEn13 - & Sedimentos de elementos auxiliares (ton/km colector/año) \\
\hline wEn14 - & Sedimentos de filtros (ton $/ \mathrm{km}$ colector/ año) \\
\hline wEn15- & Sedimentos de sistemas in-situ (ton/p.e./año) \\
\hline
\end{tabular}

\begin{tabular}{|l|l|}
\hline \multicolumn{2}{|l|}{ Indicadores de personal (página II-179) } \\
\hline Personal total (página II-180) \\
\hline wPe1 - & $\begin{array}{l}\text { Personal en tratamiento de aguas residuales por población } \\
\text { equivalente (No./ } 1000 \text { p.e.) }\end{array}$ \\
\hline wPe2 - & $\begin{array}{l}\text { Personal de la red de alcantarillado por longitud (No./100 } \\
\text { km red) }\end{array}$ \\
\hline Personal por función principal (página II-181) \\
\hline wPe3 - & Personal de administración general (\%) \\
\hline wPe4 - & $\begin{array}{l}\text { Personal encargado de la gestión de los recursos humanos } \\
(\%)\end{array}$ \\
\hline wPe5 - & Personal de finanzas y comercial (\%) \\
\hline wPe6 - & Personal de atención al cliente (\%) \\
\hline
\end{tabular}




\begin{tabular}{|c|c|}
\hline \multicolumn{2}{|c|}{ Indicadores de personal (página II-179) } \\
\hline \multirow[t]{3}{*}{ wPe -7} & Personal de servicios técnicos (\%) \\
\hline & wPe8 -Personal de planificación, diseño y construcción (\%) \\
\hline & wPe9 -Personal de operaciones y mantenimiento (\%) \\
\hline \multicolumn{2}{|c|}{ Personal de servicios técnicos por actividad (página II-183) } \\
\hline wPe10 - & $\begin{array}{l}\text { Personal técnico de tratamiento de aguas residuales } \\
\text { (No. } / 1000 \text { p.e.) }\end{array}$ \\
\hline wPe11 - & $\begin{array}{l}\text { Personal técnico del sistema de alcantarillado (No./100 km } \\
\text { colector) }\end{array}$ \\
\hline wPe12 - & $\begin{array}{l}\text { Personal de monitorización de la calidad del agua residual } \\
\text { (No./ (1000 ensayos/año)) }\end{array}$ \\
\hline wPe13 - & Personal de servicios de apoyo (\%) \\
\hline wPe14 - & Personal con titulación universitaria (\%) \\
\hline \multicolumn{2}{|c|}{ Cualificación del personal (página II-185) } \\
\hline wPe15 - & Personal con educación básica (\%) \\
\hline wPe16 - & Personal con otra cualificación (\%) \\
\hline \multicolumn{2}{|c|}{ Formación de personal (página II-186) } \\
\hline wPe17 - & Formación total del personal (horas/empleado/año) \\
\hline \multicolumn{2}{|c|}{ Seguridad y salud del personal (página II-187) } \\
\hline wPe18 - & Vacunación (\%) \\
\hline wPe19 - & Formación autorizada en espacios confinados (\%) \\
\hline \multirow[t]{2}{*}{ wPe20 - } & Accidentes laborales (No./100 empleados/año) \\
\hline & $\begin{array}{l}\text { wPe21 -Víctimas de incidentes fatales en el trabajo (No./100 } \\
\text { empleados/año) }\end{array}$ \\
\hline \multicolumn{2}{|c|}{ Absentismo (página II-188) } \\
\hline \multirow[t]{3}{*}{ wPe22 - } & Absentismo (días/100 empleados/año) \\
\hline & $\begin{array}{l}\text { wPe23 -Absentismo debido a accedentes o enfermedades } \\
\text { laborales (días } / 100 \text { empleados/año) }\end{array}$ \\
\hline & $\begin{array}{l}\text { wPe24 -Absentismo debido a otros motivos (días/100 } \\
\text { empleados/año) }\end{array}$ \\
\hline \multicolumn{2}{|c|}{ Horas extraordinarias (página II-190) } \\
\hline wPe25 - & Horas extraordinarias $(\%)$ \\
\hline
\end{tabular}

\section{Indicadores físicos (página II-190)}

Tratamiento de aguas residuales (página II-190)

\begin{tabular}{|l|l|}
\hline wPh1 - & Utilización de pretratamientos $(\%)$ \\
\hline wPh2 - & Utilización de tratamientos primarios $(\%)$ \\
\hline
\end{tabular}


Indicadores físicos (página II-190)

\begin{tabular}{|l|l}
\hline wPh3 - & Utilización de tratamientos secundarios (\%) \\
\hline wPh4 - & Utilización de tratamientos terciarios (\%) \\
\hline
\end{tabular}

Colectores (página II-192)

wPh5 - Entrada en carga de colectores por gravedad en tiempo seco \begin{tabular}{|l|l|} 
wPh5 - & $(\%)$ \\
\hline
\end{tabular}

wPh6 - Entrada en carga de colectores por gravedad en tiempo de \begin{tabular}{|l|l|}
\hline wPh7 - & Entrada en niveles de carga elevados en colectores (\%) \\
\hline
\end{tabular}

Bombeo (página II-194)

wPh8 - $\quad$ Energía de bombeo utilizada en la red de alcantarillado (\%)

\begin{tabular}{l|l} 
wPh9 - & Energía de bombeo utilizada en la EDAR (\%)
\end{tabular}

wPh10 - $\quad$ Altura de bombeo en la red de alcantarillado (\%)

Automatización y control (página II-195)

wPh11 - $\quad$ Grado de automatización (\%)

wPh12 - Grado de control remoto (\%)

\section{Indicadores operacionales (página II-196)}

Inspección y mantenimiento de colectores (página II-196)

\begin{tabular}{|l|l|}
\hline wOp1 - & Inspección de colectores (\%/año) \\
\hline
\end{tabular}

wOp2 - Limpieza de colectores (\%/año)

wOp3 - $\quad$ Inspección de pozos de registro (-/año)

wOp4 - Inspección de imbornales (-/año)

wOp5 - Limpieza de imbornales (-/año)

Inspección y mantenimiento de depósitos de retención y DSUs (página II-200)

\begin{tabular}{|l|l|}
\hline & Frecuencia de inspección de depósitos de retención y tanques
\end{tabular}

wOp6 - de tormenta (No./depósitos de retención y tanques de tormenta /año)

wOp7 - Volumen inspeccionado de depósitos de retención y tanques \begin{tabular}{|l|l} 
wOp7 - & de tormenta (-/año) \\
\hline
\end{tabular}

wOp8 - Limpieza de depósitos de retención y tanques de tormenta

\begin{tabular}{l|l} 
wOp9 - & Inspección de filtros (-/año) \\
\hline
\end{tabular}

Inspección de bombas y estaciones de bombeo (página II-203)

wOp10 - Frecuencia de inspección de estaciones de bombeo (-/año)

wOp11 - Inspección de bombas por potencia (-/año) 


\begin{tabular}{|c|c|}
\hline \multicolumn{2}{|c|}{ Indicadores operacionales (página II-196) } \\
\hline \multicolumn{2}{|c|}{ Calibración de equipos (página II-204) } \\
\hline wOp12 - & Calibración de caudalímetros en la red de alcantarillado (-/año) \\
\hline wOp13 - & Calibración de caudalímetros en la EDAR (-/año) \\
\hline wOp14 - & $\begin{array}{l}\text { Calibración de equipos de monitorización de la calidad del } \\
\text { agua residual (-/año) }\end{array}$ \\
\hline \multicolumn{2}{|c|}{$\begin{array}{l}\text { Inspección de equipos eléctricos y de transmisión de señales (página II- } \\
\text { 205) }\end{array}$} \\
\hline wOp15 - & Inspección de los sistemas eléctricos de emergencia (-/año) \\
\hline wOp16 - & Inspección de equipos de transmisión de señales (-/año) \\
\hline wOp17 - & Inspección de equipos eléctricos (-/año) \\
\hline wOp18 - & $\begin{array}{l}\text { Consumo de energía en el tratamiento de aguas residuales } \\
(\mathrm{kWh} / \mathrm{p} . \mathrm{e} \text { /año) }\end{array}$ \\
\hline \multicolumn{2}{|c|}{ Consumo de energía (página II-207) } \\
\hline wOp19 - & $\begin{array}{l}\text { Recuperación de energía en el tratamiento de aguas residuales } \\
\text { través de procesos de cogeneración }(\%)\end{array}$ \\
\hline wOp20 - & Consumo de energía estándar $\left(\mathrm{kWh} / \mathrm{m}^{3} / \mathrm{m}\right)$ \\
\hline \multicolumn{2}{|c|}{ Rehabilitación de colectores (página II-208) } \\
\hline \multirow[t]{4}{*}{ wOp21 - } & Rehabilitación de colectores (\%/año) \\
\hline & wOp22 -Restauración de colectores (\%/año) \\
\hline & wOp23 -Sustitución de colectores (\%/año) \\
\hline & $\begin{array}{l}\text { wOp24 -Reparación de colectores y juntas (No./ } 100 \mathrm{~km} \\
\mathrm{red/año)}\end{array}$ \\
\hline wOp25 - & $\begin{array}{l}\text { Sustitución, renovación o rehabilitación de pozos de registro } \\
(\% / a n ̃ o)\end{array}$ \\
\hline wOp26 - & Sustitución de tapas de pozos de registro (\%/año) \\
\hline wOp27 - & Rehabilitación de acometidas (\%/año) \\
\hline \multicolumn{2}{|c|}{ Rehabilitación de bombas (página II-212) } \\
\hline wOp28 - & Rehabilitación de bombas (\%/año) \\
\hline wOp29 - & Sustitución de bombas (\%/año) \\
\hline \multicolumn{2}{|c|}{ Entrada / Infiltración / Exfiltración (E/I/E) (página II-213) } \\
\hline wOp30 - & Entrada / Infiltración / Exfiltración (E/I/E) (\%) \\
\hline wOp31 - & Entrada $\left(\mathrm{m}^{3} / \mathrm{km} / \mathrm{año}\right)$ \\
\hline wOp32 - & Infiltración $\left(\mathrm{m}^{3} / \mathrm{km} /\right.$ año $)$ \\
\hline wOp33 - & Exfiltración (m m³ $/ \mathrm{km} /$ año) \\
\hline \multicolumn{2}{|c|}{ Averías (página II-215) } \\
\hline wOp34 - & Atascos de colectores (No./100 km red/año) \\
\hline
\end{tabular}


Indicadores operacionales (página II-196)

\begin{tabular}{|l|l|}
\hline & $\begin{array}{l}\text { wOp35 -Puntos de atasco de colectores (No./100 km } \\
\text { red/año) }\end{array}$ \\
\hline wOp36 - & $\begin{array}{l}\text { Atascos en estaciones de bombeo (No./estación de } \\
\text { bombeo/año) }\end{array}$ \\
\hline wOp37 - & $\begin{array}{l}\text { Inundaciones de colectores de aguas negras (No./100 km } \\
\text { red/año) }\end{array}$ \\
\hline wOp38 - & Inundaciones de colectores unitarios (No./100 km red/año) \\
\hline wOp39 - & Inundaciones superficiales (No./100 km red/año) \\
\hline wOp40 - & Colapso de colectores (No./100 km red/año) \\
\hline wOp41 - & Averías de bombas (horas/bomba/año) \\
\hline wOp42 - & Averías eléctricas (horas/estación de bombeo/año) \\
\hline Control de tanques de tormenta (página II-219) \\
\hline wOp43 - & Control de tanques de tormenta (\%) \\
\hline Monitorización de la calidad de aguas residuales y lodos (página II-220) \\
\hline wOp44 - & Ensayos realizados de calidad del agua residual (-/año) \\
\hline & wOp45 -Ensayos de DBO (-/año) \\
\hline wOp52 - & Ensayos realizados de lodos (-/año) \\
\hline wOp53 - & Ensayos realizados de vertidos industriales (-/año) \\
\hline Disponibilidad de vehículos (página II-229) \\
\hline wOp54 - Ensayos DQO (-/año) \\
\hline Equipamiento de seguridad (página II-229) \\
\hline wOp55 - & Detectores de gas (No./empleado) \\
\hline wOp56 - & Detectores de gas instalados permanentemente (\%) \\
\hline & wOp47 -Ensayo de sólidos suspendidos (-/año) \\
\hline & wOp40 -Ensayos -Ensayos de e. coli fecales (-/año) \\
\hline
\end{tabular}

\section{Indicadores de calidad del servicio (página II-230)}

Población servida (página II-230)

wQS1 - Población residente conectada a la red de alcantarillado (\%)

wQS2 - Población residente servida por la EDAR (\%) 
Indicadores de calidad del servicio (página II-230)

wQS3 - Población residente servida por sistemas in-situ (\%)

wQS4 - Población residente no servida (\%)

Tratamiento de aguas residuales (página II-231)

wQS5 - Aguas residuales tratadas en la EDAR (\%)

wQS6 -Pretratamiento (\%)

wQS7 -Tratamiento primario (\%)

wQS8 - Tratamiento secundario (\%)

wQS9 -Tratamiento terciario (\%)

\section{Inundaciones (página II-233)}

wQS10 - Inundación de propiedades por colectores de aguas negras en tiempo seco (n. ${ }^{\circ} / 1000$ propiedades/año)

wQS11 - Inundación de propiedades por colectores de aguas negras en tiempo de lluvia (n. $/ 1000$ propiedades/año)

wQS12 - Inundación de propiedades por colectores unitarios en tiempo seco (n. $\% / 1000$ propiedades/año)

wQS13 - Inundación de propiedades por colectores unitarios en tiempo de lluvia (n. ${ }^{\circ} / 1000$ propiedades/año)

wQS14 - Inundación de la superficie de propiedades en tiempo de lluvia (n. $\% / 1000$ propiedades/año)

Interrupciones (página II-237)

wQS15 - Interrupción del servicio de recolección y transporte de aguas residuales $(\%)$

Instalación y reparación de acometidas (página II-238) wQS16 - $\begin{aligned} & \text { Eficiencia de alta de nuevas acometidas (días/nueva } \\ & \text { acometida) }\end{aligned}$

wQS17 - $\begin{aligned} & \text { Tiempo de reparación de acometidas (días/acometida } \\ & \text { reparada) }\end{aligned}$

wQS18 - Tiempo medio de respuesta para vaciar fosas sépticas o letrinas (días/solicitud)

Quejas de los usuarios (página II-239)

wQS19 - Quejas totales (No. /1000 hab./año)

\begin{tabular}{|l|l|}
\hline & wQS20 -Quejas por atascos (No. /1000 hab./año) \\
\hline & wQS21 -Quejas por inundaciones (No. /1000 hab./año) \\
\hline & $\begin{array}{l}\text { wQS22 -Quejas por incidentes de contaminación (No. /1000 } \\
\text { hab./año) }\end{array}$ \\
\hline & wQS23 -Quejas por olores (No. /1000 hab./año) \\
\hline
\end{tabular}


Indicadores de calidad del servicio (página II-230)

wQS24 -Quejas relacionadas con roedores (No. /1000 hab./año)

wQS25 -Quejas relacionadas con la facturación (No. /1000 hab./año)

wQS26 -Otras quejas (No. /1000 hab./año)

wQS27 - Respuesta a quejas (\%)

Daños a terceros (página II-244)

wQS28 - Responsabilidad por daños a terceros (\%)

Impacto en el tráfico (página II-245)

wQS29 - Perturbaciones en el tráfico ( $\mathrm{km} /$ interrupción de tráfico)

\begin{tabular}{|c|c|}
\hline Indicad & es financieros (página II-245) \\
\hline Ingresos & página II-246) \\
\hline wFi1 - & Ingresos unitarios (EUR/p.e./año) \\
\hline & wFi2 -Ingresos por servicios (\%) \\
\hline & wFi3 -Otros ingresos $(\%)$ \\
\hline wFi4 - & Ingresos por servicios industriales $(\%)$ \\
\hline Costes $(1$ & gina II-248) \\
\hline wFi5 - & $\begin{array}{l}\text { Costes totales unitarios por población equivalente } \\
(\text { EUR/p.e./año) }\end{array}$ \\
\hline wFi6 - & $\begin{array}{l}\text { Costes totales unitarios por longitud de colector }(\mathrm{EUR} / \mathrm{km} \\
\mathrm{red} / \mathrm{año})\end{array}$ \\
\hline & $\begin{array}{l}\text { wFi7 -Costes de explotación unitarios por población } \\
\text { equivalente (EUR/p.e./año) }\end{array}$ \\
\hline & $\begin{array}{l}\text { wFi8 -Costes de explotación unitarios por longitud de } \\
\text { colector (EUR/km red/año) }\end{array}$ \\
\hline & $\begin{array}{l}\text { wFi9 -Costes de capital unitarios por población equivalente } \\
\text { (EUR/p.e./año) }\end{array}$ \\
\hline & $\begin{array}{l}\text { wFi10 -Costes de capital unitarios por longitud de colector } \\
\text { (EUR/km red/año) }\end{array}$ \\
\hline $\begin{array}{l}\text { Compon } \\
251)\end{array}$ & ntes de los costes de explotación por tipo de coste (página II- \\
\hline wFi11 - & Coste de personal interno $(\%)$ \\
\hline wFi12 - & Coste de servicios externos $(\%)$ \\
\hline wFi13 - & Coste de la energía eléctrica (\%) \\
\hline wFi14 - & Coste del material comprado $(\%)$ \\
\hline wFi15 - & Otros costes de explotación (\%) \\
\hline
\end{tabular}




\begin{tabular}{|c|c|}
\hline \multicolumn{2}{|c|}{ Indicadores financieros (página II-245) } \\
\hline \multicolumn{2}{|c|}{$\begin{array}{l}\text { Componentes de los costes de explotación por función principal } \\
\text { (internos y externalizados) (página II-253) }\end{array}$} \\
\hline wFi16 - & Coste de la dirección general $(\%)$ \\
\hline wFi17 - & Coste del área de gestión de recursos humanos (\%) \\
\hline wFi18 - & Coste del área financiera y comercial $(\%)$ \\
\hline wFi19 - & Coste del área del servicio de atención al cliente $(\%)$ \\
\hline wFi20 - & Coste del área servicio técnico (\%) \\
\hline \multicolumn{2}{|c|}{$\begin{array}{l}\text { Componentes de los costes de explotación por función técnica (página } \\
\text { II-2 }\end{array}$} \\
\hline wFi21 - & Costes de explotación del tratamiento de aguas residuales (\%) \\
\hline wFi22 - & Costes de explotación de la red de alcantarillado $(\%)$ \\
\hline wFi23 - & $\begin{array}{l}\text { Costes de explotación de la monitorización de la calidad del } \\
\text { agua residual }(\%)\end{array}$ \\
\hline wFi24 - & Costes de explotación de servicios de apoyo $(\%)$ \\
\hline \multicolumn{2}{|c|}{ Componentes de los costes de capital (página II-256) } \\
\hline wFi25 - & Costes por depreciación $(\%)$ \\
\hline wFi26 - & Coste por intereses netos $(\%)$ \\
\hline \multicolumn{2}{|c|}{ Inversiones (página II-257) } \\
\hline \multirow[t]{3}{*}{ wFi27 - } & Inversión unitaria (EUR/p.e.) \\
\hline & $\begin{array}{l}\text { wFi28 -Inversión en nuevos activos y refuerzo de activos } \\
\text { existentes }(\%)\end{array}$ \\
\hline & wFi29 -Inversión en sustitución y restauración de activos (\%) \\
\hline \multicolumn{2}{|c|}{ Eficiencia (página II-259) } \\
\hline wFi30 - & Ratio de cobertura de costes totales (-) \\
\hline wFi31 - & Ratio de cobertura de costes operacionales (-) \\
\hline wFi32 - & Retraso en el pago de recibos (días equivalentes) \\
\hline wFi33 - & Ratio de inversión (-) \\
\hline wFi34 - & Contribución de fuentes internas a la inversión = CTI $(\%)$ \\
\hline wFi35 - & Edad media de activos tangibles (\%/año) \\
\hline wFi36 - & Ratio medio de depreciación (-/año) \\
\hline wFi37 - & Ratio de cobros atrasados (-/año) \\
\hline wFi38 - & Valor de inventario (-/año) \\
\hline
\end{tabular}




\begin{tabular}{|l|l|}
\hline \multicolumn{2}{|l|}{ Indicadores financieros (página II-245) } \\
\hline Apalancamiento (página II-261) \\
\hline wFi39 - & Ratio de cobertura de deuda = DSC (\%) \\
\hline wFi40 - & Ratio de apalancamiento (-/año) \\
\hline Liquidez (página II-262) \\
\hline wFi41 - & Ratio de circulante (-) \\
\hline Rentabilidad (página II-262) \\
\hline wFi42 - & Retorno de activos no corrientes (\%/año) \\
\hline wFi43 - & Rendimiento sobre el capital (\%) \\
\hline wFi44 - & Rendimiento del capital invertido (\%) \\
\hline wFi45 - & Índice de rotación de activos (-/año) \\
\hline
\end{tabular}

\subsection{Indicadores medioambientales}

\section{Aguas residuales}

wEn1 -Cumplimiento de la EDAR con los requisitos de vertido (\%/año)

(población equivalente servida por EDAR que cumplen con los requisitos de vertido / población equivalente servida por EDAR gestionadas por el servicio) $\times 100$, en la fecha de referencia

wA1/wE5*100

wA1 - Población equivalente con tratamiento de aguas residuales satisfactorio

wE5 - Población equivalente servida con EDAR

Los requisitos de vertido son los estándares de calidad del efluente requeridos por normativa. El cumplimiento se evalúa con respecto a las cargas o concentraciones y sus posibles impactos ambientales.

Este indicador puede evaluarse para periodos inferiores a un año, pero se recomienda que se utilice únicamente cuando los datos de las variables se hayan recogido por lo menos durante un año. Se debe tener especial cuidado en la interpretación de su resultado. Deben evitarse comparaciones externas en dichas bases de tiempo. 
wEn2 -Reutilización de aguas residuales (\%)

Volumen de agua residual reutilizada / Volumen de agua residual tratada por el servicio $\times 100$, durante el periodo de evaluación

wA12/wA2*100

wA12 - Volumen de agua residual reutilizada

wA2 - Volumen de agua tratada

Este indicador puede ser evaluado para períodos inferiores a un año, pero se requiere especial cuidado en la interpretación de su resultado cuando se use para

comparaciones tanto externas como internas.

\begin{tabular}{l} 
wEn3 -Frecuencia de descargas intermitentes por reboses \\
(No./ dispositivo de desbordamiento/año) \\
(Número de alivios o descargas por reboses que ocurrieron durante el periodo \\
de evaluación x 365 / periodo de evaluación) / número de dispositivos de \\
desbordamiento en la fecha de referencia \\
(wA24*365/wH1)/wC19 \\
$\quad$ wA24 - Número de descargas por reboses \\
$\quad$ wH1 - Periodo de evaluación \\
$\quad$ wC19 - Aliviaderos \\
$\begin{array}{l}\text { Tenga en cuenta que "x365/wH1" es una expresión para realizar un cambio de } \\
\text { unidades y no debe ser considerado como una extrapolación. } \\
\text { Este indicador puede evaluarse para periodos inferiores a un año, pero se recomienda } \\
\text { que se utilice únicamente cuando los datos de las variables se hayan recogido por lo } \\
\text { menos durante un año. Se debe tener especial cuidado en la interpretación de su } \\
\text { resultado. Deben evitarse comparaciones externas en dichas bases de tiempo. }\end{array}$ \\
\hline
\end{tabular}


(Volumen total de alivios o descargas por reboses que ocurrieron durante el periodo de evaluación x 365 / periodo de evaluación / número de dispositivos de desbordamiento en la fecha de referencia

(wA25*365/wH1)/wC19

wA25 - Volumen de descargas por reboses

wH1 - Periodo de evaluación

wC19 - Aliviaderos

Tenga en cuenta que "x365/wH1" es una expresión para realizar un cambio de unidades y no debe ser considerado como una extrapolación.

Este indicador puede evaluarse para periodos inferiores a un año, pero se recomienda que se utilice únicamente cuando los datos de las variables se hayan recogido por lo menos durante un año. Se debe tener especial cuidado en la interpretación de su resultado. Deben evitarse comparaciones externas en dichas bases de tiempo. 
wEn5 -Ratio entre el volumen de las descargas intermitentes por reboses y el volumen de lluvia (\%/año)

Volumen total de descargas por reboses / volumen de lluvia x 100, durante el periodo de evaluación

wA25/wA26*100

wA25 - Volumen de descargas por reboses

wA26 - Volumen de lluvia

Este indicador puede ser evaluado para períodos inferiores a un año, pero se recomienda su únso únicamente cuando los datos para el cálculo de las variables se han recopilado durante, al menos, un año, para así permitir comparaciones con wEn4.

\section{Resíduos sólidos}

wEn6 -Producción de lodos en la EDAR (kg DS/p.e./año)

(Peso seco del lodo producido en las estaciones depuradoras de aguas residuales gestionadas por el servicio durante el período de evaluación x 365 / período de evaluación) / población equivalente atendida por las estaciones depuradoras de aguas residuales en la fecha de referencia x 1000 (wA13*365/wH1)/wE5*1000

wA13 - Lodos producidos en la EDAR

wH1 - Periodo de evaluación

wE5 - Población equivalente servida con EDAR

Tenga en cuenta que "x365/wH1" es una expresión para realizar un cambio de unidades y no debe ser considerado como una extrapolación.

Este indicador puede evaluarse para periodos inferiores a un año, pero se recomienda que se utilice únicamente cuando los datos de las variables se hayan recogido por lo menos durante un año. Se debe tener especial cuidado en la interpretación de su resultado. Deben evitarse comparaciones externas en dichas bases de tiempo. 
wEn7 -Utilización de lodos (\%)

Peso seco del lodo utilizado / peso seco del lodo tratado x 100, durante el periodo de evaluación

wA15/wA14*100

wA15 - Lodo utilizado

wA14 - Lodo tratado

La utilización de lodos incluye todos los posibles usos como: agricultura, uso forestal, productos derivados, materiales, etc.

Este indicador puede ser evaluado para períodos inferiores a un año, pero se requiere especial cuidado en la interpretación de su resultado cuando se use para

comparaciones tanto externas como internas.

\section{wEn8 -Desecho de lodos (\%)}

Peso seco del lodo desechado / peso seco del lodo tratado x 100, durante el periodo de evaluación

wA16/wA14*100

wA16 - Lodo desechado

wA14 - Lodo tratado

La disposición de lodos incluye los lodos cuyo destino es el vertedor y los residulos de los procesos de utilización de lodos.

Este indicador puede ser evaluado para períodos inferiores a un año, pero se requiere especial cuidado en la interpretación de su resultado cuando se use para comparaciones tanto externas como internas.

wEn9-Lodos destinados a vertedero $(\%)$

Peso seco del lodo destinado a vertedero / peso seco del lodo tratado $\mathrm{x}$ 100 , durante el periodo de evaluación

wA17/wA14*100

wA17 - Lodo destinado a vertedero

wA14 - Lodo tratado

Este indicador puede ser evaluado para períodos inferiores a un año, pero se requiere especial cuidado en la interpretación de su resultado cuando se use para comparaciones tanto externas como internas. 
wEn10-Lodos procesados térmicamente (\%)

Peso seco del lodo procesado térmicamente / peso seco del lodo tratado x 100, durante el periodo de evaluación

wA18/wA14*100

wA18 - Lodo procesado térmicamente

wA14 - Lodo tratado

Este indicador puede ser evaluado para períodos inferiores a un año, pero se requiere especial cuidado en la interpretación de su resultado cuando se use para comparaciones tanto externas como internas.

\section{wEn11 -Otro tipo de desechado de lodos (\%)}

Peso en seco del lodo desechados por otros medios distintos a los expuestos en wEn9 y wEn10 / peso seco del lodo tratado x 100, durante el periodo de evaluación

wA19/wA14*100

wA19 - Lodos desechados por otros medios

wA14 - Lodo tratado

Este indicador puede ser evaluado para períodos inferiores a un año, pero se requiere especial cuidado en la interpretación de su resultado cuando se use para comparaciones tanto externas como internas.

\section{wEn12 -Sedimentos de colectores (ton/km colector/año)}

(Peso drenado de los sedimentos extraídos de los colectores durante el período de evaluación x 365 / período de evaluación) / longitud total de la red de alcantarillado en la fecha de referencia

$(\mathrm{wA20} * 365 / \mathrm{wH} 1) / \mathrm{wC} 1$

wA20 - Sedimentos de colectores

wH1 - Periodo de evaluación

wC1 - Longitud de la red de alcantarillado

Tenga en cuenta que "x365/wH1" es una expresión para realizar un cambio de unidades y no debe ser considerado como una extrapolación.

Este indicador puede evaluarse para periodos inferiores a un año, pero se recomienda que se utilice únicamente cuando los datos de las variables se hayan recogido por lo menos durante un año. Se debe tener especial cuidado en la interpretación de su resultado. Deben evitarse comparaciones externas en dichas bases de tiempo. 
wEn13 -Sedimentos de elementos auxiliares (ton $/ \mathrm{km}$ colector/año)

(Peso drenado de los sedimentos extraídos de los elementos auxiliares de la red de alcantarillado durante el periodo de evaluación x 365 / período de evaluación) / longitud total de la red de alcantarillado en la fecha de referencia $(\mathrm{wA} 21 * 365 / \mathrm{wH} 1) / \mathrm{wC} 1$

wA21 - Sedimentos de elementos auxiliares

wH1 - Periodo de evaluación

wC1 - Longitud de la red de alcantarillado

Tenga en cuenta que "x365/wH1" es una expresión para realizar un cambio de unidades y no debe ser considerado como una extrapolación.

Este indicador puede evaluarse para periodos inferiores a un año, pero se recomienda que se utilice únicamente cuando los datos de las variables se hayan recogido por lo menos durante un año. Se debe tener especial cuidado en la interpretación de su resultado. Deben evitarse comparaciones externas en dichas bases de tiempo.

\section{wEn14 -Sedimentos de filtros (ton/ $\mathrm{km}$ colector/ año)}

(Peso drenado del film y arenilla extraídos en los filtros y tamices de las estaciones de depuración de aguas residuales y estaciones de bombeo durante el período de evaluación x 365 / periodo de evaluación) / longitud total de la red de alcantarillado en la fecha de referencia

$(\mathrm{wA} 22 * 365 / \mathrm{wH} 1) / \mathrm{wC} 1$

wA22 - Sedimentos de film y arenilla

wH1 - Periodo de evaluación

wC1 - Longitud de la red de alcantarillado

Tenga en cuenta que "x365/wH1" es una expresión para realizar un cambio de unidades y no debe ser considerado como una extrapolación.

Este indicador puede evaluarse para periodos inferiores a un año, pero se recomienda que se utilice únicamente cuando los datos de las variables se hayan recogido por lo menos durante un año. Se debe tener especial cuidado en la interpretación de su resultado. Deben evitarse comparaciones externas en dichas bases de tiempo. 
wEn15 -Sedimentos de sistemas in-situ (ton/p.e./año)

(Peso drenado de los sedimentos extraídos de los sistemas in-situ durante el periodo de evaluación x 365 / período de evaluación) / población equivalente atendidas por sistemas in-situ que son responsabilidad del servicio en la fecha de referencia

(wA23*365/wH1)/wE6

wA23 - Sedimentos de sistemas in-situ

wH1 - Periodo de evaluación

wE6 - Población equivalente servida por sistemas in-situ

Tenga en cuenta que "x365/wH1" es una expresión para realizar un cambio de unidades y no debe ser considerado como una extrapolación.

Este indicador puede evaluarse para periodos inferiores a un año, pero se recomienda que se utilice únicamente cuando los datos de las variables se hayan recogido por lo menos durante un año. Se debe tener especial cuidado en la interpretación de su resultado. Deben evitarse comparaciones externas en dichas bases de tiempo.

\subsection{Indicadores de personal}

Los indicadores de personal evalúan la eficiencia y la efectividad del personal de los prestadores del servicio de saneamiento, considerando sus funciones, actividades y cualificación. También se tienen en cuenta cuestiones como la formación, salud y seguridad, así como el absentismo. Para interpretar correctamente estos indicadores es necesario realizar un análisis que tenga en cuenta los datos de personal empleado en los servicios externalizados.

Los empleados incluyen a todas las personas que trabajan para el servicio a cambio de un salario. 


\section{Personal total}

\section{wPe1 -Personal en tratamiento de aguas residuales por población equivalente (No./ 1000 p.e.)}

Número equivalente de empleados a tiempo completo que trabajan en el tratamiento de aguas residuales / población equivalente servida por sistemas de tratamiento de aguas residuales gestionados por el servicio $\mathrm{x} 1000$, en la fecha de referencia

wB2/(wE5+wE6)*1000

wB2 - Personal en tratamiento de aguas residuales

wE5 - Población equivalente servida con EDAR

wE6 - Población equivalente servida por sistemas in-situ

El tratamiento de aguas residuales se refiere tanto al volumen tratado en las Estaciones Depuradoras de Aguas Residuales, como en los sistemas in-situ que son responsabilidad del servicio de saneamiento.

wPe2 -Personal de la red de alcantarillado por longitud (No./100 km red)

Número equivalente de empleados a tiempo completo que trabajan en la red de alcantarillado / longitud total de la red de alcantarillado, en la fecha de referencia wB3/wC1*100

wB3 - Personal en la red de alcantarillado

wC1 - Longitud de la red de alcantarillado

Este indicador se debe de evaluar para una fecha de referencia. 


\section{Personal por función principal}

(ver II-1.2 - Funciones de organización para la definición de funciones)

\section{wPe3 -Personal de administración general (\%)}

Número equivalente de empleados a tiempo completo encargados de la dirección, la administración central, la planificación estratégica, el márketing, las comunicaciones, las relaciones con las partes interesadas, los asuntos jurídicos, las auditorías internas, la gestión medioambiental, el desarrollo de nuevos negocios y la asistencia informática general / número equivalente de trabajadores a tiempo completo del servicio de saneamiento $\mathrm{x} 100$, en la fecha de referencia wB4/wB1*100

wB4 - Personal encargado de la administración general

wB1 - Personal total

Este indicador se debe de evaluar para una fecha de referencia.

wPe4 -Personal encargado de la gestión de los recursos humanos (\%)

Número equivalente de empleados a tiempo completo encargados de la administración, educación y formación del personal, la seguridad en el trabajo, los servicios médicos y las actividades sociales / número equivalente de trabajadores a tiempo completo del servicio de saneamiento x 100 , en la fecha de referencia wB5/wB1*100

wB5 - Personal encargado de la gestión de los recursos humanos

wB1 - Personal total

Este indicador se debe de evaluar para una fecha de referencia.

\section{wPe5 -Personal de finanzas y comercial (\%)}

Número equivalente de empleados a tiempo completo encargados de la planificación económica y financiera, la administración financiera, el control económico y la gestión de materiales / número equivalente de trabajadores a tiempo completo del servicio de saneamiento $\mathrm{x} 100$, en la fecha de referencia wB6/wB1*100

wB6 - Personal encargado de las funciones financieras y comerciales wB1 - Personal total

Este indicador se debe de evaluar para una fecha de referencia. 
wPe6 -Personal de atención al cliente (\%)

Número equivalente de empleados a tiempo completo encargados de la contabilidad, control y gestión de las relaciones con los clientes / número equivalente de trabajadores a tiempo completo del servicio de saneamiento $\mathrm{x}$ 100 , en la fecha de referencia

wB7/wB1*100

wB7 - Personal encargado del servicio al cliente

wB1 - Personal total

Este indicador se debe de evaluar para una fecha de referencia.

\section{wPe7 -Personal de servicios técnicos (\%)}

Número equivalente de empleados a tiempo completo encargados de la planificación, la construcción y las actividades de mantenimiento / número equivalente de trabajadores a tiempo completo del servicio de saneamiento $\mathbf{x}$ 100 , en la fecha de referencia

wB8/wB1*100

wB8 - Personal de servicios técnicos

wB1 - Personal total

Este indicador se debe de evaluar para una fecha de referencia.

wPe8 - Personal de planificación, diseño y construcción (\%)

Número equivalente de empleados a tiempo completo del servicio técnico encargados de la planificación, el diseño y la construcción del sistema de alcantarillado y las instalaciones de tratamiento de aguas residuales / número equivalente de trabajadores a tiempo completo del servicio de saneamiento $\mathrm{x} 100$, en la fecha de referencia wB11/wB1*100

wB11 - Personal de planificación, diseño y construcción wB1 - Personal total

Este indicador se debe de evaluar para una fecha de referencia. 
wPe9-Personal de operaciones y mantenimiento (\%)

Número equivalente de empleados a tiempo completo del servicio técnico encargados de las funciones de operaciones, mantenimiento y reparación del sistema de alcantarillado y las instalaciones de tratamiento de aguas residuales / número equivalente de trabajadores a tiempo completo del servicio de saneamiento $\mathrm{x} 100$, en la fecha de referencia wB12/wB1*100
wB12 - Personal de operaciones y mantenimiento wB1 - Personal total

Este indicador se debe de evaluar para una fecha de referencia.

\section{Personal de servicios técnicos por actividad}

(ver II-1.2 - Funciones de organización para la definición de funciones)

wPe10 -Personal técnico de tratamiento de aguas residuales (No./1000 p.e.)

Número equivalente de empleados a tiempo completo trabajando en actividades de planificación, diseño, construcción, operación, mantenimiento y reparación de sistemas de tratamiento de aguas residuales / población equivalente servida por sistemas de tratamiento de aguas residuales gestionados por el servicio x 1000 , en la fecha de referencia wB9/(wE5+wE6)*1000

wB9 - Personal técnico de tratamiento de aguas residuales

wE5 - Población equivalente servida con EDAR

wE6 - Población equivalente servida por sistemas in-situ

El tratamiento de aguas residuales se refiere tanto al volumen tratado en las Estaciones Depuradoras de Aguas Residuales, como en los sistemas in-situ que son responsabilidad del servicio de saneamiento.

Cuando el servicio cuente con laboratorios propios, el personal de monitorización de la calidad del agua residual se contabilizará en el indicador de desempeño wPE12. 
wPe11 -Personal técnico del sistema de alcantarillado (No./100 km colector)

Número equivalente de empleados a tiempo completo trabajando en actividades de planificación, diseño, construcción, operación, mantenimiento y reparación del sistema de alcantarillado / longitud total de la red de alcantarillado $x 100$, en la fecha de referencia wB10/wC1*100

wB10 - Personal técnico del sistema de alcantarillado

wC1 - Longitud de la red de alcantarillado

Cuando el servicio cuente con laboratorios propios, el personal de monitorización de la calidad del agua residual se contabilizará en el indicador de desempeño wPE12.

wPe12 -Personal de monitorización de la calidad del agua residual (No./(1000 ensayos/año))

Número equivalente de empleados a tiempo completo trabajando en el muestreo y testeo de la calidad del agua residual / (número total de ensayos de calidad de aguas residuales realizadas por los laboratorios del servicio x 365 / periodo de evaluación) x 1000

wB13/(wD47*365/wH1)*1000

wB13 - Personal de laboratorio

wD47 - Número total de ensayos de calidad del agua residual realizadas por los laboratorios del servicio

wH1 - Periodo de evaluación

Tenga en cuenta que "x365/wH1" es una expresión para realizar un cambio de unidades y no debe ser considerado como una extrapolación.

Este indicador puede ser evaluado para períodos inferiores a un año, pero se requiere especial cuidado en la interpretación de su resultado cuando se use para comparaciones tanto externas como internas.

Este indicador es únicamente aplicable cuando es el servicio de saneamiento el que realiza los test de calidad del agua residual en sus propios laboratorios. 
wPe13 -Personal de servicios de apoyo (\%)

Número equivalente de empleados a tiempo completo trabajando en los servicios de apoyo / número equivalente total de empleados a tiempo completo encargados de los servicios técnicos, en la fecha de referencia wB14/wB8*100

wB14 - Personal de servicios de apoyo

wB8 - Personal de servicios técnicos

Este indicador se debe de evaluar para una fecha de referencia.

\section{Cualificación del personal}

\section{wPe14 -Personal con titulación universitaria (\%)}

Número equivalente de empleados a tiempo completo del servicio con titulación universitaria / número equivalente de trabajadores a tiempo completo del servicio de saneamiento $\mathrm{x} 100$, en la fecha de referencia wB15/wB1*100

wB15 - Personal con titulación universitaria

wB1 - Personal total

Este indicador se debe de evaluar para una fecha de referencia.

\section{wPe15 -Personal con educación básica (\%)}

Número equivalente de empleados a tiempo completo en el servicio con nivel de estudios básico pero sin titulación universitaria / número equivalente de trabajadores a tiempo completo del servicio de saneamiento x 100 , en la fecha de referencia wB16/wB1*100

wB16 - Personal con nivel de estudios básico wB1 - Personal total

Este indicador se debe de evaluar para una fecha de referencia. 
wPe16 -Personal con otra cualificación (\%)

Número equivalente de empleados a tiempo completo sin nivel de estudios básico en el servicio / número equivalente de trabajadores a tiempo completo del servicio de saneamiento $x$ 100, en la fecha de referencia

O 100 - (personal con titulación universitaria + personal con nivel de estudios básico), en la fecha de referencia

wB17/wB1*100, o

100-(wPe14+wPe15)

wB17 - Personal con otra cualificación

wB1 - Personal total

wPe14 - Personal con titulación universitaria

wPe15 - Personal con educación básica

Este indicador se debe de evaluar para una fecha de referencia.

\section{Formación de personal}

\section{wPe17 -Formación total del personal (horas/empleado/año)}

(Número de horas de formación de personal de aguas residuales durante el periodo de evaluación x 365 / periodo de evaluación) / número equivalente de trabajadores a tiempo completo del servicio de saneamiento $\times 100$, en la fecha de referencia

$$
\begin{aligned}
& (\text { wB20*365/wH1)/wB1 } \\
& \text { wB20 - Tiempo de formación } \\
& \text { wH1 - Periodo de evaluación } \\
& \text { wB1 - Personal total }
\end{aligned}
$$

Tenga en cuenta que "x365/wH1" es una expresión para realizar un cambio de unidades y no debe ser considerado como una extrapolación.

Este indicador puede evaluarse para periodos inferiores a un año, pero se recomienda que se utilice únicamente cuando los datos de las variables se hayan recogido por lo menos durante un año. Se debe tener especial cuidado en la interpretación de su resultado. Deben evitarse comparaciones externas en dichas bases de tiempo. 


\section{Seguridad y salud del personal}

\section{wPe18-Vacunación (\%)}

Número equivalente de empleados a tiempo completo del servicio de saneamiento con certificación de vacunas actualizada para enfermedades relacionadas con las aguas residuales/ personal de operación y mantenimiento $\mathrm{x} 100$, en la fecha de referencia wB19/wB12*100

wB19 - Personal vacunado

wB12 - Personal de operaciones y mantenimiento

Este indicador se debe de evaluar para una fecha de referencia.

\section{wPe19-Formación autorizada en espacios confinados (\%)}

Número equivalente de empleados a tiempo completo del servicio de saneamiento con formación adecuada y autorizada en espacios confinados / personal de operación y mantenimiento x 100 , en la fecha de referencia wB18/wB12*100

wB18 - Personal especializado en espacios confinados wB12 - Personal de operaciones y mantenimiento

Este indicador se debe de evaluar para una fecha de referencia.

\section{wPe20 -Accidentes laborales (No./100 empleados/año)}

(Número de accidentes laborales que han requerido atención médica durante el período de evaluación x 365 / período de evaluación) / número equivalente de trabajadores a tiempo completo del servicio de saneamiento $\mathrm{x} 100$, en la fecha de referencia

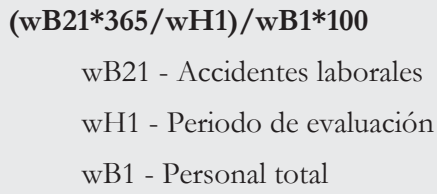

Tenga en cuenta que "x365/wH1" es una expresión para realizar un cambio de unidades y no debe ser considerado como una extrapolación.

Este indicador puede evaluarse para periodos inferiores a un año, pero se recomienda que se utilice únicamente cuando los datos de las variables se hayan recogido por lo menos durante un año. Se debe tener especial cuidado en la interpretación de su resultado. Deben evitarse comparaciones externas en dichas bases de tiempo. 
wPe21 -Víctimas de incidentes fatales en el trabajo (No./100 empleados/año)

(Número de accidentes laborales que resultan en muerte o enfermedad permanente durante el período de evaluación x 365 / período de evaluación) / número equivalente de trabajadores a tiempo completo del servicio de saneamiento $\mathrm{x} 100$, en la fecha de referencia $(\mathrm{wB} 22 * 365 / \mathrm{wH} 1) / \mathrm{wB} 1 * 100$

wB22 - Accidentes laborales fatales

wH1 - Periodo de evaluación

wB1 - Personal total

Tenga en cuenta que "x365/wH1" es una expresión para realizar un cambio de unidades y no debe ser considerado como una extrapolación.

Este indicador puede evaluarse para periodos inferiores a un año, pero se recomienda que se utilice únicamente cuando los datos de las variables se hayan recogido por lo menos durante un año. Se debe tener especial cuidado en la interpretación de su resultado. Deben evitarse comparaciones externas en dichas bases de tiempo.

\section{Absentismo}

\section{wPe22 -Absentismo (días/100 empleados/año)}

(Número total de días de absentismo del personal durante el período de evaluación x 365 / período de evaluación) / número equivalente de trabajadores a tiempo completo del servicio de saneamiento $\times 100$, en la fecha de referencia

$(\mathrm{wB} 23 * 365 / \mathrm{wH} 1) / \mathrm{wB} 1$

wB23 - Absentismo

wH1 - Periodo de evaluación

wB1 - Personal total

Tenga en cuenta que "x365/wH1" es una expresión para realizar un cambio de unidades y no debe ser considerado como una extrapolación.

Este indicador puede evaluarse para periodos inferiores a un año, pero se recomienda que se utilice únicamente cuando los datos de las variables se hayan recogido por lo menos durante un año. Se debe tener especial cuidado en la interpretación de su resultado. Deben evitarse comparaciones externas en dichas bases de tiempo. 
wPe23 -Absentismo debido a accedentes o enfermedades laborales (días /100 empleados/año)

(Número total de días de absentismo del personal debido a accidentes laborales o enfermedades provocadas en el trabajo durante el período de evaluación x 365 / período de evaluación) / número equivalente de trabajadores a tiempo completo del servicio de saneamiento x 100 , en la fecha de referencia

$(\mathrm{wB} 24 * 365 / \mathrm{wH} 1) / \mathrm{wB} 1$

wB24 - Absentismo debido a accidentes o enfermedades laborales

wH1 - Periodo de evaluación

wB1 - Personal total

Tenga en cuenta que "x365/wH1" es una expresión para realizar un cambio de unidades y no debe ser considerado como una extrapolación.

Este indicador puede evaluarse para periodos inferiores a un año, pero se recomienda que se utilice únicamente cuando los datos de las variables se hayan recogido por lo menos durante un año. Se debe tener especial cuidado en la interpretación de su resultado. Deben evitarse comparaciones externas en dichas bases de tiempo.

\section{wPe24-Absentismo debido a otros motivos (días/100 empleados/año)}

(Número total de días de absentismo del personal no debido a accidentes laborales o enfermedades provocadas en el trabajo durante el período de evaluación x 365 / período de evaluación) / número equivalente de trabajadores a tiempo completo del servicio de saneamiento $\mathrm{x} 100$, en la fecha de referencia (wB25*365/wH1)/wB1

wB25 - Absentismo debido a otras razones

wH1 - Periodo de evaluación

wB1 - Personal total

Tenga en cuenta que "x365/wH1" es una expresión para realizar un cambio de unidades y no debe ser considerado como una extrapolación.

Este indicador puede evaluarse para periodos inferiores a un año, pero se recomienda que se utilice únicamente cuando los datos de las variables se hayan recogido por lo menos durante un año. Se debe tener especial cuidado en la interpretación de su resultado. Deben evitarse comparaciones externas en dichas bases de tiempo. 


\section{Horas extraordinarias}

wPe25 -Horas extraordinarias (\%)

Horas extraordinarias de trabajo / horas de trabajo normal x 100, durante el periodo de evaluación

wB27/wB26*100

wB27 - Horas extraordinarias de trabajo

wB26 - Horas de trabajo

Este indicador está destinado a trabajadores cualificados y no cualificados.

Demasiadas horas extraordinarias pueden indicar un uso ineficiente de la mano de obra, falta de personal o mantenimiento preventivo ineficiente.

Este indicador puede ser evaluado para períodos inferiores a un año, pero se requiere especial cuidado en la interpretación de su resultado cuando se use para comparaciones tanto externas como internas.

\subsection{Indicadores físicos}

\section{Tratamiento de aguas residuales}

\section{wPh1-Utilización de pretratamientos (\%)}

Valor máximo del volumen diario de aguas residuales tratadas en todas las EDAR con pretratamiento / Suma, para todas las EDAR con pretratamiento, de la capacidad máxima de tratamiento diario $\times 100$, durante el periodo de evaluación

wA4/wC12*100

wA4 - Valor punta diario de agua residual pretratada

wC12 - Capacidad diaria de tratamiento preliminar

Este indicador puede ser evaluado para períodos inferiores a un año, pero se requiere especial cuidado en la interpretación de su resultado cuando se use para comparaciones tanto externas como internas. 
wPh2 -Utilización de tratamientos primarios (\%)

Valor máximo del volumen diario de aguas residuales tratadas en todas las EDAR con tratamiento primario / Suma, para todas las EDAR con tratamiento primario, de la capacidad máxima de tratamiento diario $\times 100$, durante el periodo de evaluación

wA6/wC13*100

wA6 - Valor punta diario de agua residual con tratamiento primario

wC13 - Capacidad diaria de tratamiento primario

Este indicador puede ser evaluado para períodos inferiores a un año, pero se requiere especial cuidado en la interpretación de su resultado cuando se use para comparaciones tanto externas como internas.

\section{wPh3 -Utilización de tratamientos secundarios (\%)}

Valor máximo del volumen diario de aguas residuales tratadas en todas las EDAR con tratamiento secundario / Suma, para todas las EDAR con tratamiento secundario, de la capacidad máxima de tratamiento diario x 100, durante el periodo de evaluación

wA8/wC14*100

wA8 - Valor punta diario de agua residual con tratamiento secundario

wC14 - Capacidad diaria de tratamiento secundario

Este indicador puede ser evaluado para períodos inferiores a un año, pero se requiere especial cuidado en la interpretación de su resultado cuando se use para

comparaciones tanto externas como internas. 
wPh4 -Utilización de tratamientos terciarios (\%)

Valor máximo del volumen diario de aguas residuales tratadas en todas las EDAR con tratamiento terciario / Suma, para todas las EDAR con tratamiento terciario, de la capacidad máxima de tratamiento diario x 100, durante el periodo de evaluación

wA10/wC15*100

wA10 - Valor punta diario de agua residual con tratamiento terciario

wC15 - Capacidad diaria de tratamiento terciario

Este indicador puede ser evaluado para períodos inferiores a un año, pero se requiere especial cuidado en la interpretación de su resultado cuando se use para comparaciones tanto externas como internas.

\section{Colectores}

wPh5 -Entrada en carga de colectores por gravedad en tiempo seco $(\%)$

Longitud de colectores por gravedad que han entrado en carga en tiempo seco durante el periodo de evaluación / longitud total de la red de alcantarillado en la fecha de referencia $\times 100$

wC2/wC1*100

wC2 - Colectores que entran en carga en tiempo seco

wC1 - Longitud de la red de alcantarillado

Este indicador puede evaluarse para periodos inferiores a un año, pero se recomienda que se utilice únicamente cuando los datos de las variables se hayan recogido por lo menos durante un año. Se debe tener especial cuidado en la interpretación de su resultado. Deben evitarse comparaciones externas en dichas bases de tiempo. 
wPh6 -Entrada en carga de colectores por gravedad en tiempo de lluvia $(\%)$

Longitud de colectores por gravedad que han entrado en carga en tiempo de lluvia durante el periodo de evaluación / longitud total de la red de alcantarillado en la fecha de referencia $\times 100$

wC3/wC1*100

wC3 - Colectores que entran en carga en tiempo de lluvia

wC1 - Longitud de la red de alcantarillado

Esta información puede obtenerse mediante medición o modelado hidráulico del sistema de aguas residuales utilizado datos reales de lluvia.

Este indicador puede evaluarse para periodos inferiores a un año, pero se recomienda que se utilice únicamente cuando los datos de las variables se hayan recogido por lo menos durante un año. Se debe tener especial cuidado en la interpretación de su resultado. Deben evitarse comparaciones externas en dichas bases de tiempo.

wPh7 -Entrada en niveles de carga elevados en colectores (\%)

Longitud de colectores que han entrado en niveles de carga elevados en tiempo de lluvia durante el periodo de evaluación / longitud total de la red de alcantarillado en la fecha de referencia $\times 100$

wC4/wC1*100

wC4 - Colectores que entran en niveles de carga elevados

wC1 - Longitud de la red de alcantarillado

Se entiende por nivel de carga elevado a niveles de agua de como mínimo $0.5 \mathrm{~m}$ por encima de la corona del colector.

Este indicador puede evaluarse para periodos inferiores a un año, pero se recomienda que se utilice únicamente cuando los datos de las variables se hayan recogido por lo menos durante un año. Se debe tener especial cuidado en la interpretación de su resultado. Deben evitarse comparaciones externas en dichas bases de tiempo. 


\section{Bombeo}

wPh8 -Energía de bombeo utilizada en la red de alcantarillado (\%)

Sumatorio $\left(\sum\right)$ para todas las bombas instaladas en la red de alcantarillado de su potencia nominal por las horas de bombeo para el periodo de evaluación / (potencia nominal de bombeo instalada en el sistema de alcantarillado $\mathrm{x}$ periodo de evaluación x 24) x 100

wD15/(wC10*wH1*24)*100

wD15 - Consumo de energía por bombeo en la red de alcantarillado

wC10 - Potencia de bombeo en la red de alcantarillado

wH1 - Periodo de evaluación

La potencia de de bombeo instalada no incluye las bomas de reserva.

Este indicador puede ser evaluado para períodos inferiores a un año, pero se requiere especial cuidado en la interpretación de su resultado cuando se use para comparaciones tanto externas como internas.

\section{wPh9 -Energía de bombeo utilizada en la EDAR (\%)}

Sumatorio $\left(\sum\right)$ para todas las bombas instaladas en la EDAR de su potencia nominal por las horas de bombeo para el periodo de evaluación / (potencia nominal de bombeo instalada en la EDAR x periodo de evaluación x 24) x 100 wD14/(wC5*wH1*24)*100

wD14 - Consumo de energía por bombeo en la EDAR

wC5 - Potencia de bombeo en la EDAR

wH1 - Periodo de evaluación

Se debe incluir las bombas de entrada a la EDAR.

Este indicador puede ser evaluado para períodos inferiores a un año, pero se requiere especial cuidado en la interpretación de su resultado cuando se use para comparaciones tanto externas como internas. 
wPh10 - Altura de bombeo en la red de alcantarillado (\%)

Número de estaciones de bombeo en la red de alcantarillado donde las bombas operaron más del $75 \%$ del tiempo durante el periodo de evaluación / número de estaciones de bombeo en la red de alcantarillado en la fecha de referencia $\times 100$

wC11/wC9*100

wC11 - Utilización de las estaciones de bombeo de la red de alcantarillado

wC9 - Estaciones de bombeo de la red de alcantarillado

No se debe incluir las bombas instaladas en la EDAR.

Este indicador puede ser evaluado para períodos inferiores a un año, pero se requiere especial cuidado en la interpretación de su resultado cuando se use para comparaciones tanto externas como internas.

\section{Automatización y control}

\section{wPh11 -Grado de automatización (\%)}

Número de unidades con control automatizado / número de unidades de control x 100, en la fecha de referencia wC17/wC16*100

wC17 - Unidades de control automático

wC16 - Unidades de control

\section{wPh12 -Grado de control remoto $(\%)$}

Número de unidades con control remoto / número de unidades de control x 100 , en la fecha de referencia

wC18/wC16*100

wC18 - Unidades de control remotas

wC16 - Unidades de control 


\subsection{Indicadores operacionales}

\section{Inspección y mantenimiento de colectores}

wOp1 -Inspección de colectores (\%/año)

(Longitud de colectores inspeccionados durante el periodo de evaluación x 365 / periodo de evaluación) / longitud total de la red de alcantarillado en la fecha de referencia $\times 100$

$(\mathrm{wD} 1 * 365 / \mathrm{wH} 1) / \mathrm{wC} 1 * 100$

wD1 - Inspección de colectores

wH1 - Periodo de evaluación

wC1 - Longitud de la red de alcantarillado

Deben incluirse las inspecciones realizadas mediante vigilancia remota y sistemas de TV. Asimismo, se incluirán las inspecciones realizadas para investigar atascos.

Tenga en cuenta que "x365/wH1" es una expresión para realizar un cambio de unidades y no debe ser considerado como una extrapolación.

Este indicador puede evaluarse para periodos inferiores a un año, pero se recomienda que se utilice únicamente cuando los datos de las variables se hayan recogido por lo menos durante un año. Se debe tener especial cuidado en la interpretación de su resultado. Deben evitarse comparaciones externas en dichas bases de tiempo. 
wOp2 -Limpieza de colectores ( $\% /$ año)

(Longitud de colectores limpiados durante el periodo de evaluación x 365 / periodo de evaluación) / longitud total de la red de alcantarillado en la fecha de referencia $\mathrm{x} 100$

(wD2*365/wH1)/wC1*100

wD2 - Limpieza de colectores

wH1 - Periodo de evaluación

wC1 - Longitud de la red de alcantarillado

La limpieza de colectores se refiere a las acciones tomadas bajo una estrategia de gestión proactiva. Incluye el corte de raíces. Las acciones de limipeza debidas a atascos se incluyen en el indicador wOp34.

Tenga en cuenta que "x365/wH1" es una expresión para realizar un cambio de unidades y no debe ser considerado como una extrapolación.

Este indicador puede evaluarse para periodos inferiores a un año, pero se recomienda que se utilice únicamente cuando los datos de las variables se hayan recogido por lo menos durante un año. Se debe tener especial cuidado en la interpretación de su resultado. Deben evitarse comparaciones externas en dichas bases de tiempo.

\section{wOp3 -Inspección de pozos de registro (-/año)}

(Número de pozos de registro inspeccionados durante el periodo de evaluación x 365 / periodo de evaluación) / número total de pozos de registro en la fecha de referencia

\section{(wD3*365/wH1)/wC21}

wD3 - Inspección de pozos de registro

wH1 - Periodo de evaluación

wC21 - Pozos de registro

Tenga en cuenta que "x365/wH1" es una expresión para realizar un cambio de unidades y no debe ser considerado como una extrapolación.

Este indicador puede evaluarse para periodos inferiores a un año, pero se recomienda que se utilice únicamente cuando los datos de las variables se hayan recogido por lo menos durante un año. Se debe tener especial cuidado en la interpretación de su resultado. Deben evitarse comparaciones externas en dichas bases de tiempo. 
wOp4 -Inspección de imbormales (-/año)

(Número de imbornales inspeccionados durante el periodo de evaluación $\mathbf{x}$ 365 / periodo de evaluación) / número total de imbornales en la fecha de referencia

(wD4*365/wH1)/wC22

wD4 - Inspección de imbornales

wH1 - Periodo de evaluación

wC22 - imbornales

La inspección de imbornales se refiere a acciones tomadas bajo una estrategia de gestión proactiva.

Si esta actividad no es responsabilidad del servicio de saneamiento, este indicador no es aplicable. Sin embargo, esta información es relevante para comprender los valores del indicador wQS14.

Tenga en cuenta que "x365/wH1" es una expresión para realizar un cambio de unidades y no debe ser considerado como una extrapolación.

Este indicador puede evaluarse para periodos inferiores a un año, pero se recomienda que se utilice únicamente cuando los datos de las variables se hayan recogido por lo menos durante un año. Se debe tener especial cuidado en la interpretación de su resultado. Deben evitarse comparaciones externas en dichas bases de tiempo. 


\section{wOp5 -Limpiera de imbormales (-/año)}

(Número de imbornales limpiados durante el periodo de evaluación x 365 /periodo de evaluación) / número total de imbornales en la fecha de referencia

$(\mathrm{wD} 5 * 365 / \mathrm{wH} 1) / \mathrm{wC} 22$

wD5 - Limpieza de imbornales

wH1 - Periodo de evaluación

wC22 - Imbornales

La inspección de imbornales se refiere a acciones tomadas bajo una estrategia de gestión proactiva.

Si esta actividad no es responsabilidad del servicio de saneamiento, este indicador no es aplicable. Sin embargo, esta información es relevante para comprender los valores del indicador wQS14.

Tenga en cuenta que "x365/wH1" es una expresión para realizar un cambio de unidades y no debe ser considerado como una extrapolación.

Este indicador puede evaluarse para periodos inferiores a un año, pero se recomienda que se utilice únicamente cuando los datos de las variables se hayan recogido por lo menos durante un año. Se debe tener especial cuidado en la interpretación de su resultado. Deben evitarse comparaciones externas en dichas bases de tiempo. 


\section{Inspección y mantenimiento de depósitos de retención y DSUs}

wOp6 -Frecuencia de inspección de depósitos de retención y tanques
de tormenta (No./depósitos de retención y tanques de tormenta /año)

(Número de inspecciones a depósitos de retención y tanques de tormenta llevadas a cabo durante el periodo de evaluación x 365 / periodo de evaluación) / número total de depósitos de retención y tanques de tormenta, en la fecha de referencia

$(\mathrm{wD6} * 365 / \mathrm{wH} 1) /(\mathrm{wC20}+\mathrm{wC23})$

wD6 - Número de inspecciones a depósitos de retención y tanques de tormenta

wH1 - Periodo de evaluación

wC20 - Número de tanques de tormenta

wC23 - Número de depósitos de retención

Tenga en cuenta que "x365/wH1" es una expresión para realizar un cambio de unidades y no debe ser considerado como una extrapolación.

Se recomienda no evaluar este indicador para períodos inferiores a un año, puesto que puede llevar a conclusiones erróneas. Si no es posible el uso de un período superior a un año, se debe tener especial cuidado en la interpretación de su resultado. Deben evitarse comparaciones externas en dichas bases de tiempo. 
wOp7 -Volumen inspeccionado de depósitos de retención y tanques de tormenta (-/año)

(Volumen inspeccionado de depósitos de retención y tanques de tormenta durante el periodo de evaluación x 365 / periodo de evaluación) / volumen total de depósitos de retención y tanques de tormenta en la fecha de referencia $(w D 7 * 365 / w H 1) / w C 24$

wD7 - Volumen inspeccionado de depósitos de retención y tanques de tormenta

wH1 - Periodo de evaluación

wC24 - Volumen de depósitos de retención y tanques de tormenta

Los tanques de tormenta únicamente se incluirán cuando tengan capacidad de almacenamiento.

Tenga en cuenta que "x365/wH1" es una expresión para realizar un cambio de unidades y no debe ser considerado como una extrapolación.

Este indicador puede evaluarse para períodos inferiores a un año, pero los valores resultantes pueden resultar engañosos. Por lo tanto, se recomienda que se evalúe con datos anuales y periodos de más de un año. Cuando se utilice para periodos cortos, se debe de prestar especial atención a las comparaciones, tanto internas como externas al servicio. 
wOp8-Limpieza de depósitos de retención y tanques de tormenta $(-/$ año $)$

(Volumen limpiado de depósitos de retención y tanques de tormenta durante el periodo de evaluación x 365 / periodo de evaluación)/ volumen total de depósitos de retención y tanques de tormenta en la fecha de referencia $(\mathrm{wD} 8 * 365 / \mathrm{wH} 1) / \mathrm{wC} 24$

wD8 - Limpieza de depósitos de retención y tanques de tormenta

wH1 - Periodo de evaluación

wC24 - Volumen de depósitos de retención y tanques de tormenta

Los tanques de tormenta únicamente se incluirán cuando tengan capacidad de almacenamiento.

Tenga en cuenta que "x365/wH1" es una expresión para realizar un cambio de unidades y no debe ser considerado como una extrapolación.

Este indicador puede evaluarse para períodos inferiores a un año, pero los valores resultantes pueden resultar engañosos. Por lo tanto, se recomienda que se evalúe con datos anuales y periodos de más de un año. Cuando se utilice para periodos cortos, se debe de prestar especial atención a las comparaciones, tanto internas como externas al servicio.

\section{wOp9-Inspección de filtros (-/año)}

(Número de filtros asociados con depósitos de retención y tanques de tormenta inspeccionados durante el periodo de evaluación x 365 / periodo de evaluación) / Número de filtros asociados con depósitos de retención y tanques de tormenta, en la fecha de referencia

(wD9*365/wH1)/wC25

wD9 - Inspección de filtros de depósitos de retención y tanques de tormenta wH1 - Periodo de evaluación

wC25 - Filtros de depósitos de retención y tanques de tormenta

Tenga en cuenta que "x365/wH1" es una expresión para realizar un cambio de unidades y no debe ser considerado como una extrapolación.

Este indicador puede evaluarse para periodos inferiores a un año, pero se recomienda que se utilice únicamente cuando los datos de las variables se hayan recogido por lo menos durante un año. Se debe tener especial cuidado en la interpretación de su resultado. Deben evitarse comparaciones externas en dichas bases de tiempo. 


\section{Inspección de bombas y estaciones de bombeo}

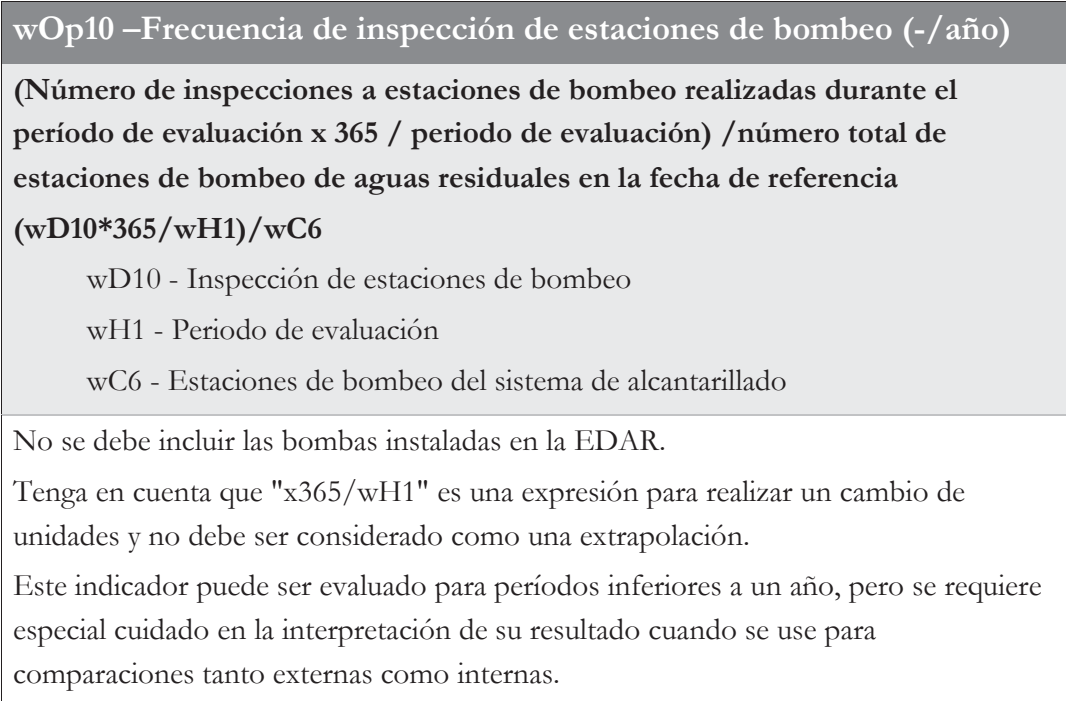

\section{wOp11 -Inspección de bombas por potencia (-/año)}

Potencia nominal total de las bombas y accesorios complementarios sujetos a inspección durante el período de evaluación x 365 / periodo de evaluación) / potencia nominal total de las estaciones de bombeo en la fecha de referencia (wD11*365/wH1)/wC10

wD11 - Inspección de bombas

wH1 - Periodo de evaluación

wC10 - Potencia de bombeo en la red de alcantarillado

No se debe incluir las bombas instaladas en la EDAR.

Tenga en cuenta que "x365/wH1" es una expresión para realizar un cambio de unidades y no debe ser considerado como una extrapolación.

Este indicador puede ser evaluado para períodos inferiores a un año, pero se requiere especial cuidado en la interpretación de su resultado cuando se use para comparaciones tanto externas como internas. 


\section{Calibración de equipos}

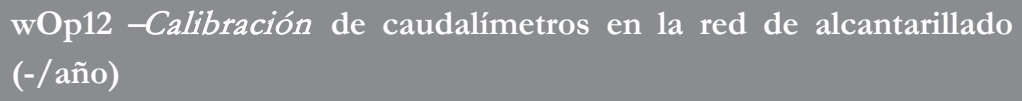

(Número de calibraciones realizadas en caudalímetros de agua permanentemente instalados en la red de alcantarillado durante el periodo de evaluación x 365 / periodo de evaluación) / número de caudalímetros de agua permanentemente instalados en la red de alcantarillado en la fecha de referencia

(wD20*365/wH1)/wC27

wD20 - Calibración de caudalímetros de agua de la red de alcantarillado

wH1 - Periodo de evaluación

wC27 - Caudalímetros de agua de la red de alcantarillado

Tenga en cuenta que "x365/wH1" es una expresión para realizar un cambio de unidades y no debe ser considerado como una extrapolación.

Este indicador puede ser evaluado para períodos inferiores a un año, pero se requiere especial cuidado en la interpretación de su resultado cuando se use para comparaciones tanto externas como internas.

\section{wOp13 - Calibración de caudalímetros en la EDAR (-/año)}

(Número de calibraciones realizadas en caudalímetros de agua permanentemente instalados en las estaciones de depuración de aguas residuales durante el periodo de evaluación x 365 / periodo de evaluación) / número de caudalímetros de agua permanentemente instalados en las estaciones de tratamiento de aguas residuales en la fecha de referencia (wD19*365/wH1)/wC26

wD19 - Calibración de caudalímetros de agua de las EDAR

wH1 - Periodo de evaluación

wC26 - Caudalímetros de agua de la EDAR

Tenga en cuenta que "x365/wH1" es una expresión para realizar un cambio de unidades y no debe ser considerado como una extrapolación.

Este indicador puede ser evaluado para períodos inferiores a un año, pero se requiere especial cuidado en la interpretación de su resultado cuando se use para comparaciones tanto externas como internas. 
wOp14 -Calibración de equipos de monitorización de la calidad del agua residual (-/año)

(Número de calibraciones automáticas en los equipos de monitorización de la calidad del agua residual permanentes realizadas en las estaciones de depuración de aguas residuales durante el periodo de evaluación x 365 / periodo de evaluación) / número de equipos de monitorización de la calidad del agua residual instalados permanentemente en las estaciones depuradoras de aguas residuales, en la fecha de referencia

$(\mathrm{wD} 21 * 365 / \mathrm{wH} 1) / \mathrm{wC} 33$

wD21 - Calibración de equipos de monitorización de la calidad del agua residual

wH1 - Periodo de evaluación

wC33 - Equipos de monitorización de la calidad del agua residual

Tenga en cuenta que "x365/wH1" es una expresión para realizar un cambio de unidades y no debe ser considerado como una extrapolación.

Este indicador puede ser evaluado para períodos inferiores a un año, pero se requiere especial cuidado en la interpretación de su resultado cuando se use para comparaciones tanto externas como internas.

\section{Inspección de equipos eléctricos y de transmisión de señales}

wOp15 -Inspección de los sistemas eléctricos de emergencia (-/año)

(Suma de la potencia nominal de los sistemas eléctricos de emergencia inspeccionados durante el periodo de evaluación x 365 / periodo de evaluación) / potencia nominal total de los sistemas eléctricos de emergencia en la fecha de referencia $\times 100$

(wD22*365/wH1)/wC30*100

wD22 - Inspección de los sistemas eléctricos de emergencia

wH1 - Periodo de evaluación

wC30 - Sistemas eléctricos de emergencia

Tenga en cuenta que "x365/wH1" es una expresión para realizar un cambio de unidades y no debe ser considerado como una extrapolación.

Este indicador puede ser evaluado para períodos inferiores a un año, pero se requiere especial cuidado en la interpretación de su resultado cuando se use para comparaciones tanto externas como internas. 
wOp16 -Inspección de equipos de transmisión de señales (-/año)

(Número de equipos de transmisión de señales inspeccionados durante el periodo de evaluación x 365 / periodo de evaluación) / número total de equipos de transmisión de señales en la fecha de referencia wD23/wC31*100

wD23 - Inspección de equipos de transmisión de señales

wC31 - Equipos de transmisión de señales

Tenga en cuenta que "x365/wH1" es una expresión para realizar un cambio de unidades y no debe ser considerado como una extrapolación.

Este indicador puede ser evaluado para períodos inferiores a un año, pero se requiere especial cuidado en la interpretación de su resultado cuando se use para comparaciones tanto externas como internas.

\section{wOp17 -Inspección de equipos eléctricos (-/año)}

(Número de equipos eléctricos inspeccionados durante el periodo de evaluación x 365 / periodo de evaluación) / número total de equipos eléctricos en la fecha de referencia

(wD24*365/wH1)/wC32*100

wD24 - Inspección de equipos eléctricos

wH1 - Periodo de evaluación

wC32 - Equipos eléctricos

Tenga en cuenta que "x365/wH1" es una expresión para realizar un cambio de unidades y no debe ser considerado como una extrapolación.

Este indicador puede ser evaluado para períodos inferiores a un año, pero se requiere especial cuidado en la interpretación de su resultado cuando se use para comparaciones tanto externas como internas. 


\section{Consumo de energía}

wOp18 -Consumo de energía en el tratamiento de aguas residuales (kWh/p.e./año)

(Energía consumida en los tratamientos de aguas residuales durante el periodo de evaluación x 365 / periodo de evaluación) / población equivalente servida por EDAR gestionadas por el servicio, en la fecha de referencia $($ wD13*365/wH1)/wE5

wD13 - Energía consumida en los tratamientos de aguas residuales

wH1 - Periodo de evaluación

wE5 - Población equivalente servida con EDAR

Los sistemas in-situ están incluidos como tratamientos de aguas residuales. El procesado termal de los lodos no debe incluirse.

Tenga en cuenta que "x365/wH1" es una expresión para realizar un cambio de unidades y no debe ser considerado como una extrapolación.

Este indicador puede ser evaluado para períodos inferiores a un año, pero se requiere especial cuidado en la interpretación de su resultado cuando se use para comparaciones tanto externas como internas.

wOp19 -Recuperación de energía en el tratamiento de aguas residuales través de procesos de cogeneración (\%)

Energía producida por procesos de cogeneración /energía consumida en los tratamientos de aguas residuales gestionadas por el servicio $\mathrm{x} 100$, durante el periodo de evaluación

wD17/wD13*100

wD17 - Energía generada por cogeneración

wD13 - Energía consumida en los tratamientos de aguas residuales

Tenga en cuenta que "x365/wH1" es una expresión para realizar un cambio de unidades y no debe ser considerado como una extrapolación.

Este indicador puede ser evaluado para períodos inferiores a un año, pero se requiere especial cuidado en la interpretación de su resultado cuando se use para comparaciones tanto externas como internas. 
wOp20 -Consumo de energía estándar $\left(\mathrm{kWh} / \mathrm{m}^{3} / \mathrm{m}\right)$

Consumo de energía al bombear aguas residuales / $\sum$ (volumen bombeado de aguas residuales $\mathrm{x}$ altura de la bomba en metros), durante el periodo de evaluación

wD12/wD16

wD12 - Consumo de energía en las bombas

wD16 - Factor de normalización

Tenga en cuenta que "x365/wH1" es una expresión para realizar un cambio de unidades y no debe ser considerado como una extrapolación.

Este indicador puede ser evaluado para períodos inferiores a un año, pero se requiere especial cuidado en la interpretación de su resultado cuando se use para comparaciones tanto externas como internas.

\section{Rehabilitación de colectores}

\section{wOp21 -Rehabilitación de colectores (\%/año)}

(Longitud de colectores defectuosos rehabilitados durante el periodo de evaluación x 365 / periodo de evaluación) / longitud total de la red de alcantarillado en la fecha de referencia $\times 100$

$(\mathrm{wD} 25 * 365 / \mathrm{wH} 1) / \mathrm{wC} 1 * 100$

wD25 - Rehabilitación de colectores

wH1 - Periodo de evaluación

wC1 - Longitud de la red de alcantarillado

Tenga en cuenta que "x365/wH1" es una expresión para realizar un cambio de unidades y no debe ser considerado como una extrapolación.

Este indicador puede evaluarse para periodos inferiores a un año, pero se recomienda que se utilice únicamente cuando los datos de las variables se hayan recogido por lo menos durante un año. Se debe tener especial cuidado en la interpretación de su resultado. Deben evitarse comparaciones externas en dichas bases de tiempo. 
wOp22 -Restauración de colectores (\%/año)

(Longitud de colectores defectuosos restaurados durante el periodo de evaluación x 365 / periodo de evaluación) / longitud total de la red de alcantarillado en la fecha de referencia $\times 100$

$(\mathrm{wD} 26 * 365 / \mathrm{wH} 1) / \mathrm{wC} 1 * 100$

wD26 - Restauración de colectores

wH1 - Periodo de evaluación

wC1 - Longitud de la red de alcantarillado

Tenga en cuenta que "x365/wH1" es una expresión para realizar un cambio de unidades y no debe ser considerado como una extrapolación.

Este indicador puede evaluarse para periodos inferiores a un año, pero se recomienda que se utilice únicamente cuando los datos de las variables se hayan recogido por lo menos durante un año. Se debe tener especial cuidado en la interpretación de su resultado. Deben evitarse comparaciones externas en dichas bases de tiempo.

\section{wOp23 -Sustitución de colectores (\%/año)}

(Longitud de colectores defectuosos sustituidos o renovados durante el periodo de evaluación x 365 / periodo de evaluación) / longitud total de la red de alcantarillado en la fecha de referencia $\mathrm{x} 100$ $(\mathrm{wD} 27 * 365 / \mathrm{wH} 1) / \mathrm{wC} 1 * 100$

wD27 - Sustitución de colectores

wH1 - Periodo de evaluación

wC1 - Longitud de la red de alcantarillado

Tenga en cuenta que "x365/wH1" es una expresión para realizar un cambio de unidades y no debe ser considerado como una extrapolación.

Este indicador puede evaluarse para periodos inferiores a un año, pero se recomienda que se utilice únicamente cuando los datos de las variables se hayan recogido por lo menos durante un año. Se debe tener especial cuidado en la interpretación de su resultado. Deben evitarse comparaciones externas en dichas bases de tiempo. 
wOp24 -Reparación de colectores y juntas (No./ $100 \mathrm{~km}$ $\mathrm{red} / \mathrm{año)}$

(Número de reparaciones llevadas a cabo en colectores defectuosos u uniones en el periodo de evaluación x 365 / periodo de evaluación) / longitud total de la red de alcantarillado en la fecha de referencia x 100 (wD28*365/wH1)/wC1*100

wD28 - Reparación de colectores y uniones

wH1 - Periodo de evaluación

wC1 - Longitud de la red de alcantarillado

Tenga en cuenta que "x365/wH1" es una expresión para realizar un cambio de unidades y no debe ser considerado como una extrapolación.

Este indicador puede evaluarse para periodos inferiores a un año, pero se recomienda que se utilice únicamente cuando los datos de las variables se hayan recogido por lo menos durante un año. Se debe tener especial cuidado en la interpretación de su resultado. Deben evitarse comparaciones externas en dichas bases de tiempo.

wOp25 -Sustitución, renovación o rehabilitación de pozos de registro (\%/año)

(Número de pozos de registro sustituidos, renovados o rehabilitados durante el periodo de evaluación x 365 / periodo de evaluación) / número de pozos de registro en la red de alcantarillado en la fecha de referencia x 100

(wD29*365/wH1)/wC21*100

wD29 - Sustitución, renovación o reparación de pozos de registro

wH1 - Periodo de evaluación

wC21 - Pozos de registro

Tenga en cuenta que "x365/wH1" es una expresión para realizar un cambio de unidades y no debe ser considerado como una extrapolación.

Este indicador puede evaluarse para periodos inferiores a un año, pero se recomienda que se utilice únicamente cuando los datos de las variables se hayan recogido por lo menos durante un año. Se debe tener especial cuidado en la interpretación de su resultado. Deben evitarse comparaciones externas en dichas bases de tiempo. 
wOp26 -Sustitución de tapas de pozos de registro (\%/año)

(Número de tapas de pozos de registro sustituidas durante el periodo de evaluación x 365 / periodo de evaluación) / número de pozos de registro en la red de alcantarillado en la fecha de referencia x 100

\section{$(\mathrm{wD} 30 * 365 / \mathrm{wH} 1) / \mathrm{wC} 21 * 100$}

wD30 - Sustitución de tapas de pozos de registro

wH1 - Periodo de evaluación

wC21 - Pozos de registro

Tenga en cuenta que "x365/wH1" es una expresión para realizar un cambio de unidades y no debe ser considerado como una extrapolación.

Este indicador puede evaluarse para periodos inferiores a un año, pero se recomienda que se utilice únicamente cuando los datos de las variables se hayan recogido por lo menos durante un año. Se debe tener especial cuidado en la interpretación de su resultado. Deben evitarse comparaciones externas en dichas bases de tiempo.

\section{wOp27 -Rehabilitación de acometidas (\%/año)}

(Número de acometidas sustituidas o renovadas durante el período de evaluación x 365 / periodo de evaluación) / número total de acometidas en la fecha de referencia $\times 100$

\section{$(\mathrm{wD} 31 * 365 / \mathrm{wH} 1) / \mathrm{wC} 29 * 100$}

wD31 - Sustitución o renovación de acometidas

wH1 - Periodo de evaluación

wC29 - Acometidas

Tenga en cuenta que "x365/wH1" es una expresión para realizar un cambio de unidades y no debe ser considerado como una extrapolación.

Este indicador puede evaluarse para periodos inferiores a un año, pero se recomienda que se utilice únicamente cuando los datos de las variables se hayan recogido por lo menos durante un año. Se debe tener especial cuidado en la interpretación de su resultado. Deben evitarse comparaciones externas en dichas bases de tiempo. 


\section{Rehabilitación de bombas}

\section{wOp28 -Rehabilitación de bombas (\%/año)}

(Potencia nominal total de las bombas sujetas a rehabilitación durante el periodo de evaluación x 365 / periodo de evaluación) / potencia nominal total de las bombas de aguas residuales en la fecha de referencia x 100

(wD32*365/wH1)/wC8*100

wD32 - Rehabilitación de bombas

wH1 - Periodo de evaluación

wC8 - Potencia de las bombas instaladas de aguas residuales

La rehabilitación incluye la sustitución parcial de elementos de la bomba.

Tenga en cuenta que "x365/wH1" es una expresión para realizar un cambio de unidades y no debe ser considerado como una extrapolación.

Este indicador puede evaluarse para periodos inferiores a un año, pero se recomienda que se utilice únicamente cuando los datos de las variables se hayan recogido por lo menos durante un año. Se debe tener especial cuidado en la interpretación de su resultado. Deben evitarse comparaciones externas en dichas bases de tiempo.

\section{wOp29 -Sustitución de bombas (\%/año)}

(Potencia nominal de las bombas sustituidas durante el periodo de evaluación x 365 / periodo de evaluación) / potencia nominal total de las bombas de aguas residuales en la fecha de referencia $\mathrm{x} 100$

$(\mathrm{wD} 33 * 365 / \mathrm{wH} 1) / \mathrm{wC} 8 * 100$

wD33 - Sustitución de bombas

wH1 - Periodo de evaluación

wC8 - Potencia de las bombas instaladas de aguas residuales

Este indicación se refiere exclusivamente a la sustición total de la bomba y el motor. Tenga en cuenta que "x365/wH1" es una expresión para realizar un cambio de unidades y no debe ser considerado como una extrapolación.

Este indicador puede evaluarse para periodos inferiores a un año, pero se recomienda que se utilice únicamente cuando los datos de las variables se hayan recogido por lo menos durante un año. Se debe tener especial cuidado en la interpretación de su resultado. Deben evitarse comparaciones externas en dichas bases de tiempo. 


\section{Entrada / Infiltración / Exfiltración (E/I/E)}

\section{wOp30 -Entrada / Infiltración / Exfiltración (E/I/E) (\%)}

Volumen de agua que entra en la red de alcantarillado, desde el agua subterránea que se infiltra hasta el agua proveniente de las conexiones erróneas, menos las fugas de la red / (agua residual recolectada + infiltración + entrada - exfiltración) x 100, durante el periodo de evaluación (wD35+wD36-wD37)/(wF1+wD35+wD36-wD37)*100

wD35 - Volumen de entrada

wD36 - Volumen infiltrado

wD37 - Volumen exflitrado

$\mathrm{wF} 1$ - Agna residual recolectada

Este indicador puede ser evaluado para períodos inferiores a un año, pero se requiere especial cuidado en la interpretación de su resultado cuando se use para comparaciones tanto externas como internas.

\section{wOp31 -Entrada $\left(\mathrm{m}^{3} / \mathrm{km} /\right.$ año $)$}

(Volumen de agua que entra en el sistema de alcantarillado debido a conexiones erróneas durante el periodo de evaluación x 365 / periodo de evaluación) / longitud total de la red de alcantarillado en la fecha de referencia $(w D 35 * 365 / w H 1) / w C 1$

wD35 - Volumen de entrada

wH1 - Periodo de evaluación

wC1 - Longitud de la red de alcantarillado

Tenga en cuenta que "x365/wH1" es una expresión para realizar un cambio de unidades y no debe ser considerado como una extrapolación.

Este indicador puede ser evaluado para períodos inferiores a un año, pero se requiere especial cuidado en la interpretación de su resultado cuando se use para comparaciones tanto externas como internas. 


\section{wOp32 -Infiltración $\left(\mathrm{m}^{3} / \mathrm{km} /\right.$ año $)$}

(Volumen de agua subterránea que entra a los colectores durante el período de evaluación x 365 / periodo de evaluación) / longitud total de la red de alcantarillado en la fecha de referencia

(wD36*365/wH1)/wC1

wD36 - Volumen infiltrado

wH1 - Periodo de evaluación

wC1 - Longitud de la red de alcantarillado

Tenga en cuenta que "x365/wH1" es una expresión para realizar un cambio de unidades y no debe ser considerado como una extrapolación.

Este indicador puede ser evaluado para períodos inferiores a un año, pero se requiere especial cuidado en la interpretación de su resultado cuando se use para

comparaciones tanto externas como internas.

\section{wOp33 - Exfiltración ( $\mathrm{m}^{3} / \mathrm{km} /$ año $)$}

(Volumen de aguas residuales fugadas desde la red al exterior durante el período de evaluación x 365 / periodo de evaluación) / longitud total de la red de alcantarillado en la fecha de referencia

$(\mathrm{wD} 37 * 365 / \mathrm{wH} 1) / \mathrm{wC} 1$

wD37 - Volumen exflitrado

wH1 - Periodo de evaluación

wC1 - Longitud de la red de alcantarillado

Tenga en cuenta que "x365/wH1" es una expresión para realizar un cambio de unidades y no debe ser considerado como una extrapolación.

Este indicador puede ser evaluado para períodos inferiores a un año, pero se requiere especial cuidado en la interpretación de su resultado cuando se use para comparaciones tanto externas como internas. 


\section{Averías}

wOp34 -Atascos de colectores (No./100 km red/año)

(Número de atascos que ocurrieron en los colectores durante el periodo de evaluación x 365 / periodo de evaluación) / longitud total de la red de alcantarillado en la fecha de referencia $\times 100$

(wD38*365/wH1)/wC1*100

wD38 - Atascos de colectores

wH1 - Periodo de evaluación

wC1 - Longitud de la red de alcantarillado

No se deben incluir los atascos en las estaciones de bombeo. Los atascos en las acometidas se deben incluir únicamente si son responsabilidad del servicio de saneamiento.

Tenga en cuenta que "x365/wH1" es una expresión para realizar un cambio de unidades y no debe ser considerado como una extrapolación.

Este indicador puede ser evaluado para períodos inferiores a un año, pero se requiere especial cuidado en la interpretación de su resultado cuando se use para comparaciones tanto externas como internas.

wOp35 -Puntos de atasco de colectores (No./100 km red/año)

(Número de puntos individuales en los colectores donde ocurrieron atascos durante el periodo de evaluación x 365 / periodo de evaluación) / longitud total de la red de alcantarillado en la fecha de referencia x100 $(\mathrm{wD} 39 * 365 / \mathrm{wH} 1) / \mathrm{wC} 1 * 100$

wD39 - Puntos de atasco de colectores

wH1 - Periodo de evaluación

wC1 - Longitud de la red de alcantarillado

Los puntos de atasco frecuentes sólo se contabilizarán una vez. No se deben incluir los atascos en las estaciones de bombeo. Los puntos de atasco en las acometidas únicamente se contabilizarán si éstas son responsabilidad del servicio de saneamiento.

Tenga en cuenta que "x365/wH1" es una expresión para realizar un cambio de unidades y no debe ser considerado como una extrapolación.

Este indicador puede ser evaluado para períodos inferiores a un año, pero se requiere especial cuidado en la interpretación de su resultado cuando se use para comparaciones tanto externas como internas. 
wOp36-Atascos en estaciones de bombeo (No./estación de bombeo/año)

(Número de atascos que ocurrieron en estaciones de bombeo durante el periodo de evaluación x 365 / periodo de evaluación) /número de estaciones de bombeo de aguas residuales en la red de alcantarillado en la fecha de referencia

$(\mathrm{wD} 40 * 365 / \mathrm{wH} 1) / \mathrm{wC} 6 * 100$

wD40 - Atasco de estaciones de bombeo

wH1 - Periodo de evaluación

wC6 - Estaciones de bombeo del sistema de alcantarillado

Los atascos en las estaciones de bombeo incluyen los atascos en las bombas y válvulas. Los atascos en los colectores no deben incluirse.

Tenga en cuenta que "x365/wH1" es una expresión para realizar un cambio de unidades y no debe ser considerado como una extrapolación.

Este indicador puede ser evaluado para períodos inferiores a un año, pero se requiere especial cuidado en la interpretación de su resultado cuando se use para comparaciones tanto externas como internas.

wOp37 -Inundaciones de colectores de aguas negras (No./100 km $\mathrm{red} / \mathrm{año)}$

(Número de inundaciones producidas por colectores de aguas negras durante el periodo de evaluación x 365 / periodo de evaluación) / longitud total de la red de alcantarillado en la fecha de referencia $\times 100$

$(\mathrm{wD} 41 * 365 / \mathrm{wH} 1) / \mathrm{wC} 1 * 100$

wD41 - Inundaciones debidas a colectores de aguas negras

wH1 - Periodo de evaluación

wC1 - Longitud de la red de alcantarillado

Se deben incluir únicamente los incidentes producidos en colectores de aguas residuales que sean responsabilidad del servicio de saneamiento.

Tenga en cuenta que "x365/wH1" es una expresión para realizar un cambio de unidades y no debe ser considerado como una extrapolación.

Este indicador puede evaluarse para periodos inferiores a un año, pero se recomienda que se utilice únicamente cuando los datos de las variables se hayan recogido por lo menos durante un año. Se debe tener especial cuidado en la interpretación de su resultado. Deben evitarse comparaciones externas en dichas bases de tiempo. 
wOp38 -Inundaciones de colectores unitarios (No./100 km red/año)

(Número de inundaciones producidas por colectores unitarios durante el periodo de evaluación x 365 / periodo de evaluación) / longitud total de la red de alcantarillado en la fecha de referencia x100

$(\mathrm{wD} 42 * 365 / \mathrm{wH} 1) / \mathrm{wC} 1 * 100$

wD42 - Inundaciones debidas a colectores unitarios

wH1 - Periodo de evaluación

wC1 - Longitud de la red de alcantarillado

Se deben incluir únicamente los incidentes producidos en colectores unitarios que sean responsabilidad del servicio de saneamiento.

Tenga en cuenta que "x365/wH1" es una expresión para realizar un cambio de unidades y no debe ser considerado como una extrapolación.

Este indicador puede evaluarse para periodos inferiores a un año, pero se recomienda que se utilice únicamente cuando los datos de las variables se hayan recogido por lo menos durante un año. Se debe tener especial cuidado en la interpretación de su resultado. Deben evitarse comparaciones externas en dichas bases de tiempo.

\section{wOp39 -Inundaciones superficiales (No./100 km red/año)}

(Número de inundaciones de la superficie que ocurrieron durante el periodo de evaluación x 365 / periodo de evaluación) / longitud total de la red de alcantarillado en la fecha de referencia $\times 100$

(wD43*365/wH1)/wC1*100

wD43 - Inundaciones superficiales

wH1 - Periodo de evaluación

wC1 - Longitud de la red de alcantarillado

Estos incluyen solo inundaciones superficiales debido a la insuficiencia del sistema de drenaje pluvial (incluidos los colectores unitarios) que son responsabilidad del servicio de saneamiento. La insuficiencia se relaciona con todas las causas (por ejemplo, diseño, operación, etc.).

Tenga en cuenta que "x365/wH1" es una expresión para realizar un cambio de unidades y no debe ser considerado como una extrapolación.

Este indicador puede evaluarse para periodos inferiores a un año, pero se recomienda que se utilice únicamente cuando los datos de las variables se hayan recogido por lo menos durante un año. Se debe tener especial cuidado en la interpretación de su resultado. Deben evitarse comparaciones externas en dichas bases de tiempo. 
wOp40 - Colapso de colectores (No./100 km red/año)

(Número de colectores que han colapsado durante el periodo de evaluación $\mathbf{x}$ 365 / periodo de evaluación) / longitud total de la red de alcantarillado en la fecha de referencia $\mathrm{x} 100$

$(\mathrm{wD} 44 * 365 / \mathrm{wH} 1) / \mathrm{wC} 1 * 100$

wD44 - Colapso de colectores

wH1 - Periodo de evaluación

wC1 - Longitud de la red de alcantarillado

No se deben incluir los colapsos en las acometidas.

Tenga en cuenta que "x365/wH1" es una expresión para realizar un cambio de unidades y no debe ser considerado como una extrapolación.

Este indicador puede evaluarse para periodos inferiores a un año, pero se recomienda que se utilice únicamente cuando los datos de las variables se hayan recogido por lo menos durante un año. Se debe tener especial cuidado en la interpretación de su resultado. Deben evitarse comparaciones externas en dichas bases de tiempo.

\section{wOp41 -Averías de bombas (horas/bomba/año)}

(Suma, para todas las bombas, del número de horas que cada bomba ha estado averiada, durante el periodo de evaluación x 365 / periodo de evaluación) / Número total de bombas en la red de alcantarillado gestionadas por el servicio, en la fecha de referencia

(wD34*365/wH1)/wC7

wD34 - Bombas averiadas

wH1 - Periodo de evaluación

wC7 - Bombas de la red de alcantarillado

Las bombas de las EDAR no se deben incluir.

Tenga en cuenta que "x365/wH1" es una expresión para realizar un cambio de unidades y no debe ser considerado como una extrapolación.

Este indicador puede evaluarse para periodos inferiores a un año, pero se recomienda que se utilice únicamente cuando los datos de las variables se hayan recogido por lo menos durante un año. Se debe tener especial cuidado en la interpretación de su resultado. Deben evitarse comparaciones externas en dichas bases de tiempo. V 
wOp42 -Averías eléctricas (horas/estación de bombeo/año)

(Suma, para todas las bombas, del número de horas en las que cada estación de servicio ha estado fuera de servicio durante el periodo de evaluación, debido a interrupciones en el suministro de energía x 365 / periodo de evaluación) /número de estaciones de bombeo de aguas residuales en la red de alcantarillado en la fecha de referencia

(wD18*365/wH1)/wC6

wD18 - Averías eléctricas

wH1 - Periodo de evaluación

wC6 - Estaciones de bombeo del sistema de alcantarillado

Este indicador evalúa el tiempo en que la estación está fuera de servicio debido a averías eléctricas, sin tener en cuenta la fuente de electricidad utilizada (sistema de generación normal o de reserva). Esto significa que el tiempo en el que una estación de bombeo está funcionando con el generador de reserva no debería ser contado como una avería eléctrica. Este indicador pretende medir el desempeño del servicio de saneamiento, no del servicio eléctrico.

Este indicador puede evaluarse para periodos inferiores a un año, pero se recomienda que se utilice únicamente cuando los datos de las variables se hayan recogido por lo menos durante un año. Se debe tener especial cuidado en la interpretación de su resultado. Deben evitarse comparaciones externas en dichas bases de tiempo.

\section{Control de tanques de tormenta}

\section{wOp43-Control de tanques de tormenta ( $\%)$}

Número de tanques de tormenta controlados por reguladores de caudal dinámicos o estáticos en la fecha de referencia / número total de tanques de tormenta $\mathrm{x} 100$, en la fecha de referencia wD45/wC20*100

wD45 - Control de tanques de tormenta wC20 - Número de tanques de tormenta 


\section{Monitorización de la calidad de aguas residuales y lodos}

wOp44 -Ensayos realizados de calidad del agua residual (-/año)

(Número total de ensayos de calidad del agua residual realizados durante el periodo de evaluación x 365 / periodo de evaluación) / número total de ensayos de calidad de aguas residuales requeridos por las normas o la legislación aplicables, durante el periodo de evaluación (wD46*365/wH1)/wD57

wD46 - Ensayos realizados de calidad del agua residual

wH1 - Periodo de evaluación

wD57 - Ensayos requeridos de calidad del agua residual

Este indicador sólo considerará los ensayos que son responsabilidad del servicio, realizados en puntos donde la monitorización de la calidad del agua residual es obligatoria.

Tenga en cuenta que "x365/wH1" es una expresión para realizar un cambio de unidades y no debe ser considerado como una extrapolación.

Este indicador puede evaluarse para periodos inferiores a un año, pero se recomienda que se utilice únicamente cuando los datos de las variables se hayan recogido por lo menos durante un año. Se debe tener especial cuidado en la interpretación de su resultado. Deben evitarse comparaciones externas en dichas bases de tiempo. 
wOp45 -Ensayos de DBO (-/año)

(Número de ensayos de DBO realizados durante el periodo de evaluación x 365 / periodo de evaluación) / número de ensayos de DBO requeridos por las normas o la legislación aplicables, durante el periodo de evaluación

(wD48*365/wH1)/wD58

wD48 - Ensayos de DBO realizados

wH1 - Periodo de evaluación

wD58 - Ensayos de DBO requeridos

Este indicador sólo considerará los ensayos que son responsabilidad del servicio, realizados en puntos donde la monitorización de la calidad del agua residual es obligatoria.

Tenga en cuenta que "x365/wH1" es una expresión para realizar un cambio de unidades y no debe ser considerado como una extrapolación.

Este indicador puede evaluarse para periodos inferiores a un año, pero se recomienda que se utilice únicamente cuando los datos de las variables se hayan recogido por lo menos durante un año. Se debe tener especial cuidado en la interpretación de su resultado. Deben evitarse comparaciones externas en dichas bases de tiempo. 
wOp46 -Ensayos DQO (-/año)

(Número de ensayos de DQO realizados durante el periodo de evaluación x 365 / periodo de evaluación) / número de ensayos de DQO requeridos por las normas o la legislación aplicables, durante el periodo de evaluación

(wD49*365/wH1)/wD59

wD49 - Ensayos de DQO realizados

wH1 - Periodo de evaluación

wD59 - Ensayos de DQO requeridos

Este indicador sólo considerará los ensayos que son responsabilidad del servicio, realizados en puntos donde la monitorización de la calidad del agua residual es obligatoria.

Tenga en cuenta que "x365/wH1" es una expresión para realizar un cambio de unidades y no debe ser considerado como una extrapolación.

Este indicador puede evaluarse para periodos inferiores a un año, pero se recomienda que se utilice únicamente cuando los datos de las variables se hayan recogido por lo menos durante un año. Se debe tener especial cuidado en la interpretación de su resultado. Deben evitarse comparaciones externas en dichas bases de tiempo. 
wOp47 -Ensayo de sólidos suspendidos (-/año)

(Número de ensayos de sólidos suspendidos realizados durante el periodo de evaluación x 365 / periodo de evaluación) / número de ensayos de sólidos suspendidos requeridos por las normas o la legislación aplicables, durante el periodo de evaluación (wD50*365/wH1)/wD60

wD50 - Ensayo de sólidos suspendidos realizados

wH1 - Periodo de evaluación

wD60 - Ensayo de sólidos suspendidos requeridos

Este indicador sólo considerará los ensayos que son responsabilidad del servicio, realizados en puntos donde la monitorización de la calidad del agua residual es obligatoria.

Tenga en cuenta que "x365/wH1" es una expresión para realizar un cambio de unidades y no debe ser considerado como una extrapolación.

Este indicador puede evaluarse para periodos inferiores a un año, pero se recomienda que se utilice únicamente cuando los datos de las variables se hayan recogido por lo menos durante un año. Se debe tener especial cuidado en la interpretación de su resultado. Deben evitarse comparaciones externas en dichas bases de tiempo. 
wOp48 -Ensayos de fósforo (-/año)

(Número de ensayos de fósforo realizados durante el periodo de evaluación x 365 / periodo de evaluación) / número de ensayos de fósforo requeridos por las normas o la legislación aplicables, durante el periodo de evaluación

(wD51*365/wH1)/wD61

wD51 - Ensayos de fósforo realizados

wH1 - Periodo de evaluación

wD61 - Ensayos de fósforo requeridos

Este indicador sólo considerará los ensayos que son responsabilidad del servicio, realizados en puntos donde la monitorización de la calidad del agua residual es obligatoria.

Tenga en cuenta que "x365/wH1" es una expresión para realizar un cambio de unidades y no debe ser considerado como una extrapolación.

Este indicador puede evaluarse para periodos inferiores a un año, pero se recomienda que se utilice únicamente cuando los datos de las variables se hayan recogido por lo menos durante un año. Se debe tener especial cuidado en la interpretación de su resultado. Deben evitarse comparaciones externas en dichas bases de tiempo. 
wOp49-Ensayos de nitrógeno (-/año)

(Número de ensayos de nitrógeno realizados durante el periodo de evaluación x 365 / periodo de evaluación) / número de ensayos de nitrógeno requeridos por las normas o la legislación aplicables, durante el periodo de evaluación.

(wD52*365/wH1)/wD62

wD52 - Ensayos de nitrógeno realizados

wH1 - Periodo de evaluación

wD62 - Ensayos de nitrógeno requeridos

Número total de esnayos que evalúan el nitrógeno y los compuestos que contienen nitrógeno.

Este indicador sólo considerará los ensayos que son responsabilidad del servicio, realizados en puntos donde la monitorización de la calidad del agua residual es obligatoria.

Tenga en cuenta que "x365/wH1" es una expresión para realizar un cambio de unidades y no debe ser considerado como una extrapolación.

Este indicador puede evaluarse para periodos inferiores a un año, pero se recomienda que se utilice únicamente cuando los datos de las variables se hayan recogido por lo menos durante un año. Se debe tener especial cuidado en la interpretación de su resultado. Deben evitarse comparaciones externas en dichas bases de tiempo. 
wOp50 -Ensayos de e. coli fecales (-/año)

(Número de ensayos de e. coli fecales realizados durante el periodo de evaluación x 365 / periodo de evaluación) / número de ensayos de e. coli fecales requeridos por las normas o la legislación aplicables, durante el periodo de evaluación

(wD53*365/wH1)/wD63

wD53 - Ensayos de e. coli fecales realizados

wH1 - Periodo de evaluación

wD63 - Ensayos de e. coli fecales requeridos

Este indicador sólo considerará los ensayos que son responsabilidad del servicio, realizados en puntos donde la monitorización de la calidad del agua residual es obligatoria.

Tenga en cuenta que "x365/wH1" es una expresión para realizar un cambio de unidades y no debe ser considerado como una extrapolación.

Este indicador puede evaluarse para periodos inferiores a un año, pero se recomienda que se utilice únicamente cuando los datos de las variables se hayan recogido por lo menos durante un año. Se debe tener especial cuidado en la interpretación de su resultado. Deben evitarse comparaciones externas en dichas bases de tiempo. 
wOp51 -Otros ensayos (-/año)

(Número de otros ensayos de calidad del agua residuales realizados durante el periodo de evaluación x 365 / periodo de evaluación) / número de otros ensayos de calidad de aguas residuales requeridos por las normas o la legislación aplicables, durante el periodo de evaluación (wD54*365/wH1)/wD64

wD54 - Otros test de calidad del agua residual realizados

wH1 - Periodo de evaluación

wD64 - Otros test de calidad del agua residual requeridos

Este indicador sólo considerará los ensayos que son responsabilidad del servicio, realizados en puntos donde la monitorización de la calidad del agua residual es obligatoria.

Tenga en cuenta que "x365/wH1" es una expresión para realizar un cambio de unidades y no debe ser considerado como una extrapolación.

Este indicador puede evaluarse para periodos inferiores a un año, pero se recomienda que se utilice únicamente cuando los datos de las variables se hayan recogido por lo menos durante un año. Se debe tener especial cuidado en la interpretación de su resultado. Deben evitarse comparaciones externas en dichas bases de tiempo. 
wOp52 -Ensayos realizados de lodos (-/año)

(Número de ensayos realizados de lodos producidos durante el periodo de evaluación x 365 / periodo de evaluación) / número de ensayos de lodos requeridos por las normas o la legislación aplicables, durante el periodo de evaluación

(wD55*365/wH1)/wD65

wD55 - Ensayos realizados de lodos

wH1 - Periodo de evaluación

wD65 - Ensayos requeridos de lodos

Este indicador sólo considerará los ensayos que son responsabilidad del servicio, realizados en puntos donde la monitorización de la calidad del agua residual es obligatoria.

Tenga en cuenta que "x365/wH1" es una expresión para realizar un cambio de unidades y no debe ser considerado como una extrapolación.

Este indicador puede evaluarse para periodos inferiores a un año, pero se recomienda que se utilice únicamente cuando los datos de las variables se hayan recogido por lo menos durante un año. Se debe tener especial cuidado en la interpretación de su resultado. Deben evitarse comparaciones externas en dichas bases de tiempo.

\section{wOp53 -Ensayos realizados de vertidos industriales (-/año)}

(Número de ensayos realizados de vertidos industriales en la red de alcantarillado durante el periodo de evaluación x 365 / periodo de evaluación) / número de ensayos de vertidos industriales requeridos por las normas o la legislación aplicables, durante el periodo de evaluación

(wD56*365/wH1)/wD66

wD56 - Ensayos realizados de vertidos industriales

wH1 - Periodo de evaluación

wD66 - Ensayos requeridos de vertidos industriales

Este indicador sólo considerará los ensayos realizados en puntos donde la monitorización de la calidad del agua residual es obligatoria.

Tenga en cuenta que "x365/wH1" es una expresión para realizar un cambio de unidades y no debe ser considerado como una extrapolación.

Este indicador puede evaluarse para periodos inferiores a un año, pero se recomienda que se utilice únicamente cuando los datos de las variables se hayan recogido por lo menos durante un año. Se debe tener especial cuidado en la interpretación de su resultado. Deben evitarse comparaciones externas en dichas bases de tiempo. 


\section{Disponibilidad de vehículos}

wOp54 -Disponibilidad de vehículos (No./100 km red)

Número promedio diario de vehículos disponibles para trabajos de campo relacionado / longitud total de la red de alcantarillado en la fecha de referencia x100

wD67/wC1*100

wD67 - Vehículos permanentes

wC1 - Longitud de la red de alcantarillado

En el caso de prestadores con más de un servicio, sólo se considerará la proporción de vehículos que estén relacionados con las actividades del servicio de saneamiento. Todos los vehículos disponibles se contabilizarán, independientemente de su propiedad, prestador o subcontratistas. Se excluirán los vehículos utilizados en el ámbito de actividades subcontratadas. No se incluirá la maquinaria pesada.

\section{Equipamiento de seguridad}

wOp55 -Detectores de gas (No./empleado)

Número de detectores de gas (incluyendo: $\mathrm{O} 2, \mathrm{H} 2 \mathrm{~S}, \mathrm{CH} 4$ y CO2) / personal de operaciones y mantenimiento, en la fecha de referencia wD68/wB12

wD68 - Detectores de gas

wB12 - Personal de operaciones y mantenimiento

Todos los detectores de gas que estén disponibles serán contabilizados, independientemente de su propiedad (prestador del servicio o subcontratista). Se deben incluir tanto los detectores de gas instalados permanentemente como los portátiles, siempre que estén calibrados.

\section{wOp56 -Detectores de gas instalados permanentemente (\%)}

Número de detectores de gas permanentemente instalados (incluyendo: O2, H2S, CH4 y CO2) / número de detectores de gas x 100, en la fecha de referencia

wD69/wD68*100

wD69 - Detectores de gas permanentemente instalados

wD68 - Detectores de gas 


\subsection{Indicadores de calidad del servicio}

Los indicadores de calidad de servicio miden el nivel de servicio prestado a los usuarios. Las áreas a evaluar incluyen el nivel de cobertura del servicio, inundaciones, interrupciones y relaciones con los usuarios, como son la respuesta a solicitudes y quejas, daños a terceros y la interrupción del tráfico causada por la realización de actividades relacionadas con el servicio de saneamiento.

\section{Población servida}

\section{wQS1 -Población residente conectada a la red de alcantarillado(\%)}

Población residente conectada a la red de alcantarilladogestionada por el servicio / población residente $\mathrm{x} 100$, en la fecha de referencia wE4/wE1*100

wE4 - Población residente conectada a la red de colectores wE1 - Población residente

\section{wQS2 -Población residente servida por la EDAR (\%)}

Población residente servida por estaciones depuradoras de agua residual gestionadas por el servicio/ población residente $\mathrm{x} 100$, en la fecha de referencia wE2/wE1*100

wE2 - Población residente servida por estaciones depuradoras de aguas residuales

wE1 - Población residente

\section{wQS3 -Población residente servida por sistemas in-situ ( $\%)$}

Población residente servida por sistemas in-situ gestionados por el servicio / población residente $\mathrm{x} \mathbf{1 0 0}$, en la fecha de referencia wE3/wE1*100

wE3 - Población residente servida por sistemas in-situ wE1 - Población residente 
wQS4 -Población residente no servida (\%)

Población residente cuya agua residual no es ni recogida ni tratada / población residente $\mathrm{x} \mathbf{1 0 0}$, en la fecha de referencia wE7/wE1*100

wE7 - Población residente sin servicio

wE1 - Población residente

\section{Tratamiento de aguas residuales}

\section{wQS5 -Aguas residuales tratadas en la EDAR (\%)}

Volumen de agua residual tratada en las estaciones depuradoras de aguas residuales / agua residual recolectada x 100, durante el periodo de referencia (wA2-wA11)/wF1*100

wA2 - Volumen de agua tratada

wA11 - Agua residual tratada en sistemas in-situ

$\mathrm{wF} 1$ - Agua residual recolectada

Este indicador puede evaluarse para periodos inferiores a un año, pero se recomienda que se utilice únicamente cuando los datos de las variables se hayan recogido por lo menos durante un año. Se debe tener especial cuidado en la interpretación de su resultado. Deben evitarse comparaciones externas en dichas bases de tiempo.

wQS6 - Pretratamiento (\%)

Volumen de agua residual que recibe únicamente pretratamiento en las EDAR/ agua residual recolectada $\times 100$, durante el periodo de referencia

wA3/wF1*100

wA3 - Agua residual pretratada

$\mathrm{wF} 1$ - Agua residual recolectada

Este indicador puede evaluarse para periodos inferiores a un año, pero se recomienda que se utilice únicamente cuando los datos de las variables se hayan recogido por lo menos durante un año. Se debe tener especial cuidado en la interpretación de su resultado. Deben evitarse comparaciones externas en dichas bases de tiempo. 
wQS7 - Tratamiento primario (\%)

Volumen de agua residual que recibe únicamente tratamiento primario en las EDAR / agua residual recolectada x 100, durante el periodo de referencia

wA5/wF1*100

wA5 - Agua residual con tratamiento primario

wF1 - Agua residual recolectada

Este indicador puede evaluarse para periodos inferiores a un año, pero se recomienda que se utilice únicamente cuando los datos de las variables se hayan recogido por lo menos durante un año. Se debe tener especial cuidado en la interpretación de su resultado. Deben evitarse comparaciones externas en dichas bases de tiempo.

\section{wQS8 - Tratamiento secundario (\%)}

Volumen de agua residual que recibe tratamiento secundario en las EDAR / agua residual recolectada $\times 100$, durante el periodo de referencia

wA7/wF1*100

wA7 - Agua residual con tratamiento secundario

$\mathrm{wF1}$ - Agua residual recolectada

Este indicador puede evaluarse para periodos inferiores a un año, pero se recomienda que se utilice únicamente cuando los datos de las variables se hayan recogido por lo menos durante un año. Se debe tener especial cuidado en la interpretación de su resultado. Deben evitarse comparaciones externas en dichas bases de tiempo.

\section{wQS9 - Tratamiento terciario (\%)}

Volumen de agua residual que recibe tratamiento terciario en las EDAR / agua residual recolectada $\times 100$, durante el periodo de referencia wA9/wF1*100

wA9 - Agua residual con tratamiento terciario

$\mathrm{wF} 1$ - Agua residual recolectada

Este indicador puede evaluarse para periodos inferiores a un año, pero se recomienda que se utilice únicamente cuando los datos de las variables se hayan recogido por lo menos durante un año. Se debe tener especial cuidado en la interpretación de su resultado. Deben evitarse comparaciones externas en dichas bases de tiempo. 


\section{Inundaciones}

wQS10 -Inundación de propiedades por colectores de aguas negras en tiempo seco (n. ${ }^{\circ} / 1000$ propiedades/año)

(Número de propiedades afectadas por la inundación de colectores de aguas negras en tiempo seco, durante el periodo de evaluación x 365 / periodo de evaluación) / número de propiedades conectadas a la red en la fecha de referencia $\times 1000$

(wF2*365/wH1)/wC28*1000

wF2 - Propiedades inundadas por colectores de aguas negras en tiempo seco

wH1 - Periodo de evaluación

wC28 - Propiedades conectadas

Solo se deben incluir las inundaciones de colectores de aguas residuales que son responsabilidad del servicio de saneamiento. Las inundaciones pueden afectar propiedades que no están conectadas al sistema de alcantarillado. Estas deben ser incluidas.

Tenga en cuenta que "x365/wH1" es una expresión para realizar un cambio de unidades y no debe ser considerado como una extrapolación.

Este indicador puede evaluarse para periodos inferiores a un año, pero se recomienda que se utilice únicamente cuando los datos de las variables se hayan recogido por lo menos durante un año. Se debe tener especial cuidado en la interpretación de su resultado. Deben evitarse comparaciones externas en dichas bases de tiempo. 
wQS11 -Inundación de propiedades por colectores de aguas negras en tiempo de lluvia (n. $\% / 1000$ propiedades/año)

(Número de propiedades afectadas por la inundación de colectores de aguas negras en tiempo de lluvia, durante el periodo de evaluación x 365 / periodo de evaluación) / número de propiedades conectadas a la red en la fecha de referencia $\times 1000$

$(\mathrm{wF} 3 * 365 / \mathrm{wH} 1) / \mathrm{wC} 28 * 1000$

wF3 - Propiedades inundadas por colectores de aguas negras en tiempo de lluvia

wH1 - Periodo de evaluación

wC28 - Propiedades conectadas

Solo se deben incluir las inundaciones de colectores de aguas residuales que son responsabilidad del servicio de saneamiento. Las inundaciones pueden afectar propiedades que no están conectadas al sistema de alcantarillado. Estas deben ser incluidas.

Tenga en cuenta que "x365/wH1" es una expresión para realizar un cambio de unidades y no debe ser considerado como una extrapolación.

Este indicador puede evaluarse para periodos inferiores a un año, pero se recomienda que se utilice únicamente cuando los datos de las variables se hayan recogido por lo menos durante un año. Se debe tener especial cuidado en la interpretación de su resultado. Deben evitarse comparaciones externas en dichas bases de tiempo. 
wQS12 - Inundación de propiedades por colectores unitarios en tiempo seco (n. ${ }^{\circ} / 1000$ propiedades/año)

(Número de propiedades afectadas por la inundación de colectores unitarios en tiempo seco, durante el periodo de evaluación x 365 / periodo de evaluación) / número de propiedades conectadas a la red en la fecha de referencia $\times 1000$

$(\mathrm{wF} 4 * 365 / \mathrm{wH} 1) / \mathrm{wC} 28 * 1000$

$\mathrm{wF} 4$ - Propiedades inundadas por colectores unitarios en tiempo seco

wH1 - Periodo de evaluación

wC28 - Propiedades conectadas

Solo se deben incluir las inundaciones de colectores unitarios que son responsabilidad del servicio de saneamiento. Las inundaciones pueden afectar propiedades que no están conectadas al sistema de alcantarillado. Estas deben ser incluidas.

Tenga en cuenta que "x365/wH1" es una expresión para realizar un cambio de unidades y no debe ser considerado como una extrapolación.

Este indicador puede evaluarse para periodos inferiores a un año, pero se recomienda que se utilice únicamente cuando los datos de las variables se hayan recogido por lo menos durante un año. Se debe tener especial cuidado en la interpretación de su resultado. Deben evitarse comparaciones externas en dichas bases de tiempo. 
wQS13 -Inundación de propiedades por colectores unitarios en tiempo de lluvia (n. $\% / 1000$ propiedades/año)

(Número de propiedades afectadas por la inundación de colectores unitarios en tiempo de lluvia, durante el periodo de evaluación x 365 / periodo de evaluación) / número de propiedades conectadas a la red en la fecha de referencia $\times 1000$

$(\mathrm{wF} 5 * 365 / \mathrm{wH} 1) / \mathrm{wC} 28 * 1000$

wF5 - Propiedades inundadas por colectores unitarios en tiempo de lluvia wH1 - Periodo de evaluación

wC28 - Propiedades conectadas

Solo se deben incluir las inundaciones de colectores unitarios que son responsabilidad del servicio de saneamiento. Las inundaciones pueden afectar propiedades que no están conectadas al sistema de alcantarillado. Estas deben ser incluidas.

Tenga en cuenta que "x365/wH1" es una expresión para realizar un cambio de unidades y no debe ser considerado como una extrapolación.

Este indicador puede evaluarse para periodos inferiores a un año, pero se recomienda que se utilice únicamente cuando los datos de las variables se hayan recogido por lo menos durante un año. Se debe tener especial cuidado en la interpretación de su resultado. Deben evitarse comparaciones externas en dichas bases de tiempo. 
wQS14 -Inundación de la superficie de propiedades en tiempo de lluvia (n. ${ }^{\circ} / 1000$ propiedades/año)

(Número de propiedades afectadas por inundaciones de la superficie en tiempo de lluvia, durante el periodo de evaluación x 365 / periodo de evaluación) / número de propiedades conectadas a la red en la fecha de referencia $\times 1000$

$(\mathrm{wF} 6 * 365 / \mathrm{wH} 1) / \mathrm{wC} 28 * 1000$

wF6 - Inundación de la superficie de propiedades en tiempo de lluvia

wH1 - Periodo de evaluación

wC28 - Propiedades conectadas

Estos incluyen solo inundaciones superficiales debido a la insuficiencia del sistema de drenaje pluvial (incluidos los colectores unitarios) que son responsabilidad del servicio de saneamiento. La insuficiencia se relaciona con todas las causas (por ejemplo, diseño, operación, etc.).

Tenga en cuenta que "x365/wH1" es una expresión para realizar un cambio de unidades y no debe ser considerado como una extrapolación.

Este indicador puede evaluarse para periodos inferiores a un año, pero se recomienda que se utilice únicamente cuando los datos de las variables se hayan recogido por lo menos durante un año. Se debe tener especial cuidado en la interpretación de su resultado. Deben evitarse comparaciones externas en dichas bases de tiempo.

\section{Interrupciones}

wQS15 -Interrupción del servicio de recolección y transporte de aguas residuales $(\%)$

Suma, para el periodo de evaluación, del número de propiedades afectadas por la interrupción del servicio multiplicadas por la duración respectiva de las interrupciones en horas / (número de propiedades conectadas a la red en la fecha de referencia $\times 24 \times$ periodo de evaluación) $\times 100$ wF7/(wC28*24*wH1)*100

wF7 - Interrupción del servicio de saneamiento

wC28 - Propiedades conectadas

wH1 - Periodo de evaluación

Este indicador puede evaluarse para periodos inferiores a un año, pero se recomienda que se utilice únicamente cuando los datos de las variables se hayan recogido por lo menos durante un año. Se debe tener especial cuidado en la interpretación de su resultado. Deben evitarse comparaciones externas en dichas bases de tiempo. 


\section{Instalación y reparación de acometidas}

wQS16 -Eficiencia de alta de nuevas acometidas (días/nueva
acometida)

Tiempo total empleado para establecer nuevas acometidas / número de nuevas acometidas dadas de alta, durante el periodo de evaluación wF9/wF8

wF9 - Tiempo de establecimiento de nuevas acometidas wF8 - Alta de nuevas acometidas

Esta variable se refiere a nuevos contratos, cuando la acometida física ya existe. El tiempo se contabiliza desde la solicitud del cliente hasta la disponibilidad del servicio. Este indicador puede evaluarse para periodos inferiores a un año, pero se recomienda que se utilice únicamente cuando los datos de las variables se hayan recogido por lo menos durante un año. Se debe tener especial cuidado en la interpretación de su resultado. Deben evitarse comparaciones externas en dichas bases de tiempo.

\section{wQS17 -Tiempo de reparación de acometidas (días/acometida reparada)}

Tiempo total empleado para reparar acometidas / número total de acometidas reparadas, durante el periodo de evaluación

$(\mathrm{wF} 11 * 365 / \mathrm{wH} 1) / \mathrm{wF} 10$

wF11 - Tiempo de reparación de acometidas

wH1 - Periodo de evaluación

wF10 - Acometidas reparadas

El tiempo se contabiliza desde que se reporta el fallo hasta que el servicio se reanuda. Este indicador puede evaluarse para periodos inferiores a un año, pero se recomienda que se utilice únicamente cuando los datos de las variables se hayan recogido por lo menos durante un año. Se debe tener especial cuidado en la interpretación de su resultado. Deben evitarse comparaciones externas en dichas bases de tiempo. 
wQS18 -Tiempo medio de respuesta para vaciar fosas sépticas o letrinas (días/solicitud)

Suma, para todas las solicitudes, del tiempo de respuesta para vaciar fosas sépticas o letrinas / número total de solicitudes de vaciado de fosas sépticas o del contenido de letrinas durante el periodo de evaluación wF24/wF23

wF24 - Tiempo de respuesta de vaciado de fosas sépticas

wF23 - Solicitudes de vaciado de fosas sépticas

El tiempo de respuesta es el período, en días, desde la solicitud para vaciar las fosas sépticas o letrinas hasta el día en que se reanuda el servicio.

Tenga en cuenta que "x365/wH1" es una expresión para realizar un cambio de unidades y no debe ser considerado como una extrapolación.

Este indicador puede evaluarse para periodos inferiores a un año, pero se recomienda que se utilice únicamente cuando los datos de las variables se hayan recogido por lo menos durante un año. Se debe tener especial cuidado en la interpretación de su resultado. Deben evitarse comparaciones externas en dichas bases de tiempo.

\section{Quejas de los usuarios}

wQS19 -Quejas totales (No. /1000 hab./año)

(Número total de quejas relacionadas con el servicio de saneamiento, durante el periodo de evaluación x 365 / periodo de evaluación) / población residente durante el periodo de evaluación x 1000

(wF12*365/wH1)/wE1*1000

wF12 - Quejas totales

wH1 - Periodo de evaluación

wE1 - Población residente

Tenga en cuenta que "x365/wH1" es una expresión para realizar un cambio de unidades y no debe ser considerado como una extrapolación.

Este indicador puede evaluarse para periodos inferiores a un año, pero se recomienda que se utilice únicamente cuando los datos de las variables se hayan recogido por lo menos durante un año. Se debe tener especial cuidado en la interpretación de su resultado. Deben evitarse comparaciones externas en dichas bases de tiempo. 
wQS20 -Quejas por atascos (No. /1000 hab./año)

(Número de quejas relacionadas con atascos, durante el periodo de evaluación x 365 / periodo de evaluación) / población residente durante el periodo de evaluación $\mathrm{x} 1000$

$(w F 13 * 365 / w H 1) / w E 1 * 1000$

$\mathrm{wF} 13$ - Quejas por atascos

wH1 - Periodo de evaluación

wE1 - Población residente

Solo deben tenerse en cuenta las quejas relacionadas con el sistema que es responsabilidad del servicio de saneamiento.

Tenga en cuenta que "x365/wH1" es una expresión para realizar un cambio de unidades y no debe ser considerado como una extrapolación.

Este indicador puede evaluarse para periodos inferiores a un año, pero se recomienda que se utilice únicamente cuando los datos de las variables se hayan recogido por lo menos durante un año. Se debe tener especial cuidado en la interpretación de su resultado. Deben evitarse comparaciones externas en dichas bases de tiempo.

\section{wQS21 -Quejas por inundaciones (No. /1000 hab./año)}

(Número de quejas relacionadas con inundaciones, durante el periodo de evaluación x 365 / periodo de evaluación) / población residente durante el periodo de evaluación x 1000

$(\mathrm{wF} 14 * 365 / \mathrm{wH} 1) / \mathrm{wE} 1 * 1000$

$\mathrm{wF} 14$ - Quejas por inundaciones

wH1 - Periodo de evaluación

wE1 - Población residente

Solo deben tenerse en cuenta las quejas relacionadas con el sistema que es responsabilidad del servicio de saneamiento.

Tenga en cuenta que "x365/wH1" es una expresión para realizar un cambio de unidades y no debe ser considerado como una extrapolación.

Este indicador puede evaluarse para periodos inferiores a un año, pero se recomienda que se utilice únicamente cuando los datos de las variables se hayan recogido por lo menos durante un año. Se debe tener especial cuidado en la interpretación de su resultado. Deben evitarse comparaciones externas en dichas bases de tiempo. 
wQS22 -Quejas por incidentes de contaminación (No. /1000 hab./año)

(Número de quejas relacionadas con incidentes de contaminación, durante el periodo de evaluación x 365 / periodo de evaluación) / población residente durante el periodo de evaluación x 1000 $(\mathrm{wF} 15 * 365 / \mathrm{wH} 1) / \mathrm{wE} 1 * 1000$

wF15 - Quejas por incidentes de contaminación

wH1 - Periodo de evaluación

wE1 - Población residente

Solo deben tenerse en cuenta las quejas relacionadas con el sistema que es responsabilidad del servicio de saneamiento.

Tenga en cuenta que "x365/wH1" es una expresión para realizar un cambio de unidades y no debe ser considerado como una extrapolación.

Este indicador puede evaluarse para periodos inferiores a un año, pero se recomienda que se utilice únicamente cuando los datos de las variables se hayan recogido por lo menos durante un año. Se debe tener especial cuidado en la interpretación de su resultado. Deben evitarse comparaciones externas en dichas bases de tiempo.

\section{wQS23 -Quejas por olores (No. /1000 hab./año)}

(Número de quejas relacionadas con olores, durante el periodo de evaluación x 365 / periodo de evaluación) / población residente durante el periodo de evaluación x 1000

(wF16*365/wH1)/wE1*1000

wF16 - Quejas por olores

wH1 - Periodo de evaluación

wE1 - Población residente

Solo deben tenerse en cuenta las quejas relacionadas con el sistema que es responsabilidad del servicio de saneamiento.

Tenga en cuenta que "x365/wH1" es una expresión para realizar un cambio de unidades y no debe ser considerado como una extrapolación.

Este indicador puede evaluarse para periodos inferiores a un año, pero se recomienda que se utilice únicamente cuando los datos de las variables se hayan recogido por lo menos durante un año. Se debe tener especial cuidado en la interpretación de su resultado. Deben evitarse comparaciones externas en dichas bases de tiempo. 
wQS24 -Quejas relacionadas con roedores (No. /1000 hab./año)

(Número de quejas relacionadas con roedores, durante el periodo de evaluación x 365 / periodo de evaluación) / población residente durante el periodo de evaluación $\mathrm{x} 1000$

$(\mathrm{wF} 17 * 365 / \mathrm{wH} 1) / \mathrm{wE} 1 * 1000$

wF17 - Quejas relacionadas con roedores

wH1 - Periodo de evaluación

wE1 - Población residente

Solo deben tenerse en cuenta las quejas relacionadas con el sistema que es responsabilidad del servicio de saneamiento.

Tenga en cuenta que "x365/wH1" es una expresión para realizar un cambio de unidades y no debe ser considerado como una extrapolación.

Este indicador puede evaluarse para periodos inferiores a un año, pero se recomienda que se utilice únicamente cuando los datos de las variables se hayan recogido por lo menos durante un año. Se debe tener especial cuidado en la interpretación de su resultado. Deben evitarse comparaciones externas en dichas bases de tiempo.

wQS25 -Quejas relacionadas con la facturación(No. /1000 hab./año)

(Número de quejas relacionadas con la facturación, durante el periodo de evaluación x 365 / periodo de evaluación) / población residente durante el periodo de evaluación $\mathrm{x} 1000$

$(w F 18 * 365 / w H 1) / w E 1 * 1000$

wF18 - Quejas relacionadas con la facturación

wH1 - Periodo de evaluación

wE1 - Población residente

Solo deben tenerse en cuenta las quejas relacionadas con el sistema que es responsabilidad del servicio de saneamiento.

Tenga en cuenta que "x365/wH1" es una expresión para realizar un cambio de unidades y no debe ser considerado como una extrapolación.

Este indicador puede evaluarse para periodos inferiores a un año, pero se recomienda que se utilice únicamente cuando los datos de las variables se hayan recogido por lo menos durante un año. Se debe tener especial cuidado en la interpretación de su resultado. Deben evitarse comparaciones externas en dichas bases de tiempo. 
wQS26 -Otras quejas (No. /1000 hab./año)

(Número de otras quejas, durante el periodo de evaluación x 365 / periodo de evaluación) / población residente durante el periodo de evaluación x 1000

$(\mathrm{wF} 19 * 365 / \mathrm{wH} 1) / \mathrm{wE} 1 * 1000$

wF19 - Otras quejas

wH1 - Periodo de evaluación

wE1 - Población residente

Solo deben tenerse en cuenta las quejas relacionadas con el sistema que es responsabilidad del servicio de saneamiento.

Tenga en cuenta que "x365/wH1" es una expresión para realizar un cambio de unidades y no debe ser considerado como una extrapolación.

Este indicador puede evaluarse para periodos inferiores a un año, pero se recomienda que se utilice únicamente cuando los datos de las variables se hayan recogido por lo menos durante un año. Se debe tener especial cuidado en la interpretación de su resultado. Deben evitarse comparaciones externas en dichas bases de tiempo.

\section{wQS27 -Respuesta a quejas (\%)}

Número de respuestas a las quejas presentadas dentro del tiempo objetivo / número total de quejas relacionadas con el servicio de saneamiento x 100 , durante el periodo de evaluación

wF20/wF12*100

$\mathrm{wF} 20$ - Respuestas a quejas

wF12 - Quejas totales

Este indicador es aplizable si existe un sistema de normas garantizadas.

Tenga en cuenta que "x365/wH1" es una expresión para realizar un cambio de unidades y no debe ser considerado como una extrapolación.

Este indicador puede evaluarse para periodos inferiores a un año, pero se recomienda que se utilice únicamente cuando los datos de las variables se hayan recogido por lo menos durante un año. Se debe tener especial cuidado en la interpretación de su resultado. Deben evitarse comparaciones externas en dichas bases de tiempo. 


\section{Daños a terceros}

wQS28 -Responsabilidad por daños a terceros (\%)

Número de incidentes relacionados con accidentes bien de personas que no trabajan para el servicio, o que han causado daños a bienes, activos, vehículos o pertenencias de terceros / número total de accidentes (que son responsabilidad del servicio) x 100, durante el periodo de evaluación wF21/wF22*100

wF21 - Daños a terceros

wF22 - Accidentes

Tenga en cuenta que "x365/wH1" es una expresión para realizar un cambio de unidades y no debe ser considerado como una extrapolación.

Este indicador puede evaluarse para periodos inferiores a un año, pero se recomienda que se utilice únicamente cuando los datos de las variables se hayan recogido por lo menos durante un año. Se debe tener especial cuidado en la interpretación de su resultado. Deben evitarse comparaciones externas en dichas bases de tiempo. 


\section{Impacto en el tráfico}

wQS29-Perturbaciones en el tráfico (km/ interrupción de tráfico)

$\sum$ Para todas las perturbaciones de tráfico debidas a actividades relacionadas con el servicio de alcantarillado (Longitud del carril de tráfico no disponible $\mathrm{x}$ duración de la interrupción) / número de perturbaciones de tráfico debidas a las actividades de la red de alcantarillado x periodo de evaluación x 24, durante el periodo de evaluación

wF26/wF25*wH1*24

wF26 - Interrupción del tráfico

wF25 - Perturbaciones en el tráfico

wH1 - Periodo de evaluación

Las perturbaciones del tráfico incluyen actividades relacionadas con trabajos de inspección, limpieza, mantenimiento, construcción y rehabilitación en el sistema de alcantarillado, donde el tráfico se interrumpe al menos en un carril. No se considerarán las calzadas donde el tráfico promedio sea inferior a 5000 vehículos por día durante las obras.

Tenga en cuenta que "x365/wH1" es una expresión para realizar un cambio de unidades y no debe ser considerado como una extrapolación.

Este indicador puede evaluarse para periodos inferiores a un año, pero se recomienda que se utilice únicamente cuando los datos de las variables se hayan recogido por lo menos durante un año. Se debe tener especial cuidado en la interpretación de su resultado. Deben evitarse comparaciones externas en dichas bases de tiempo.

\subsection{Indicadores económicos y financieros}

Los indicadores en este grupo abordan la efectividad y eficiencia del uso de los recursos financieros. Además, proporcionan un medio para interpretar la gestión empresarial, indicando el comportamiento financiero y la capacidad de expansión del prestador. El EURO se utiliza como unidad de referencia para permitir comparaciones internacionales más fáciles. Se incluyen los ingresos, costes, componentes de los costes de explotación por tipo de coste, por función principal y por actividad técnica, composición de los costes de capital, inversiones, eficiencia, apalancamiento, liquidez e indicadores de rentabilidad. 


\section{Ingresos}

wFi1 -Ingresos unitarios (EUR/p.e./año)

(Ingresos de operación - costes capitalizados de activos construidos por el servicio) durante el periodo de evaluación / población equivalente total servida en la fecha de referencia

(wG2-wG33)/wE8

wG2 - Ingresos de operación

wG33 - Costes capitalizados de activos construidos por el servicio

wE8 - Población equivalente total servida

Tenga en cuenta que wG2-wG33 = wG1 (ingresos totales). Se recomienda no evaluar este indicador para períodos inferiores a un año, puesto que puede llevar a conclusiones erróneas. Si no es posible el uso de un período superior a un año, se debe tener especial cuidado en la interpretación de su resultado. Deben evitarse comparaciones externas en dichas bases de tiempo. Ver sección II-1.3, Tabla 61 y Tabla 62.

\section{wFi2 -Ingresos por servicios (\%)}

Ingresos por servicios / ingresos totales x 100, durante el periodo de evaluación

\section{wG3/wG1*100}

wG3 - Ingresos por servicios

wG1 - Ingresos totales

Los ingresos por servicios incluyen los ingresos por servicios domésticos, comerciales e industriales.

Se recomienda no evaluar este indicador para períodos inferiores a un año, puesto que puede llevar a conclusiones erróneas. Si no es posible el uso de un período superior a un año, se debe tener especial cuidado en la interpretación de su resultado. Deben evitarse comparaciones externas en dichas bases de tiempo. Ver sección II-1.3, Tabla 61 y Tabla 62. 


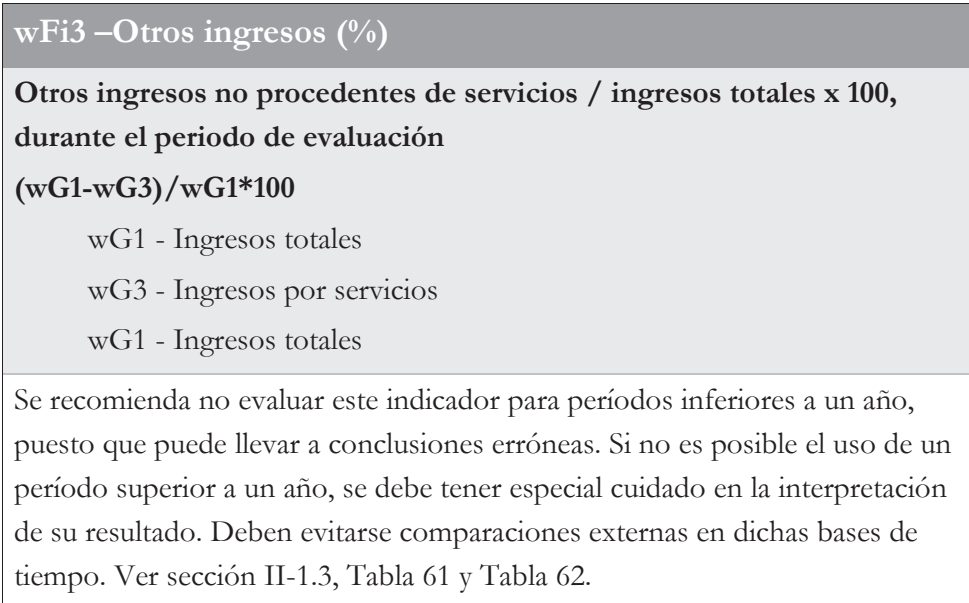

\section{wFi4 -Ingresos por servicios industriales ( $\%)$}

Ingresos por servicios industriales / ingresos totales $\mathrm{x} 100$, durante el periodo de evaluación

wG4/wG3*100

wG4 - Ingresos por servicios industriales

wG3 - Ingresos por servicios

Se recomienda no evaluar este indicador para períodos inferiores a un año, puesto que puede llevar a conclusiones erróneas. Si no es posible el uso de un período superior a un año, se debe tener especial cuidado en la interpretación de su resultado. Deben evitarse comparaciones externas en dichas bases de tiempo. Ver sección II-1.3, Tabla 61 y Tabla 62. 


\section{Costes}

Ver sección II-1.3. Definiciones financieras)

wFi5 -Costes totales unitarios por población equivalente
(EUR/p.e./año)

Costes de explotación más costes de capital relacionados con el servicio de saneamiento (recolección y tratamiento) / población equivalente total servida en la fecha de referencia

wG5/wE8

wG5 - Costes totales
wE8 - Población equivalente total servida

Se recomienda no evaluar este indicador para períodos inferiores a un año, puesto que puede llevar a conclusiones erróneas. Si no es posible el uso de un período superior a un año, se debe tener especial cuidado en la interpretación de su resultado. Deben evitarse comparaciones externas en dichas bases de tiempo. Ver sección II-1.3, Tabla 61 y Tabla 62.

Los indicadores wFi5 y wFi6 se utilizarán de forma alternativa. wFi6 se aplica si estos costes se refieren solo a la red de alcantarillado.

wFi6 - Costes totales unitarios por longitud de colector $(\mathrm{EUR} / \mathrm{km}$ $\mathrm{red} / \mathrm{año)}$

Costes de explotación más costes de capital relacionados con el servicio de alcantarillado / longitud total de la red de alcantarillado en la fecha de referencia

wG5/wC1

wG5 - Costes totales

wC1 - Longitud de la red de alcantarillado

Se recomienda no evaluar este indicador para períodos inferiores a un año, puesto que puede llevar a conclusiones erróneas. Si no es posible el uso de un período superior a un año, se debe tener especial cuidado en la interpretación de su resultado. Deben evitarse comparaciones externas en dichas bases de tiempo. Ver sección II-1.3, Tabla 61 y Tabla 62.

Los indicadores wFi5 y wFi6 se utilizarán de forma alternativa. wFi6 se aplica si estos costes se refieren solo a la red de alcantarillado. 
wFi7 -Costes de explotación unitarios por población equivalente (EUR/p.e./año)

Costes de explotación relacionados con la recogida y tratamiento de aguas residuales / población equivalente total servida en la fecha de referencia

wG6/wE8

wG6 - Costes de explotación

wE8 - Población equivalente total servida

Se recomienda no evaluar este indicador para períodos inferiores a un año, puesto que puede llevar a conclusiones erróneas. Si no es posible el uso de un período superior a un año, se debe tener especial cuidado en la interpretación de su resultado. Deben evitarse comparaciones externas en dichas bases de tiempo. Ver sección II-1.3, Tabla 61 y Tabla $62 .$.

Los indicadores wFi7 y wFi8 se utilizarán de forma alternativa. wFi8 se aplica si estos costes se refieren solo a la red de alcantarillado.

wFi8 - Costes de explotación unitarios por longitud de colector (EUR/km red/año)

Costes de explotación relacionados con el servicio de alcantarillado / longitud total de la red de alcantarillado en la fecha de referencia wG6/wC1

wG6 - Costes de explotación

wC1 - Longitud de la red de alcantarillado

Se recomienda no evaluar este indicador para períodos inferiores a un año, puesto que puede llevar a conclusiones erróneas. Si no es posible el uso de un período superior a un año, se debe tener especial cuidado en la interpretación de su resultado. Deben evitarse comparaciones externas en dichas bases de tiempo. Ver sección II-1.3, Tabla 61 y Tabla 62.

Los indicadores wFi7 y wFi8 se utilizarán de forma alternativa. wFi8 se aplica si estos costes se refieren solo a la red de alcantarillado. 
wFi9 -Costes de capital unitarios por población equivalente (EUR/p.e./año)

Costes capitales relacionados con la recogida y tratamiento de aguas residuales / población equivalente total servida en la fecha de referencia wG7/wE8

wG7 - Costes de capital

wE8 - Población equivalente total servida

Se recomienda no evaluar este indicador para períodos inferiores a un año, puesto que puede llevar a conclusiones erróneas. Si no es posible el uso de un período superior a un año, se debe tener especial cuidado en la interpretación de su resultado. Deben evitarse comparaciones externas en dichas bases de tiempo. Ver sección II-1.3, Tabla 61 y Tabla 62.

Los indicadores wFi9 y wFi10 se utilizarán de forma alternativa. wFi10 se aplica si estos costes se refieren solo a la red de alcantarillado.

wFi10 -Costes de capital unitarios por longitud de colector (EUR/km red/año)

\section{Costes capitales relacionados con el servicio de alcantarillado /}

longitud total de la red de alcantarillado en la fecha de referencia wG7/wC1

$$
\begin{aligned}
& \text { wG7 - Costes de capital } \\
& \text { wC1 - Longitud de la red de alcantarillado }
\end{aligned}
$$

Se recomienda no evaluar este indicador para períodos inferiores a un año, puesto que puede llevar a conclusiones erróneas. Si no es posible el uso de un período superior a un año, se debe tener especial cuidado en la interpretación de su resultado. Deben evitarse comparaciones externas en dichas bases de tiempo. Ver sección II-1.3, Tabla 61 y Tabla 62.

Los indicadores wFi9 y wFi10 se utilizarán de forma alternativa. wFi10 se aplica si estos costes se refieren solo a la red de alcantarillado. 


\section{Componentes de los costes de explotación por tipo de coste}

wFi11 -Coste de personal interno ( $\%)$

Costes de la mano de obra interna / costes de explotación x 100, durante el período de evaluación

wG9/wG6*100

wG9 - Costes de la mano de obra interna

wG6 - Costes de explotación

Este indicador puede ser evaluado para períodos inferiores a un año, pero se requiere especial cuidado en la interpretación de su resultado cuando se use para comparaciones tanto externas como internas.

\section{wFi12 - Coste de servicios externos (\%)}

Coste de los servicios externos / costes de explotación x 100, durante el período de evaluación

wG10/wG6*100

wG10 - Coste de los servicios externos

wG6 - Costes de explotación

Este indicador puede ser evaluado para períodos inferiores a un año, pero se requiere especial cuidado en la interpretación de su resultado cuando se use para comparaciones tanto externas como internas.

\section{wFi13 - Coste de la energía eléctrica $(\%)$}

Coste de la energía eléctrica / costes de explotación x 100, durante el período de evaluación

wG11/wG6*100

wG11 - Coste de la energía eléctrica

wG6 - Costes de explotación

Este indicador puede ser evaluado para períodos inferiores a un año, pero se requiere especial cuidado en la interpretación de su resultado cuando se use para comparaciones tanto externas como internas. 
wFi14 -Coste del material comprado (\%)

Coste del material comprado / costes de explotación x 100, durante el período de evaluación

wG12/wG6*100

wG12 - Coste del material comprado

wG6 - Costes de explotación

Este indicador puede ser evaluado para períodos inferiores a un año, pero se requiere especial cuidado en la interpretación de su resultado cuando se use para comparaciones tanto externas como internas.

wFi15 -Otros costes de explotación (\%)

(Arrendamiento y alquiler + tasas, gravámenes e impuestos + ganancias y pérdidas excepcionales + otros costes de operación) / costes de explotación $\mathrm{x}$ 100 , durante el período de evaluación

(wG13+wG14+wG15+wG16)/wG6*100

wG13 - Arrendamiento y alquiler

wG14 - Tasas, gravámenes e impuestos

wG15 - Ganancias y pérdidas extraordinarias

wG16 - Otros costes de operación

wG6 - Costes de explotación

Este indicador puede ser evaluado para períodos inferiores a un año, pero se requiere especial cuidado en la interpretación de su resultado cuando se use para comparaciones tanto externas como internas. 


\section{Componentes de los costes de explotación por función principal (internos y externalizados)}

\section{wFi16 -Coste de la dirección general (\%)}

Costes de explotación de dirección general / costes de explotación x 100, durante el período de evaluación

wG17/wG6*100

wG17 - Coste de explotación de la dirección general

wG6 - Costes de explotación

Véase la Figura 15 y la Tabla 55 hasta la Tabla 60 para la definición de las funciones.

Este indicador incluye no solo los costes de las funciones internas, sino también, cuando corresponde, los costes de las funciones subcontratadas.

Este indicador puede ser evaluado para períodos inferiores a un año, pero se requiere especial cuidado en la interpretación de su resultado cuando se use para

comparaciones tanto externas como internas.

\section{wFi17 -Coste del área de gestión de recursos humanos (\%)}

Costes de explotación de la gestión de recursos humanos / costes de explotación x 100, durante el período de evaluación

wG18/wG6*100

wG18 - Costes de explotación de la función de gestión de recursos humanos

wG6 - Costes de explotación

Véase la Figura 15 y la Tabla 55 hasta la Tabla 60 para la definición de las funciones. Este indicador incluye no solo los costes de las funciones internas, sino también, cuando corresponde, los costes de las funciones subcontratadas.

Este indicador puede ser evaluado para períodos inferiores a un año, pero se requiere especial cuidado en la interpretación de su resultado cuando se use para comparaciones tanto externas como internas. 
wFi18 -Coste del área financiera y comercial ( $\%)$

Costes de explotación del área financiera y comercial / costes de explotación $\mathrm{x}$ 100 , durante el período de evaluación

wG19/wG6*100

wG19 - Costes de explotación del área financiera y comercial

wG6 - Costes de explotación

Véase la Figura 15 y la Tabla 55 hasta la Tabla 60 para la definición de las funciones. Este indicador incluye no solo los costes de las funciones internas, sino también, cuando corresponde, los costes de las funciones subcontratadas.

Este indicador puede ser evaluado para períodos inferiores a un año, pero se requiere especial cuidado en la interpretación de su resultado cuando se use para comparaciones tanto externas como internas.

\section{wFi19-Coste del área del servicio de atención al cliente (\%)}

Costes de explotación del servicio de atención al cliente / costes de explotación x 100, durante el período de evaluación wG20/wG6*100

wG20 - Costes de explotación del servicio de atención al cliente

wG6 - Costes de explotación

Véase la Figura 15 y la Tabla 55 hasta la Tabla 60 para la definición de las funciones. Este indicador incluye no solo los costes de las funciones internas, sino también, cuando corresponde, los costes de las funciones subcontratadas.

Este indicador puede ser evaluado para períodos inferiores a un año, pero se requiere especial cuidado en la interpretación de su resultado cuando se use para comparaciones tanto externas como internas. 
wFi20 -Coste del área servicio técnico (\%)

Costes de explotación del servicio técnico / costes de explotación x 100, durante el período de evaluación

wG21/wG6*100

wG21 - Coste del servicio técnico

wG6 - Costes de explotación

Véase la Figura 15 y la Tabla 55 hasta la Tabla 60 para la definición de las funciones. Este indicador incluye no solo los costes de las funciones internas, sino también, cuando corresponde, los costes de las funciones subcontratadas.

Este indicador puede ser evaluado para períodos inferiores a un año, pero se requiere especial cuidado en la interpretación de su resultado cuando se use para comparaciones tanto externas como internas.

\section{Componentes de los costes de explotación por función técnica}

(Ver 1.2 - Funciones de organización para la definición de funciones)

wFi21 -Costes de explotación del tratamiento de aguas residuales (\%)

Costes de explotación del tratamiento de aguas residuales / costes de explotación x 100, durante el periodo de evaluación

wG22/wG6*100

wG22 - Costes de explotación del tratamiento de aguas residuales

wG6 - Costes de explotación

Este indicador puede ser evaluado para períodos inferiores a un año, pero se requiere especial cuidado en la interpretación de su resultado cuando se use para comparaciones tanto externas como internas.

\section{wFi22 - Costes de explotación de la red de alcantarillado (\%)}

Costes de explotación de la red de alcantarillado / costes de explotación x 100, durante el periodo de evaluación

wG23/wG6*100

wG23 - Costes de explotación de la red de alcantarillado

wG6 - Costes de explotación

Este indicador puede ser evaluado para períodos inferiores a un año, pero se requiere especial cuidado en la interpretación de su resultado cuando se use para comparaciones tanto externas como internas. 
wFi23 - Costes de explotación de la monitorización de la calidad del agua residual $(\%)$

Costes de explotación de la monitorización de la calidad del agua residual / costes de explotación x 100, durante el periodo de evaluación

wG24/wG6*100

wG24 - Costes de explotación de la monitorización de la calidad del agua residual

wG6 - Costes de explotación

Este indicador puede ser evaluado para períodos inferiores a un año, pero se requiere especial cuidado en la interpretación de su resultado cuando se use para comparaciones tanto externas como internas.

\section{wFi24 -Costes de explotación de servicios de apoyo (\%)}

Costes de explotación de servicios de apoyo / costes de explotación x 100, durante el periodo de evaluación

wG25/wG6*100

wG25 - Costes de explotación de servicios de apoyo

wG6 - Costes de explotación

Este indicador puede ser evaluado para períodos inferiores a un año, pero se requiere especial cuidado en la interpretación de su resultado cuando se use para comparaciones tanto externas como internas.

\section{Componentes de los costes de capital}

\section{wFi25 - Costes por depreciación (\%)}

Costes por depreciación / costes capitales x 100, durante el periodo de evaluación

wG26/wG7*100

wG26 - Costes por depreciación

wG7 - Costes de capital

Este indicador puede ser evaluado para períodos inferiores a un año, pero se requiere especial cuidado en la interpretación de su resultado cuando se use para comparaciones tanto externas como internas. 


\section{wFi26 - Coste por intereses netos $(\%)$}

(Coste de los intereses - ingresos por intereses) / costes capitales x 100, durante el periodo de evaluación

wG29/wG7*100

wG29 - Intereses netos

wG7 - Costes de capital

Este indicador puede ser evaluado para períodos inferiores a un año, pero se requiere especial cuidado en la interpretación de su resultado cuando se use para comparaciones tanto externas como internas.

\section{Inversiones}

\section{wFi27 -Inversión unitaria (EUR/p.e.)}

Costes de inversión (gastos en la red de alcantarillado, plantas de tratamiento y equipo) / población equivalente servida por el servicio de saneamiento, durante el período de evaluación

wG30/wE8

wG30 - Inversión en activos tangibles del servicio de saneamiento

wE8 - Población equivalente total servida

Se recomienda no evaluar este indicador para períodos inferiores a un año, puesto que puede llevar a conclusiones erróneas. Los valores anuales deberían ser analizados durante varios años, y no de manera aislada. Si no es posible el uso de un período superior a un año, se debe tener especial cuidado en la interpretación de su resultado. Deben evitarse comparaciones externas en dichas bases de tiempo. 
wFi28 -Inversión en nuevos activos y refuerzo de activos existentes $(\%)$

Costes de inversión en activos nuevos y en el refuerzo de los activos existentes / costes totales de inversión $\mathrm{x} 100$, durante el período de evaluación

wG31/wG30*100

wG31 - Inversión en activos nuevos y en el fortalecimiento de los activos existentes

wG30 - Inversión en activos tangibles del servicio de saneamiento

Se recomienda no evaluar este indicador para períodos inferiores a un año, puesto que puede llevar a conclusiones erróneas. Los valores anuales deberían ser analizados durante varios años, y no de manera aislada. Si no es posible el uso de un período superior a un año, se debe tener especial cuidado en la interpretación de su resultado. Deben evitarse comparaciones externas en dichas bases de tiempo.

\section{wFi29 -Inversión en sustitución y restauración de activos (\%)}

Costes de inversión en la sustitución y restauración ("igual por igual”) de activos / costes totales de inversión x 100, durante el período de evaluación

wG32/wG30*100

wG32 - Inversión en la sustitución y renovación de activos

wG30 - Inversión en activos tangibles del servicio de saneamiento

"Igual por igual" significa que va a proporcionar la misma funcionalidad. Se recomienda no evaluar este indicador para períodos inferiores a un año, puesto que puede llevar a conclusiones erróneas. Los valores anuales deberían ser analizados durante varios años, y no de manera aislada. Si no es posible el uso de un período superior a un año, se debe tener especial cuidado en la interpretación de su resultado. Deben evitarse comparaciones externas en dichas bases de tiempo. 


\section{Eficiencia}

wFi30 - Ratio de cobertura de costes totales (-)

Ingresos totales / costes totales, durante el período de evaluación wG1/wG5

wG1 - Ingresos totales

wG5 - Costes totales

Se recomienda no evaluar este indicador para períodos inferiores a un año, puesto que puede llevar a conclusiones erróneas. Si no es posible el uso de un período superior a un año, se debe tener especial cuidado en la interpretación de su resultado. Deben evitarse comparaciones externas en dichas bases de tiempo. Ver sección II-1.3, Tabla 61 y Tabla 62.

\section{wFi31 -Ratio de cobertura de costes operacionales (-)}

Ingresos totales / costes de explotación, durante el período de evaluación wG1/wG6

wG1 - Ingresos totales

wG6 - Costes de explotación

Se recomienda no evaluar este indicador para períodos inferiores a un año, puesto que puede llevar a conclusiones erróneas. Si no es posible el uso de un período superior a un año, se debe tener especial cuidado en la interpretación de su resultado. Deben evitarse comparaciones externas en dichas bases de tiempo. Ver sección II-1.3, Tabla 61 y Tabla 62.

\section{wFi32 -Retraso en el pago de recibos (días equivalentes)}

Cuentas por cobrar provenientes del servicio de saneamiento en la fecha de referencia / ingresos por ventas, durante el período de evaluación wG34/wG3*wH1

wG34 - Cuentas a cobrar

wG3 - Ingresos por servicios

wH1 - Periodo de evaluación

Se recomienda no evaluar este indicador para períodos inferiores a un año, puesto que puede llevar a conclusiones erróneas. Si no es posible el uso de un período superior a un año, se debe tener especial cuidado en la interpretación de su resultado. Deben evitarse comparaciones externas en dichas bases de tiempo. Ver sección II-1.3. 
wFi33 - Ratio de inversión (-)

Inversiones sujetas a depreciación / costes de depreciación, durante el período de evaluación

wG35/wG26

wG35 - Inversiones sujetas a depreciación

wG26 - Costes por depreciación

Las inversiones sujetas a depreciación están incluidas en las inversiones referenciadas en la sección II-1.3, Tabla 63. Se recomienda no evaluar este indicador para períodos inferiores a un año, puesto que puede llevar a conclusiones erróneas. Los valores anuales deberían ser analizados durante varios años, y no de manera aislada. Si no es posible el uso de un período superior a un año, se debe tener especial cuidado en la interpretación de su resultado. Deben evitarse comparaciones externas en dichas bases de tiempo.

\section{wFi34 -Contribución de fuentes internas a la inversión = CTI (\%)}

Inversiones financiadas por el flujo de caja / inversiones totales x 100, durante el período de evaluación

wG36/wG30*100

wG36 - Inversiones financiadas por el flujo de caja

wG30 - Inversión en activos tangibles del servicio de saneamiento

Se recomienda no evaluar este indicador para períodos inferiores a un año, puesto que puede llevar a conclusiones erróneas. Si no es posible el uso de un período superior a un año, se debe tener especial cuidado en la interpretación de su resultado. Deben evitarse comparaciones externas en dichas bases de tiempo. Ver sección II-1.3, Tabla 64.

\section{wFi35 -Edad media de activos tangibles (\%/año)}

Valor histórico depreciado de los activos tangibles / valor histórico de los activos tangibles $\mathrm{x} 100$, durante el año

wG37/wG38*100

wG37 - Valor histórico depreciado de los activos tangibles

wG38 - Valor histórico de los activos tangibles

Este indicador debe ser evaluado de forma anual. Si, en la hoja de balances, los valores tangibles no se reevalúan con la inflación, sección II-1.3, Tabla 65 muestra el valor neto de los activos tangibles como la diferencia entre los valores históricos y los depreciados. Este indicador expresa la edad media de los activos tangibles en términos de vida económica y técnica, siendo 100 el total. 
wFi36 -Ratio medio de depreciación (-/año)

Costes de depreciación / valor histórico de los activos tangibles, durante el año

wG26/wG38

wG26 - Costes por depreciación

wG38 - Valor histórico de los activos tangibles

Este indicador debe ser evaluado de forma anual.

\section{wFi37 -Ratio de cobros atrasados (-/año)}

[1 - (deuda anual de los clientes / cantidad facturada durante el año)], durante el año

1-(wG39/wG40)

wG39 - Deuda anual de los clientes

wG40 - Cantidad anual facturada por año

Este indicador debe ser evaluado de forma anual.

\section{wFi38 -Valor de inventario (-/año)}

Valor de todo el inventario al final del año fiscal / ingresos de operación durante el año

wG47/wG2

wG47 - Inventario

wG2 - Ingresos de operación

Este indicador debe ser evaluado de forma anual.

\section{Apalancamiento}

\section{wFi39 - Ratio de cobertura de deuda = DSC $(\%)$}

Flujo de caja / deuda financiera $\mathrm{x} 100$, durante el período de evaluación wG41/wG42*100

wG41 - Flujo de caja

wG42 - Servicio de deuda financiera

Se recomienda no evaluar este indicador para períodos inferiores a un año, puesto que puede llevar a conclusiones erróneas. Si no es posible el uso de un período superior a un año, se debe tener especial cuidado en la interpretación de su resultado. Deben evitarse comparaciones externas en dichas bases de tiempo. Ver sección II-1.3, Tabla 64. 
wFi40 -Ratio de apalancamiento (-/año)

Deuda total / capital social, al final del año fiscal. wG43/wG44

wG43 - Deuda total

wG44 - Capital de los accionistas

Este indicador debe ser evaluado de forma anual. Los prestadores con un alto ratio de cobertura del servicio de la deuda (RCSD) suelen tener un bajo ratio del capital social de la deuda. También es afectada por la revaluación de activos fijos y, por lo tanto, se debe tener cuidado al usar este indicador.

Este indicador debe ser evaluado para una fecha de referencia.

\section{Liquidez}

\section{wFi41 -Ratio de circulante (-)}

Activo circulante / pasivo circulante, en la fecha de referencia wG45/wG49

wG45 - Activo circulante

wG49 - Pasivo circulante

Este indicador debe ser evaluado para una fecha de referencia. Ver sección II-1.3, Tabla 61, Tabla 62 y Tabla 64 para definiciones. Este ratio mide la capacidad de pago a corto plazo del prestador.

\section{Rentabilidad}

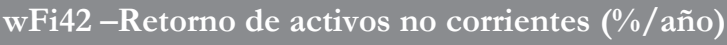

Ingresos de operación / (valor histórico de los activos tangibles - valor histórico depreciado de los activos tangibles) x 100, durante el año wG50/(wG38-wG37)*100

wG50 - Beneficio de operación

wG38 - Valor histórico de los activos tangibles

wG37 - Valor histórico depreciado de los activos tangibles

Este indicador mide la productividad de los activos fijos en uso. Debe ser evaluado sobre una base anual. Los valores anuales deberían ser analizados durante varios años, y no de manera aislada. Este indicador mide también la rentabilidad de los activos fijos, relacionando los ingresos netos con el valor neto de los activos tangibles. Ver sección II-1.3, Tabla 61, Tabla 62 y Tabla 64 para definiciones. 
wFi43 - Rendimiento sobre el capital (\%)

Ingresos netos (ingresos netos tras el pago de intereses e impuestos) / capital de los accionistas $\times 100$, durante el año

wG52/wG44*100

wG52 - Beneficio neto

wG44 - Capital de los accionistas

Este indicador debe ser evaluado de forma anual. Los valores anuales deberían ser analizados durante varios años, y no de manera aislada. Este indicador mide también la rentabilidad financiera, relacionando los ingresos netos con capital de los accionistas. Ver sección II-1.3, Tabla 61, Tabla 62 y Tabla 64 para definiciones.

wFi44 -Rendimiento del capital invertido (\%)

(Ingresos de operación (BAII) - impuestos relacionados) / activos totales $\mathbf{x}$ 100 , durante el año

(wG50-wG51)/wG46*100

wG50 - Beneficio de operación

wG51 - Impuestos relacionados con el beneficio de operación

wG46 - Activos totales

Este indicador debe ser evaluado de forma anual. Ver sección II-1.3, Tabla 61, Tabla 62 y Tabla 64 para definiciones. para definiciones. Este indicador expresa la rentabilidad neta que un accionista gana con su capital empleado.

\section{wFi45 -Índice de rotación de activos (-/año)}

Ingresos por ventas / activos totales, durante el año wG3/wG46

wG3 - Ingresos por servicios

wG46 - Activos totales

Se recomienda no evaluar este indicador para períodos inferiores a un año, puesto que puede llevar a conclusiones erróneas. Si no es posible el uso de un período superior a un año, se debe tener especial cuidado en la interpretación de su resultado. Deben evitarse comparaciones externas en dichas bases de tiempo. Ver sección II-1.3, Tabla 61, Tabla 62 y Tabla 64 para definiciones.. 



\section{VARIABLES}

Esta sección contiene la especificación de cada variable requerida para calcular los indicadores de desempeño propuestos. Tiene los siguientes objetivos:

- permitir una interpretación completa de los conceptos descritos en el cuerpo del texto;

- servir de guía en la creación de un sistema de información para la evaluación de indicadores de desempeño;

- apoyar las auditorias.

Cada prestador debe evaluar exclusivamente las variables requeridas por los indicadores de desempeño previamente seleccionados.

Si el prestador del servicio de saneamiento es responsable de otras actividades productivas, sólo se considerará el componente básico del servicio de saneamiento para la evaluación de las variables.

Cada formulario de variable contiene el mismo tipo de información. Para variables evaluadas en un momento dado (por ejemplo, número de empleados), es altamente recomendable que se adopte la misma fecha para todas las variables que requieran una fecha de referencia. Una regla similar se aplica a las variables que se refieren a un período preestablecido de evaluación (por ejemplo, averías en las tuberías).

Es muy recomendable se definan los grados de confianza para cada variable de entrada, de acuerdo con I-5 y II-5. 


\subsection{Sección A - Datos medioambientales}

\section{wA1- Población equivalente con tratamiento de aguas residuales satisfactorio (p.e.)}

Población equivalente servida por EDAR que cumplen con los requisitos de vertido en la fecha de referencia

\section{DATO DE ENTRADA}

Los requisitos de vertido se refieren a los estándares de calidad de los efluentes que se aplican. El cumplimiento se evalúa en función de las concentraciones y sus posibles impactos ambientales.

USADA EN LOS INDICADORES: wEn1

\section{wA2- Volumen de agua tratada $\left(\mathrm{m}^{3}\right)$}

Volumen de agua residual tratada en las EDAR o en los sistemas de tratamiento de aguas residuales in situ que son responsabilidad del servicio, durante el período de evaluación.

WA3+wA5+wA7+wA9+wA11

USADA EN LOS INDICADORES: wEn2,wQs5

\section{wA3-Agua residual pretratada $\left(\mathrm{m}^{3}\right)$}

Volumen de agua residual que recibe únicamente pretratamiento en las estaciones depuradoras de aguas residuales, durante el periodo de evaluación.

\section{DATO DE ENTRADA}

USADA EN LOS INDICADORES: wEn2(wA2), wQS5(wA2), wQS6

USADA EN LAS VARIABLES: WA2 
wA4- Valor punta diario de agua residual pretratada $\left(\mathrm{m}^{3} / \mathrm{d}\right.$ lía)

Valor máximo del volumen diario de aguas residuales tratadas en todas las EDAR con pretratamiento, durante el periodo de evaluación.

\section{DATO DE ENTRADA}

Esta variable es el máximo del volumen diario individual tratado en el sistema, y no la suma de los máximos diarios individuales para cada planta de tratamiento.

USADA EN LOS INDICADORES: wPh1

\section{wA5-Agua residual con tratamiento primario $\left(\mathrm{m}^{3}\right)$}

Volumen de agua residual que recibe únicamente tratamiento primario en las estaciones depuradoras de aguas residuales, durante el periodo de evaluación.

\section{DATO DE ENTRADA}

USADA EN LOS INDICADORES: wEn2(wA2), wQS5(wA2), wQS7

USADA EN LAS VARIABLES: WA2

wA6- Valor punta diario de agua residual con tratamiento primario $\left(\mathrm{m}^{3} /\right.$ día $)$

Valor máximo del volumen diario de aguas residuales tratadas en todas las EDAR con tratamiento primario, durante el periodo de evaluación.

\section{DATO DE ENTRADA}

Esta variable es el máximo del volumen diario individual tratado en el sistema, y no la suma de los máximos diarios individuales para cada planta de tratamiento.

USADA EN LOS INDICADORES: wPh2

\section{wA7-Agua residual con tratamiento secundario $\left(\mathrm{m}^{3}\right)$}

Volumen de agua residual que recibe tratamiento secundario en las estaciones depuradoras de aguas residuales, durante el periodo de evaluación.

\section{DATO DE ENTRADA}

USADA EN LOS INDICADORES: wEn2(wA2), wQS5(wA2), wQS8

USADA EN LAS VARIABLES: wA2 
wA8- Valor punta diario de agua residual con tratamiento secundario ( $\mathrm{m}^{3} /$ día)

Valor máximo del volumen diario de aguas residuales tratadas en todas las EDAR con tratamiento secundario, durante el periodo de evaluación.

\section{DATO DE ENTRADA}

Esta variable es el máximo del volumen diario individual tratado en el sistema, y no la suma de los máximos diarios individuales para cada planta de tratamiento.

USADA EN LOS INDICADORES: wPh3

\section{wA9-Agua residual con tratamiento terciario $\left(\mathrm{m}^{3}\right)$}

Volumen de agua residual que recibe tratamiento terciario en las estaciones depuradoras de aguas residuales, durante el periodo de evaluación.

\section{DATO DE ENTRADA}

USADA EN LOS INDICADORES: wEn2(wA2), wQS5(wA2), wQS9

USADA EN LAS VARIABLES: WA2

wA10- Valor punta diario de agua residual con tratamiento terciario $\left(\mathrm{m}^{3} /\right.$ día)

Valor máximo del volumen diario de aguas residuales tratadas en todas las EDAR con tratamiento terciario, durante el periodo de evaluación.

\section{DATO DE ENTRADA}

Esta variable es el máximo del volumen diario individual tratado en el sistema, y no la suma de los máximos diarios individuales para cada planta de tratamiento.

USADA EN LOS INDICADORES: wPh4

\section{wA11- Agua residual tratada en sistemas in-situ $\left(\mathrm{m}^{3}\right)$}

Volumen de agua residual tratada en sistemas in-situ, durante el periodo de evaluación.

\section{DATO DE ENTRADA}

USADA EN LOS INDICADORES: wEn2(wA2), wQS5

USADA EN LAS VARIABLES: WA2 
wA12- Volumen de agua residual reutilizada $\left(\mathrm{m}^{3}\right)$

Volumen de agua residual tratada reutilizada en el periodo de evaluación.

\section{DATO DE ENTRADA}

USADA EN LOS INDICADORES: wEn2

\section{wA13- Lodos producidos en la EDAR (ton DS)}

Peso seco del lodo producido en las Estaciones depuradoras de aguas residuales (EDAR) gestionadas por el servicio durante el período de evaluación.

\section{DATO DE ENTRADA}

USADA EN LOS INDICADORES: wEn6

\section{wA14- Lodo tratado (ton DS)}

Todo el peso seco de los lodos tratados por el servicio durante el periodo de evaluación, incluyendo no solo el peso seco de los lodos producidos en las estaciones depuradoras de aguas residuales, sino también el peso seco de los aportes de lodos de otras

\section{DATO DE ENTRADA}

El lodo tratado puede incluir lodos de los sistemas in situ.

USADA EN LOS INDICADORES: $\quad$ wEn7,wEn8,wEn9,wEn10,wEn11

\section{wA15- Lodo utilizado (ton DS)}

Peso seco del lodo, tratador por el servicio, que se utiliza durante el periodo de evaluación, incluyendo por ejemplo, agricultura, usos forestales, productos y materiales.

\section{DATO DE ENTRADA}

USADA EN LOS INDICADORES: wEn7 
wA16- Lodo desechado (ton DS)

Peso seco de los lodos tratados por el servicio que se desecha en vertederos, se incinera o su utiliza cualquier otra forma de disposición, durante el periodo de evaluación.

\section{DATO DE ENTRADA O:}

WA17+WA18+WA19

USADA EN LOS INDICADORES: wEn8

wA17- Lodo destinado a vertedero (ton DS)

Peso seco del lodo destinado a vertedero durante el periodo de evaluación.

DATO DE ENTRADA

USADA EN LOS INDICADORES: wEn8(wA16), wEn9

USADA EN LAS VARIABLES: wA16

\section{wA18- Lodo procesado térmicamente (ton DS)}

Peso seco del lodo procesado térmicamente durante el periodo de evaluación.

\section{DATO DE ENTRADA}

USADA EN LOS INDICADORES: wEn8(wA16), wEn10

USADA EN LAS VARIABLES: wA16

\section{wA19- Lodos desechados por otros medios (ton DS)}

Peso en seco del lodo desechado por otros medios distintos a los expuestos en wA17 y wA18 durante el periodo de evaluación.

\section{DATO DE ENTRADA}

USADA EN LOS INDICADORES: wEn8(wA16), wEn11

USADA EN LAS VARIABLES: WA16 
wA20- Sedimentos de colectores (ton)

Peso drenado de los sedimentos extraídos de los colectores durante el período de evaluación.

\section{DATO DE ENTRADA}

USADA EN LOS INDICADORES: wEn12

\section{wA21- Sedimentos de elementos auxiliares (ton)}

Peso drenado de los sedimentos extraídos de los elementos auxiliares de la red de alcantarillado durante el periodo de evaluación.

\section{DATO DE ENTRADA}

USADA EN LOS INDICADORES: wEn13

\section{wA22- Sedimentos de film y arenilla (ton)}

Peso drenado del film y arenilla extraídos en los filtros y tamices de las estaciones de depuración de aguas residuales y estaciones de bombeo durante el período de evaluación.

\section{DATO DE ENTRADA}

USADA EN LOS INDICADORES: wEn14

\section{wA23- Sedimentos de sistemas in-situ (ton)}

Peso drenado de los sedimentos extraídos de los sistemas in-situ durante el periodo de evaluación.

\section{DATO DE ENTRADA}

USADA EN LOS INDICADORES: wEn15

\section{wA24- Número de descargas por reboses (No.)}

Número de descargas por reboses o alivios que ocurrieron durante el período de evaluación.

\section{DATO DE ENTRADA}

USADA EN LOS INDICADORES: wEn3 
wA25- Volumen de descargas por reboses $\left(\mathrm{m}^{3}\right)$

Volumen total de descargas por reboses o alivios que ocurrieron durante el periodo de evaluación.

DATO DE ENTRADA

USADA EN LOS INDICADORES: wEn4,wEn5

\section{wA26- Volumen de lluvia $\left(\mathrm{m}^{3}\right)$}

Volumen de lluvia en la cuenca durante el período de evaluación.

DATO DE ENTRADA

Ver II-4.2-Perfil del prestador para ver la definición de cuenca.

USADA EN LOS INDICADORES: wEn5

\subsection{Sección B - Datos de personal}

\section{wB1- Personal total (No.)}

Número equivalente de trabajadores a tiempo completo del servicio de saneamiento, en la fecha de referencia.

\section{DATO DE ENTRADA}

Como empleado se incluye a todas las personas que trabajan para el servicio a cambio de un salario.

USADA EN LOS INDICADORES: wPe3,wPe4,wPe5,wPe6,wPe7,wPe8,wPe9,wPe14,wPe15, wPe16,wPe17,wPe20,wPe21,wPe22,wPe23,wPe24

USADA EN LAS VARIABLES: wB17

\section{wB2- Personal en tratamiento de aguas residuales (No.)}

Número equivalente de empleados a tiempo completo que trabajan en el tratamiento de aguas residuales en la fecha de referencia.

\section{DATO DE ENTRADA}

El tratamiento de aguas residuales se refiere tanto a las estaciones depuradoras de aguas residuales (EDAR) como a los sistemas in-situ.

USADA EN LOS INDICADORES: wPe1 
wB3- Personal en la red de alcantarillado (No.)

Número equivalente de empleados a tiempo completo que trabajan en la red de alcantarillado en la fecha de referencia.

\section{DATO DE ENTRADA}

USADA EN LOS INDICADORES: wPe2

\section{wB4- Personal encargado de la administración general (No.)}

Número total equivalente de empleados a tiempo completo encargados de la dirección, la administración central, la planificación estratégica, el marketing, las comunicaciones, las relaciones con las partes interesadas, los asuntos jurídicos, las auditorías.

\section{DATO DE ENTRADA}

USADA EN LOS INDICADORES: wPe3

\section{wB5- Personal encargado de la gestión de los recursos humanos (No.)}

Número equivalente de empleados a tiempo completo encargados de la administración, educación y formación del personal, la seguridad en el trabajo, los servicios médicos y las actividades sociales, en la fecha de referencia.

\section{DATO DE ENTRADA}

USADA EN LOS INDICADORES: wPe4

wB6- Personal encargado de las funciones financieras y comerciales (No.)

Número equivalente de empleados a tiempo completo encargados de la planificación económica y financiera, la administración financiera, el control económico y la compra y gestión de materiales, en la fecha de referencia.

\section{DATO DE ENTRADA}

USADA EN LOS INDICADORES: wPe 5 
Número equivalente de empleados a tiempo completo encargados de la contabilidad, control y gestión de las relaciones con los clientes, en la fecha de referencia.

\section{DATO DE ENTRADA}

USADA EN LOS INDICADORES: wPe6

\section{wB8- Personal de servicios técnicos (No.)}

Número equivalente de empleados a tiempo completo encargados de la planificación, la construcción y las actividades de mantenimiento, en la fecha de referencia.

\section{DATO DE ENTRADA O}

WB11+wB12, O

wB9+wB10+wB13

USADA EN LOS INDICADORES: wPe7,wPe13

\section{wB9- Personal técnico de tratamiento de aguas residuales (No.)}

Número equivalente de empleados a tiempo completo trabajando en actividades de planificación, diseño, construcción, operación, mantenimiento y reparación de sistemas de tratamiento de aguas residuales, en la fecha de referencia.

\section{DATO DE ENTRADA}

En este indicador, el tratamiento de aguas residuales se refiere tanto a las estaciones depuradoras de aguas residuales como a los sistemas in-situ que son responsabilidad del servicio. El personal encargado del muestreo y las pruebas de calidad llevados USADA EN LOS INDICADORES: wPe7(wB8), wPe10, wPe13(wB8)

USADA EN LAS VARIABLES: wB8 
Número equivalente de empleados a tiempo completo trabajando en actividades de planificación, diseño, construcción, operación, mantenimiento y reparación del sistema de alcantarillado, en la fecha de referencia.

\section{DATO DE ENTRADA}

El personal encargado del muestreo y las pruebas de calidad llevados a cabo en los laboratorios del servicio no se tendrá en cuenta en esta variable. Ver definiciones de la sección 1.2-Funciones de organización.

USADA EN LOS INDICADORES: wPe7(wB8), wPe11, wPe13(wB8)

USADA EN LAS VARIABLES: wB8

\section{wB11- Personal de planificación, diseño y construcción (No.)}

Número equivalente de empleados a tiempo completo del servicio técnico encargados de la planificación, el diseño y la construcción del sistema de alcantarillado y las instalaciones de tratamiento de aguas residuales, en la fecha de referencia.

\section{DATO DE ENTRADA}

Ver definiciones en la sección 1.2-Funciones de organización.

USADA EN LOS INDICADORES: wPe7(wB8), wPe8, wPe13(wB8)

USADA EN LAS VARIABLES: wB8

\section{wB12- Personal de operaciones y mantenimiento (No.)}

Número equivalente de empleados a tiempo completo del servicio técnico encargados de las funciones de operaciones, mantenimiento y reparación del sistema de alcantarillado y las instalaciones de tratamiento de aguas residuales, en la fecha de referencia.

\section{DATO DE ENTRADA}

USADA EN LOS INDICADORES: wPe7(wB8), wPe9, wPe13(wB8), wPe18, wPe19, wOp55 USADA EN LAS VARIABLES: wB8 
wB13- Personal de laboratorio (No.)

Número equivalente de empleados a tiempo completo trabajando en el muestreo y testeo de la calidad del agua residual, en la fecha de referencia.

\section{DATO DE ENTRADA}

En el caso de servicios con más de un servicio, cada empleado se contabilizará en base a la proporción de tiempo dedicado a las actividades relacionadas con el servicio de saneamiento. Ver las definiciones de la sección 1.2-Funciones de organización. USADA EN LOS INDICADORES: wPe7(wB8), wPe12, wPe13(wB8)

USADA EN LAS VARIABLES: wB8

\section{wB14- Personal de servicios de apoyo (No.)}

Número total equivalente de empleados a tiempo completo trabajando en la reposición de stock central, en talleres centrales y en la flota de vehículos, en la fecha de referencia.

\section{DATO DE ENTRADA}

En el caso de servicios con más de un servicio, cada empleado se contabilizará en base a la proporción de tiempo dedicado a las actividades relacionadas con el servicio de saneamiento. Ver las definiciones de la sección 1.2-Funciones de organización.

USADA EN LOS INDICADORES: wPe13

\section{wB15- Personal con titulación universitaria (No.)}

Número equivalente de empleados a tiempo completo con titulación universitaria, en la fecha de referencia.

\section{DATO DE ENTRADA}

En el caso de servicios con más de un servicio, cada empleado se contabilizará en base a la proporción de tiempo dedicado a las actividades relacionadas con el servicio de saneamiento. Los empleados incluyen el personal tanto permanente como temporal

USADA EN LOS INDICADORES: wPe14, wPe16(wB17)

USADA EN LAS VARIABLES: wB17 
wB16- Personal con nivel de estudios básico (No.)

Número equivalente de empleados a tiempo completo en el servicio sin titulación universitaria pero con nivel de estudios básico, en la fecha de referencia.

\section{DATO DE ENTRADA}

La definición de educación básica que se use debe referirse a los requerimientos del país a fecha de evaluación del indicador. Las definiciones pueden variar para cada país. En el caso de servicios con más de un servicio, cada empleado se contabilizará en

USADA EN LOS INDICADORES: wPe15, wPe16(wB17)

USADA EN LAS VARIABLES: wB17

\section{wB17- Personal con otra cualificación (No.)}

Número equivalente de empleados a tiempo completo sin nivel de estudios básico en el servicio, en la fecha de referencia

O Personal total - (personal con titulación universitaria + personal con nivel de estudios básico).

wB1-(wB15+wB16)

La definición de educación básica que se use debe referirse a los requerimientos del país a fecha de evaluación del indicador. Las definiciones pueden variar para cada país. En el caso de servicios con más de un servicio, cada empleado se contabilizará en USADA EN LOS INDICADORES: wPe16 
wB18- Personal especializado en espacios confinados (No.)

Número equivalente de empleados a tiempo completo del servicio de saneamiento con formación adecuada y autorizada en espacios confinados, en la fecha de referencia.

\section{DATO DE ENTRADA}

Se recomienda la "formación autorizada en espacios confinados" para todo el personal que deba acceder a un espacio confinado designado para fines de inspección, limpieza, mantenimiento, reparación o cualquier forma de trabajo. Trabajar en espacios confinados puede provocar lesiones o incluso la muerte si no se toman las precauciones adecuadas. Por lo tanto, solo las personas capacitadas deben acceder o trabajar en espacios confinados. Un espacio confinado es un espacio con ventilación restringida donde es posible que se deban tomar precauciones de seguridad especiales porque la atmósfera puede estar contaminada en cualquier momento (por polvo, humo, neblina, vapor, gas u otra sustancia dañina) o puede ser deficiente en oxígeno (EN 752-1, 1985 y ASOTT, 2002).

USADA EN LOS INDICADORES: wPe19

\section{wB19- Personal vacunado (No.)}

Número equivalente de empleados a tiempo completo del servicio de saneamiento con certificación de vacunas actualizada para enfermedades relacionadas con las aguas residuales, en la fecha de referencia.

\section{DATO DE ENTRADA}

USADA EN LOS INDICADORES: wPe18

\section{wB20 - Tiempo de formación (horas)}

Número de horas de formación de personal de aguas residuales, durante el periodo de evaluación.

\section{DATO DE ENTRADA}

En el caso de servicios con más de un servicio, se debe establecer una proporción de las actividades relacionadas con el servicio de saneamiento. Para la contabilidad de esta variable, las horas de capacitación proporcionadas a los empleados que trab USADA EN LOS INDICADORES: wPe17 
wB21- Accidentes laborales (No.)

Número total de accidentes laborales que han requerido atención médica durante el período de evaluación.

\section{DATO DE ENTRADA}

Si el servicio del servicio de saneamiento es responsable de otras actividades productivas, se debe establecer una proporción del tiempo dedicado a las actividades de saneamiento.

USADA EN LOS INDICADORES: wPe20

\section{wB22- Accidentes laborales fatales (No.)}

Número de accidentes laborales que resultan en muerte o enfermedad permanente, durante el período de evaluación.

\section{DATO DE ENTRADA}

USADA EN LOS INDICADORES: wPe21

\section{wB23-Absentismo (días)}

Número total de días de absentismo producido durante el período de evaluación.

\section{DATO DE ENTRADA}

USADA EN LOS INDICADORES: wPe22, wPe24 (wB25), wPe22

USADA EN LAS VARIABLES: wB25

wB24- Absentismo debido a accidentes o enfermedades laborales (días)

Número total de días de absentismo producido debido a accidentes laborales o enfermedades provocadas en el trabajo durante el período de evaluación.

\section{DATO DE ENTRADA}

USADA EN LOS INDICADORES: wPe23, wPe24(wB25)

USADA EN LAS VARIABLES: wB25 
wB25- Absentismo debido a otras razones (días)

Número total de días de absentismo no producido debido a accidentes laborales o enfermedades provocadas en el trabajo durante el período de evaluación.

WB23-WB24

USADA EN LOS INDICADORES: wPe24

\section{wB26- Horas de trabajo (horas)}

Número total de horas de trabajo normal de todos los empleados del servicio durante el período de evaluación (horas de trabajo total - ausencia por vacaciones).

\section{DATO DE ENTRADA}

USADA EN LOS INDICADORES: wPe25

\section{wB27- Horas extraordinarias de trabajo (horas)}

Número total de horas extras de los empleados del servicio durante el período de evaluación.

\section{DATO DE ENTRADA}

USADA EN LOS INDICADORES: $\quad$ wPe25

\subsection{Sección C - Datos de activos físicos}

\section{wC1- Longitud de la red de alcantarillado $(\mathrm{km})$}

Longitud total de la red de alcantarillado gestionada por el servicio en la fecha de referencia.

\section{DATO DE ENTRADA}

Se excluyen las conexiones al servicio.

USADA EN LOS INDICADORES: wEn12, wEn13, wEn14, wPe2, wPe11, wPh5, wPh6, wPh7, wOp1, wOp2, wOp21, wOp22, wOp23, wOp24, wOp31, wOp32, wOp33, wOp34, wOp35, wOp37, wOp38, wOp39, wOp40, wOp54, wFi6, wFi8, wFi10 
wC2- Colectores que entran en carga en tiempo seco (m)

Longitud de colectores por gravedad que han entrado en carga en tiempo seco durante el periodo de evaluación.

\section{DATO DE ENTRADA}

Se excluyen las conexiones al servicio.

USADA EN LOS INDICADORES: wPh5

\section{wC3- Colectores que entran en carga en tiempo de lluvia (m)}

Longitud de colectores por gravedad que han entrado en carga en tiempo de lluvia durante el periodo de evaluación.

\section{DATO DE ENTRADA}

Se excluyen las conexiones al servicio.

USADA EN LOS INDICADORES: wPh6

\section{wC4-Colectores que entran en niveles de carga elevados (m)}

Longitud de colectores que han entrado en un alto nivel de carga, durante el periodo de evaluación.

\section{DATO DE ENTRADA}

Un nivel elevado de carga supone que el agua alcanza un nivel de al menos $0,5 \mathrm{~m}$ por encima de la corona de la tubería (la corona de la tubería es la parte superior exterior del colector). Se excluyen las conexiones al servicio.

USADA EN LOS INDICADORES: wPh7

\section{wC5- Potencia de bombeo en la EDAR (kW)}

Potencia nominal total de bombeo instalada en la EDAR en la fecha de referencia.

\section{DATO DE ENTRADA}

Se incluirán las bombas de entrada de la EDAR. La potencia de la bomba instalada no incluye las bombas de auxiliares (las utilizadas de reserva).

USADA EN LOS INDICADORES: wPh9 
wC6- Estaciones de bombeo del sistema de alcantarillado (No.)

Número de estaciones de bombeo de aguas residuales en la red de alcantarillado, incluidas las estaciones de bombeo de entrada de la planta de tratamiento de aguas residuales, en la fecha de referencia.

\section{DATO DE ENTRADA}

USADA EN LOS INDICADORES: wOp10,wOp36,wOp42,

\section{wC7- Bombas de la red de alcantarillado (No.)}

Número total de bombas en la red de alcantarillado gestionadas por el servicio, en la fecha de referencia.

\section{DATO DE ENTRADA}

Al contabilizar el número total de bombas del sistema, las bombas pequeñas pueden ser excluidas si su influencia en términos de la fiabilidad del sistema es despreciable.

USADA EN LOS INDICADORES: wOp41

\section{wC8- Potencia de las bombas instaladas de aguas residuales (kW)}

Potencia nominal total de las bombas de aguas residuales instaladas en la red de alcantarillado, incluyendo las bombas de entrada en la EDAR, en la fecha de referencia.

\section{DATO DE ENTRADA}

La potencia instalada de las bombas no incluye las bombas de reserva (usadas para la sustitución de bombas defectuosas).

USADA EN LOS INDICADORES: wOp28,wOp29

\section{wC9- Estaciones de bombeo de la red de alcantarillado (No.)}

Número total de estaciones de bombeo de la red de alcantarillado en el fecha de referencia.

\section{DATO DE ENTRADA}

Esta variable no incluye estaciones de bombeo en EDAR.

USADA EN LOS INDICADORES: wPh10 
wC10- Potencia de bombeo en la red de alcantarillado (kW)

Potencia nominal total de bombeo instalada en la red de alcantarillado en la fecha de referencia.

\section{DATO DE ENTRADA}

La potencia de la bomba instalada no incluye las bombas de auxiliares (las utilizadas de reserva).

USADA EN LOS INDICADORES: $\quad$ wPh8,wOp11

wC11- Utilización de las estaciones de bombeo de la red de alcantarillado (No.)

Número de estaciones de bombeo en la red de alcantarillado donde las bombas operaron más del $75 \%$ del tiempo durante el periodo de evaluación.

\section{DATO DE ENTRADA}

El porcentaje de tiempo de operación de cada estación de bombeo se evalúa dividiendo el número total de horas de operación de las bombas instaladas durante el período de evaluación por las horas de operación anuales máximas para las bombas instaladas (número de bombas x 24 x wH1).

USADA EN LOS INDICADORES: wPh10

wC12- Capacidad diaria de tratamiento preliminar $\left(\mathrm{m}^{3} / \mathrm{día}\right)$

Suma, para todas las EDAR con pretratamiento, de la capacidad máxima de tratamiento diario, durante el periodo de evaluación.

DATO DE ENTRADA

USADA EN LOS INDICADORES: wPh1

wC13- Capacidad diaria de tratamiento primario $\left(\mathrm{m}^{3} /\right.$ día $)$

Suma, para todas las EDAR con tratamiento primario, de la capacidad máxima de tratamiento diario, durante el periodo de evaluación.

\section{DATO DE ENTRADA}

USADA EN LOS INDICADORES: wPh2 
Suma, para todas las EDAR con tratamiento secundario, de la capacidad máxima de tratamiento diario, durante el periodo de evaluación.

DATO DE ENTRADA

USADA EN LOS INDICADORES: wPh3

wC15- Capacidad diaria de tratamiento terciario $\left(\mathrm{m}^{3} / \mathrm{d}\right.$ lía)

Suma, para todas las EDAR con tratamiento terciario, de la capacidad máxima de tratamiento diario, durante el periodo de evaluación.

\section{DATO DE ENTRADA}

USADA EN LOS INDICADORES: $\quad$ wPh4

\section{wC16- Unidades de control (No.)}

El número total de unidades de control, en la fecha de referencia, se define como conjuntos funcionalmente independientes de dispositivos de control del sistema (por ejemplo, válvulas de control o interruptores de bomba) utilizados para la recolección, bombeo, almacenamiento, tratamiento y recuperación de energía de aguas residuales.

\section{DATO DE ENTRADA}

Por ejemplo, el conjunto de válvulas y otros dispositivos de control utilizados para controlar múltiples instalaciones de bombeo y almacenamiento deben considerarse como una sola unidad de control. Se puede utilizar un criterio similar, por ejemplo, para cada unidad de proceso en las plantas de tratamiento e instalaciones de bombeo y almacenamiento asociadas (por ejemplo, unidad de filtración).

USADA EN LOS INDICADORES: wPh11,wPh12 
wC17- Unidades de control automático (No.)

Número total de unidades de control automatizadas del sistema, en la fecha de referencia, definidas como conjuntos funcionalmente independientes de dispositivos de control del sistema (por ejemplo, válvulas de control o interruptores de bomba) que son controlados localmente por un controlador lógico programable, utilizado para la recolección, bombeo, almacenamiento, tratamiento y recuperación de energía de aguas residuales.

DATO DE ENTRADA

USADA EN LOS INDICADORES: wPh11

\section{wC18- Unidades de control remotas (No.)}

Número total de unidades de control remoto del sistema de aguas residuales conectadas a un sistema de control central, en la fecha de referencia, generalmente a través del cableado de información o la conexión de radio.

\section{DATO DE ENTRADA}

USADA EN LOS INDICADORES: wPh12

\section{wC19- Aliviaderos (No.)}

Número de aliviaderos, en la fecha de referencia.

\section{DATO DE ENTRADA}

USADA EN LOS INDICADORES: wEn3,wEn4,

\section{wC20 - Número de tanques de tormenta (No.)}

Número de tanques de tormenta, también llamados depósitos anti-DSU (desbordamientos del sistema unitario), en el sistema de alcantarillado en la fecha de referencia.

\section{DATO DE ENTRADA}

USADA EN LOS INDICADORES: wOp6,wOp43 
wC21- Pozos de registro (No.)

Número de pozos de registro en la red de alcantarillado en la fecha de referencia.

DATO DE ENTRADA

USADA EN LOS INDICADORES: wOp3,wOp25,wOp26

wC22- Ibornales (No.)

Número de imbornales en la red de alcantarillado en la fecha de referencia.

DATO DE ENTRADA

USADA EN LOS INDICADORES: wOp4,wOp5

\section{wC23- Número de depósitos de retención (No.)}

Número de depósitos de retención (con o sin derivación) en la red de alcantarillado en la fecha de referencia.

\section{DATO DE ENTRADA}

USADA EN LOS INDICADORES: wOp6

wC24- Volumen de depósitos de retención y tanques de tormenta $\left(\mathrm{m}^{3}\right)$

Volumen total de depósitos de retención y tanques de tormenta, también llamados depósitos anti-DSU (desbordamientos del sistema unitario), en la fecha de referencia.

\section{DATO DE ENTRADA}

USADA EN LOS INDICADORES: wOp7,wOp8

wC25- Filtros de depósitos de retención y tanques de tormenta (No.)

Número de filtros asociados con depósitos de retención y tanques de tormenta, también llamados depósitos anti-DSU (desbordamientos del sistema unitario), durante el periodo de evaluación.

\section{DATO DE ENTRADA}

USADA EN LOS INDICADORES: wOp9 
wC26- Caudalímetros de agua de la EDAR (No.)

Número de caudalímetros permanentemente instalados en las estaciones de tratamiento de aguas residuales en la fecha de referencia.

\section{DATO DE ENTRADA}

USADA EN LOS INDICADORES: wOp13

wC27- Caudalímetros de agua de la red de alcantarillado (No.)

Número de caudalímetros permanentemente instalados en la red de alcantarillado en la fecha de referencia.

\section{DATO DE ENTRADA}

USADA EN LOS INDICADORES: wOp12

\section{wC28- Propiedades conectadas (No.)}

Número de propiedades conectadas a la red de alcantarillado gestionada por el servicio, en la fecha de referencia.

\section{DATO DE ENTRADA}

USADA EN LOS INDICADORES: WQS10,wQS11,wQS12,wQS13,wQS14,wQS15

\section{wC29- Acometidas (No.)}

Número total de acometidas en la fecha de referencia.

DATO DE ENTRADA

USADA EN LOS INDICADORES: wOp27

\section{wC30- Sistemas eléctricos de emergencia $(\mathrm{kW})$}

Potencia nominal total de los sistemas eléctricos de emergencia en la fecha de referencia.

\section{DATO DE ENTRADA}

USADA EN LOS INDICADORES: wOp15 
wC31- Equipos de transmisión de señales (No.)

Número total de equipos de transmisión de señales en la fecha de referencia.

DATO DE ENTRADA

USADA EN LOS INDICADORES: wOp16

wC32- Equipos eléctricos (No.)

Número total de equipos eléctricos en la fecha de referencia.

DATO DE ENTRADA

USADA EN LOS INDICADORES: WOp17

wC33- Equipos de monitorización de la calidad del agua residual (No.)

Número de equipos de monitorización de la calidad del agua residual instalados permanentemente en las estaciones depuradoras de aguas residuales, en la fecha de referencia.

DATO DE ENTRADA

USADA EN LOS INDICADORES: wOp14

\subsection{Sección D - Datos operacionales}

\section{wD1- Inspección de colectores $(\mathrm{km})$}

Longitud de colectores inspeccionados durante el periodo de evaluación.

\section{DATO DE ENTRADA}

Si una tubería se inspecciona más de una vez en el periodo de evaluación, se contabilizará solo una vez. Esta convención puede causar sesgos en el indicador cuando se adopta un período de evaluación no anual. Se incluirá la inspección online por vigilancia remota y alarmas así como la inspección en TV.

USADA EN LOS INDICADORES: wOp1 
wD2- Limpieza de colectores $(\mathrm{km})$

Longitud de colectores limpiados para prevenir obstrucciones y atascos durante el periodo de evaluación.

\section{DATO DE ENTRADA}

Limpieza de colectores se refiere a aquellas acciones realizadas bajo una estrategia proactiva de gestión. Si una tubería se inspecciona más de una vez en el período de evaluación, se contabilizará solo una vez. Esta convención puede causar sesgos en el indicador cuando se adopta un período de evaluación no anual. Se incluirá el corte de raíces. La limpieza realizada para solucionar las obstrucciones ya existentes se refleja en wOp34.

USADA EN LOS INDICADORES: wOp2

\section{wD3- Inspección de pozos de registro (No.)}

Numero de pozos de registro inspeccionados durante el periodo de evaluación.

\section{DATO DE ENTRADA}

Si se inspecciona un pozo de registro más de una vez en el periodo de evaluación, se registrará tantas veces como inspecciones se hayan realizado.

USADA EN LOS INDICADORES: wOp3

\section{wD4- Inspección de imbornales (No.)}

Numero de imbornales inspeccionadas durante el periodo de evaluación.

\section{DATO DE ENTRADA}

La inspección de imbornales se refiere a aquellas acciones realizadas bajo una estrategia proactiva de gestión. Si un imbornal se inspecciona más de una vez en el periodo de evaluación, se registrará tantas veces como inspecciones se hayan realizado.

USADA EN LOS INDICADORES: wOp4 
wD5- Limpieza de imbornales (No.)

Numero de imbornales limpiados durante el periodo de evaluación.

\section{DATO DE ENTRADA}

La limpieza de imbornales se refiere a aquellas acciones realizadas bajo una estrategia proactiva de gestión. Si un imbornal se limpia más de una vez en el periodo de evaluación, se registrará tantas veces como limpiezas se hayan realizado.

USADA EN LOS INDICADORES: wOp5

wD6- Número de inspecciones a depósitos de retención y tanques de tormenta (No.)

Número de inspecciones a depósitos de retención y tanques de tormenta llevadas a cabo durante el periodo de evaluación.

\section{DATO DE ENTRADA}

Si un depósito de retención o tanque de tormenta se inspecciona más de una vez en el periodo de evaluación, se registrará tantas veces como inspecciones se hayan realizado.

USADA EN LOS INDICADORES: wOp6

wD7- Volumen inspeccionado de depósitos de retención y tanques de tormenta $\left(\mathrm{m}^{3}\right)$

Volumen inspeccionado de depósitos de retención y tanques de tormenta durante el periodo de evaluación.

\section{DATO DE ENTRADA}

Si un depósito de retención o tanque de tormenta se inspecciona más de una vez en el periodo de evaluación, se registrará tantas veces como inspecciones se hayan realizado.

USADA EN LOS INDICADORES: wOp7 
wD8- Limpieza de depósitos de retención y tanques de tormenta $\left(\mathrm{m}^{3}\right)$

Volumen limpiado de depósitos de retención y tanques de tormenta durante el periodo de evaluación.

\section{DATO DE ENTRADA}

Si un depósito de retención o tanque de tormenta se limpia más de una vez en el periodo de evaluación, se registrará tantas veces como limpiez̧as se hayan realizado. Solo se considerarán los tanques de tormenta que tengan capacidad de almacenamiento.

USADA EN LOS INDICADORES: wOp8

wD9- Inspección de filtros de depósitos de retención y tanques de tormenta (No.)

Número de filtros asociados con depósitos de retención y tanques de tormenta inspeccionados durante el periodo de evaluación.

\section{DATO DE ENTRADA}

Si un filtro se inspecciona más de una vez en el periodo de evaluación, se registrará tantas veces como inspecciones se hayan realizado.

USADA EN LOS INDICADORES: wOp9

\section{wD10- Inspección de estaciones de bombeo (No.)}

Número de inspecciones a estaciones de bombeo realizadas durante el período de evaluación.

\section{DATO DE ENTRADA}

Si una bomba se inspecciona más de una vez en el periodo de evaluación, se registrará tantas veces como inspecciones se hayan realizado.

USADA EN LOS INDICADORES: wOp10 
wD11- Inspección de bombas (kW)

Suma de la potencia nominal de las bombas y accesorios complementarios sujetos a inspección durante el período de evaluación.

\section{DATO DE ENTRADA}

Se excluyen las bombas instaladas en los procesos de tratamiento. Si una bomba se inspecciona más de una vez en el periodo de evaluación, se registrará tantas veces como inspecciones se hayan realizado.

USADA EN LOS INDICADORES: wOp11

\section{wD12- Consumo de energía en las bombas (kWh)}

Sumatorio $(\Sigma)$ para todas las bombas instaladas de su potencia nominal $\mathbf{x}$ número de horas en las que están en funcionamiento, durante el periodo de evaluación.

wD14+wD15

USADA EN LOS INDICADORES: wOp20

wD13- Energía consumida en los tratamientos de aguas residuales $(\mathrm{kWh})$

Energía consumida durante el periodo de evaluación por los tratamientos de aguas residuales gestionadas por el servicio.

\section{DATO DE ENTRADA}

El tratamiento de aguas residuales incluye los sistemas in-situ; el procesado térmico de los lodos no debe ser incluido.

USADA EN LOS INDICADORES: wOp18,wOp19

\section{wD14- Consumo de energía por bombeo en la EDAR (kWh)}

Sumatorio $\left(\sum\right)$ para todas las bombas instaladas en la EDAR de su potencia nominal por las horas de bombeo, para el periodo de evaluación.

\section{DATO DE ENTRADA}

Se incluirán las bombas de entrada de la EDAR.

USADA EN LOS INDICADORES: wPh9, wOp20(wD12)

USADA EN LAS VARIABLES: wD12 
wD15- Consumo de energía por bombeo en la red de alcantarillado (kWh)

Sumatorio $\left(\sum\right)$ para todas las bombas instaladas en la red de alcantarillado de su potencia nominal por las horas de bombeo, para el periodo de evaluación.

DATO DE ENTRADA

USADA EN LOS INDICADORES: wPh8

USADA EN LAS VARIABLES: WD12

\section{wD16- Factor de normalización $\left(\mathrm{m}^{3} \mathrm{x} \mathrm{m}\right)$}

Suma, para todas las bombas del sistema, de D2(i), siendo D2(i): D2(i) = V(i) $\mathrm{x} h(\mathrm{i})$, donde $\mathrm{V}$ es el volumen total $\left(\mathrm{m}^{3}\right)$ bombeado por la bomba y durante el periodo de evaluación, y h(i) es la altura proporcionada por la bomba (m).

\section{DATO DE ENTRADA}

USADA EN LOS INDICADORES: wOp20

\section{wD17- Energía generada por cogeneración (kWh)}

Energía producida por procesos de cogeneración durante el periodo de evaluación.

\section{DATO DE ENTRADA}

USADA EN LOS INDICADORES: WOp19 
wD18-Averías eléctricas (hora)

Suma, para todas las bombas, del número de horas en las que cada estación de servicio ha estado fuera de servicio durante el periodo de evaluación, debido a interrupciones en el suministro de energía.

\section{DATO DE ENTRADA}

Esta variable evalúa el tiempo en el que la estación de bombeo está fuera de servicio debido a averías eléctricas, sin tener en cuenta la fuente de electricidad utilizada (sistema de generación de energía normal o de reserva). Esto significa que el tiempo en el que una estación de bombeo está funcionando con el generador de reserva no debería ser considerado como avería de potencia. El indicador pretende medir el desempeño del servicio de alcantarillado, no del servicio de abastecimiento de energía eléctrica.

USADA EN LOS INDICADORES: wOp42

\section{wD19- Calibración de caudalímetros de agua de las EDAR (No.)}

Número de calibraciones realizadas en caudalímetros de agua permanentemente instalados en las estaciones de depuración de aguas residuales durante el periodo de evaluación.

\section{DATO DE ENTRADA}

Si un contador de agua se calibra más de una vez al año, debe de registrarse tantas veces como calibraciones se hayan realizado.

USADA EN LOS INDICADORES: wOp13

\section{wD20- Calibración de caudalímetros de agua de la red de alcantarillado (No.)}

Número de calibraciones realizadas en caudalímetros de agua permanentemente instalados en la red de alcantarillado durante el periodo de evaluación.

\section{DATO DE ENTRADA}

Si un contador de agua se calibra más de una vez al año, debe de registrarse tantas veces como calibraciones se hayan realizado.

USADA EN LOS INDICADORES: wOp12 
wD21- Calibración de equipos de monitorización de la calidad del agua residual (No.)

Número de calibraciones automáticas en los equipos de monitorización de la calidad del agua residual permanentes realizadas en las estaciones de depuración de aguas residuales durante el periodo de evaluación.

\section{DATO DE ENTRADA}

Si un equipo se calibra más de una vez al año, debe de registrarse tantas veces como calibraciones se hayan realizado.

USADA EN LOS INDICADORES: wOp14

\section{wD22- Inspección de los sistemas eléctricos de emergencia (kW)}

Suma de la potencia nominal de los sistemas eléctricos de emergencia inspeccionados durante el periodo de evaluación.

\section{DATO DE ENTRADA}

Si un equipo se inspecciona más de una vez en el periodo de evaluación, se registrará tantas veces como inspecciones se hayan realizado.

USADA EN LOS INDICADORES: WOp15

\section{wD23- Inspección de equipos de transmisión de señales (No.)}

Número de equipos de transmisión de señales inspeccionados durante el periodo de evaluación.

\section{DATO DE ENTRADA}

Si un equipo se inspecciona más de una vez en el periodo de evaluación, se registrará tantas veces como inspecciones se hayan realizado.

USADA EN LOS INDICADORES: wOp16 
wD24- Inspección de equipos eléctricos (No.)

Número de equipos eléctricos inspeccionados durante el periodo de evaluación.

\section{DATO DE ENTRADA}

Si un equipo se inspecciona más de una vez en el periodo de evaluación, se registrará tantas veces como inspecciones se hayan realizado.

USADA EN LOS INDICADORES: wOp17

\section{wD25- Rehabilitación de colectores $(\mathrm{km})$}

Longitud de los colectores defectuosos rehabilitados o renovados durante el periodo de evaluación.

\section{DATO DE ENTRADA}

Esta variable incluye no solo wD26 y wD27 sino también la longitud de los colectores rehabilitados con otras técnicas. Para la evaluación de esta variable, solo se considerará la longitud del defecto.

USADA EN LOS INDICADORES: wOp21

\section{wD26- Restauración de colectores $(\mathrm{km})$}

Longitud de colectores defectuosos restaurados (por ejemplo: revestidos) durante el periodo de evaluación.

\section{DATO DE ENTRADA}

Se excluyen las conexiones al servicio.

USADA EN LOS INDICADORES: wOp22

\section{wD27- Sustitución de colectores $(\mathrm{km})$}

Longitud de colectores defectuosos sustituidos o renovados durante el periodo de evaluación.

\section{DATO DE ENTRADA}

Se excluyen las conexiones al servicio.

USADA EN LOS INDICADORES: wOp23 
wD28- Reparación de colectores y uniones (No.)

Número de reparaciones llevadas a cabo en colectores defectuosos u uniones en el periodo de evaluación.

\section{DATO DE ENTRADA}

Se excluyen las conexiones al servicio. Se incluyen las uniones de colectores.

USADA EN LOS INDICADORES: wOp24

wD29- Sustitución, renovación o reparación de pozos de registro (No.)

Número de pozos de registro sustituidos, renovados o rehabilitados durante el periodo de evaluación.

DATO DE ENTRADA

USADA EN LOS INDICADORES: wOp25

wD30- Sustitución de tapas de pozos de registro (No.)

Número de tapas de pozos de registro sustituidas durante el periodo de evaluación.

DATO DE ENTRADA

USADA EN LOS INDICADORES: wOp26

wD31- Sustitución o renovación de acometidas (No.)

Número de acometidas sustituidas o renovadas durante el período de evaluación.

DATO DE ENTRADA

USADA EN LOS INDICADORES: wOp27 


\section{wD32- Rehabilitación de bombas (kW)}

Potencia nominal total de las bombas sujetas a rehabilitación (restauración o renovación de alguno de sus elementos relevantes, necesarios para que la unidad recupere su rendimiento original), incluyendo las bombas de la entrada de la EDAR, durante el periodo de evaluación.

\section{DATO DE ENTRADA}

La rehabilitación puede implicar la sustitución de algún elemento de la bomba.

USADA EN LOS INDICADORES: wOp28

\section{wD33- Sustitución de bombas (kW)}

Potencia nominal de las bombas sustituidas, incluyendo las que se encuentra en la EDAR, durante el periodo de evaluación.

\section{DATO DE ENTRADA}

Esta variable se refiere exclusivamente a la sustitución total de la bomba y el motor. La potencia nominal a contabilizar se referirá al nuevo equipo.

USADA EN LOS INDICADORES: wOp29

\section{wD34- Bombas averiadas (hora)}

Suma, para todas las bombas, del número de horas que cada bomba ha estado averiada, durante el periodo de evaluación.

\section{DATO DE ENTRADA}

Al contabilizar el número total de bombas del sistema, las bombas pequeñas pueden ser excluidas si su influencia en términos de la fiabilidad del sistema es despreciable.

USADA EN LOS INDICADORES: wOp41 
wD35- Volumen de entrada $\left(\mathrm{m}^{3}\right)$

Volumen de agua que entra en el sistema de alcantarillado debido a conexiones erróneas durante el periodo de evaluación.

\section{DATO DE ENTRADA}

Las conexiones erróneas incluyen conexiones incorrectas a la red de alcantarillado (por ejemplo, escorrentía superficial directa que entra a través de tapas de los pozos de registro de redes de aguas residuales separativas).

USADA EN LOS INDICADORES: wOp30,wOp30,wOp31,

USADA EN LAS VARIABLES:

wD36- Volumen infiltrado $\left(\mathrm{m}^{3}\right)$

Volumen de agua subterránea que entra a los colectores durante el período de evaluación.

\section{DATO DE ENTRADA}

USADA EN LOS INDICADORES: wOp30,wOp32

\section{wD37- Volumen exflitrado $\left(\mathrm{m}^{3}\right)$}

Volumen de aguas residuales fugadas desde la red al exterior durante el período de evaluación.

\section{DATO DE ENTRADA}

USADA EN LOS INDICADORES: wOp30,wOp30,wOp33

\section{wD38- Atascos de colectores (No.)}

Número de atascos que ocurrieron en los colectores durante el periodo de evaluación.

\section{DATO DE ENTRADA}

No se incluirán los atascos en las estaciones de bombeo. Los atascos en las acometidas se incluirán solo cuando sean responsabilidad del servicio de saneamiento.

USADA EN LOS INDICADORES: wOp34 
wD39- Puntos de atasco de colectores (No.)

Número de puntos individuales en los colectores donde ocurrieron atascos durante el periodo de evaluación.

\section{DATO DE ENTRADA}

Los puntos donde se producen atascos frecuentemente deben ser contabilizadas una sola vez; no se incluirán los atascos en las estaciones de bombeo.

Los atascos en las acometidas se incluirán solo cuando sean responsabilidad del servicio de saneamiento.

USADA EN LOS INDICADORES: wOp35

wD40- Atasco de estaciones de bombeo (No.)

Número de atascos que ocurrieron en estaciones de bombeo durante el periodo de evaluación.

\section{DATO DE ENTRADA}

Los atascos en estaciones de bombeo incluyen los atascos en bombas y válvulas. No se incluirán los atascos ocurridos en los colectores de la red. Si los atascos ocurren más de una vez en una estación de bombeo, se contabilizará tantas veces como atascos haya habido.

USADA EN LOS INDICADORES: wOp36

\section{wD41- Inundaciones debidas a colectores de aguas negras (No.)}

Número de inundaciones producidas por colectores de aguas negras (redes separativas) durante el periodo de evaluación.

\section{DATO DE ENTRADA}

Se deben incluir solo los incidentes relacionados con colectores de aguas residuales que sean responsabilidad del servicio.

USADA EN LOS INDICADORES: wOp37 
wD42- Inundaciones debidas a colectores unitarios (No.)

Número de inundaciones producidas por colectores unitarios durante el periodo de evaluación.

\section{DATO DE ENTRADA}

Se deben incluir solo los incidentes relacionados con colectores unitarios que sean responsabilidad del servicio.

USADA EN LOS INDICADORES: wOp38

\section{wD43- Inundaciones superficiales (No.)}

Número de inundaciones de la superficie que ocurrieron durante el periodo de evaluación.

\section{DATO DE ENTRADA}

Se incluyen solo inundaciones de la superficie debidas a la insuficiencia del sistema de alcantarillado (incluyendo colectores unitarios) que es responsabilidad del servicio de alcantarillado. La insuficiencia del sistema se relaciona con todas las posibles causas (diseño, operación, etc.).

USADA EN LOS INDICADORES: wOp39

\section{wD44- Colapso de colectores (No.)}

Número de colectores que han colapsado durante el periodo de evaluación.

\section{DATO DE ENTRADA}

No se incluyen los colapsos en las acometidas.

USADA EN LOS INDICADORES: WOp40

\section{wD45- Control de tanques de tormenta (No.)}

Número de tanques de tormenta controlados por reguladores de caudal dinámicos o estáticos en la fecha de referencia.

DATO DE ENTRADA

USADA EN LOS INDICADORES: WOp43 
wD46- Ensayos realizados de calidad del agua residual (No.)

Número total de ensayos de calidad del agua residual realizados durante el periodo de evaluación.

\section{wD48+wD49+wD50+wD51+wD52+wD53+wD54}

Esta variable solo tendrá en cuenta los ensayos que son responsabilidad del servicio, en los puntos donde el control de calidad es obligatorio, dondequiera que se realicen. Incluye no solo los test realizados en los laboratorios del servicio, sino también los subcontratados.

USADA EN LOS INDICADORES: $\quad$ wOp44

wD47- Número total de ensayos de calidad del agua residual realizadas por los laboratorios del servicio (No.)

Número total de ensayos de calidad de aguas residuales y lodos realizados por los laboratorios del servicio, durante el periodo de evaluación.

\section{DATO DE ENTRADA}

Esta variable incluye no solo las pruebas obligatorias de aguas residuales y lodos, sino también las pruebas de control de procesos. No se incluirán los ensayos externalizados.

USADA EN LOS INDICADORES: wPe12

USADA EN LAS VARIABLES:

\section{wD48- Ensayos de DBO realizados (No.)}

Número de ensayos de DBO realizados durante el periodo de evaluación.

\section{DATO DE ENTRADA}

Esta variable solo tendrá en cuenta los ensayos que son responsabilidad del servicio, en los puntos donde el control de calidad es obligatorio, dondequiera que se realicen. Incluye no solo los test realizados en los laboratorios del servicio, sino también los subcontratados.

USADA EN LOS INDICADORES: wOp44(wD46), wOp45

USADA EN LAS VARIABLES: wD46 
wD49- Ensayos de DQO realizados (No.)

Número de ensayos de DQO realizados durante el periodo de evaluación.

\section{DATO DE ENTRADA}

Esta variable solo tendrá en cuenta los ensayos que son responsabilidad del servicio, en los puntos donde el control de calidad es obligatorio, dondequiera que se realicen. Incluye no solo los test realizados en los laboratorios del servicio, sino también los subcontratados.

USADA EN LOS INDICADORES: wOp44(wD46), wOp46

USADA EN LAS VARIABLES: wD46

\section{wD50- Ensayo de sólidos suspendidos realizados (No.)}

Número de ensayos de sólidos suspendidos realizados durante el periodo de evaluación.

\section{DATO DE ENTRADA}

Esta variable solo tendrá en cuenta los ensayos que son responsabilidad del servicio, en los puntos donde el control de calidad es obligatorio, dondequiera que se realicen. Incluye no solo los test realizados en los laboratorios del servicio, sino también los subcontratados.

USADA EN LOS INDICADORES: wOp44(wD46), wOp47

USADA EN LAS VARIABLES: wD46

\section{wD51- Ensayos de fósforo realizados (No.)}

Número de ensayos de fósforo realizados durante el periodo de evaluación.

\section{DATO DE ENTRADA}

Esta variable solo tendrá en cuenta los ensayos que son responsabilidad del servicio, en los puntos donde el control de calidad es obligatorio, dondequiera que se realicen. Incluye no solo los test realizados en los laboratorios del servicio, sino también los subcontratados.

USADA EN LOS INDICADORES: wOp44(wD46), wOp48

USADA EN LAS VARIABLES: wD46 
wD52- Ensayos de nitrógeno realizados (No.)

Número de ensayos de nitrógeno realizados durante el periodo de evaluación.

\section{DATO DE ENTRADA}

Esta variable solo tendrá en cuenta los ensayos que son responsabilidad del servicio, en los puntos donde el control de calidad es obligatorio, dondequiera que se realicen. Incluye no solo los test realizados en los laboratorios del servicio, sino también los subcontratados.

USADA EN LOS INDICADORES: wOp44(wD46), wOp49

USADA EN LAS VARIABLES: $w \mathrm{D} 46$

\section{wD53- Ensayos de e. coli fecales realizados (No.)}

Número de ensayos de e. coli fecales realizados durante el periodo de evaluación.

\section{DATO DE ENTRADA}

Esta variable solo tendrá en cuenta los ensayos que son responsabilidad del servicio, en los puntos donde el control de calidad es obligatorio, dondequiera que se realicen. Incluye no solo los test realizados en los laboratorios del servicio, sino también los subcontratados.

USADA EN LOS INDICADORES: wOp44(wD46), wOp50

USADA EN LAS VARIABLES: wD46

\section{wD54- Otros test de calidad del agua residual realizados (No.)}

Número de otros ensayos de calidad del agua residuales realizados durante el periodo de evaluación.

\section{DATO DE ENTRADA}

Esta variable solo tendrá en cuenta los ensayos que son responsabilidad del servicio, en los puntos donde el control de calidad es obligatorio, dondequiera que se realicen. Incluye no solo los test realizados en los laboratorios del servicio, sino también los subcontratados.

USADA EN LOS INDICADORES: wOp44(wD46), wOp51

USADA EN LAS VARIABLES: wD46 
wD55- Ensayos realizados de lodos (No.)

Número de ensayos realizados de lodos producidos durante el periodo de evaluación.

\section{DATO DE ENTRADA}

Incluye no solo los test realizados en los laboratorios del servicio, sino también los subcontratados.

USADA EN LOS INDICADORES: wOp52

\section{wD56- Ensayos realizados de vertidos industriales (No.)}

Número de ensayos realizados de vertidos industriales en la red de alcantarillado durante el periodo de evaluación.

\section{DATO DE ENTRADA}

Incluye no solo los test realizados en los laboratorios del servicio, sino también los subcontratados.

USADA EN LOS INDICADORES: wOp53

\section{wD57- Ensayos requeridos de calidad del agua residual (No.)}

Número total de ensayos de calidad de aguas residuales requeridos por las normas o la legislación aplicables, durante el periodo de evaluación.

wD58+wD59+wD60+wD61+wD62+wD63+wD64

USADA EN LOS INDICADORES: wOp44

\section{wD58- Ensayos de DBO requeridos (No.)}

Número de ensayos de DBO requeridos por las normas o la legislación aplicables, durante el periodo de evaluación.

\section{DATO DE ENTRADA}

USADA EN LOS INDICADORES: wOp44(wD57), wOp45

USADA EN LAS VARIABLES: wD57 
wD59- Ensayos de DQO requeridos (No.)

Número de ensayos de DQO requeridos por las normas o la legislación aplicables, durante el periodo de evaluación.

DATO DE ENTRADA

USADA EN LOS INDICADORES: WOp44(wD57), wOp46

USADA EN LAS VARIABLES: wD57

wD60- Ensayo de sólidos suspendidos requeridos (No.)

Número de ensayos de sólidos suspendidos requeridos por las normas o la legislación aplicables, durante el periodo de evaluación.

DATO DE ENTRADA

USADA EN LOS INDICADORES: wOp44(wD57), wOp47

USADA EN LAS VARIABLES: wD57

wD61- Ensayos de fósforo requeridos (No.)

Número de ensayos de fósforo requeridos por las normas o la legislación aplicables, durante el periodo de evaluación.

DATO DE ENTRADA

USADA EN LOS INDICADORES: wOp44(wD57), wOp48

USADA EN LAS VARIABLES: wD57

wD62- Ensayos de nitrógeno requeridos (No.)

Número de ensayos de nitrógeno requeridos por las normas o la legislación aplicables, durante el periodo de evaluación.

DATO DE ENTRADA

USADA EN LOS INDICADORES: wOp44(wD57), wOp49

USADA EN LAS VARIABLES: wD57 
wD63- Ensayos de e. coli fecales requeridos (No.)

Número de ensayos de e. coli fecales requeridos por las normas o la legislación aplicables, durante el periodo de evaluación.

\section{DATO DE ENTRADA}

USADA EN LOS INDICADORES: wOp44(wD57), wOp50

USADA EN LAS VARIABLES: wD57

\section{wD64- Otros test de calidad del agua residual requeridos (No.)}

Número de otros ensayos de calidad de aguas residuales requeridos por las normas o la legislación aplicables, durante el periodo de evaluación.

\section{DATO DE ENTRADA}

USADA EN LOS INDICADORES: wOp44(wD57), wOp51

USADA EN LAS VARIABLES: wD57

\section{wD65- Ensayos requeridos de lodos (No.)}

Número de ensayos de lodos requeridos por las normas o la legislación aplicables, durante el periodo de evaluación.

\section{DATO DE ENTRADA}

USADA EN LOS INDICADORES: wOp52

\section{wD66- Ensayos requeridos de vertidos industriales (No.)}

Número de ensayos de vertidos industriales requeridos por las normas o la legislación aplicables, durante el periodo de evaluación.

\section{DATO DE ENTRADA}

USADA EN LOS INDICADORES: wOp53 
wD67- Vehículos permanentes (No.)

Número promedio diario de vehículos disponibles para trabajos de campo relacionado con el servicio de saneamiento, en la fecha de referencia.

\section{DATO DE ENTRADA}

En el caso de prestadores con más de un servicio, solo se considerará la porción de vehículos relacionada con las actividades del servicio de saneamiento. Todos los vehículos disponibles se contabilizarán, independientemente de su propiedad, prestador o subcontratistas. Se excluirán los vehículos utilizados en el ámbito de actividades subcontratadas. No se incluirá la maquinaria pesada.

USADA EN LOS INDICADORES: wOp54

\section{wD68- Detectores de gas (No.)}

Número de detectores de gas (incluyendo: $\mathrm{O}_{2}, \mathrm{H}_{2} \mathrm{~S}, \mathrm{CH}_{4}$ y $\mathrm{CO}_{2}$ ) en la fecha de referencia.

\section{DATO DE ENTRADA}

Todos los detectores de gas que estén disponibles deberán contabilizarse, independientemente de su propiedad, empresa o subcontratistas. Se deben incluir todos los detectores de gas, tanto los instalados de manera permanente como los portátiles, siempre que estén calibrados.

USADA EN LOS INDICADORES: wOp55,wOp56

\section{wD69- Detectores de gas permanentemente instalados (No.)}

Número de detectores de gas permanentemente instalados (incluyendo: $\mathbf{O}_{2}$, $\mathrm{H}_{2} \mathrm{~S}, \mathrm{CH}_{4}$ y $\mathrm{CO}_{2}$ ) en la fecha de referencia.

\section{DATO DE ENTRADA}

USADA EN LOS INDICADORES: wOp56 


\subsection{Sección E - Datos sobre demografía y clientes}

\section{wE1- Población residente (hab.)}

Población total que vive permanentemente en el área que es responsabilidad del servicio de saneamiento, en la fecha de referencia.

\section{DATO DE ENTRADA}

USADA EN LOS INDICADORES: wQS1, wQS2, wQS3,wQS4, wQS19, wQS20,wQS21, wQS22, wQS23, wQS24,wQS25, wQS26

wE2- Población residente servida por estaciones depuradoras de aguas residuales (hab.)

Población residente servida por estaciones depuradoras de agua residual gestionadas por el servicio, en la fecha de referencia.

\section{DATO DE ENTRADA}

USADA EN LOS INDICADORES: WQS2

\section{wE3- Población residente servida por sistemas in-situ (hab.)}

Población residente servida por sistemas in-situ gestionados por el servicio (p.ej. fosas sépticas, letrinas,...), en la fecha de referencia.

\section{DATO DE ENTRADA}

USADA EN LOS INDICADORES: wQS3

\section{wE4- Población residente conectada a la red de alcantarillado (hab.)}

Población residente conectada a la red de alcantarilladogestionada por el servicio, en la fecha de referencia.

\section{DATO DE ENTRADA}

USADA EN LOS INDICADORES: wQS1 
wE5- Población equivalente servida con EDAR (p.e.)

Población equivalente servida por EDAR gestionadas por el servicio, en la fecha de referencia.

\section{DATO DE ENTRADA}

Esta variable se estima utilizando las cargas promedio de $\mathrm{DBO}_{5}$ a la entrada de las EDAR y la definición de población equivalente (ver II-1.4-Definiciones complementarias).

USADA EN LOS INDICADORES: wEn1,wEn6,wPe1,wPe10,wOp18

\section{wE6- Población equivalente servida por sistemas in-situ (p.e.)}

Población equivalente atendidas por sistemas in-situ que son responsabilidad del servicio en la fecha de referencia.

\section{DATO DE ENTRADA}

Esta variable se estima utilizando las cargas promedio de $\mathrm{DBO}_{5}$ de entrada a los sistemas in-situ y la definición de población equivalente (ver II-1.4-Definiciones complementarias).

USADA EN LOS INDICADORES: wEn15,wPe1,wPe10

\section{wE7- Población residente sin servicio (hab.)}

Población residente cuya agua residual no es ni recogida ni tratada, en la fecha de referencia.

\section{DATO DE ENTRADA}

USADA EN LOS INDICADORES: WQS4 
wE8- Población equivalente total servida (p.e.)

Población total que produce aguas residuales que la empresa recolecta o trata, en la fecha de referencia, incluidas las aguas residuales importadas y las contribuciones industriales expresadas en población equivalente.

\section{DATO DE ENTRADA}

Esta variable se estima utilizando las cargas promedio de $\mathrm{DBO}_{5}$, los caudales de aguas residuales y la definición de población equivalente (ver II-1.4-Definiciones complementarias).

USADA EN LOS INDICADORES: $\quad$ wFi1,wFi5,wFi7,wFi9,wFi27

\subsection{Sección F - Datos de calidad del servicio}

wF1- Agua residual recolectada $\left(\mathrm{m}^{3}\right)$
$\begin{aligned} & \text { Agua residual recolectada, correspondiente al volumen de insumos } \\ & \text { domésticos, comerciales e industriales, en la red de alcantarillado durante el } \\ & \text { periodo de evaluación. }\end{aligned}$
DATO DE ENTRADA
$\begin{aligned} & \text { Este dato debe ser obtenido de la medida del caudal en tiempo seco y sustrayendo la } \\ & \text { infiltración, en condiciones de tiempo seco. En el caso en el que no hayan medidas de } \\ & \text { candal en tiempo seco, el agua residual recogida se puede estimar basada en un factor de } \\ & \text { retorno, que es un porcentaje del agua abastecida que es vertida como agua residual. } \\ & \text { UsADA EN LOS INDICADORES: wOp30,wQS5,wQS6,wQS7,wQS8,wOp48 }\end{aligned}$

wF2- Propiedades inundadas por colectores de aguas negras en tiempo seco (No.)

Número de propiedades afectadas por la inundación de colectores de aguas negras en tiempo seco, durante el periodo de evaluación.

DATO DE ENTRADA

USADA EN LOS INDICADORES: WQS10 
wF3- Propiedades inundadas por colectores de aguas negras en tiempo de lluvia (No.)

Número de propiedades afectadas por la inundación de colectores de aguas residuales en tiempo de lluvia, durante el periodo de evaluación.

DATO DE ENTRADA

USADA EN LOS INDICADORES: wQS11

wF4- Propiedades inundadas por colectores unitarios en tiempo seco (No.)

Número de propiedades afectadas por la inundación de colectores unitarios en tiempo seco, durante el periodo de evaluación.

DATO DE ENTRADA

USADA EN LOS INDICADORES: WQS12

wF5- Propiedades inundadas por colectores unitarios en tiempo de lluvia (No.)

Número de propiedades afectadas por la inundación de colectores unitarios en tiempo de lluvia, durante el periodo de evaluación.

\section{DATO DE ENTRADA}

USADA EN LOS INDICADORES: WQS13

wF6- Inundación de la superficie de propiedades en tiempo de lluvia (No.)

Número de propiedades afectadas por inundaciones de la superficie en tiempo de lluvia, durante el periodo de evaluación.

DATO DE ENTRADA

USADA EN LOS INDICADORES: WQS14 
wF7- Interrupción del servicio de saneamiento (No.)

Suma, para el periodo de evaluación, del número de propiedades afectadas por la interrupción del servicio multiplicadas por la duración respectiva de las interrupciones en horas.

\section{DATO DE ENTRADA}

USADA EN LOS INDICADORES: WQS15

\section{wF8- Alta de nuevas acometidas (No.)}

Número de nuevas acometidas dadas de alta durante el periodo de evaluación.

\section{DATO DE ENTRADA}

Esta variable se refiere a nuevos contratos, cuando la acometida física ya existe.

USADA EN LOS INDICADORES: WQS16

\section{wF9- Tiempo de establecimiento de nuevas acometidas (día)}

Tiempo total empleado para establecer nuevas acometidas, desde la solicitud del cliente hasta la disponibilidad del servicio, durante el periodo de evaluación.

\section{DATO DE ENTRADA}

USADA EN LOS INDICADORES: WQS16

\section{wF10- Acometidas reparadas (No.)}

Número total de acometidas reparadas durante el periodo de evaluación.

\section{DATO DE ENTRADA}

Esta variable incluye todos los fallos reportados en acometidas además de los reportados por los clientes.

USADA EN LOS INDICADORES: WQS17 
wF11- Tiempo de reparación de acometidas (día)

Tiempo total empleado para reparar acometidas, desde que el fallo se reporta hasta que el servicio es reestablecido, durante el periodo de evaluación.

\section{DATO DE ENTRADA}

Esta variable incluye todos los fallos reportados en acometidas además de los reportados por los clientes.

USADA EN LOS INDICADORES: WQS17

\section{wF12- Quejas totales (No.)}

Número total de quejas relacionadas con el servicio de saneamiento, durante el periodo de evaluación.

wF13+wF14+wF15+wF16+wF17+wF18+wF19

Esta variable incluye todas las quejas, sean presenciales, telefónicas o escritas.

USADA EN LOS INDICADORES: wQS19, wQS27

\section{wF13- Quejas por atascos (No.)}

Número de quejas relacionadas con atascos, durante el periodo de evaluación.

\section{DATO DE ENTRADA}

Esta variable incluye todas las quejas relacionadas con los atascos, sean presenciales, telefónicas o escritas.

USADA EN LOS INDICADORES: WQS20

USADA EN LAS VARIABLES: wF12

\section{wF14- Quejas por inundaciones (No.)}

Número de quejas relacionadas con inundaciones, durante el periodo de evaluación.

\section{DATO DE ENTRADA}

Esta variable incluye todas las quejas relacionadas con inundaciones, sean presenciales, telefónicas o escritas.

USADA EN LOS INDICADORES: WQS19(wF12), wQS20, wQS27(wF12)

USADA EN LAS VARIABLES: wF12 
wF15- Quejas por incidentes de contaminación (No.)

Número de quejas relacionadas con incidentes de contaminación, durante el periodo de evaluación.

\section{DATO DE ENTRADA}

Esta variable incluye todas las quejas relacionadas con incidentes de contaminación, sean presenciales, telefónicas o escritas.

USADA EN LOS INDICADORES: wQS19(wF12), wQS22, wQS27(wF12)

USADA EN LAS VARIABLES: wF12

\section{wF16- Quejas por olores (No.)}

Número de quejas relacionadas con olores, durante el periodo de evaluación.

\section{DATO DE ENTRADA}

Esta variable incluye todas las quejas relacionadas con olores, sean presenciales, telefónicas o escritas.

USADA EN LOS INDICADORES: WQS19(wF12), wQS23, wQS27(wF12)

USADA EN LAS VARIABLES: wF12

\section{wF17- Quejas relacionadas con roedores (No.)}

Número de quejas relacionadas con roedores, durante el periodo de evaluación.

\section{DATO DE ENTRADA}

Esta variable incluye todas las quejas relacionadas con roedores, sean presenciales, telefónicas o escritas.

USADA EN LOS INDICADORES: WQS19(wF12), wQS24, wQS27(wF12)

USADA EN LAS VARIABLES: wF12 
wF18- Quejas relacionadas con la facturación(No.)

Número de quejas relacionadas con la facturación, durante el periodo de evaluación.

\section{DATO DE ENTRADA}

Esta variable incluye todas las quejas relacionadas con la facturación, sean presenciales, telefónicas o escritas.

USADA EN LOS INDICADORES: wQS19(wF12), wQS25, wQS27(wF12)

USADA EN LAS VARIABLES: wF12

\section{wF19- Otras quejas (No.)}

Número de otras quejas, durante el periodo de evaluación.

\section{DATO DE ENTRADA}

Esta variable incluye todas las quejas relacionadas otras quejas, sean presenciales, telefónicas o escritas.

USADA EN LOS INDICADORES: wQS19(wF12), wQS26, wQS27(wF12)

USADA EN LAS VARIABLES: $w F 12$

\section{wF20- Respuestas a quejas (No.)}

Número de respuestas a las quejas presentadas dentro del tiempo objetivo, durante el periodo de evaluación.

\section{DATO DE ENTRADA}

El tiempo objetivo es el tiempo especificado por el proveedor del servicio de saneamiento, por un regulador u otra agencia autorizada, que se establece para que el servicio responda a una queja telefónica, escrita u otra forma de queja, interrupción del servicio o fallo del sistema.

USADA EN LOS INDICADORES: WQS27 
wF21- Daños a terceros (No.)

Número de incidentes, ocurridos durante el periodo de evaluación, relacionados con accidentes bien de personas que no trabajan para el servicio, o que han causado daños a bienes, activos, vehículos o pertenencias de terceros.

DATO DE ENTRADA

USADA EN LOS INDICADORES: WQS28

\section{wF22- Accidentes (No.)}

Número total de accidentes que son responsabilidad del servicio, durante el periodo de evaluación.

\section{DATO DE ENTRADA}

USADA EN LOS INDICADORES: WQS28

\section{wF23- Solicitudes de vaciado de fosas sépticas (No.)}

Número total de solicitudes de vaciado de fosas sépticas o del contenido de letrinas de hoyo durante el periodo de evaluación.

\section{DATO DE ENTRADA}

USADA EN LOS INDICADORES: WQS18

\section{wF24- Tiempo de respuesta de vaciado de fosas sépticas (día)}

Suma, para todas las solicitudes, del tiempo de respuesta para vaciar fosas sépticas o letrinas, durante el periodo de evaluación.

\section{DATO DE ENTRADA}

El tiempo de respuesta es el periodo en días desde la solicitud de vaciado de fosas sépticas o letrinas hasta el día en que se restaura el servicio.

USADA EN LOS INDICADORES: WQS18 
wF25- Perturbaciones en el tráfico (No.)

Número de perturbaciones en el tráfico durante el periodo de evaluación.

\section{DATO DE ENTRADA}

Las perturbaciones del tráfico incluyen actividades relacionadas con la inspección, limpieza, mantenimiento, construcción y trabajos de rehabilitación en el sistema de alcantarillado, donde el tráfico se interrumpe por lo menos en un carril. No se considerarán las vías donde el tráfico promedio sea inferior a 5000 vehículos por día durante las obras.

USADA EN LOS INDICADORES: WQS29

\section{wF26- Interrupción del tráfico (km x hora)}

$\sum$ Para todas las perturbaciones de tráfico debidas a actividades relacionadas con el servicio de alcantarillado (Longitud del carril de tráfico no disponible $\mathbf{x}$ duración de la interrupción), durante el periodo de evaluación.

\section{DATO DE ENTRADA}

Las perturbaciones del tráfico incluyen actividades relacionadas con la inspección, limpieza, mantenimiento, construcción y trabajos de rehabilitación en el sistema de alcantarillado, donde el tráfico se interrumpe por lo menos en un carril. No se considerarán las vías donde el tráfico promedio sea inferior a 5000 vehículos por día durante las obras.

USADA EN LOS INDICADORES: WQS29

\subsection{Sección G - Datos financieros}

\section{wG1- Ingresos totales (EUR)}

Ingresos totales de operación (wG2) menos costes capitalizados de activos construidos por el servicio (wG33), relacionados con el servicio de saneamiento, durante el período de evaluación.

\section{wG2-wG33}

Los costes capitalizados de activos construidos por el servicio deberían ser considerados como una corrección económica de los costes operacionales.

Consecuentemente, deberían ser registrados como una cantidad negativa con el fin de obtener los ingresos totales

USADA EN LOS INDICADORES: wFi2,wFi3,wFi3,wFi30,wFi31 
wG2- Ingresos de operación (EUR)

Ingresos totales de operación durante el período de evaluación, incluyendo ingresos por servicios (wG3), trabajos en curso, costes capitalizados de activos construidos por el prestador (wG33) y otros ingresos por explotación relacionados con el servicio $\mathrm{d}$

\section{DATO DE ENTRADA}

Ver sección II-1.3, Tabla 61 y Tabla 62, para más detalles. El tipo de cambio de las monedas locales se remitirá al final del año.

USADA EN LOS INDICADORES: wFi1, wFi2(wG1), wFi3(wG1), wFi30(wG1), wFi31(wG1), wFi38

USADA EN LAS VARIABLES: wG1

\section{wG3- Ingresos por servicios (EUR)}

Ingresos de explotación del servicio de saneamiento, durante el período de evaluación.

\section{DATO DE ENTRADA}

Ver sección II-1.3, Tabla 61 y Tabla 62, para más detalles. El tipo de cambio de las monedas locales se remitirá al final del año.

USADA EN LOS INDICADORES: wFi2,wFi3,wFi4,wFi32,wFi45

\section{wG4- Ingresos por servicios industriales (EUR)}

Ingresos de explotación por servicios de alcantarillado a industrias, durante el período de evaluación.

\section{DATO DE ENTRADA}

Ver sección II-1.3, Tabla 61 y Tabla 62, para más detalles. El tipo de cambio de las monedas locales se remitirá al final del año.

USADA EN LOS INDICADORES: wFi4 
wG5- Costes totales (EUR)

Costes totales, incluyendo costes de capital y de explotación, relacionados con el servicio de saneamiento, durante el período de evaluación.

\section{wG6+wG7}

Ver sección II-1.3, Tabla 61 y Tabla 62, para más detalles.. El tipo de cambio de las monedas locales se remitirá al final del año.

USADA EN LOS INDICADORES: wFi5,wFi6,wFi30

\section{wG6- Costes de explotación (EUR)}

Costes netos totales de explotación, mantenimiento y mano de obra interna (es decir, excluyendo los costes capitalizados de activos construidos por la empresa) durante el período de evaluación, relacionados con el servicio de saneamiento.

\section{wG8+wG9}

Esta variable debe ser equivalente a la suma de las variables wFi11, wFi12, wFi13 y wFi15, que desglosan los costes de explotación por tipo de coste. Ver sección II-1.3, Tabla 61 y Tabla 62, para más detalles.

El tipo de cambio de las monedas locales se remitirá al final del año.

USADA EN LOS INDICADORES: wFi5, wFi6(wG5), wFi7, wFi8, wFi11, wFi12, wFi13, wFi14, wFi15, wFi16, wFi17, wFi18, wFi19, wFi20, wFi21, wFi22, wFi23, wFi24, wFi30(wG5), wFi31

USADA EN LAS VARIABLES: wG5

\section{wG7- Costes de capital (EUR)}

Costes totales por intereses netos y por depreciación (basados en valores contables) durante el período de evaluación, relacionados con el servicio de saneamiento.

\section{wG26+wG29}

Tiene que considerarse el valor neto del interés, así como deberían contabilizarse los intereses a favor como una reducción en los costes capitales y no como un ingreso. Ver sección II-1.3, Tabla 61 y Tabla 62, para más detalles.

USADA EN LOS INDICADORES: wFi5, wFi6(wG5), wFi9, wFi10, wFi25, wFi26, wFi30(wG5)

USADA EN LAS VARIABLES: wG5 
wG8- Costes operativos (EUR)

Costes de operación, relacionados con el servicio de saneamiento, durante el período de evaluación, incluyendo el valor neto (obtenido como el prorrateo negativo de los costes capitalizados de activos construidos por la empresa) de: energía, servicios externos, arrendamiento y alquiler, coste del material comprado, ganancias y pérdidas extraordinarias, tasas, gravámenes e impuestos, y otros costes de operación. No debe incluirse la mano de obra.

\section{wG10+wG11+wG12+wG13+wG14+wG15+wG16}

Ver sección II-1.3, Tabla 61 y Tabla 62, para más detalles. El tipo de cambio de las monedas locales se remitirá al final del año.

USADA EN LOS INDICADORES: wFi5(wG6), wFi6(wG5), wFi7(wG6), wFi8(wG6), wFi11(wG6), wFi12(wG6), wFi13(wG6), wFi14(wG6), wFi15(wG6), wFi16(wG6), wFi17(wG6), wFi18(wG6), wFi19(wG6), wFi20(wG6), wFi21(wG6), wFi22(wG6), wFi23(wG6), wFi24(wG6), wFi30(wG5), wFi31(wG6)

USADA EN LAS VARIABLES: wG6

\section{wG9- Costes de la mano de obra interna (EUR)}

Coste de la mano de obra interna relacionada con el servicio de saneamiento, durante el período de evaluación, referidas al valor neto (obtenido por el prorrateo negativo de los costes capitalizados de activos construidos por la empresa) del personal cuyo salario proviene directamente del servicio.

\section{DATO DE ENTRADA}

Ver sección II-1.3, Tabla 61 y Tabla 62, para más detalles. Los costes de mano de obra incluyen salarios y otros costes que se derivan directamente de ellos, como pagos complementarios o complementos de seguridad social. El tipo d

USADA EN LOS INDICADORES: wFi5(wG6), wFi6(wG5), wFi7(wG6), wFi8(wG6), wFi11, wFi12(wG6), wFi13(wG6), wFi14(wG6), wFi15(wG6), wFi16(wG6), wFi17(wG6), wFi18(wG6), wFi19(wG6), wFi20(wG6), wFi21(wG6), wFi22(wG6), wFi23(wG6), wFi24(wG6), wFi30(wG5), wFi31(wG6)

USADA EN LAS VARIABLES: wG5 (wG6), wG6 
Valor neto (obtenido por el prorrateo negativo de los costes capitalizados de activos construidos por la empresa) del coste de los servicios externos (es decir, subcontratas), incluyendo el coste de la mano de obra externa, relacionados con el servicio de saneamiento, durante el período de evaluación.

\section{DATO DE ENTRADA}

Ver sección II-1.3, Tabla 61 y Tabla 62, para más detalles. El tipo de cambio de las monedas locales se remitirá al final del año.

USADA EN LOS INDICADORES: wFi5(wG6), wFi6(wG5), wFi7(wG6), wFi8(wG6), wFi11(wG6), wFi12, wFi13(wG6), wFi14(wG6), wFi15(wG6), wFi16(wG6), wFi17(wG6), wFi18(wG6), wFi19(wG6), wFi20(wG6), wFi21(wG6), wFi22(wG6), wFi23(wG6), wFi24(wG6), wFi30(wG5), wFi31(wG6)

USADA EN LAS VARIABLES: wG5 (wG6), wG6 (wG8), wG8

\section{wG11- Coste de la energía eléctrica (EUR)}

Coste total de la energía eléctrica relacionado con el servicio de saneamiento, dentro del período de evaluación.

\section{DATO DE ENTRADA}

Ver sección II-1.3, Tabla 61 y Tabla 62, para más detalles. Esta variable incluye no solo el componente proporcional al consumo de energía, sino todos los demás componentes de los costes de energía, como las tarifas eléctricas y los impuestos. También se incluye el consumo de energía para otras actividades diferentes del bombeo de aguas residuales.

El tipo de cambio de las monedas locales se remitirá al final del año.

USADA EN LOS INDICADORES: wFi5(wG6), wFi6(wG5), wFi7(wG6), wFi8(wG6), wFi11(wG6), wFi12(wG6), wFi13, wFi14(wG6), wFi15(wG6), wFi16(wG6), wFi17(wG6), wFi18(wG6), wFi19(wG6), wFi20(wG6), wFi21(wG6), wFi22(wG6), wFi23(wG6), wFi24(wG6), wFi30(wG5), wFi31(wG6)

USADA EN LAS VARIABLES: wG5 (wG6), wG6 (wG8), wG8 
wG12- Coste del material comprado (EUR)

Valor neto (obtenido por el prorrateo negativo de los costes capitalizados de activos construidos por la empresa) de todos los materiales, reactivos y otros consumibles no incluidos en los costes de los servicios externos, relacionados con el servicio de saneamiento, durante el período de evaluación.

\section{DATO DE ENTRADA}

Ver sección II-1.3, Tabla 61 y Tabla 62, para más detalles. El tipo de cambio de las monedas locales se remitirá al final del año.

USADA EN LOS INDICADORES: wFi5(wG6), wFi6(wG5), wFi7(wG6), wFi8(wG6), wFi11(wG6), wFi12(wG6), wFi13(wG6), wFi14, wFi15(wG6), wFi16(wG6), wFi17(wG6), wFi18(wG6), wFi19(wG6), wFi20(wG6), wFi21(wG6), wFi22(wG6), wFi23(wG6), wFi24(wG6), wFi30(wG5), wFi31(wG6)

USADA EN LAS VARIABLES: wG5 (wG6), wG6 (wG8), wG8

\section{wG13- Arrendamiento y alquiler (EUR)}

Valor neto (obtenido por el prorrateo negativo de los costes capitalizados de activos construidos por la empresa) del coste total por arrendamientos y alquileres, relacionados con el servicio de saneamiento, durante el período de evaluación.

\section{DATO DE ENTRADA}

Ver sección II-1.3, Tabla 61 y Tabla 62, para más detalles. El tipo de cambio de las monedas locales se remitirá al final del año.

USADA EN LOS INDICADORES: wFi5(wG6), wFi6(wG5), wFi7(wG6), wFi8(wG6), wFi11(wG6), wFi12(wG6), wFi13(wG6), wFi14(wG6), wFi15, wFi16(wG6), wFi17(wG6), wFi18(wG6), wFi19(wG6), wFi20(wG6), wFi21(wG6), wFi22(wG6), wFi23(wG6), wFi24(wG6), wFi30(wG5), wFi31(wG6)

USADA EN LAS VARIABLES: wG5 (wG6), wG6 (wG8), wG8 
wG14- Tasas, gravámenes e impuestos (EUR)

Todas las tasas y licencias estrictamente relacionadas con operaciones del sistema de aguas residuales que se pagan a las autoridades gubernamentales o municipales (excluyendo los impuestos directos sobre EBT), durante el período de evaluación.

\section{DATO DE ENTRADA}

Ver sección II-1.3, Tabla 61 y Tabla 62, para más detalles. El tipo de cambio de las monedas locales se remitirá al final del año.

USADA EN LOS INDICADORES: wFi5(wG6), wFi6(wG5), wFi7(wG6), wFi8(wG6), wFi11(wG6), wFi12(wG6), wFi13(wG6), wFi14(wG6), wFi15, wFi16(wG6), wFi17(wG6), wFi18(wG6), wFi19(wG6), wFi20(wG6), wFi21(wG6), wFi22(wG6), wFi23(wG6), wFi24(wG6), wFi30(wG5), wFi31(wG6)

USADA EN LAS VARIABLES: wG5 (wG6), wG6 (wG8), wG8

\section{wG15- Ganancias y pérdidas extraordinarias (EUR)}

Beneficios o gastos excepcionales relacionados con las ventas / cancelación de activos fijos, relacionados con el servicio de saneamiento, durante el período de evaluación.

\section{DATO DE ENTRADA}

Ver sección II-1.3, Tabla 61 y Tabla 62, para más detalles. El tipo de cambio de las monedas locales se remitirá al final del año.

USADA EN LOS INDICADORES: wFi5(wG6), wFi6(wG5), wFi7(wG6), wFi8(wG6), wFi11(wG6), wFi12(wG6), wFi13(wG6), wFi14(wG6), wFi15, wFi16(wG6), wFi17(wG6), wFi18(wG6), wFi19(wG6), wFi20(wG6), wFi21(wG6), wFi22(wG6), wFi23(wG6), wFi24(wG6), wFi30(wG5), wFi31(wG6)

USADA EN LAS VARIABLES: wG5 (wG6), wG6 (wG8), wG8 
Valor neto (obtenido por el prorrateo negativo de los costes capitalizados de activos construidos por la empresa) de otros costes de operación no incluidos en materiales, sustancias químicas y otros consumibles para mantenimiento y reparación, arrendamien

\section{DATO DE ENTRADA}

Ver sección II-1.3, Tabla 61 y Tabla 62, para más detalles. El tipo de cambio de las monedas locales se remitirá al final del año.

USADA EN LOS INDICADORES: wFi5(wG6), wFi6(wG5), wFi7(wG6), wFi8(wG6), wFi11(wG6), wFi12(wG6), wFi13(wG6), wFi14(wG6), wFi15, wFi16(wG6), wFi17(wG6), wFi18(wG6), wFi19(wG6), wFi20(wG6), wFi21(wG6), wFi22(wG6), wFi23(wG6), wFi24(wG6), wFi30(wG5), wFi31(wG6)

USADA EN LAS VARIABLES: wG5 (wG6), wG6 (wG8), wG8

\section{wG17- Coste de explotación de la dirección general (EUR)}

Parte de los costes de explotación relativos al valor neto (obtenido por el prorrateo negativo de los costes capitalizados de activos construidos por el servicio) de los costes de dirección, administración central, planificación estratégica, marketing y comunicaciones, relaciones con las partes interesadas, asuntos jurídicos, auditorías internas, gestión medioambiental, desarrollo de nuevos negocios y asistencia informática general, relacionados con el servicio de saneamiento, durante el período de evaluación.

\section{DATO DE ENTRADA}

Esta variable incluye no solo los costes de las funciones internas, sino también, cuando corresponde, los costos de las funciones subcontratadas. Ver sección II-1.3, Figura 15 y Tabla 55, para más detalles. El tipo de cambio de las monedas locales se remitirá al final del año.

USADA EN LOS INDICADORES: wFi16 
wG18- Costes de explotación de la función de gestión de recursos humanos (EUR)

Parte de los costes de explotación relativos al valor neto (obtenido por el prorrateo negativo de los costes capitalizados de activos construidos por el prestador) de los costes del personal de administración, educación y formación del personal, la seguridad en el trabajo, los servicios médicos y las actividades sociales, relacionados con el servicio de saneamiento, durante el período de evaluación.

\section{DATO DE ENTRADA}

Esta variable incluye no solo los costes de las funciones internas, sino también, cuando corresponde, los costos de las funciones subcontratadas. Ver sección II-1.3, Figura 15 y Tabla 56, para más detalles. El tipo de cambio de las monedas locales se remitirá al final del año.

USADA EN LOS INDICADORES: wFi17

\section{wG19- Costes de explotación del área financiera y comercial (EUR)}

Parte de los costes de explotación relativos al valor neto (obtenido por el prorrateo negativo de los costes capitalizados de activos construidos por el prestador) de los costes de planificación económica y financiera, administración financiera, control económico y gestión de materiales, relacionados con el servicio de saneamiento, durante el período de evaluación.

\section{DATO DE ENTRADA}

Esta variable incluye no solo los costes de las funciones internas, sino también, cuando corresponde, los costos de las funciones subcontratadas. Ver sección II-1.3, Figura 15 y Tabla 57, para más detalles. El tipo de cambio de las monedas locales se remitirá al final del año.

USADA EN LOS INDICADORES: wFi18 
Parte de los costes de explotación relativos al valor neto (obtenido por el prorrateo negativo de los costes capitalizados de activos construidos por el prestador) y actividades de gestión, relacionados con el servicio de saneamiento, durante el período de evaluación.

\section{DATO DE ENTRADA}

Esta variable incluye no solo los costes de las funciones internas, sino también, cuando corresponde, los costos de las funciones subcontratadas. Ver sección II-1.3, Figura 15 y Tabla 58, para más detalles. El tipo de cambio de las monedas locales se remitirá al final del año.

USADA EN LOS INDICADORES: wFi19

\section{wG21- Coste del servicio técnico (EUR)}

Parte de los costes de explotación relativos al valor neto (obtenido por el prorrateo negativo de los costes capitalizados de activos construidos por el prestador) de los costes de la planificación técnica, diseño, construcción, operaciones y mantenimiento (incluyendo la reparación de activos) del servicio de saneamiento, durante el período de evaluación.

\section{DATO DE ENTRADA}

Esta variable incluye no solo los costes de las funciones internas, sino también, cuando corresponde, los costos de las funciones subcontratadas. Ver sección II-1.3, Figura 15, Tabla 59 y Tabla 60, para más detalles. El tipo de cambio de las monedas locales se remitirá al final del año.

USADA EN LOS INDICADORES: wFi20 
wG22- Costes de explotación del tratamiento de aguas residuales (EUR)

Parte de los costes de explotación relativos al valor neto (obtenido por el prorrateo negativo de los costes capitalizados de activos construidos por el prestador) de los costes del tratamiento de aguas residuales, durante el período de evaluación.

\section{DATO DE ENTRADA}

Para facilitar la evaluación, esta variable se puede dividir en subvariables más detalladas.

USADA EN LOS INDICADORES: wFi21

\section{wG23- Costes de explotación de la red de alcantarillado (EUR)}

Parte de los costes de explotación relativos al valor neto (obtenido por el prorrateo negativo de los costes capitalizados de activos construidos por el prestador) de los costes de la red de alcantarillado, durante el período de evaluación.

\section{DATO DE ENTRADA}

Para facilitar la evaluación, esta variable se puede dividir en subvariables más detalladas.

USADA EN LOS INDICADORES: wFi22

wG24- Costes de explotación de la monitorización de la calidad del agua residual (EUR)

Parte de los costes de explotación relativos al valor neto (obtenido por el prorrateo negativo de los costes capitalizados de activos construidos por el prestador) de los costes de monitorización del agua residual, durante el período de evaluación.

\section{DATO DE ENTRADA}

En el caso de prestadores con más de un servicio, cada empleado se contabilizará en base a la proporción de tiempo dedicado a actividades relacionadas con el servicio de saneamiento. Para facilitar la evaluación, esta variable se puede dividir en subvariables más detalladas.

USADA EN LOS INDICADORES: wFi23 
wG25- Costes de explotación de servicios de apoyo (EUR)

Parte de los costes de explotación relativos al valor neto (obtenido por el prorrateo negativo de los costes capitalizados de activos construidos por el prestador) de los costes de los servicios de apoyo, durante el período de evaluación.

\section{DATO DE ENTRADA}

En el caso de prestadores con más de un servicio, cada empleado se contabilizará en base a la proporción de tiempo dedicado a actividades relacionadas con el servicio de saneamiento. Para facilitar la evaluación, esta variable se puede dividir en subvariables más detalladas.

USADA EN LOS INDICADORES: wFi24

\section{wG26- Costes por depreciación (EUR)}

Costes por depreciación (basados en valores contables), relacionados con el servicio de saneamiento, durante el período de evaluación.

\section{DATO DE ENTRADA}

Ver sección II-1.3, Tabla 61 y Tabla 62, para más detalles. El tipo de cambio de las monedas locales se remitirá al final del año.

USADA EN LOS INDICADORES: wFi5(wG7), wFi6(wG5), wFi9(wG7), wFi10(wG7), wFi25, wFi26(wG7), wFi30(wG5), wFi33, wFi36

USADA EN LAS VARIABLES: wG7

wG27- Coste de los intereses (EUR)

Coste de los intereses, relacionados con el servicio de saneamiento, durante el período de evaluación.

\section{DATO DE ENTRADA}

Ver sección II-1.3, Tabla 61 y Tabla 62, para más detalles.El tipo de cambio de las monedas locales se remitirá al final del año.

USADA EN LOS INDICADORES: wFi5(wG7), wFi6(wG5), wFi9(wG7), wFi10(wG7), wFi25(wG7), wFi26, wFi30(wG5)

USADA EN LAS VARIABLES: wG5(wG7), wG7(wG29), wG29 
wG28- Ingresos por intereses (EUR)

Ingresos totales por intereses, relacionados con el servicio de saneamiento, durante el período de evaluación.

\section{DATO DE ENTRADA}

Los ingresos por intereses deberían ser considerados como una corrección económica de los intereses a cargo, no como un ingreso. Consecuentemente, deberían ser registrados como una cantidad negativa con el fin de obtener los costes totales netos. Ver sección II-1.3, Tabla 61 y Tabla 62, para más detalles. El tipo de cambio de las monedas locales se remitirá al final del año.

USADA EN LOS INDICADORES: wFi5(wG7), wFi6(wG5), wFi9(wG7), wFi10(wG7), wFi25(wG7), wFi26, wFi30(wG5)

USADA EN LAS VARIABLES: wG5(wG7), wG7(wG29), wG29

\section{wG29- Intereses netos (EUR)}

Coste de los intereses - ingresos por intereses, relacionados con el servicio de saneamiento, durante el período de evaluación.

\section{wG27-wG28}

En muchas ocasiones los intereses a cargo son mayores que los ingresos por intereses, lo que significa que el interés neto es un coste.

Ver sección II-1.3, Tabla 61 y Tabla 62, para más detalles. El tipo de cambio de las monedas locales se remitirá al final del año.

USADA EN LOS INDICADORES: wFi5(wG7), wFi6(wG5), wFi9(wG7), wFi10(wG7), wFi25(wG7), wFi26, wFi30(wG5)

USADA EN LAS VARIABLES: wG5(wG7), wG7 
Coste total de las inversiones en tangibles (gastos en la red de alcantarillado, plantas de tratamiento y equipo), incluyendo los costes capitalizados de activos construidos por el prestador (la parte de wG33 relativa a los activos tangibles), relacionados con el servicio de saneamiento, durante el período de evaluación.

\section{wG31+wG32}

Véase el diagrama de la sección II-1.3 - Definiciones financieras.

Los activos tangibles incluyen las inversiones en edificios de apoyo, vehículos, etc. El tipo de cambio de las monedas locales se remitirá al final del año.

USADA EN LOS INDICADORES: wFi27,wFi28,wFi29,wFi34

\section{wG31- Inversión en activos nuevos y en el fortalecimiento de los activos existentes (EUR)}

Coste total de las inversiones en activos tangibles que constituyen un nuevo desarrollo para el servicio (nuevos activos y fortalecimiento de los activos existentes), incluyendo los costes capitalizados de activos construidos por el prestador (la parte de wG33 relativa a los activos tangibles recientemente construidos o refuerzos), relacionados con el servicio de saneamiento, durante el período de evaluación.

\section{DATO DE ENTRADA}

El tipo de cambio de las monedas locales se remitirá al final del año.

USADA EN LOS INDICADORES: wFi27(wG30), wFi28, wFi29(wG30), wFi34(wG30)

USADA EN LAS VARIABLES: WG30 
wG32- Inversión en la sustitución y renovación de activos (EUR)

Coste total de las inversiones relativas a la sustitución y restauración de los activos existentes del abastecimiento ("Igual por igual", es decir, manteniendo aproximadamente la misma funcionalidad de la infraestructura existente) incluyendo los costes capitalizados de activos construidos por el prestador (la parte de wG33 relativa a la sustitución y renovación de los activos existentes), relacionado con el servicio de saneamiento, durante el período de evaluación.

\section{DATO DE ENTRADA}

El tipo de cambio de las monedas locales se remitirá al final del año.

USADA EN LOS INDICADORES: wFi27(wG30), wFi28(wG30), wFi29, wFi34(wG30)

USADA EN LAS VARIABLES: wG30 
wG33- Costes capitalizados de activos construidos por el servicio (EUR)

Costes totales capitalizados de activos construidos por el servicio relacionados con el servicio de alcantarillado, durante el período de evaluación.

\section{DATO DE ENTRADA}

Esta variable incluye los costes totales capitalizados de activos construidos por el prestador relacionados con las inversiones tanto en activos tangibles como intangibles que constituyen un nuevo desarrollo para el servicio y con las inversiones para la sustitución de activos existentes. En estos términos representa:

1) Un aumento de las inversiones construidas externamente y por lo tanto incluidas en el wG2 y otros datos relacionados;

2) una corrección económica del valor bruto de los costes de operación y mantenimiento y de mano de obra interna asignados en la declaración de pérdidas y ganancias (ver sección II-1.3, Tabla 61, para más detalles.) y, por tanto, introducida como cantidad negativa en los costes de wG8, wG9 y otros datos relacionados;

3) una corrección económica de los ingresos de explotación asignados en el declaración de pérdidas y ganancias (ver sección II-1.3, Tabla 61 y Tabla 62, para más detalles) y, por tanto, introducida como cantidad negativa para obtener los ingresos en wG1.

El tipo de cambio de las monedas locales se remitirá al final del año.

USADA EN LOS INDICADORES: wFi1, wFi2(wG1), wFi3(wG1), wFi30(wG1),

$$
\text { wFi31(wG1) }
$$

USADA EN LAS VARIABLES: wG1

\section{wG34- Cuentas a cobrar (EUR)}

Cuentas a cobrar, relacionado con el servicio de saneamiento, durante el período de evaluación.

\section{DATO DE ENTRADA}

Para evaluar los indicadores de gestión anuales, deberían utilizarse las cuentas a cobrar a fin de año.

USADA EN LOS INDICADORES: wFi32 
wG35- Inversiones sujetas a depreciación (EUR)

Inversiones en activos sujetas a depreciación, de acuerdo con los principios de contabilidad generalmente aceptados, relacionado con el servicio de saneamiento, durante el período de evaluación.

\section{DATO DE ENTRADA}

Ver sección II-1.3, Tabla 63, para más detalles. El tipo de cambio de las monedas locales se remitirá al final del año.

USADA EN LOS INDICADORES: wFi33

\section{wG36- Inversiones financiadas por el flujo de caja (EUR)}

Inversiones financiadas por el flujo de caja (valoradas como la suma del beneficio neto, la depreciación y la variación del capital de trabajo), relacionado con el servicio de saneamiento, durante el período de evaluación.

\section{DATO DE ENTRADA}

Ver sección II-1.3, Tabla 64, para más detalles. El tipo de cambio de las monedas locales se remitirá al final del año.

USADA EN LOS INDICADORES: wFi34

\section{wG37- Valor histórico depreciado de los activos tangibles (EUR/año)}

Suma, para todos los activos tangibles, del valor depreciado aplicado desde la fecha de adquisición, durante el año, relacionado con el servicio de saneamiento.

\section{DATO DE ENTRADA}

Ver sección II-1.3, Tabla 63 y Tabla 64, para más detalles. Esta variable se refiere a valores anuales. El tipo de cambio de las monedas locales se remitirá al final del año.

USADA EN LOS INDICADORES: wFi35, wFi42 
wG38- Valor histórico de los activos tangibles (EUR/año)

Se refiere al valor contable bruto de los gastos totales en activos tangibles infraestructurales y no infraestructurales, relacionado con el servicio de saneamiento.

\section{DATO DE ENTRADA}

Ver sección II-1.3, Tabla 63 y Tabla 64, para más detalles. Esta variable se refiere a valores anuales. El tipo de cambio de las monedas locales se remitirá al final del año. USADA EN LOS INDICADORES: wFi35,wFi36,wFi42

\section{wG39- Deuda anual de los clientes (EUR/año)}

Deuda anual de los clientes, relacionado con el servicio de saneamiento.

\section{DATO DE ENTRADA}

Esta variable se refiere a valores anuales. El tipo de cambio de las monedas locales se remitirá al final del año.

USADA EN LOS INDICADORES: wFi37

\section{wG40 - Cantidad anual facturada por año (EUR/año)}

Cantidad anual facturada por año, relacionado con el servicio de saneamiento.

\section{DATO DE ENTRADA}

Esta variable se refiere a valores anuales. El tipo de cambio de las monedas locales se remitirá al final del año.

USADA EN LOS INDICADORES: $\quad$ wFi37

\section{wG41- Flujo de caja (EUR)}

El total disponible es la suma del beneficio neto, la depreciación y el valor neto de la variación del capital de trabajo, relacionado con el servicio de saneamiento, durante el período de evaluación.

\section{DATO DE ENTRADA}

Ver sección II-1.3, Tabla 64, para más detalles. El tipo de cambio de las monedas locales se remitirá al final del año.

USADA EN LOS INDICADORES: wFi39 
wG42- Servicio de deuda financiera (EUR)

E1 servicio de deuda financiera contiene los gastos por interés ((wG27), el coste de préstamos y los principales (=capitales) instrumentos de reembolso de deuda, relacionado con el servicio de saneamiento, durante el período de evaluación.

\section{DATO DE ENTRADA}

El tipo de cambio de las monedas locales se remitirá al final del año.

USADA EN LOS INDICADORES: wFi39

\section{wG43- Deuda total (EUR/año}

Suma del pasivo a largo plazo (bonos y deudas financieras a largo plazo) y del pasivo circulante, al final del año fiscal, relacionado con el servicio de saneamiento.

wG48+wG49

El tipo de cambio de las monedas locales se remitirá al final del año.

USADA EN LOS INDICADORES: wFi40, wFi43(wG44)

USADA EN LAS VARIABLES: wG44

\section{wG44- Capital de los accionistas (EUR/año)}

Superávit del activo sobre el pasivo, relacionado con el servicio de saneamiento, al final del año fiscal.

\section{wG46-wG43}

El capital de los accionistas incluye el capital emitido en acciones, las reservas de capital, otras reservas y beneficio neto para el año.

Ver sección II-1.3, Tabla 65, para más detalles. El tipo de cambio de las monedas locales se remitirá al final del año.

USADA EN LOS INDICADORES: wFi40,wFi43 


\section{wG45- Activo circulante (EUR)}

El activo circulante incluye dinero en efectivo en bancos y en mano, cuentas a cobrar de agua potable, otros cobros de facturas, inventarios y gastos prepagados, relacionado con el servicio de saneamiento, durante el período de evaluación.

\section{DATO DE ENTRADA}

Cuando esta variable se refiere a valores anuales, debe ser evaluada al final de los ejercicios fiscales.

Ver sección II-1.3, Tabla 65, para más detalles. El tipo de cambio de las monedas locales se remitirá al final del año.

USADA EN LOS INDICADORES: wFi41

\section{wG46- Activos totales (EUR/año)}

Suma de los activos intangibles (incluyendo las plusvalías y el valor neto de licencias y derechos), los activos del sistema de abastecimiento de agua (incluyendo el valor neto de las instalaciones del abastecimiento y el valor neto de otros activos), los activos financieros (incluyendo el valor neto de las inversiones financieras) y los activos circulantes (wG45), relacionado con el servicio de saneamiento, al final del año fiscal.

\section{DATO DE ENTRADA}

Ver sección II-1.3, Tabla 65, para más detalles. El tipo de cambio de las monedas locales se remitirá al final del año. En la bibliografía, el término "activos totales" es equivalente a "capital invertido".

USADA EN LOS INDICADORES: wFi40(wG44), wFi43(wG44), wFi44, wFi45

USADA EN LAS VARIABLES: wG44 
wG47- Inventario (EUR)

Valor contable de los materiales relacionados con el servicio del aguas residuales que serán utilizados en el proceso de producción y que están en stock en el abastecimiento en la fecha de referencia.

\section{DATO DE ENTRADA}

Cuando esta variable esté referida a valores anuales, debería evaluarse para los años fiscales.

Ver sección II-1.3, Tabla 65, para más detalles. El tipo de cambio de las monedas locales se remitirá al final del año. Esta variable es un subset de wG45.

USADA EN LOS INDICADORES: wFi38

\section{wG48- Pasivo a largo plazo (EUR/año)}

Suma de los bonos y deudas financieras a largo plazo, relacionados con el servicio de saneamiento, en la fecha de referencia.

\section{DATO DE ENTRADA}

El tipo de cambio de las monedas locales se remitirá al final del año.

USADA EN LOS INDICADORES: wFi40(wG43), wFi43(wG44)

USADA EN LAS VARIABLES: wG43, wG44(wG43)

\section{wG49- Pasivo circulante (EUR)}

El pasivo circulante incluye cuentas las por pagar, la parte actual de la deuda a largo plazo y los diversos pasivos circulantes, relacionados con el servicio de saneamiento, en la fecha de referencia.

\section{DATO DE ENTRADA}

Cuando esta variable esté referida a valores anuales, debería evaluarse para los años fiscales. Ver sección II-1.3, Tabla 65, para más detalles.

USADA EN LOS INDICADORES: wFi40(wG43), wFi41, wFi43(wG44)

USADA EN LAS VARIABLES: wG43, wG44(wG43) 
wG50- Beneficio de operación (EUR/año)

Beneficios antes de intereses e impuestos (BAII), relacionadas con el servicio de saneamiento, durante el año.

\section{DATO DE ENTRADA}

Esta variable se refiere a valores anuales. Ver sección II-1.3, Tabla 65, para más detalles.

USADA EN LOS INDICADORES: wFi42,wFi44

wG51- Impuestos relacionados con el beneficio de operación (EUR/año)

Subconjunto de los impuestos totales específicamente relacionados con el beneficio de operación (BAII), relacionados con el servicio de saneamiento, durante el año.

\section{DATO DE ENTRADA}

Esta variable se refiere a valores anuales. Ver sección II-1.3, Tabla 65, para más detalles. El tipo de cambio de las monedas locales se remitirá al final del año.

USADA EN LOS INDICADORES: wFi44

\section{wG52- Beneficio neto (EUR/año)}

Beneficio neto tras el pago de intereses e impuestos, relacionados con el servicio de saneamiento abastecimiento de agua, al final del año fiscal.

\section{DATO DE ENTRADA}

Esta variable se refiere a valores anuales. El beneficio neto representa el beneficio final, después de que se hayan pagado los impuestos sobre los beneficios antes de impuestos. Ver sección II-1.3. El tipo de cambio de las monedas locales se remitirá al final del año.

USADA EN LOS INDICADORES: wFi43 


\subsection{Sección $\mathbf{H}$ - Datos de tiempo}

\section{wH1- Periodo de evaluación (días)}

\section{Periodo de tiempo adoptado para evaluar los datos (variables, indicadores e}

información de contexto).

\section{DATO DE ENTRADA}

El sistema de indicadores de gestión IWA pretende ser usado anualmente y, por tanto, es altamente recomendado que se elija el año como período de evaluación de referencia. Sin embargo, dado que los servicios pueden necesitar estudiar la evolución de su desempeño dentro del año, el sistema de indicadores está preparado para adaptarse a otros períodos de evaluación en la mayoría de indicadores.

En este caso, y para asegurar la coherencia de unidades y permitir la comparación de ID, todos los ID expresados en términos de tiempo se formulan de tal manera que los valores calculados para otros períodos de evaluación se convierten en valores anuales. Se debe tener en cuenta que el comportamiento de la mayoría de las variables no es uniforme durante el año, debido a efectos aleatorios o estacionales o a la planificación de actividades. Todas las comparaciones basadas en ID evaluadas a partir de datos no anuales deben tener en cuenta este hecho, a fin de evitar cualquier sesgo.

USADA EN LOS INDICADORES: wEn3, wEn4, wEn6, wEn12, wEn13, wEn14, wEn15, wPe12, wPe17, wPe20, wPe21, wPe22, wPe23, wPe24, wPh8, wPh9, wOp1, wOp2, wOp3, wOp4, wOp5, wOp6, wOp7, wOp8, wOp9, wOp10, wOp11, wOp12, wOp13, wOp14, wOp15, wOp17, wOp18, wOp21, wOp22, wOp23,wOp24, wOp25, wOp26, wOp27, wOp28, wOp29, wOp31, wOp32, wOp33, wOp34, wOp35, wOp36, wOp37, wOp38, wOp39, wOp40, wOp41, wOp42, wOp44, wOp45, wOp46, wOp47, wOp48, wOp49, wOp50, wOp51, wOp52, wOp53, wQS10, wQS11, wQS12, wQS13, wQS14, wQS15, wQS17, wQS19, wQS20, wQS21, wQS22, wQS23, wQS24, wQS25,wQS26, wQS29, wFi32

\subsection{Lista alfabética de variables}

\section{Datos mediambientales, página II-266}

Agua residual con tratamiento primario, wA5

Agua residual con tratamiento secundario, wA7

Agua residual con tratamiento terciario, wA9

Agua residual pretratada, wA3

Agua residual tratada en sistemas in-situ, wA11 
Lodo destinado a vertedero, wA17

Lodo desechado, wA16

Lodo procesado térmicamente, wA18

Lodo tratado, wA14

Lodo utilizado, wA15

Lodos desechados por otros medios, wA19

Lodos producidos en la EDAR, wA13

Número de alivios, wA24

Población equivalente con tratamiento de aguas residuales satisfactorio, wA1

Sedimentos de colectores, wA20

Sedimentos de elementos auxiliares, wA21

Sedimentos de film y arenilla, wA22

Sedimentos de sistemas in-situ, wA23

Valor punta diario de agua residual con tratamiento primario, wA6

Valor punta diario de agua residual con tratamiento secundario, wA8

Valor punta diario de agua residual con tratamiento terciario, wA10

Valor punta diario de agua residual pretratada, wA4

Volumen de agua residual reutilizada, wA12

Volumen de agua tratada, wA2

Volumen de descargas por reboses, wA25

Volumen de lluvia, wA26

\section{Datos de personal, página II-272}

Absentismo debido a accidentes o enfermedades laborales, wB24

Absentismo debido a otras razones, wB25

Absentismo, wB23

Accidentes laborales fatales, wB22

Accidentes laborales, wB21

Horas de trabajo, wB26

Horas extraordinarias de trabajo, wB27 
Personal con nivel de estudios básico, wB16

Personal con otra cualificación, wB17

Personal con titulación universitaria, wB15

Personal de laboratorio, wB13

Personal de operaciones y mantenimiento, wB12

Personal de planificación, diseño y construcción, wB11

Personal de servicios de apoyo, wB14

Personal de servicios técnicos, wB8

Personal en la red de alcantarillado, wB3

Personal en tratamiento de aguas residuales, wB2

Personal encargado de la administración general, wB4

Personal encargado de la gestión de los recursos humanos, wB5

Personal encargado de las funciones financieras y comerciales, wB6

Personal encargado del servicio al cliente, wB7

Personal especializado en espacios confinados, wB18

Personal técnico de tratamiento de aguas residuales, wB9

Personal técnico del sistema de alcantarillado, wB10

Personal total, wB1

Personal vacunado, wB19

Tiempo de formación, wB20

\section{Datos de activos físicos, página II-280}

Acometidas, wC29

Aliviaderos, wC19

Bombas de la red de alcantarillado, wC7

Capacidad diaria de tratamiento preliminar, wC12

Capacidad diaria de tratamiento primario, wC13

Capacidad diaria de tratamiento secundario, wC14

Capacidad diaria de tratamiento terciario, wC15

Colectores que entran en carga en tiempo de lluvia, wC3

Colectores que entran en carga en tiempo seco, wC2

Colectores que entran en niveles de carga elevados, wC4"

Caudalímetros de agua de la EDAR, wC26

Caudalímetros de agua de la red de alcantarillado, wC27 
Equipos de monitorización de la calidad del agua residual, wC33

Equipos de transmisión de señales, wC31

Equipos eléctricos, wC32

Estaciones de bombeo de la red de alcantarillado, wC9

Estaciones de bombeo del sistema de alcantarillado, wC6

Filtros de depósitos de retención y tanques de tormenta, wC25

Imbornales, wC22

Longitud de la red de alcantarillado, wC1

Número de depósitos de retención, wC23

Número de tanques de tormenta, wC20

Potencia de bombeo en la EDAR, wC5

Potencia de bombeo en la red de alcantarillado, wC10

Potencia de las bombas instaladas de aguas residuales, wC8

Pozos de registro, wC21

Propiedades conectadas, wC28

Sistemas eléctricos de emergencia, wC30

Unidades de control automático, wC17

Unidades de control remotas, wC18

Unidades de control, wC16

Utilización de las estaciones de bombeo de la red de alcantarillado, wC11

Volumen de depósitos de retención y tanques de tormenta, wC24

\section{Datos operacionales, página II-288}

Atasco de estaciones de bombeo, wD40

Atascos de colectores, wD38

Averías eléctricas, wD18

Bombas averiadas, wD34

Calibración de caudalímetros de agua de la red de alcantarillado, wD20

Calibración de caudalímetros de agua de las EDAR, wD19

Calibración de equipos de monitorización de la calidad del agua residual, wD21 
Colapso de colectores, wD44

Consumo de energía en las bombas, wD12

Consumo de energía por bombeo en la EDAR, wD14

Consumo de energía por bombeo en la red de alcantarillado, wD15

Control de tanques de tormenta, wD45

Detectores de gas permanentemente instalados, wD69

Detectores de gas, wD68

Energía consumida en los tratamientos de aguas residuales, wD13

Energía generada por cogeneración, wD17

Ensayo de sólidos suspendidos realizados, wD50

Ensayo de sólidos suspendidos requeridos, wD60

Ensayos de DBO realizados, wD48

Ensayos de DBO requeridos, wD58

Ensayos de DQO realizados, wD49

Ensayos de DQO requeridos, wD59

Ensayos de e. coli fecales realizados, wD53

Ensayos de e. coli fecales requeridos, wD63

Ensayos de fósforo realizados, wD51

Ensayos de fósforo requeridos, wD61

Ensayos de nitrógeno realizados, wD52

Ensayos de nitrógeno requeridos, wD62

Ensayos realizados de calidad del agua residual, wD46

Ensayos realizados de lodos, wD55

Ensayos realizados de vertidos industriales, wD56

Ensayos requeridos de calidad del agua residual, wD57

Ensayos requeridos de lodos, wD65

Ensayos requeridos de vertidos industriales, wD66

Factor de normalización, wD16

Inspección de bombas, wD11

Inspección de colectores, $\mathrm{wD} 1$

Inspección de equipos de transmisión de señales, wD23

Inspección de equipos eléctricos, $\mathrm{wD} 24$

Inspección de estaciones de bombeo, wD10 
Inspección de filtros de depósitos de retención y tanques de tormenta, wD9

Inspección de imbornales, wD4

Inspección de los sistemas eléctricos de emergencia, wD22

Inspección de pozos de registro, wD3

Inundaciones debidas a colectores de aguas negras, wD41

Inundaciones debidas a colectores unitarios, $\mathrm{wD} 42$

Inundaciones superficiales, wD43

Limpięa de colectores, wD2

Limpieza de depósitos de retención y tanques de tormenta, wD8

Limpieza de imbornales, wD5

Número de inspecciones a depósitos de retención y tanques de tormenta, wD6

Número total de ensayos de calidad del agua residual realizadas por los laboratorios del servicio, wD47

Otros test de calidad del agua residual realizados, wD54

Otros test de calidad del agua residual requeridos, wD64

Puntos de atasco de colectores, wD39

Rehabilitación de bombas, wD32

Rehabilitación de colectores, wD25

Reparación de colectores y uniones, wD28

Restauración de colectores, wD26

Sustitución de bombas, wD33

Sustitución de colectores, wD27

Sustitución de tapas de pozos de registro, wD30

Sustitución o renovación de acometidas, wD31

Sustitución, renovación o reparación de pozos de registro, wD29

Vehículos permanentes, wD67

Volumen de entrada, wD35

Volumen exflitrado, wD37

Volumen infiltrado, wD36

Volumen inspeccionado de depósitos de retención y tanques de tormenta, wD7 
Datos sobre demografía y clientes, página II-309

Población equivalente servida con EDAR, wE5

Población equivalente servida por sistemas in-situ, wE6

Población equivalente total servida, wE8

Población residente conectada a la red de colectores, wE4

Población residente servida por estaciones depuradoras de aguas residuales, wE2

Población residente servida por sistemas in-situ, wE3

Población residente sin servicio, wE7

Población residente, wE1

Datos de calidad del servicio, página II-311

Accidentes, wF22

Acometidas reparadas, $\mathrm{wF} 10$

Agua residual recolectada, wF1

Alta de nuevas acometidas, wF8

Daños a terceros, wF21

Interrupción del servicio de saneamiento, wF7

Interrupción del tráfico, wF26

Inundación de la superficie de propiedades en tiempo de lluvia, wF6

Otras quejas, wF19

Perturbaciones en el tráfico, wF25

Propiedades inundadas por colectores de aguas negras en tiempo de lluvia, wF3

Propiedades inundadas por colectores de aguas negras en tiempo seco, wF2

Propiedades inundadas por colectores unitarios en tiempo de lluvia, wF5

Propiedades inundadas por colectores unitarios en tiempo seco, wF4

Quejas por atascos, wF13

Quejas por incidentes de contaminación, wF15

Quejas por inundaciones, wF14

Quejas por olores, wF16 
Quejas relacionadas con la facturación, wF18

Quejas relacionadas con roedores, $\mathrm{wF} 17$

Quejas totales, wF12

Respuestas a quejas, wF20

Solicitudes de vaciado de fosas sépticas, $\mathrm{wF} 23$

Tiempo de establecimiento de nuevas acometidas, wF9

Tiempo de reparación de acometidas, wF11

Tiempo de respuesta de vaciado de fosas sépticas, wF24

\section{Datos económicos y financieros, página II-318}

Activo circulante, wG45

Activos totales, wG46

Arrendamiento y alquiler, wG13

Beneficio de operación, wG50

Beneficio neto, wG52

Cantidad anual facturada por año, wG40

Capital de los accionistas, wG44

Coste de explotación de la dirección general, wG17

Coste de la energía eléctrica, wG11

Coste de los intereses, wG27

Coste de los servicios externos, wG10

Coste del material comprado, wG12

Coste del servicio técnico, wG21

Costes capitalizados de activos construidos por el servicio, wG33

Costes de capital, wG7

Costes de explotación de la función de gestión de recursos humanos, wG18

Costes de explotación de la monitorización de la calidad del agua residual, wG24

Costes de explotación de la red de alcantarillado, wG23

Costes de explotación de servicios de apoyo, wG25

Costes de explotación del área financiera y comercial, wG19

Costes de explotación del servicio de atención al cliente, wG20 
Costes de explotación del tratamiento de aguas residuales, wG22

Costes de explotación, wG6

Costes de la mano de obra interna, wG9

Costes operativos, wG8

Costes por depreciación, wG26

Costes totales, wG5

Cuentas a cobrar, wG34

Deuda anual de los clientes, wG39

Deuda total, wG43

Flujo de caja, wG41

Ganancias y pérdidas extraordinarias, wG15

Impuestos relacionados con el beneficio de operación, wG51

Ingresos de operación, wG2

Ingresos por intereses, wG28

Ingresos por servicios industriales, wG4

Ingresos por servicios, wG3

Ingresos totales, wG1

Intereses netos, wG29

Inventario, wG47

Inversión en activos nuevos y en el fortalecimiento de los activos existentes, wG31

Inversión en activos tangibles del servicio de saneamiento, wG30

Inversión en la sustitución y renovación de activos, wG32

Inversiones financiadas por el flujo de caja, wG36

Inversiones sujetas a depreciación, wG35

Otros costes de operación, wG16

Pasivo a largo plazo, wG48

Pasivo circulante, wG49

Servicio de deuda financiera, wG42

Tasas, gravámenes e impuestos, wG14

Valor histórico de los activos tangibles, wG38

Valor histórico depreciado de los activos tangibles, wG37 
Datos de tiempo, página II-340

Periodo de evaluación, wH1 



\section{INFORMACIÓN DE CONTEXTO}

\subsection{Lista de referencia rápida de IC}

\begin{tabular}{|c|c|}
\hline \multicolumn{2}{|c|}{ Perfil del prestador (página II-358) } \\
\hline wCI1 - & Identificación del servicio (-) \\
\hline wCI2 - & Ámbito geográfico \\
\hline wCI3 - & Tipo de actividad \\
\hline wCI4 - & Tipo de propiedad de los activos \\
\hline wCI5 - & Tipo de operaciones \\
\hline wCI6 - & Personal total (No.) \\
\hline wCI7 - & $\begin{array}{l}\text { Tiempo de trabajo anual por empleado } \\
\text { (horas/empleado/año) }\end{array}$ \\
\hline wCI8 - & Ingresos anuales (€/año) \\
\hline \multirow[t]{10}{*}{ wCI9 - } & Coste anuales (€/año) \\
\hline & wCI10 -Costes de externalización (€/año) \\
\hline & wCI11 -Costes de externalización de gestión general (€/año) \\
\hline & $\begin{array}{l}\text { wCI12 -Costes de externalización de recursos humanos } \\
\text { (€/año) }\end{array}$ \\
\hline & $\begin{array}{l}\text { wCI13 -Costes de externalización de la gestión financiera y } \\
\text { comercial }(€ / \text { año) }\end{array}$ \\
\hline & $\begin{array}{l}\text { wCI14 -Costes de externalización del servicio de atención al } \\
\text { usuario (€/año) }\end{array}$ \\
\hline & $\begin{array}{l}\text { wCI15 -Costes de externalización de los servicios de } \\
\text { planificación y diseño }(€ / \text { año) }\end{array}$ \\
\hline & $\begin{array}{l}\text { wCI16 -Costes de externalización de los servicios de } \\
\text { construcción }(€ / \text { año) }\end{array}$ \\
\hline & $\begin{array}{l}\text { wCI17 -Costes de externalización de los servicios de } \\
\text { operación y mantenimiento (€/año) }\end{array}$ \\
\hline & $\begin{array}{l}\text { wCI18 -Costes de externalización de los servicios de } \\
\text { laboratorio }(€ / \text { año })\end{array}$ \\
\hline wCI19 - & Inversión media anual (€/año) \\
\hline wCI20 - & Impuestos sobre la renta $(€ /$ año $)$ \\
\hline \multicolumn{2}{|c|}{ Datos del servicio (página II-362) } \\
\hline wCI21 - & Tipos de sistemas gestionados por el prestador \\
\hline \multirow[t]{2}{*}{ wCI22 - } & Población residente (hab.) \\
\hline & $\begin{array}{l}\text { wCI23 -Población residente conectada a la red de } \\
\text { alcantarillado(hab.) }\end{array}$ \\
\hline
\end{tabular}




\begin{tabular}{|c|c|}
\hline & $\begin{array}{l}\text { wCI24 -Población residente conectada a la red de } \\
\text { alcantarillado en alta (hab.) }\end{array}$ \\
\hline & $\begin{array}{l}\text { wCI25 -Población residente servida por estaciones } \\
\text { depuradoras de aguas residuales (hab.) }\end{array}$ \\
\hline & $\begin{array}{l}\text { wCI26 -Población residente servida por sistemas in-situ } \\
\text { (hab.) }\end{array}$ \\
\hline wCI27 - & Población servida punta (hab.) \\
\hline wCI28 - & Carga contaminante punta en EDAR (p.e.) \\
\hline wCI29 - & Agua residual recolectada diariamente ( $\mathrm{m}^{3} /$ día) \\
\hline wCI30 - & aguas residuales industriales $(\%)$ \\
\hline wCI31 - & Agua residual importada (m³/día) \\
\hline wCI32 - & Agua residual exportada (m³/día) \\
\hline Nivel de & amiento de agua residual (página II-364) \\
\hline wCI33 - & Agua residual pretratada $\left(\mathrm{m}^{3} /\right.$ día $)$ \\
\hline wCI34 - & Agua residual con tratamiento primario ( $\mathrm{m}^{3} /$ día) \\
\hline wCI35 - & Agua residual con tratamiento secundario ( $\mathrm{m}^{3} /$ día) \\
\hline wCI36 - & Agua residual con tratamiento terciario $\left(\mathrm{m}^{3} /\right.$ día $)$ \\
\hline wCI37 - & Agua residual sin tratamiento $\left(\mathrm{m}^{3} /\right.$ día) \\
\hline wCI38 - & Lodos producidos en la EDAR (ton DS/año) \\
\hline wCI39 - & Lodos tratados en la EDAR (ton DS/año) \\
\hline wCI40 - & Lodo desechado (ton DS/año) \\
\hline wCI41 - & Sedimentos de film y arenilla (ton/año) \\
\hline Servicio & uario (página II-366) \\
\hline wCI42 - & Existencia de un sistema de registro de quejas \\
\hline wCI43 - & $\begin{array}{l}\text { Existencia de un sistema formalizado para registrar quejas } \\
\text { para evaluar la calidad del servicio y gestión de activos }\end{array}$ \\
\hline wCI44 - & Existencia de un sistema de normas garantizadas \\
\hline Cuenca ( & na II-366) \\
\hline wCI45 - & Cuenca $(\mathrm{km} 2)$ \\
\hline wCI46 - & Área impermeable de la cuenca $(\mathrm{km} 2)$ \\
\hline Activos & os (página II-367) \\
\hline Red de al & tarillado (página II-367) \\
\hline wCI47 - & Sistemas de aguas residuales (No.) \\
\hline wCI48 - & Longitud de la red de alcantarillado $(\mathrm{km})$ \\
\hline & wCI49 -Longitud de colectores unitarios (km) \\
\hline
\end{tabular}




\begin{tabular}{|c|c|}
\hline & wCI50 -Longitud de colectores de aguas residuales $(\mathrm{km})$ \\
\hline & wCI51 -Longitud de colectores de aguas pluviales (km) \\
\hline & wCI52 -Longitud de impulsiones (km) \\
\hline & wCI53 -Longitud de otros colectores (km) \\
\hline wCI54 - & Expansión de la red de alcantarillado (km/año) \\
\hline \multicolumn{2}{|c|}{ Materiales de los colectores } \\
\hline & wCI55 -Colectores de gres ( $\%)$ \\
\hline & wCI56 -Colectores de fibrocemento (\%) \\
\hline & wCI57 -Colectores de hormigón (\%) \\
\hline & wCI58 -Colectores de policloruro de vinilo (PVC) (\%) \\
\hline & wCI59 -Colectores de polietileno (\%) \\
\hline & wCI60 -Colectores de fundición (\%) \\
\hline & wCI61 -Colectores de acero (\%) \\
\hline & wCI62 -Colectores de piedra (\%) \\
\hline & wCI63 -Colectores de ladrillo (\%) \\
\hline & wCI64 -Colectores de otros materiales (\%) \\
\hline & wCI65 -Colectores con material desconocido (\%) \\
\hline \multicolumn{2}{|c|}{ Diámetros de los colectores } \\
\hline & wCI66 -Colectores de diámetro <= 150 mm (\%) \\
\hline & $\begin{array}{l}\text { wCI67 -Colectores de diámetro entre } 150<\mathrm{D}<=450 \mathrm{~mm} \\
(\%)\end{array}$ \\
\hline & $\begin{array}{l}\text { wCI68 -Colectores de diámetro entre } 450<\mathrm{D}<=900 \mathrm{~mm} \\
(\%)\end{array}$ \\
\hline & $\begin{array}{l}\text { wCI69 -Colectores de diámetro entre } 900<\mathrm{D}<=1200 \mathrm{~mm} \\
(\%)\end{array}$ \\
\hline & $\begin{array}{l}\text { wCI70 -Colectores de diámetro entre } 1200<\mathrm{D}<=2200 \\
\mathrm{~mm}(\%)\end{array}$ \\
\hline & wCI71 -Colectores de diámetro > $2200 \mathrm{~mm}(\%)$ \\
\hline & wCI72 -Colectores con diámetro desconocido (\%) \\
\hline \multicolumn{2}{|c|}{ Edad de la red de alcantarillado } \\
\hline & wCI73 -Colectores instalados después de 1995 (\%) \\
\hline & $\begin{array}{l}\text { wCI74 -Colectores instalados entre } 1985 \text { y } 1994 \text { inclusive } \\
(\%)\end{array}$ \\
\hline & $\begin{array}{l}\text { wCI75 -Colectores instalados entre } 1975 \text { y } 1984 \text { inclusive } \\
(\%)\end{array}$ \\
\hline & $\begin{array}{l}\text { wCI76 -Colectores instalados entre } 1950 \text { y } 1974 \text { inclusive } \\
(\%)\end{array}$ \\
\hline
\end{tabular}




\begin{tabular}{|c|c|}
\hline & $\begin{array}{l}\text { wCI77 -Colectores instalados entre } 1925 \text { y } 1949 \text { inclusive } \\
(\%)\end{array}$ \\
\hline & wCI78 -Colectores instalados antes de $1925(\%)$ \\
\hline & wCI79 -Colectores con edad desconocida (\%) \\
\hline wCI80 - & Edad media del sistema de alcantarillado (años) \\
\hline Pozos de & istro e imbornales (página II-372) \\
\hline wCI81 - & Pozos de registro (No.) \\
\hline wCI82 - & Máxima profundidad de pozos de registro (m) \\
\hline wCI83 - & Mediana de la profundidad de pozos de registro (m) \\
\hline wCI84 - & Mínima profundidad de pozos de registro (m) \\
\hline wCI85 - & Imbornales (No.) \\
\hline Aliviadero & tanques de tormenta (página II-373) \\
\hline wCI86 - & Aliviaderos (No.) \\
\hline wCI87 - & $\begin{array}{l}\text { Número de tanques de tormenta o dispositivos de } \\
\text { desbordamiento del sistema unitario (DSU) (No.) }\end{array}$ \\
\hline wCI88 - & Número de tanques de tormenta de aguas pluviales (No.) \\
\hline Puntos de & rtido (página II-373) \\
\hline wCI89 - & Puntos de vertido (No.) \\
\hline wCI90 - & Emisarios submarinos (No.) \\
\hline wCI91 - & Colectores afectados por mareas $(\mathrm{km})$ \\
\hline Acometid & (página II-374) \\
\hline wCI92 - & Acometidas (No.) \\
\hline & wCI93 -Acometidas domésticas (No.) \\
\hline & wCI94 -Acometidas industriales (No.) \\
\hline & wCI95 -Acometidas a sistemas in-situ (No.) \\
\hline & wCI96 -Otras acometidas (No.) \\
\hline wCI97 - & Densidad de acometidas (No./km) \\
\hline Almacena: & ento de aguas residuales (página II-375) \\
\hline wCI98 - & Número de depósitos de retención (No.) \\
\hline wCI99 - & Volumen total de almacenamiento $\left(\mathrm{m}^{3}\right)$ \\
\hline Almacenat & ento de aguas pluviales (página II-375) \\
\hline wCI100 - & Número de depósitos de retención de aguas pluviales (No.) \\
\hline wCI101 - & Otras unidades de almacenamiento de aguas pluviales (No.) \\
\hline
\end{tabular}




\begin{tabular}{|c|c|}
\hline wCI102 - & Estaciones de bombeo del sistema de alcantarillado (No.) \\
\hline wCI103 - & Potencia de las bombas instaladas de aguas residuales $(\mathrm{kW})$ \\
\hline wCI104 - & Agua residual bombeada $(\%)$ \\
\hline wCI105 - & Interrupciones del suministro eléctrico (horas) \\
\hline \multicolumn{2}{|c|}{ Estaciones Depuradoras de Aguas Residuales (EDAR) (página II-376) } \\
\hline \multirow[t]{4}{*}{ wCI106 - } & Número total de EDAR (No.) \\
\hline & wCI107 -Número de EDAR de sistemas separativos (No.) \\
\hline & wCI108 -Número de EDAR de sistemas unitarios (No.) \\
\hline & $\begin{array}{l}\text { wCI109 -Número de EDAR de sistemas mixtos (separativos } \\
+ \text { unitarios) (No.) }\end{array}$ \\
\hline wCI110 - & Número de EDAR <= 500 p.e. (No.) \\
\hline wCI111 - & Número de $500<$ EDAR < = 2000 p.e. (No.) \\
\hline wCI112 - & Número de $2000<$ EDAR $<=5000$ p.e. (No.) \\
\hline wCI113 - & Número de $5000<$ EDAR <= 10000 p.e. (No.) \\
\hline wCI114 - & Número de $10000<$ EDAR <= 25000 p.e. (No.) \\
\hline wCI115 - & Número de $25000<$ EDAR $<=50000$ p.e. (No.) \\
\hline wCI116 - & Número de $50000<$ EDAR <= 100000 p.e. (No.) \\
\hline wCI117 - & Número de $100000<$ EDAR <= 150000 p.e. (No.) \\
\hline wCI118 - & Número de EDAR > 150000 p.e. (No.) \\
\hline \multicolumn{2}{|c|}{ Capacidad de tratamiento } \\
\hline & wCI119 -Capacidad de tratamiento preliminar p.e. \\
\hline & wCI120 -Capacidad de tratamiento primario p.e. \\
\hline & wCI121 -Capacidad de tratamiento secundario p.e. \\
\hline & wCI122 -Capacidad de tratamiento terciario p.e. \\
\hline wCI123 - & $\begin{array}{l}\text { Capacidad de almacenaje punta de aguas residuales en la } \\
\text { EDAR }\left(\mathrm{m}^{3}\right)\end{array}$ \\
\hline wCI124 - & Capacidad de bombeo en la entrada de la EDAR (kW) \\
\hline \multicolumn{2}{|c|}{ Recursos tecnológicos (página II-379) } \\
\hline \multicolumn{2}{|c|}{ Sistemas de información computacional (TI Tecnología de la Información) } \\
\hline & wCI125 -Planificación y toma de decisiones \\
\hline & wCI126 -Inspección \\
\hline & wCI127 -Mantenimiento \\
\hline & wCI128 -Reclamaciones de los clientes \\
\hline & wCI129-Otros \\
\hline
\end{tabular}




\begin{tabular}{|c|c|}
\hline \multicolumn{2}{|c|}{ Monitorización, automatización y control } \\
\hline & wCI130 -Caudalímetros (No.) \\
\hline & wCI131 -Muestreadores de calidad (No.) \\
\hline & wCI132 -Bombeo (\%) \\
\hline & wCI133 -Tratamiento \\
\hline & wCI134 -Monitorización y control \\
\hline & wCI135 -Control integrado (\%) \\
\hline \multicolumn{2}{|l|}{ Mapeo } \\
\hline & wCI136 -Mapeo actualizado (\%) \\
\hline & wCI137 -Mapeo digital (\%) \\
\hline \multicolumn{2}{|c|}{ Demografía y economía (página II-382) } \\
\hline \multicolumn{2}{|c|}{ Demografía (página II-382) } \\
\hline wCI138 - & Densidad de población (hab./km2) \\
\hline wCI139 - & Ocupación de los hogares (hab./hogar) \\
\hline \multicolumn{2}{|c|}{ Crecimiento de la población } \\
\hline wCI140 - & Índice actual de crecimiento de la población ( $\%$ por año) \\
\hline wCI141 - & Índice previsto de crecimiento de la población ( $\%$ por año) \\
\hline \multicolumn{2}{|c|}{ Economía (página II-383) } \\
\hline wCI142 - & Producto Nacional Bruto per cápita (€ por cápita/año) \\
\hline wCI143 - & Tasa de inflación (\%/año) \\
\hline \multicolumn{2}{|c|}{ Tipo de cambio de EUR } \\
\hline wCI144 - & Promedio anual de la tasa de cambio de $€$ (Moneda local/€) \\
\hline wCI145 - & $\begin{array}{l}\text { Tasa de cambio de } € \text { al final del período de evaluación } \\
\text { (Moneda local/€) }\end{array}$ \\
\hline wCI146 - & Tasa de desempleo $(\%)$ \\
\hline \multicolumn{2}{|c|}{ Medioambiente (página II-384) } \\
\hline \multicolumn{2}{|c|}{ Precipitación anual (página II-384) } \\
\hline wCI147 - & Precipitación media anual (mm/año) \\
\hline wCI148 - & Máxima precipitación anual (mm/año) \\
\hline wCI149 - & Mínima precipitación anual (mm/año) \\
\hline \multicolumn{2}{|c|}{ Precipitaciones de corta duración (página II-384) } \\
\hline wCI150 - & Disponibilidad de datos estadísticos locales \\
\hline wCI151 - & $\begin{array}{l}\text { Lluvia de duración de } 10 \text { min y periodo de retorno de } 10 \\
\text { años (mm/año) }\end{array}$ \\
\hline
\end{tabular}




\begin{tabular}{|ll|}
\hline wCI152 - & $\begin{array}{l}\text { Lluvia de duración de } 60 \text { min y periodo de retorno de } 10 \\
\text { años (mm/año) }\end{array}$ \\
\hline Temperatura del aire (página II-385) \\
\hline wCI153 - & Temperatura media diaria del aire $\left({ }^{\circ} \mathrm{C}\right)$ \\
\hline wCI154 - & Temperatura máxima diaria del aire $\left({ }^{\circ} \mathrm{C}\right)$ \\
\hline wCI155 - & Temperatura mínima diaria del aire $\left({ }^{\circ} \mathrm{C}\right)$ \\
\hline Topografía (página II-385) \\
\hline wCI156 - & Altitud máxima $(\mathrm{m})$ \\
\hline wCI157 - & Altitud mínima $(\mathrm{m})$ \\
\hline Medio receptor (página II-386) \\
\hline wCI158 - & Medio receptor \\
\hline wCI159 - & Áreas especiales protegidas \\
\hline wCI160 - & Áreas especiales protegidas $(\mathrm{km} 2)$ \\
\hline
\end{tabular}




\subsection{Perfil del prestador}

\section{wCI1 - Identificación del servicio(-)}

Nombre del servicio de saneamiento, persona de contacto, dirección, teléfono, fax, correo electrónico

\section{wCI2 - Ámbito geográfico}

Ámbito de la actividad de la organización en su conjunto.

VALORES

- Nacional

- Estatal

- Regional

- Local

Se debe elegir una sola opción. Especifique la designación del área cubierta por el servicio.

\section{wCI3 - Tipo de actividad}

Ámbito de la actividad de la organización en su conjunto.

\section{VALORES}

- Recogida de aguas residuales

- Transporte de aguas residuales

- Tratamiento de aguas residuales

- Disposición de aguas residuales

- Recogida de aguas pluviales

- Transporte de aguas pluviales

- Tratamiento de aguas pluviales

- Disposición de aguas pluviales

- Abastecimiento de agua

- Abastecimiento de electricidad

- Abastecimiento de gas

- Recogida de residuos

- Otros (especificar)

Varias opciones son válidas. 
wCI4 - Tipo de propiedad de los activos

Propiedad de la infraestructura del abastecimiento.

VALORES

- Público

- Privado

- Mixto

Se debe escoger una única opción.

\section{wCI5 - Tipo de operaciones}

Tipo de dirección operativa del abastecimiento.

VALORES

- Público

- Privado

- Mixto

Se debe escoger una única opción.

\section{wCI6 - Personal total(No.)}

Número equivalente de trabajadores a tiempo completo del servicio de saneamiento

También usada como la variable wB1

\section{wCI7 - Tiempo de trabajo anual por empleado(horas/empleado/año)}

Número medio de horas trabajadas por año para un empleado a tiempo completo (horas brutas trabajadas - ausencia por vacaciones).

Ratio de variables wB26/wB1

\section{wCI8 - Ingresos anuales(€/año)}

Ingresos totales de operación menos costes capitalizados de activos construidos por el servicio, relacionados con el servicio de saneamiento, durante el período de evaluación.

Véase la Tabla 61 y la Tabla 62, sección 1.3-Definiciones financieras. Equivalente a wG1 si ésta se calcula para un año. 
wCI9 - Coste anuales(€/año)

Costes totales, incluyendo costes de capital y de explotación, relacionados con el servicio de saneamiento, durante el período de evaluación.

Véase la Tabla 61 y la Tabla 62, sección 1.3-Definiciones financieras. Equivalente a wG5 si ésta se calcula para un año.

\begin{tabular}{l} 
wCI10 - Costes de externalización(€/año) \\
$\begin{array}{l}\text { Costes anuales de externalización, en relación con el servicio de saneamiento, } \\
\text { durante el periodo de evaluación. }\end{array}$ \\
\hline
\end{tabular}

\section{wCI11 - Costes de externalización de gestión general(€/año)}

Costes anuales de las funciones de gestión general que están externalizadas, con respecto al servicio de saneamiento.

Véase la Tabla 55, sección 1.2-Funciones de organización

\section{wCI12 - Costes de externalización de recursos humanos(€/año)}

Costes anuales de lo servicios de recursos humanos que están externalizados, con respecto al servicio de saneamiento.

Véase la Tabla 56, sección 1.2-Funciones de organización

\section{wCI13 - Costes de externalización de la gestión financiera y $\operatorname{comercial}(€ /$ año $)$}

Costes anuales de las funciones financieras y comerciales que están externalizadas, con respecto al servicio de saneamiento.

Véase la Tabla 57, sección 1.2-Funciones de organización

\section{wCI14 - Costes de externalización del servicio de atención al usuario(€/año)}

Costes anuales de los servicios de atención al usuario que están externalizados, con respecto al servicio de saneamiento.

Véase la Tabla 58, sección 1.2-Funciones de organización 


\begin{tabular}{l} 
wCI15 - Costes de externalización de los servicios de \\
planificación y diseño(€/año) \\
$\begin{array}{l}\text { Costes anuales de los servicios de planificación y diseño que están } \\
\text { externalizados, con respecto al servicio de saneamiento. }\end{array}$ \\
Véase la Tabla 59, sección 1.2-Funciones de organización \\
\hline
\end{tabular}

\section{wCI16 - Costes de externalización de los servicios de construcción(€/año)}

Costes anuales de los servicios construcción que están externalizados (proporción por el valor de las obras nuevas y la renovación de activos realizada por un contratista externo, incluidas las nuevas conexiones de servicio y extensiones de red), con respecto al servicio de saneamiento.

Véase la Tabla 59, sección 1.2-Funciones de organización

\section{wCI17 - Costes de externalización de los servicios de operación y mantenimiento(€/año)}

Costes anuales de los servicios de operación y mantenimiento que están externalizados, con respecto al servicio de saneamiento.

Véase la Tabla 60, sección 1.2-Funciones de organización

\section{wCI18 - Costes de externalización de los servicios de laboratorio(€/año)}

Costes anuales de los servicios de laboratorio que están externalizados, con respecto al servicio de saneamiento.

Véase la Tabla 60, sección 1.2-Funciones de organización

\section{wCI19 - Inversión media anual(€/año)}

Coste promedio anual de las inversiones (gastos para infraestructura y equipos asociados), en relación con el servicio de saneamiento.

También usada como la variable wG30, si ésta se calcula de forma anual 
wCI20 - Impuestos sobre la renta(€/año)

Todos los impuestos y gravámenes sobre los ingresos brutos relacionados con el sistema de alcantarillado y las actividades de tratamiento de aguas residuales, en relación con el servicio de saneamiento.

Véase la Tabla 62, sección 1.3-Definiciones financieras

\subsection{Datos del servicio}

\section{wCI21 - Tipos de sistemas gestionados por el prestador}

Clasificación del tipo de sistema dependiendo del tipo de servicio al que esté dirigido. VALORES

- Alcantarillado en baja (excluyendo colectores en alta)

- Alcantarillado en alta

- Tratamiento de aguas residuales

- Sistemas in-situ

- Instalaciones sólo de aguas pluviales

Varias opciones son válidas.

\section{wCI22 - Población residente(hab.)}

Población total que vive permanentemente en el área que es responsabilidad del servicio de saneamiento, en la fecha de referencia.

También usada como la variable wE1

\section{wCI23 - Población residente conectada a la red de colectores(hab.)}

Población residente conectada a la red de alcantarilladogestionada por el servicio, en la fecha de referencia.

También usada como la variable wE4 
wCI24 - Población residente conectada a la red de alcantarillado en $\operatorname{alta}($ hab.)

Población residente conectada a la red de alcantarillado en alta gestionada por el servicio, en la fecha de referencia.

wCI25 - Población residente servida por estaciones depuradoras de aguas residuales(hab.)

Población residente servida por estaciones depuradoras de agua residual gestionadas por el servicio, en la fecha de referencia.

También usada como la variable wE2

wCI26 - Población residente servida por sistemas in-situ(hab.)

Población residente servida por sistemas in-situ gestionados por el servicio (p.ej. fosas sépticas, letrinas,...), en la fecha de referencia.

También usada como la variable wE3

wCI27 - Población servida punta(hab.)

Número máximo de personas residentes y no residentes en el área que es responsabilidad del servicio de saneamiento.

wCI28 - Carga contaminante punta en EDAR(p.e.)

Suma de la carga contaminante punta de DBO5 que ingresa en las estaciones depuradoras de aguas residuales, según la definición de población equivalente

wCI29 - Agua residual recolectada diariamente $\left(\mathrm{m}^{3} /\right.$ día $)$

Promedio diario de aguas residuales recolectadas, correspondiente al volumen de insumos domésticos, comerciales e industriales del sistema de alcantarillado

Ratio de variables $\mathrm{wF} 1 / \mathrm{wH} 1$ 
wCI30 - Aguas residuales industriales(\%)

Volumen de agua residual industrial recolectada / agua residual recolectada $\mathrm{x} 100$

\section{wCI31 - Agua residual importada( $\mathrm{m}^{3} /$ día $)$}

Volumen anual de aguas residuales importadas durante el año / 365

\section{wCI32 - Agua residual exportada(m³ / día)}

Volumen anual de aguas residuales exportadas durante el año / 365

\section{Nivel de tratamiento de agua residual}

\section{wCI33 - Agua residual pretratada( $\mathrm{m}^{3} /$ día $)$}

Volumen promedio anual diario de agua residual que recibe únicamente pretratamiento en las estaciones depuradoras de aguas residuales

Ratio de variables wA3/wH1

\section{wCI34 - Agua residual con tratamiento primario( $\mathrm{m}^{3} / \mathrm{d}$ ía $)$}

Volumen promedio anual diario de agua residual que recibe únicamente tratamiento primario en las estaciones depuradoras de aguas residuales

Ratio de variables wA5/wH1

\section{wCI35 - Agua residual con tratamiento secundario( $\mathrm{m}^{3} /$ día $)$}

Volumen promedio anual diario de agua residual que recibe tratamiento secundario en las estaciones depuradoras de aguas residuales

Ratio de variables wA7/wH1 
wCI36 - Agua residual con tratamiento terciario(m³ $/$ día)

Volumen promedio anual diario de agua residual que recibe tratamiento terciario en las estaciones depuradoras de aguas residuales

Ratio de variables wA9/wH1

\section{wCI37 - Agua residual sin tratamiento( $\mathrm{m}^{3} /$ día)}

Volumen promedio anual diario de agua residual descargado al medio sin ningún tratamiento (no incluye los volúmenes de agua descargados provenientes de reboses)

\section{wCI38 - Lodos producidos en la EDAR(ton DS/año)}

Peso seco del lodo producido en las Estaciones depuradoras de aguas residuales gestionadas por el servicio.

También usada como la variable wA13, si ésta se calcula de forma anual

\section{wCI39 - Lodos tratados en la EDAR(ton DS/año)}

Peso seco del lodo (de todas las fuentes) tratado en las estaciones depuradoras de aguas residuales gestionadas por el servicio.

\section{wCI40 - Lodo desechado (ton DS/año)}

Peso seco de los lodos tratados por el servicio que se desecha en vertederos, se incinera o su utiliza cualquier otra forma de disposición.

También usada como la variable wA16, si ésta se calcula de forma anual

\section{wCI41 - Sedimentos de film y arenilla(ton/año)}

Peso drenado del film y arenilla extraídos en los filtros y tamices de las estaciones de depuración de aguas residuales y estaciones de bombeo.

También usada como la variable wA22, si ésta se calcula de forma anual 


\section{Servicio al usuario}

\section{wCI42 - Existencia de un sistema de registro de quejas}

Existencia de registros que anotan el número total de quejas verbales y escritas, lo que permite determinar la naturaleza de la queja examinando las entradas individuales

VALORES

- Sí

- No

\section{wCI43 - Existencia de un sistema formalizado para registrar quejas} para evaluar la calidad del servicio y gestión de activos

Existencia de un sistema de registro de quejas y procesamiento de datos que se utiliza para resolver quejas, evaluar la calidad del servicio, su desempeño y la planificación de la gestión de activos.

VALORES

- Sí

- No

\section{wCI44 - Existencia de un sistema de normas garantizadas}

Existencia de un sistema de normas garantizadas que establezcan los derechos de los clientes, incluyendo al menos: tiempo máximo para obtener una nueva acometida y para reparar una existente, tiempo máximo de respuestas escritas, horarios para asistir a las instalaciones de los clientes.

VALORES

- Sí

- No

\section{Cuenca}

\section{wCI45 - Cuenca $(\mathrm{km} 2)$}

Extensión del área que recibe las aguas que proveen parte o la totalidad de la escorrentía captada por el sistema de alcantarillado

\section{wCI46 - Área impermeable de la cuenca (km2)}

Área dentro de la cuenca que es impermeable 


\subsection{Activos físicos}

\section{Red de alcantarillado}

wCI47 - Sistemas de aguas residuales(No.)

Número de sistemas autónomos de aguas residuales gestionados por el servicio en la fecha de referencia

wCI48 - Longitud de la red de alcantarillado $(\mathrm{km})$

Longitud total de la red de alcantarillado gestionada por el servicio en la fecha de referencia.

También usada como la variable wC1

Excluye las acometidas

wCI49 - Longitud de colectores unitarios $(\mathrm{km})$

Longitud de colectores unitarios (aguas residuales + pluviales) gestionados por el servicio en la fecha de referencia

wCI50 - Longitud de colectores de aguas residuales $(\mathrm{km})$

Longitud de colectores de aguas residuales (redes separativas) gestionados por el servicio en la fecha de referencia

wCI51 - Longitud de colectores de aguas pluviales $(\mathrm{km})$

Longitud de colectores de aguas pluviales (redes separativas) gestionados por el servicio en la fecha de referencia

wCI52 - Longitud de impulsiones(km)

Longitud de tuberías a trabajando a presión por bombeo gestionadas por el servicio en la fecha de referencia 
wCI53 - Longitud de otros colectores $(\mathrm{km})$

Longitud de otros colectores (p.ej. Alcantarillado simplificado, etc.) gestionados por el servicio en la fecha de referencia.

\section{wCI54 - Expansión de la red de alcantarillado(km/año)}

Incremento anual de la longitud de la red de alcantarillado que es responsabilidad del servicio de saneamiento (excluyendo acometidas)

\section{Materiales de los colectores}

wCI55 - Colectores de gres $(\%)$

Longitud de colectores de gres / longitud total de la red de alcantarillado x 100

\begin{tabular}{|l|}
\hline wCI56 - Colectores de fibrocemento $(\%)$ \\
Longitud de colectores de fibrocemento (asbestos) / longitud total de la red \\
de alcantarillado x 100
\end{tabular}

\section{wCI57 - Colectores de hormigón(\%)}

Longitud de colectores de hormigón (concreto) / longitud total de la red de alcantarillado x 100

wCI58 - Colectores de policloruro de vinilo (PVC) $(\%)$

Longitud de colectores de policloruro de vinilo (PVC) / longitud total de la red de alcantarillado x 100 
wCI59 - Colectores de polietileno( $\%)$

Longitud de colectores de polietileno / longitud total de la red de alcantarillado x 100

wCI60 - Colectores de fundición(\%)

Longitud de colectores de fundición / longitud total de la red de alcantarillado $\mathrm{x} 100$

wCI61 - Colectores de acero( $\%)$

Longitud de colectores de acero / longitud total de la red de alcantarillado x 100

wCI62 - Colectores de piedra(\%)

Longitud de colectores de piedra / longitud total de la red de alcantarillado x 100

\section{wCI63 - Colectores de ladrillo(\%)}

Longitud de colectores de ladrillo / longitud total de la red de alcantarillado x 100

\section{wCI64 - Colectores de otros materiales( $\%)$}

Longitud de colectores de otros materiales / longitud total de la red de alcantarillado x 100 
wCI65 - Colectores con material desconocido(\%)

Longitud de colectores de material desconocido / longitud total de la red de alcantarillado x 100

\section{Diámetros de los colectores}

\begin{tabular}{|l|}
\hline wCI66 - Colectores de diámetro $<=150 \mathrm{~mm}(\%)$ \\
$\begin{array}{l}\text { Longitud de colectores con diámetro }<=150 \mathrm{~mm} / \text { longitud total de la red de } \\
\text { alcantarillado x } 100\end{array}$ \\
\hline
\end{tabular}

wCI67 - Colectores de diámetro entre $150<\mathrm{D}<=450 \mathrm{~mm}(\%)$

Longitud de colectores con diámetro entre $150 \mathrm{~mm}<$ diámetro <= $450 \mathrm{~mm} /$ longitud total de la red de alcantarillado x 100

wCI68 - Colectores de diámetro entre $450<\mathrm{D}<=900 \mathrm{~mm}(\%)$

Longitud de colectores con diámetro entre $450 \mathrm{~mm}<$ diámetro <= $900 \mathrm{~mm}$ / longitud total de la red de alcantarillado x 100

wCI69 - Colectores de diámetro entre $900<\mathrm{D}<=1200 \mathrm{~mm}(\%)$

Longitud de colectores con diámetro entre $900 \mathrm{~mm}<$ diámetro $<=1200 \mathrm{~mm}$ / longitud total de la red de alcantarillado x 100

wCI70 - Colectores de diámetro entre $1200<\mathrm{D}<=2200 \mathrm{~mm}(\%)$

Longitud de colectores con diámetro entre $1200 \mathrm{~mm}<$ diámetro <= 2200 $\mathrm{mm} /$ longitud total de la red de alcantarillado $\mathrm{x} 100$ 
wCI71 - Colectores de diámetro > $2200 \mathrm{~mm}(\%)$

Longitud de colectores con diámetro $>2200 \mathrm{~mm}$ / longitud total de la red de alcantarillado x 100

wCI72 - Colectores con diámetro desconocido( $\%)$

Longitud de colectores con diámetro desconocido / longitud total de la red de alcantarillado x 100

\section{Edad de la red de alcantarillado}

\begin{tabular}{|l|}
\hline wCI73 - Colectores instalados después de 2016 (\%) \\
$\begin{array}{l}\text { Longitud de colectores instalados después de } 2016 \text { (inclusive) / longitud total } \\
\text { de la red de alcantarillado x } 100\end{array}$ \\
\hline
\end{tabular}

\section{wCI74 - Colectores instalados entre 2001 y 2015 inclusive $(\%)$}

Longitud de colectores instalados entre 2001 y 2015 inclusive / longitud total de la red de alcantarillado $\times 100$

wCI75 - Colectores instalados entre 1976 y 2000 inclusive(\%)

Longitud de colectores instalados entre 1976 y 2000 inclusive / longitud total de la red de alcantarillado x 100

wCI76 - Colectores instalados entre 1951 y 1975 inclusive( $\%)$

Longitud de colectores instalados entre 1981 y 1975 inclusive / longitud total de la red de alcantarillado $\mathrm{x} 100$ 
wCI77 - Colectores instalados entre 1926 y 1950 inclusive(\%)

Longitud de colectores instalados entre 1926 y 1950 inclusive / longitud total de la red de alcantarillado x 100

wCI78 - Colectores instalados antes de 1925(\%)

Longitud de colectores instalados antes de 1925 / longitud total de la red de alcantarillado x 100

\section{wCI79 - Colectores con edad desconocida $(\%)$}

Longitud de los colectores con edad desconocida / longitud total de la red de alcantarillado x 100

\section{wCI80 - Edad media del sistema de alcantarillado(años)}

Edad media de la red de alcantarillado basada en la distribución de edades y longitudes

Esta información es un valor aproximado calculado a partir de la información anterior, ignorando la categoría de colectores de edad desconocida.

\section{Pozos de registro e imbornales}

\section{wCI81 - Pozos de registro(No.)}

Número de pozos de registro en la red de alcantarillado

\section{wCI82 - Máxima profundidad de pozos de registro(m)}

Profundidad máxima de los pozos de registro en el sistema de alcantarillado

wCI83 - Mediana de la profundidad de pozos de registro(m)

Mediana de la profundidad de los pozos de registro en el sistema de alcantarillado 
wCI84 - Mínima profundidad de pozos de registro(m)

Profundidad mínima de los pozos de registro en el sistema de alcantarillado

wCI85 - Imbornales (No.)

Número de imbornales en la red de alcantarillado.

También usada como la variable wC22

\section{Aliviaderos y tanques de tormenta}

wCI86 - Aliviaderos(No.)

Número de aliviaderos (tanques de tormenta) del sistema de alcantarillado

wCI87 - Número de tanques de tormenta del sistema unitario (DSU)(No.)

Número de tanques de tormenta (aliviaderos o Desbordamientos del sistema unitario - DSU) en el sistema unitario en el sistema de alcantarillado

También usada como la variable wC20

wCI88 - Número de tanques de tormenta de aguas pluviales(No.)

Número de tanques de tormenta (aliviaderos) de aguas pluviales (sistemas separativos) en la red de alcantarillado

\section{Puntos de vertido}

\section{wCI89 - Puntos de vertido(No.)}

Número de puntos de vertidos gestionados por el servicio en aguas no marinas 
wCI90 - Emisarios submarinos(No.)

Número de emisarios submarinos en aguas marinas gestionados por el servicio

wCI91 - Colectores afectados por mareas $(\mathrm{km})$

Longitud de colectores afectados por la influencia de mareas

\section{Acometidas}

\section{wCI92 - Acometidas(No.)}

Número total de acometidas del servicio

También usada como la variable wC29

wCI93 - Acometidas domésticas(No.)

Número de acometidas de propiedades residenciales o edificios. Se deben excluir las acometidas residenciales de sistemas in-situ

wCI94 - Acometidas industriales(No.)

Número de acometidas provenientes de instalaciones industriales sin tratamiento previo industrial de las aguas vertidas

wCI95 - Acometidas a sistemas in-situ(No.)

Número de acometidas de sistemas in-situ (residenciales, comerciales e industriales) con algún pretratamiento. 
wCI96 - Otras acometidas(No.)

Número de acometidas de propiedades o edificios no residenciales (edificios comerciales, hospitales, colegios, etc.), excluyendo las acometidas de sistemas in-situ e industriales con tratamiento.

\section{wCI97 - Densidad de acometidas(No./km)}

Número de acometidas / longitud total de la red de alcantarillado

Ratio de variables wC29/wC1

\section{Almacenamiento de aguas residuales}

\section{wCI98 - Número de depósitos de retención(No.)}

Número de depósitos de retención (con o sin derivación) en la red de alcantarillado en la fecha de referencia.

\section{wCI99 - Volumen total de almacenamiento $\left(\mathrm{m}^{3}\right)$}

Volumen total de almacenamiento de los depósitos de retención (con o sin derivación) en el sistema de alcantarillado

\section{Almacenamiento de aguas pluviales}

wCI100 - Número de depósitos de retención de aguas pluviales(No.)

Número de depósitos de retención de únicamente aguas pluviales en el sistema de alcantarillado

\section{wCI101 - Otras unidades de almacenamiento de aguas pluviales(No.)}

Número de otras unidades de almacenamiento de aguas pluviales gestionadas por el servicio (p.ej. Lagunas superficiales) 


\section{Estaciones de bombeo}

wCI102 - Estaciones de bombeo del sistema de alcantarillado(No.)

Número de estaciones de bombeo de aguas residuales en la red de alcantarillado, incluidas las estaciones de bombeo de entrada de la planta de tratamiento de aguas residuales

También usada como la variable wC6

wCI103 - Potencia de las bombas instaladas de aguas residuales(kW)

Potencia nominal total de las bombas de aguas residuales instaladas en la red de alcantarillado, incluyendo las bombas de entrada en la EDAR

También usada como la variable wC8

wCI104 - Agua residual bombeada( $\%)$

Volumen anual de agua residual bombeada / agua residual recolectada $\mathrm{x} 100$

\section{wCI105 - Interrupciones del suministro eléctrico(horas)}

Suma, para todas las estaciones de bombeo, del número de horas que cada estación está fuera de servicio o que está funcionando con los sistemas de generación de energía auxiliares (grupos electrógenos, etc.) debido a interrupciones del suministro eléctric

\section{Estaciones Depuradoras de Aguas Residuales (EDAR)}

\section{wCI106 - Número total de EDAR(No.)}

Número total de estaciones depuradoras de aguas residuales (EDAR) gestionadas por el servicio 
wCI107 - Número de EDAR de sistemas separativos(No.)

Número total de estaciones depuradoras de aguas residuales (EDAR) gestionadas por el servicio, que reciben aguas residuales de sistemas de alcantarillado separativos

\section{wCI108 - Número de EDAR de sistemas unitarios(No.)}

Número total de estaciones depuradoras de aguas residuales (EDAR) gestionadas por el servicio, que reciben aguas residuales de sistemas de alcantarillado unitarios

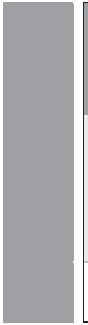

\section{wCI109 - Número de EDAR de sistemas mixtos (separativos + unitarios)(No.)}

Número total de estaciones depuradoras de aguas residuales (EDAR) gestionadas por el servicio, que reciben aguas residuales de sistemas de alcantarillado mixtos (separativos y unitarios)

\section{wCI110 - Número de EDAR <= 500 p.e.(No.)}

Número de EDAR gestionadas por el servicio que tratan diariamente menos de 500 personas equivalentes

\section{wCI111 - Número de $500<$ EDAR <= 2000 p.e.(No.)}

Número de EDAR gestionadas por el servicio que tratan diariamente más de 500 personas equivalentes y hasta 2000 p.e

wCI112 - Número de $2000<$ EDAR < = 5000 p.e.(No.)

Número de EDAR gestionadas por el servicio que tratan diariamente más de 2000 personas equivalentes y hasta 5000 p.e 
wCI113 - Número de $5000<$ EDAR <= 10000 p.e.(No.)

Número de EDAR gestionadas por el servicio que tratan diariamente más de 5000 personas equivalentes y hasta 10000 p.e

wCI114 - Número de $10000<$ EDAR <= 25000 p.e.(No.)

Número de EDAR gestionadas por el servicio que tratan diariamente más de 10000 personas equivalentes y hasta 25000 p.e

\section{wCI115 - Número de $25000<$ EDAR <= 50000 p.e.(No.)}

Número de EDAR gestionadas por el servicio que tratan diariamente más de 25000 personas equivalentes y hasta 50000 p.e

\section{wCI116 - Número de $50000<$ EDAR $<=100000$ p.e.(No.)}

Número de EDAR gestionadas por el servicio que tratan diariamente más de 50000 personas equivalentes y hasta 100000 p.e

\section{wCI117 - Número de $100000<$ EDAR <= 150000 p.e.(No.)}

Número de EDAR gestionadas por el servicio que tratan diariamente más de 100000 personas equivalentes y hasta 150000 p.e

\section{wCI118 - Número de EDAR > 150000 p.e.(No.)}

Número de EDAR gestionadas por el servicio que tratan diariamente más de 150000 personas equivalentes 
Capacidad de tratamiento

\begin{tabular}{|l|} 
wCI119 - Capacidad de tratamiento preliminar (p.e.) \\
Capacidad de tratamiento preliminar instalada \\
\hline
\end{tabular}

wCI120 - Capacidad de tratamiento primario (p.e.)

Capacidad de tratamiento primario instalada

wCI121 - Capacidad de tratamiento secundario (p.e.)

Capacidad de tratamiento secundario instalada

wCI122 - Capacidad de tratamiento terciario (p.e.)

Capacidad de tratamiento terciario instalada

wCI123 - Capacidad de almacenaje punta de aguas residuales en la $\operatorname{EDAR}\left(\mathrm{m}^{3}\right)$

Máximo volumen de agua residual que puede ser almacenado en las estaciones de depuración de aguas residuales (EDAR)

\section{wCI124 - Capacidad de bombeo en la entrada de la EDAR(kW)}

Potencia nominal total de bombas de entrada en las estaciones de depuración de aguas residuales (EDAR)

\section{Recursos tecnológicos}

Esta información de contexto trata sobre sistemas de información computacional (TI Tecnología de la Información) y recoge información del uso de equipos electrónicos, especialmente computadoras, para almacenar, analizar y enviar información. 
Sistemas de información computacional (TI Tecnología de la Información)

\begin{tabular}{|l|}
\hline wCI125 - Planificación y toma de decisiones \\
Uso habitual de TI para apoyar la planificación y la decisión \\
VALORES \\
- Sí \\
- No
\end{tabular}

\section{wCI126 - Inspección}

Uso habitual de TI para apoyar las actividades de inspección (especifique CCTV, cuando corresponda)

\section{VALORES}

- Sí

- No

\section{wCI127 - Mantenimiento}

Uso habitual de TI para apoyar las actividades de mantenimiento

\section{VALORES}

- Sí

- No

\section{wCI128 - Reclamaciones de los clientes}

Uso habitual de TI para respaldar la calidad del servicio al cliente y evaluar su opinión acerca del servicio

\section{VALORES}

$$
\text { - Sí }
$$

- No

\section{wCI129 - Otros}

Uso habitual de TI para apoyar otras actividades de gestión relevantes

\section{VALORES}

- Sí

- No 


\section{Monitorización, automatización y control}

A continuación, se evalúa la disponibilidad de los aparatos de monitorización, automatización y control.

\begin{tabular}{|l|}
\hline wCI130 - Caudalímetros(No.) \\
$\begin{array}{l}\text { Número de caudalímetros instalados en el sistema de aguas residuales, ya sea } \\
\text { de forma permanente o temporal, durante el año }\end{array}$ \\
\hline
\end{tabular}

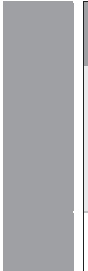

\section{wCI131 - Muestreadores de calidad(No.)}

Número de muestreadores automáticos y sensores en línea utilizados en el sistema de aguas residuales, ya sea de forma permanente o temporal, durante el aก̃o

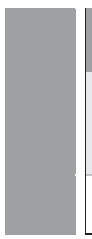

\section{wCI132 - Bombeo(\%)}

Número de estaciones de bombeo con unidades de control automático / número total de estaciones de bombeo x 100

\begin{tabular}{|l|} 
wCI133 - Tratamiento \\
Uso habitual de dispositivos automáticos para controlar unidades de \\
tratamiento \\
VALOREs \\
- Sí \\
\hline
\end{tabular}

\section{wCI134 - Monitorización y control}

Disponibilidad y uso habitual de las instalaciones de monitorización y control (por ejemplo, telelectura, SCADA, medidas de la red en tiempo real)

VALORES

- Sí

- No 
wCI135 - Control integrado(\%)

Número de estaciones integradas / número total de estaciones x 100

Las estaciones integradas aquellas que cuentan con dispositivos de control automático que están integrados en una red de automatización o están directamente conectados a una instalación de control central.

\section{Mapeo}

wCI136 - Mapeo actualizado(\%)

Longitud de colectores mapeados con una tolerancia de captura compatible con una escala 400 p.p.m / longitud total de la red de alcantarillado

400 p.p.m. $=1: 2500$

\section{wCI137 - Mapeo digital(\%)}

Longitud de colectores digitalizados con una tolerancia de captura compatible con una escala 400 p.p.m / longitud total de la red de alcantarillado 400 p.p.m. $=1: 2500$

\subsection{Demografía y economía}

\section{Demografía}

\section{wCI138 - Densidad de población(hab./km2)}

Población residente / área bajo la responsabilidad del servicio de saneamiento

Basada en estadísticas oficiales, siempre que estén disponibles.

\section{wCI139 - Ocupación de los hogares(hab./hogar)}

Población residente / número total de unidades de viviendas (casas + apartamentos) 


\section{Crecimiento de la población}

Basado en estadísticas oficiales, siempre que sea posible.

wCI140 - Índice actual de crecimiento de la población(\% por año)

Variación de la población durante los últimos diez años / población en el primer año de este periodo) $\mathrm{x} 10$

En áreas de crecimiento rápido debería adoptarse un periodo de 5 años.

wCI141 - Índice previsto de crecimiento de la población(\% por año)

Índice de crecimiento anual promedio previsto para los diez futuros años.

\section{Economía}

wCI142 - Producto Nacional Bruto per cápita(€ por cápita/año)

Producto Nacional Bruto / población total del país.

Se deben utilizar valores oficiales.

\section{wCI143 - Tasa de inflación(\%/año)}

Variación porcentual anual del índice de precios al consumidor en el país.

Se deben utilizar valores oficiales.

\section{Tipo de cambio de EUR}

wCI144 - Promedio anual de la tasa de cambio de $€($ Moneda local/€)

Tasa de cambio de la moneda local para el $€$, evaluado como la media de los valores al final de cada mes, para el año de referencia.

wCI145 - Tasa de cambio de $€$ al final del período de evaluación(Moneda local/€)

Tasa de cambio de la moneda local para el $€$ al final del período de evaluación. 
wCI146 - Tasa de desempleo( $\%)$

Porcentaje de la fuerza laboral que busca trabajo activamente pero no lo encuentra Se deben utilizar valores oficiales.

\subsection{Medioambiente}

Estas estadísticas se refieren al área de servicio.

\section{Precipitación anual}

Las cifras proporcionadas deben ser las cifras promedio de los últimos 30 años o el período continuo más largo. Estas estadísticas se refieren al área servica por el servicio de saneamiento.

\section{wCI147 - Precipitación media anual(mm/año)}

Precipitación media anual (media de los últimos 30 años).

\section{wCI148 - Máxima precipitación anual(mm/año)}

Máxima precipitación anual evaluada como la máxima de las máximas anuales de los últimos 30 años.

\section{wCI149 - Mínima precipitación anual(mm/año)}

Mínima precipitación anual evaluada como la mínima de las mínimas anuales de los últimos 30 años.

\section{Precipitaciones de corta duración}

Basado en la serie temporal disponible más larga

\begin{tabular}{|l|}
\hline wCI150 - Disponibilidad de datos estadísticos locales \\
\hline VALORES \\
- Sí \\
- No \\
Si la respuesta es "Sí", seleccionar los siguientes elementos: \\
\hline
\end{tabular}


wCI151 -Lluvia de duración de 10 min y periodo de retorno de 10 años ( $\mathrm{mm} / \mathrm{año)}$

Máxima intensidad para una precipitación de 10 minutos de duración y un periodo de retorno de 10 años (valor obtenido de 1 as curvas IDF)

wCI152 - Lluvia de duración de 60 min y periodo de retorno de 10 años ( $\mathrm{mm} / \mathrm{año})$

Máxima intensidad para una precipitación de 60 minutos de duración y un periodo de retorno de 10 años (valor obtenido de 1 as curvas IDF)

\section{Temperatura del aire}

Proporcionar la media de los últimos 30 años. Si esto no es posible, proporcionar el periodo más largo del que se disponga.

wCI153 - Temperatura media diaria del aire $\left({ }^{\circ} \mathrm{C}\right)$

Temperatura media diaria del aire en el año (media de los últimos 30 años).

\section{wCI154 - Temperatura máxima diaria del aire $\left({ }^{\circ} \mathrm{C}\right)$}

Temperatura media del aire en el día más caluroso del año (media de los últimos 30 años).

\section{wCI155 - Temperatura mínima diaria del aire $\left({ }^{\circ} \mathrm{C}\right)$}

Temperatura media del aire en el día más frío del año (media de los últimos 30 años).

\section{Topografía}

\section{wCI156 - Altitud máxima(m)}

Máxima elevación sobre el nivel del mar en el área del sistema de aguas residuales que es responsabilidad del servicio de saneamiento 
wCI157 - Altitud mínima(m)

Mínima elevación sobre el nivel del mar en el área del sistema de aguas residuales que es responsabilidad del servicio de saneamiento

\section{Medio receptor}

\begin{tabular}{|l}
\hline wCI158 - Medio receptor \\
\hline Especificar el medio receptor \\
\hline - \\
- Océanos \\
- Estuarios y otras aguas costeras \\
- Torrentes \\
- Lagos \\
- Lagunas \\
- Embalses o bahías cerradas \\
- Humedales \\
- Suelo
\end{tabular}

Varias opciones son válidas.

\section{wCI159 - Áreas especiales protegidas}

\section{VALORES}

- Sí

- No

Si la respuesta es "Sí", seleccionar el siguiente elemento:

\section{wCI160 - Áreas especiales protegidas(km2)}

Si hay áreas clasificadas como especiales protegidas, el área total de éstas 


\section{INCERTIDUMBRE Y PROPAGACIÓN DE LA INCERTIDUMBRE}

\section{Exactitud, fiabilidad e incertidumbre}

Esta sección resume la base del procedimiento que se puede implementar para evaluar las bandas de exactitud de los ID. En el apartado I-5, se destaca la relevancia de conocer el grado de confianza de los datos de entrada y se presentan los conceptos de fiabilidad de las fuentes y exactitud de los datos:

- La exactitud engloba la cercanía de los valores observados, computados o estimados a los valores reales. La exactitud se relaciona con la fidelidad del resultado y se distingue de la precisión en que ésta se relaciona con la fidelidad de la operación utilizada para obtener el resultado.

- La fiabilidad (de la fuente) es la medida en que la fuente de datos proporciona información consistente, estable y resultados uniformes para observaciones repetidas o mediciones en condiciones similares a lo largo del tiempo.

Cuando se opera algebraicamente con los datos para calcular un ID, la confianza del resultado depende de la confianza de los datos de entrada. No parece muy relevante o significativo retener el concepto de fiabilidad (de la fuente) para un valor que se calcula a partir de una combinación de fuentes. Sin embargo, se considera crucial estimar cómo la incertidumbre de los datos de entrada afecta la incertidumbre del resultado.

De acuerdo con el Vocabulario Internacional de Términos Básicos y Generales de Metrología, la incertidumbre (de una medida) es un parámetro, asociado al resultado de una medición, que caracteriza la dispersión de los valores que razonablemente podrían atribuirse la medida.

Si el proveedor de datos indica que el valor de un determinado dato es $A \pm U_{A}$, significa que confía en que el valor verdadero está a una distancia $U_{A}$ de $A$. Siendo $\mathrm{U}_{\mathrm{A}}$ la incertidumbre (expandida). También es habitual expresar la incertidumbre como un valor relativo, como un porcentaje de la media de la variable a la que se refiere. El término "está seguro" puede significar cosas diferentes para diferentes personas. Estadísticamente, debe expresarse en función de un nivel de confianza (es decir, la probabilidad de que el valor 
verdadero esté de hecho dentro del intervalo especificado). Un intervalo de confianza del 95\%, por ejemplo, corresponde al supuesto de que el proveedor de datos afirma que la probabilidad de que el valor verdadero esté fuera de la banda $\left[\mathrm{A}-\mathrm{U}_{\mathrm{A}} ; \mathrm{A}+\mathrm{U}_{\mathrm{A}}\right]$ no es superior al $5 \%$ (uno de cada veinte).

La incertidumbre está causada generalmente por una amplia combinación de factores con efectos distribuidos aleatoriamente. Si este es el caso, la diferencia entre el valor verdadero y sus medidas es una variable con una distribución normal. La incertidumbre se puede medir en términos de la desviación estándar correspondiente $(\sigma)$. En la práctica, las medidas más comunes de incertidumbre son:

$$
\begin{gathered}
\mathrm{U}=1 \sigma \text { (correspondiendo a un nivel de confianza de } \sim 68 \% \text { ) } \\
\mathrm{U}=2 \sigma \text { (correspondiendo a un nivel de confianza de } \sim 95 \%) \\
\mathrm{O} \\
\mathrm{U}=3 \sigma \text { (correspondiendo a un nivel de confianza de } \sim 99 \%)
\end{gathered}
$$

La incertidumbre se expresa generalmente en términos relativos $\left(\mathrm{u}_{\mathrm{A}}=\right.$ $\left.\mathrm{U}_{\mathrm{A}} / \mathrm{A}\right)$.

Se recomienda especificar la exactitud de los datos de entrada en una banda de exactitud, expresada en términos de incertidumbre relativa:

\begin{tabular}{|cl|}
\hline $\begin{array}{l}\text { Banda de } \\
\text { exactitud }\end{array}$ & Errores asociados relativos \\
\hline $0-5 \%$ & Mejor que o igual a $+/-5 \%$ \\
\hline $5-20 \%$ & Peor que $\pm 5 \%$, pero mejor que o igual a $+/-20 \%$ \\
\hline $20-50 \%$ & Peor que $\pm 20 \%$, pero mejor que o igual a $+/-50 \%$ \\
\hline$>50$ & Peor que $\pm 50 \%$ \\
\hline
\end{tabular}

Para evaluar la banda de exactitud del ID, es necesario utilizar el concepto de incertidumbre. 


\section{Ley de propagación de la incertidumbre}

Los ID resultan de una combinación de variables a partir de las cuatro operaciones algebraicas básicas: sumas, restas, productos y divisiones. Veamos cómo se propaga la incertidumbre en estos casos simples, antes de presentar una expresión más general.

Supongamos que dos magnitudes medidas $\mathrm{A}$ y $\mathrm{B}$ tienes incertidumbres $\mathrm{U}_{\mathrm{A}} \mathrm{y}$ $\mathrm{U}_{\mathrm{B}}$ respectivamente. De este modo, las expresaríamos como $\left(\mathrm{A} \pm \mathrm{U}_{\mathrm{A}}\right), \mathrm{y}(\mathrm{B} \pm$ $\mathrm{U}_{\mathrm{B}}$ ). A partir de las cantidades medidas (A y B), se calcula una nueva cantidad C. ¿Cuál es la incertidumbre, $\mathrm{U}_{z}$, en $\mathrm{Z}$ ? A los fines de este manual, utilizaremos una versión simplificada del tratamiento estadístico adecuado. La propagación de la incertidumbre se describe en detalle en los coeficientes de correlación de la ISO "Guide to the Expression of Uncertainty in Measurement"14.

(a) Sumas y restas: $\mathrm{C}=\mathrm{A}+\mathrm{B}+\ldots$ o $\mathrm{C}=\mathrm{A}-\mathrm{B}-\ldots$ o combinaciones de ambas:

La incertidumbre de C es $U_{C}=\sqrt{\left(U_{A}\right)^{2}+\left(U_{B}\right)^{2}+\cdots}$.

(b) Multiplicaciones y divisiones: $\mathrm{C}=\mathrm{A} \times \mathrm{B} \times \ldots$ o $\mathrm{C}=\mathrm{A} / \mathrm{B} / \ldots \mathrm{O}$ combinaciones de ambas:

La incertidumbre relativa de C es $u_{C}=\sqrt{\left(u_{A}\right)^{2}+\left(u_{B}\right)^{2}+\cdots}$.

En este caso se ha asumido implícitamente (para facilitar la compresión) que $\mathrm{U}_{\mathrm{w}}=1 \sigma_{\mathrm{w}}$ (correspondiente a un intervalo de confianza del 68).

(c) Expresión general para una cantidad $z=f\left(w_{1}, w_{2}, \ldots, w_{\mathrm{N}}\right)$ que depende de $N$ elementos de entrada $w_{1}, w_{2}, \ldots, w_{\mathrm{N}}$, cuando $w_{1}, w_{2}, \ldots, w_{\mathrm{N}}$ siendo estos independientes entre ellos:

14 Guide to the expression of uncertainty of uncertainty in measurement, International Organization for Standardization, Geneva (1993). 
La desviación media de z es:

$U_{z}=\sqrt{\left|\frac{\partial f}{\partial w}\right|^{2}\left(U_{w}\right)^{2}+\left|\frac{\partial f}{\partial x}\right|^{2}\left(U_{x}\right)^{2}\left|\frac{\partial f}{\partial y}\right|^{2}\left(U_{y}\right)^{2}+\ldots}$

(c) Expresión general para una cantidad $z=f\left(w_{1}, w_{2}, \ldots, w_{\mathrm{N}}\right)$ que depende de $N$ elementos de entrada $w_{1}, w_{2}, \ldots, w_{\mathrm{N}}$ :

En este caso se adopta la expresión general de la propagación de la incertidumbre.

Asumiendo $\mathrm{U}=1 \sigma$, la incertidumbre de $\mathrm{z}$ es:

$$
\sigma_{z}^{2}=\sum_{i=1}^{N}\left(\frac{\partial f}{\partial w_{i}}\right)^{2} \sigma_{i}^{2}+2 \sum_{i=1}^{N} j \sum_{j=i+1}^{N} \frac{\partial f}{\partial w_{i}} \frac{\partial f}{\partial w_{j}} \rho_{i j}
$$

donde $\sigma_{i}^{2}$ es la varianza de $w_{i}$ y $\rho_{i j}$ es el coeficiente de correlación de la covarianza de $w_{i}$ y $w_{j}$. Si las variables de entrada son independientes (como es a menudo el caso), entonces la covarianza el cero y el segundo término de la ecuación anterior desaparece. Esta ecuación era tradicionalmente llamada "ley general de la propagación de errores". Sin embargo, lo que realmente muestra es cómo la incertidumbre (y no el error) de las variables de entrada se combina. 


\section{Manual de Buenas Prácticas}

\section{Indicadores de Desempeño para Servicios de Saneamiento}

Grupo Especialista en Benchmarking y Evaluación del Desempeño de la IWA

Los manuales de evaluación de desempeño y benchmarking de la IWA se han convertido en una referencia a nivel mundial desde la publicación del primero de ellos en el año 2000. Su éxito se debe a que se trata de un sistema detallado, coherente y flexible que cuenta con definiciones precisas para cada elemento. Por ello, ha sido y es utilizado en un gran número de iniciativas de diversa indole, como proyectos de evaluación interna del desempeño y benchmarking, y por parte de prestadores de servicios, reguladores, administraciones, etc.

El presente volumen completa la serie de tres manuales de la IWA sobre evaluación del desempeño y benchmarking que han sido traducidos al castellano. Los otros dos títulos sobre Indicadores para Servicios de Abastecimiento de Agua y sobre Benchmarking para Servicios de Agua, fueron traducidos con anterioridad.

Este volumen, se centra exclusivamente en los servicios de saneamiento y aguas residuales, presentando los indicadores de desempeño relevantes para evaluar estos servicios, junto con el marco metodológico desarrollado por la IWA para poder elaborar a medida un sistema de indicadores.

Se trata de una versión actualizada de la primera edición publicada en 2003, en la que, manteniendo los indicadores del manual original, se ha actualizado la primera parte de la obra armonizándola para ser coherente con la metodología presentada en el manual gemelo de servicios de abastecimiento de agua, actualizado en 2014.

De este modo, en la primera parte del manual, el lector encontrará información detallada sobre el marco metodológico de indicadores de la IWA, acerca de cómo implementar un sistema de indicadores y la relación de este manual con los otros dos.

En la segunda parte se presenta el sistema de indicadores de la IWA para servicios de saneamiento incluyendo los indicadores, variables e información de contexto. Esta parte ha mantenido su esencia original en cuanto a los elementemos presentados.

Este manual conforma una valiosa referencia para todos aquellos interesados en una adecuada gestión y mejora del desempeño de los servicios de saneamiento, siendo de especial utilidad para operadores, reguladores, legisladores y las agencias financieras. 